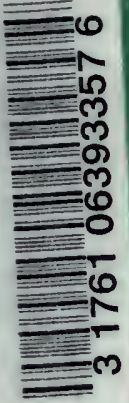




$$
7^{9-87}
$$




AN INTRODUCTION TO OCEANOGRAPHY 



\section{AN INTRODUCTION TO}

\section{OCEANOGRAPHY}

WITH SPECIAL REFERENCE TO GEOGRAPHY AND GEOPHYSICS

BY

JAMES JOHNSTONE, D.Sc.

Professor of Oceanography in the University of Liverpool

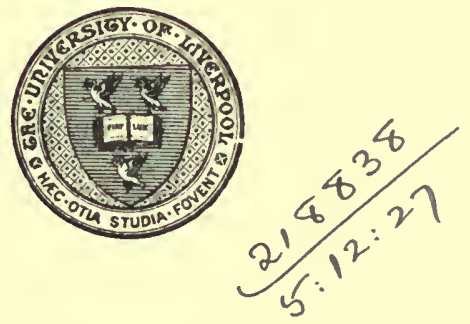

THE UNIVERSITY PRESS OF LIVERPOOL LIMITED HODDFR AND STOUGHTON LIMITED, LONDON 1923 



\section{CONTENTS}

\section{Preface}

Chapter I. The World-Ocean . • page 1

Chapter II.

Chapter III.

\section{The Origin of the Oceans}

The origin of the earth, 8 ; the gaseousmolten hypotheses, 8 ; the tetrahedral earth hypothesis, 10; spherical harmonio deformation, 11; failure of these hypotheses, 14; planetesimal hypothesis, 15 ; growth by accretion, 20 ; rotational changes, field-tracts, 21; oceanic and continental regions, 29 ; permanence of the oceans, 31 ; smallness of these effects, 32 .

\section{The Depths of the Ocean}

Estimation of depth, 34; sounding machines, 36 ; the bottom gradients, 39 ; continental shelf, 40 ; continental slope, 41; form of the ocean floor, 44; contours, 45; the Antarctic Ocean, 47; the Arctic Ocean, 48 ; the Atlantic Ocean, 50 ; the Pacific Ocean, 56; the Indian Ocean, 58.

Chapter IV. The Sea Botтom 2 - original nature of the deposits, 63; classification, 65; categories of deposits, 66 ; littoral deposits, 68 ; shallow-water deposits, 68 ; terrigenous muds, 71; neritic deposits, 74; oceanic neritic deposits, 78 ; coral forma. tions, 79 ; origin of coral reefs, 82; pelagic deposits, 88; plankton, 90 ; pteropod ooze, 92 ; globigerina ooze, 92 ; radiolarian ooze, 94; diatom ooze, 96; red clay, 96 ; pelagic oozes in general, 97 .

Chapter V. The Oceanic Margins

The foreshore, 103 ; foreshore gradients, 104; shallow-water bottom gradient, 106 ; the marginal seas, 107 ; the epi-continental seas, 108; the Mediterranean and relict seas, 109 ; marginal sea-bottom deposits, 111; foreshore neritic deposits, 112; shallow-water neritic deposits, 112; the continental margins, 113; interior of the earth, 114 ; isostasy, 117 ; earth-movements and isostasy, 121; the shield-lands, 122; the oceanic abysses, 122 ; the great features of the continental margins, 124; the continental displacement hypothesis, 127 . 
viii

Chapter VI.

Chapter VII.
The Chemistry of Sea Water .

Chemistry of sea-water, 133 ; composition of sea-salts, 134; salinity, 137 ; variations of salinity, 138 ; salinity charts, 140 ; the gases of sea-water, 146; alkalinity, 148; photosynthesis and carbon dioxide, 151; distribution of gases in sea-water, 154; food substances in the sea, 156 ; origin of the salts of sea water, 160 .

\section{The Physical Characters of} SeA Water

Pressure, 165 ; temperature, 167 ; temperature variations, 170 ; oceanic isotherms, 174 ; ice, 184 ; vertical temperature variations, 188 ; seasonal temperature changes, 192 ; density of sea-water, 192; osmotic pressure, 195; optical characters, 196.

Chapter VIII. The TIDes - . . P
The tides from ordinary observation, 199; rise and fall, 199 ; t tide gauges, 200 ; sea level, 201 ; range, 202 ; periodicity, 202 ; springs and neaps, 202 ; types of tides, 204 ; tidal streams, 206; tide-generating force, 210 ; aperiodic tidal variations, 217 ; theories of the tides, 219 ; the equilibrium theory, 220 ; the progressive wave theory, 220 ; stationary wave theory, 222 ; tidal predictions, 225; empirical prediction methods, 226 ; establishment of a port, 230 ; prediction by harmonic methods, 239 ; the "tidal satellites," 241 ; tidal constituents, 242 ; harmonic analysis, 245 ; harmonic synthesis, 249 ; tides as marine agencies, 250 ; long period tidal variations, 251.

\section{Chapter IX.}

\section{The Oceanic Circulation}

The general scheme, 255; causes, 257 ; Ferrell's law, 260; effect of the earth's rotation, 263 ; currents as they are, 263 ; equatorial currents, 264 ; the effect of the land, 265 ; depth, 266 ; salinity, 267; the great oceanic currents, 270; Atlantic currents, 270 ; Gulf Stream, 271 ; Labrador stream, 271; Sargasso Sea and the Atlantic stream, 271; South Atlantic currents, 273; Pacific oceanic circulation, 276 ; the Indian Ocean, 279; the Polar seas, 283; the marginal seas, 285 ; the North Sea, 286 ; seasonal variations, 287 ; mid-Atlantic circulation, 288 ; the Atlantic gyral, 289 ; the vertical circulation, 293; methods of investigation, 296. 
Chapter X. Secular Changes in the Ocean 301

The shield-lands, 303 ; oceanic depressions, 304; oceanic-continental margins, 304; the Pacific Ocean, 309; the Atlantic Ocean, 314; the Indian Ocean, 319; History of the oceans, 321 ; Evidence available, 321 ; paleontological evidence, 323 ; ancient land and sea, 325.

Appendix. Literature Consulted . . 337

INDEX $\quad . \quad$. $\quad$. . . 343 



\section{PREFACE}

The modern science of oceanography has been developed. to such an extent during the last twenty-five years that it is now impossible to deal comprehensively with its results in a book of any reasonable size. There is hardly any limit to the amount of descriptive detail that might be given with respect to such subjects as the currents of the ocean and its tributary seas; the distribution of the various kinds of bottom deposits; or the chemistry of sea water in all parts of the world. Further, the science blends into marine biology in such an intimate manner that two lines of treatment are now quite necessary: Physical Oceanography on the one hand and Hydrobiology on the other. It has also its mathematical sides in the modern theories of the tides and in hydrodynamics, and for the study of these subjects a certain discipline and technique are necessary that have been acquired by only very few scientific men. Lastly the study of the ocean can be approached from the aspect of geography and geophysics.

Although an attempt has been made here to deal in a general way with the science of oceanography, it is rather with the outlook of the student of geography and geology that the book has been written. Even then the method of treatment is as general as possible, so that it is hoped that a summary account of marine science from the physical side has been provided, and that it will be useful not only to those whose main interest is in geography and geology but also to biologists-who, it may be noted, have mainly been responsible for the development of our science of oceanography.

A very great difficulty in such a book as this is the illustrations. A multitude of charts and maps is quite 
necessary in order that the presentation of the results may be helpful in the highest degree. This wealth of illustration is, of course, quite impossible at the present time, and so the best kind of reader will have to make very frequent use of a good modern atlas of physical geography, and he will also have to consult the small scale Admiralty charts for details of ocean depths, currents, tidal streams, and the like. The figures contained in the text are, of course, in the nature of sketches, and the amount of reduction and simplification that has been involved in their preparation precludes the statement of much desirable detail. For this the reader must seek elsewhere, but he will certainly find the task of doing so interesting to a remarkable extent.

No references are given in the body of the book, but I have prepared a short Appendix which gives most of the authorities consulted, and which will also be a guide to the reader who cares to go further with the subject. The books and journals mentioned are mostly such as are easily obtained in any good library.

UNIVERSITY OF LIVERPOOL, October, 1923. 


\section{CHAPTER I}

\section{THE WORLD-OCEAN}

When we look at the Ocean as it is represented on a globe certain regularities become apparent: that is, the distribution of land and water does not seem to be purely arbitrary. Figures 1 to 6 , which follow hereafter, are made from photographs of a globe, and they may be taken to represent telescopic views of the earth, seen, it is true, under rather favourable conditions. These appearances we must now discuss. Fig. 1 is a view of the Antarctic hemisphere. Here we see a circumpolar land

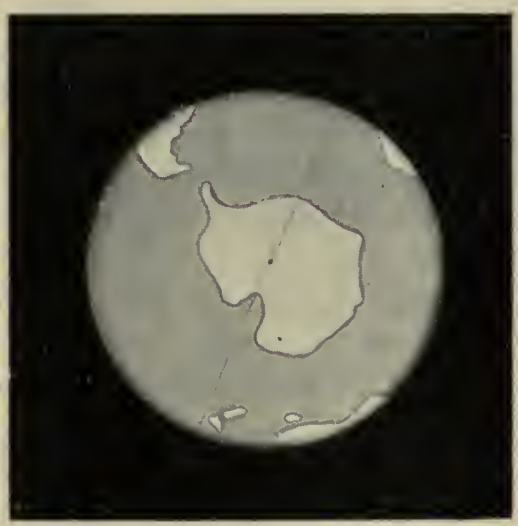

Fig. 1. Telescopic view of the earth : the Antarctic aspect.

mass, the Antarctic continent. Although the land boundaries of this are not yet precisely known, the depths of the surrounding ocean indicate very clearly that it is 
a truly continental earth feature. About it there is the great southern ocean and this is nowhere less than 600 miles in width. Three meridians may be taken as dividing it into as many sectors. These are:

(1) About $75^{\circ}$ West longitude. This meridian passes through Graham Land in Antaretica, and Tierra del Fuego, in South America. Here the Southern Ocean is most constricted, and it is also more shallow than elsewhere. At its narrowest part it is about 600 miles wide.

(2) About $20^{\circ}$ East longitude. This meridian passes through the South pole and the Cape of Good Hope. The Southern ocean is here rather over 2,000 miles in width.

(3) About $140^{\circ}$ East longitude. This passes through the pole and the Australian Continent in the neighbourhood of the Gulf of Carpentaria. In its vicinity the Southern Ocean is about 1,600 miles in width.

Thus there is a nearly symmetrical arrangement of land and sea round about the South pole. There is a polar land-mass of considerable elevation, and round it there is a circumpolar oceanic region. Opening out from this, between America and Africa is the South Atlantic Ocean, and this covers a sector of $90^{\circ}$. Between Africa and Australia, and covering a sector of $120^{\circ}$, is the Indian Ocean, while between Australia and South America, a sector of about $150^{\circ}$, is the Pacific. If the arrangement were strictly symmetrical these three sectors would each be $120^{\circ}$.

Fig. 2 represents the view seen where the North Pole is in the centre of the field. Here there is very roughly the opposite kind of distribution of land and water from that which Fig. 1 represents. In the centre, round about the North Pole, there is an oceanic area of considerable dimensions and depths, and round this again is a circumpolar land-mass, the principal boundaries of which are 
the Eur-Asian and North American Continents. The land ring is broken through in three places: between Siberia and Alaska, in the narrow Behring Straits, is the entrance into the Pacific; between Europe and the eastern coast of Greenland is the Norwegian Sea (and the entrance to the North Atlantic), while between Greenland and North America is Davis Straits. 'These communications between the Arctic, and the Pacific and Atlantic Oceans are, as we shall see later, rather shallow and not truly "oceanic" in character. They do not obscure our general picture.

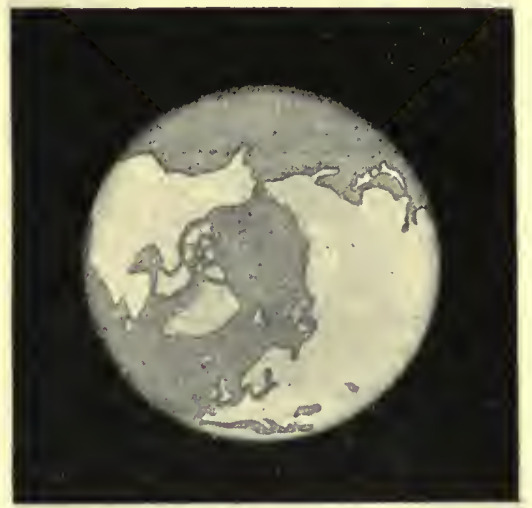

FIG. 2. Telescopic view of the earth : the Arctic aspect.

which is that of a Polar oceanic area surrounded by continental land masses with fringes of islands.

Three Oceanic "Gulfs" open out from the great Southern Ocean.

Fig. 3 represents the Pacific water hemisphere.

Here we see the greatest oceanic area of all. The Pacific Ocean is bounded by the coasts of America and Asia and there is only the very small interruption formed by Behring Strait. Then the Asian land boundary is continued across to Australia by an archipelago round which the ocean is 


\section{AN INTRODUCTION TO OCEANOGRAPHY}

relatively shallow. Below Australia the Pacific passes into the Southern Ocean.

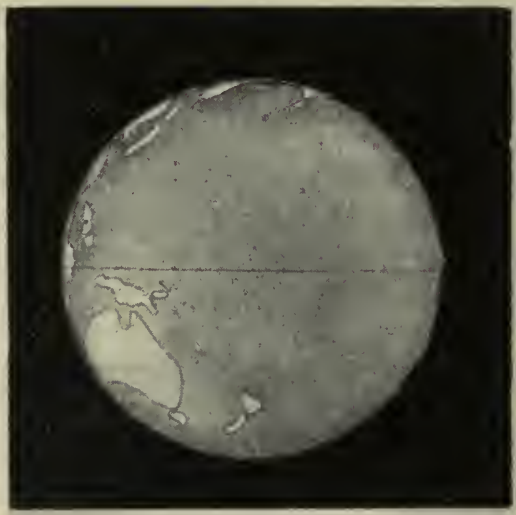

FIa. 3. Telescopic view of the earth : the Pacific aspect.

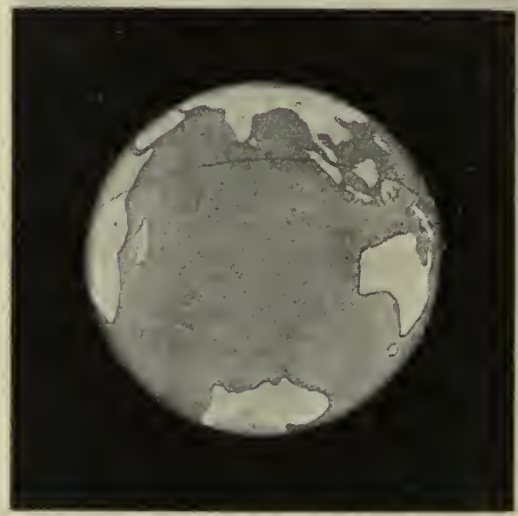

Fia. 4. Telescopic view of the earth : the Indian Ocean.

This is our second Oceanic Gulf.

The third Oceanic Gulf is the Atlantic one and this, like the Pacific Ocean, joins together the Antarctic and Arctic 
Oceans. It is convenient, for reasons that will appear in the next chapter, to regard it as consisting of two oceanic areas, North and South Atlantics. To the south the communication between Atlantic and Antarctic is very wide and deep, while to the north the opening into the Arctic is constricted and shallow. Also each of the continents of Africa and South America presents towards the other a bold promontory, Cape Verde and Cape San Roque respectively, and these suggest the division of the whole Atlantic into North and South regions.

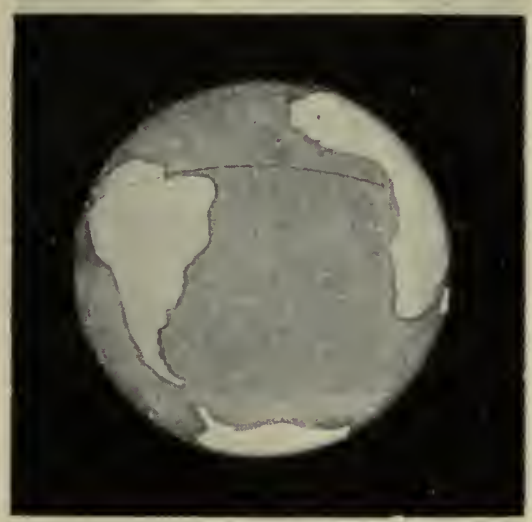

FIG. 5. Telescopic view of the earth : the South Atlantic aspect.

Fig. 6 represents the North Atlantic Basin, directly continuous on the south with the South Atlantic and bounded on the north in the way that we have noticed.

Now it is obvious that there are certain features in this distribution of land and sea on the surface of the earth that call for explanation. These are:

(1) The north polar oceanic region placed antipodally to the south polar continental region.

(2) The northerly, roughly annular, continental land region which we set over against the southerly, annular, oceanic region. 
(3) The condition that the great oceans are (roughly) antipodal to the great continental regions.

(4) The general forms of the continents-these diminish in breadth from north to south (North and South America and Africa) and, as a consequence, the great land margins run obliquely towards and across the equator.

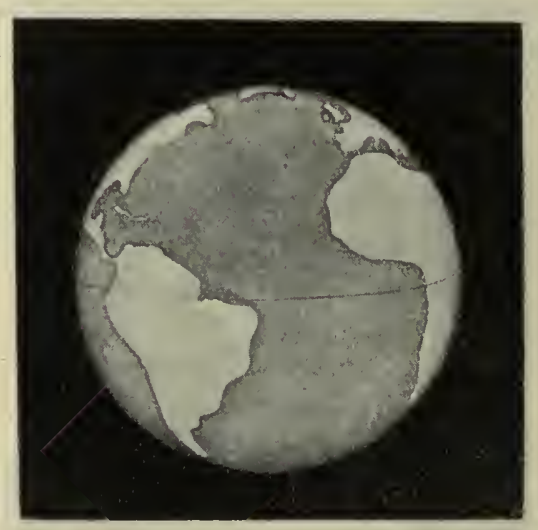

Fig. 6. Telescopic view of the earth: the North Atlantic aspect.

(5) A rough tri-radiate arrangement of land and ocean round the poles. This is shown best by the ways in which S. America, Africa and Australia are directed towards the Antarctic Continent, but it is also suggested in the contours of North Anerica, Greenland and Asia. These land masses are broad to the north, where they form the boundaries of the Arctic Ocean and they taper away towards the equator. This arrangement is the reverse of that which we see in the southern hemisphere. 


\section{CHAPTER II}

\section{THE ORIGIN OF THE OCEANS}

The precise distribution of land and sea on the face of the earth is, to a great extent, "accidental" : that is, it is due to the operation of a great number of causes, no one of which is much more important than any other. Round the coasts of all the continents there is an extensive region where the sea is not more than about 1,000 fathoms in depth, and here the changes in the extent and form of the land have been very frequent in geological, and even in historic time. There is continual erosion of the coast and the extent and rate of this depend on the nature of the materials of the land. Thus shallow, submarine flats are formed on the one hand while, on the other, the eroded materials may be carried away by the sea to form shoals elsewhere. Then there are movements of elevation and depression, both of the dry land and of the sea-floor, and the result is that the ocean transgresses on the land and vice versa. So the contours of the continents fluctuate to a considerable degree and large tracts of the surface of the earth are alternately land and water.

In spite of this flux certain broad, general features of the earth are relatively permanent: they are the deep depressions forming the oceanic basins and the great continental plateaus and mountain ranges. These are the characteristic and noticeable markings of the earth as a whole. Even if they are not absolutely permanent, they still maintain a recognisable form in spite of extensive changes in the precise outlines of land and sea. They are geological rather than geographical earth-features. They are not "accidental" in the sense in which we have employed the term above, but they are due to the operation 
of several large causes which are predominant among the numerous ones to which the fluctuations of land and oceanic contours are due.

The origin of the earth.-These larger causes to which continental and oceanic forms are due are cosmic ones, but they must have terrestrial peculiarities. It has been noted that the surface markings of the moon and the planet Mars differ notably from those of the earth. If those markings indicate areas of elevation and depression (as in the case of the earth), then the evolution of superficial planetary features must have taken different directions in each case, and we must seek for causes which have been in operation on the earth, but not at all, or not to the same extent, in its nearest neighbours in the solar system. Differences may easily be found, as for instance, in the different masses of the three bodies; that of the moon being only $1 / 80 \mathrm{th}$, and that of Mars 1/10th, of the mass of the earth. We have to deal, then, with factors which are both cosmic and terrestrial ones. Hypotheses of the origin of the continents and oceans must, therefore, depend, to some extent, on the hypothesis of the origin of the earth itself that we adopt.

The gaseous-molten hypotheses. - The classical hypothesis of the origin of the earth is, of course, the Kant-Laplace one, and its main outlines must be familiar to the reader. It leads us to consider an earth which was originally gaseous, and then molten, and very much larger than it now is. As this fluid globe cooled it contracted and, therefore, its rotatory speed increased so that centrifugal forces developed. Modern mathematical research has greatly modified the crudities of the original hypothesis and has shown that the rotating molten earth must have become pear-shaped-the stalk of the pear being a protuberance on the equator. This knob became detached when the rotatory velocity exceeded a certain limit, and so the moon originated, repeating the process by which the earth itself became detached from the parent, solar 
mass. Tidal evolution followed : the moon, in its primitive orbit, set up enormous tidal waves in the body of the fluid earth, and these set up friction which had the threefold effect of reducing the rotatory speed of the earth, reducing the rotatory speed of the moon and increasing the distance of the latter from the earth. Moon and earth cooled down still further and skinned over, so to speak, by the formation of solid, rocky crusts. For a time these crusts must have been highly unstable, so that they became broken up again and again, but by and by they became permanent and the water vapour previously held in the earth's atmosphere condensed to form the primitive ocean. The crater-like elevations on the surface of the moon may be taken to represent the results of the original instability of the crust and the "boiling-out" of the original gases held in the fluid body. The mass of the moon is, of course, too small to generate a gravitational field intense enough to hold water vapour and the other gases that now form the earth's atmosphere. Sub-aerial or aqueous erosion did not therefore, occur, nor was there chemical action by an atmosphere, and so the original markings have remained.

The consequence of this hypothesis is the idea that the earth was originally intensely hot and has been losing heat throughout its geological history. That it is still hot inside is shown by observations of subterranean temperatures. This rise of temperature as we descend into the interior of the earth is very variable: in Great Britain it may increase at the rate of $1^{\circ} \mathrm{F}$. for every 30 feet, or $1^{\circ} \mathrm{F}$. for every 130 feet. Taking an average, however, and adopting the very risky method of extrapolating from the curve showing the gradient, we can find what is the expected temperature at the earth's centre, and so get some quite improbable value, such as $350,000^{\circ} \mathrm{F}$. There is, of course, no reason why we should not conclude, with just as much probability, that the heated regions beneath the earth's surface are strictly local, not continuous with each other, and at no great depth. That there are localised regions 
where the temperature is high enough to hold rock in the fluid condition is quite certain: volcanic phenomena demonstrate this, but that the whole earth at a depth of 50 to 100 miles is so intensely hot as to be potentially fluid is really a deduction from the gaseous-molten hypothesis of origin. If-as is undoubtedly the case-the assumption involves us in serious difficulties we are quite at liberty to reject it on the nature of the evidence in its favour. Now the parent hypothesis, and the observed temperature increase with increasing depth, have left us with the very generally accepted belief that the earth as a whole, was originally intensely hot, is still very hot inside and is, and has been, cooling rather slowly. The superficial layer is, however, cold although the internal mass is hot and is cooling. Therefore the core must still be contracting while the crust has ceased to contract merely because the core is losing heat. It follows, then, that the crust must fall in, so to speak, upon the shrinking interior and, therefore, become crumpled, folded, buckled or otherwise deformed. Here we have a basis for an hypothesis of the origin of the oceanic depressions and the continental elevations.

The tetrahedral earth hypothesis.-Admitting, then, that the earth as a whole is, and has been losing heat, we have an hypothesis which, merely as a consequence of that assumption, professes to account for the existing series of large elevations and depressions of the crust. A closed tube collapsing under external pressure sometimes assumes a shape which is roughly triangular in section and a hollow globe similarly collapsing is said to cave in so as to approximate in shape to a regular tetrahedron. In such a solid there are four faces each of them an equilateral triangle in shape, there are six edges of equal length and four solid angles. If the earth tended to contract, on loss of heat, in such a way we should expect to find that the central parts of the tetrahedral faces would be nearer to the centre than are the solid angles, or coigns, and so the 
water of the ocean would gravitate towards the central faces and the land masses would be placed round the coigns. One such prominent land-mass is the Antarctic Continent, and so we place a coign of the tetrahedron there. Then the three meridians diverging from the centre of this are approximately fixed in position, for evidently one must pass through the southern apex of South America, and the other two must be at angles of $120^{\circ}$ distant on either side. The other three coigns will then be situated on these meridans and roughly in $\mathrm{N}$. latitude $33^{\circ}$. If they are joined by great circles the trace of the enclosed tetrahedron on the surface of the earth is complete.

By no possibility can a regular tetrahedron be traced on the earth's surface so as to approximate to this hypothetical distribution of continents and oceans. The proof of this will be shown by trying. In order, even to make a rough approximation, the tetrahedron must be deformed, and with this sacrifice of its attractive simplicity the hypothesis loses much of its interest. But, apart altogether from this practical test we are not certain that its basal assumption - that the earth as a whole is losing heat and contracting round its centre-is justified. And, that being so, the lack of approximation of theory and test seems to be fatal.

The hypothesis of spherical harmonic deformation.Starting with the hypothesis of the molten earth the present distribution of land and water may be explained in another way (which appears to be exclusive of the tetrahedral hypothesis). In the molten condition the earth body was, of course, far from being rigid. It protruded equatorially in a very oblate, spheroidal shape and then calved off the moon from a part of its equatorial bulge. That left it asymmetrical along both the polar diameter and along another at right angles to this. As it cooled and contracted it would become more rigid, but until its material became as unyielding as if it were solid granite, the centre of gravity of the earth could not have been its 
centre of rotation. This is because the material must have been crushed under its own gravity. As the earth rotated it must, therefore, have wobbled.

Assuming, then, that its centre of gravity was not the same as the centre of figure, certain consequences may be traced. If the centre of gravity were nearer to the North than to the South Pole, water would tend to accumulate on the former region, while at the latter, land would protrude. If it were slightly pear-shaped so that the axis of rotation passed through the long diameter of the pear, water would accumulate round the "waist" of the figure. The equatorial bulge would not be a simple swelling but a series of low, annular ridges with furrows between them. Further, it may be assumed that the substance of the primitive earth was heterogeneous and, that being so, the heavier materials would tend to fly out towards the periphery by reason of centrifugal force. Thus the figure of the earth, as it progressively stiffened would take a certain form such that some regions on its surface would be nearer to the centre of gravity than some other ones. So there would be areas of depression and elevation, and the water of the ocean would tend to accumulate on the former. The mathematical investigation of the origin of these elevations and depressions, as a consequence of the assumptions made, cannot be reproduced here, and it may be sufficient to indicate that it lcads to a distribution rather like that which now exists. We must, however, take some liberties with geographical features: there should be land at the North Pole instead of an obvious oceanic depression and the boundary between the continental and oceanic areas has to be taken at a depth given by the 1,400-fathom contour line. There must be a considerable degree of "smoothing" of the shapes of the continents. When these qualifications are considered along with the original assumption of an earth body, solidifying from the molten state, the hypothesis loses much of its appeal. Nevertheless it has some plausibility, 
at all events, and it may be that it does not depend absolutely upon a juvenile, molten earth. Like the tetrahedral theory it presents us with an earth in which the oceanic depressions are permanent surface features: that is, they owe their origin to the causes that have produced the solid earth-body.

Now it is certainly the case that the centre of figure of the earth is not the centre of rotation. Very careful observations made during several decades have shown that the latitude of a place is not constant in its value. Latitude is a measurement from the zenith, that is the point in the celestial sphere cut by a prolongation of the earth's axis, and so it follows that the latter is not quite fixed. In other words the poles are points that shift about on the earth's surface.

This shifting of the pole is, of course, a very small motion: its effect is that the latitude of a place varies by about 0.27 second of arc, which means a shifting of the pole by about 30 feet, or so, periodically. The shifting follows a path on the earth's surface which is a sort of complicated spiral, so that it is not cumulative. But another motion enters into the total effect. There is a small periodic change in the latitude which affects all stations simultaneously, and this is to be explained by supposing that the centre of rotation shifts up and down and along the axis of rotation by about 10 feet. As it shifts, so the axis sways upon the shifting point, and so we get the total effect.

It was known that there would be such a precession of the earth's axis, and (before it was actually observed) it was predicted by Euler and given a period of 10 months : that was on the assumption that the earth-body was absolutely unyielding. Every 10 months, then, the north and south poles would have rotated in small circles of about 30 feet in diameter, always pursuing a re-entrant path. The actual period is, however, about 14 months, and this is because the earth is not perfectly rigid, but 


\section{AN INTRODUCTION TO OCEANOGRAPHY}

really yields a little to the tide-generating force set up by the combined gravitational field of the sun and moon. Such earth-body tides have actually been observed.

Failure of the gaseous-molten hypothesis.-There are, of course, huge difficulties in accounting for an original, intensely hot, immensely attenuated nebula with a movement of slow rotation. But even when we concede the existence of this nebula further difficulties arise. If it is given certain provisional dimensions, a mass, a rotational speed and a physical state (a temperature, etc.) its further development may be deduced. The original crudities of the hypothesis have been removed. The nebular matter that formed the planets could not have been cast off in the form of rings, on the Saturnian model, but was calved off in the way suggested above: this follows from Sir George Darwin's mathematical investigation. But even so the process must have had certain dynamical consequences, and these ought to be traceable to-day in the distances of the planets from the sun and the distance of the satellites from the planets; in the masses and rotational speeds of the various bodies; in their revolutionary paths, etc. Observation is now fastidious enough, and mathematical analysis sufficiently penetrating, to show that the consequences to be expected are not apparent to observation. Therefore the nebular hypothesis, even its later modified form, cannot be sustained. It leaves us also with the notion of an earth body which was originally intensely hot and fluid, and which has long been cooling and contracting. If that were so, certain consequences are to be expected : the amount of contraction ought to be calculable within certain limits. There should be limiting values to the amount of contraction of the earth's crust which results from the shrinking away from it of the contracting core. Somewhere in the materials accessible to us there ought to be relics of the original crust that finally solidified. The hypothesis, in fact, must 
come to such a state that it becomes the subject of physicomathematical investigation, and so far as that has proceeded it does not support the gaseous-molten conception. It must be again noted that there is no really convincing evidence of an earth with an intensely hot interior, now or in the past, and there is no good evidence that the earth body is cooling and not actually getting warmer.

The planetesimal hypothesis of the earth's origin.-The above hypothesis, as it is elaborated by Chamberlin and Moulton, makes a new start. Given the discrete universe* we have the picture of a very large number of massive bodies pursuing paths which are like those of the molecules in an imperfect gas. Originally the rather crude idea of stellar collisions between these bodies was entertained. But the distribution of the stars is such that there are prodigious distances between them on the average-that is the density of the visible universe is exceedingly small. Therefore, the probability of collisions can be calculated, since we know a certain amount as to the velocities of the stars and their spacing apart from each other. This probability of collision is very small.

But the probability of a near approach of two stars is much greater. By "approach" we mean that they may come so near as to perturb each other. It is permissible to assume a certain physical state of the perturbing stars: such a state as that of the sun. Here we have an intensely hot body from which eruptions (as shown in the solar prominences and sunspots) occur with considerable force. The heated and expansive material of the sun is held by its own gravitation, so that erupted substance mostly returns to its surface. If, however, another cosmic body of sufficient mass were to approach the sun near enough it would set up a tide in the solar mass and cause an eruption.

* Some hundreds of millions of cosmic bodies of rather small dimensions instead of one large body. Why? There is some reason for it, Lodge says. To ask for the reason leads on into philosophical, rather than cosmogonical speculation. 
With a close enough approach disruption of the solar body would occur.

There is, in fact, a limit within which two cosmic bodies could not approach each other and still hold together by their own gravities. The moon is far outside this limit, with respect to the earth, yet quite significant tides are set up by it in the yielding ocean and there are even very small tides in the solid earth. Given, then, a very close approach on the part of the sun and another cosmic body of much the same order of mass, and fragmentation of one or both bodies must ensue. Such fragmentation might be the first stage in the evolution of a new planctary system.

Just as the model for the Kant-Laplace nebular hypothesis was given in the ring system of Saturn, so the model for the planetesimal hypothesis is afforded by the spiral nebulae which are such conspicuous features of the heavens. It is not to be thought that these spiral nebulae are really stages in, or actual examples of the evolution of planetary systems. Their distances and dimensions appear to be very great so that we see in them something incomparably greater than a planetary system of the order of magnitude of our one. Possibly they may represent stellar galaxies, or universes similar to the system that we see grouped about the Milky Way. In any case, however, they have suggested the possible mechanisms of a planetary evolution.

That mechanism is fairly simple (at this stage of the hypothesis, at all events).

One of the two cosmic bodies (which are of nearly equal magnitude) we may call the "eruptive sun," and the other the "projectile." They are assumed to approach each other, not " dead on " but nearly so. As they come within each other's gravitational field they will take hyperbolic paths about each other, approaching from, and then receding to, very great distances. If they are approximately in the same physical state the same series 
of events must occur in each. Here, however, we trace only the events that occur in the eruptive sun, and it is assumed that the latter is in rotation. When the projectile approaches to within a certain distance, which will depend on the masses of the two bodies, the attraction will become

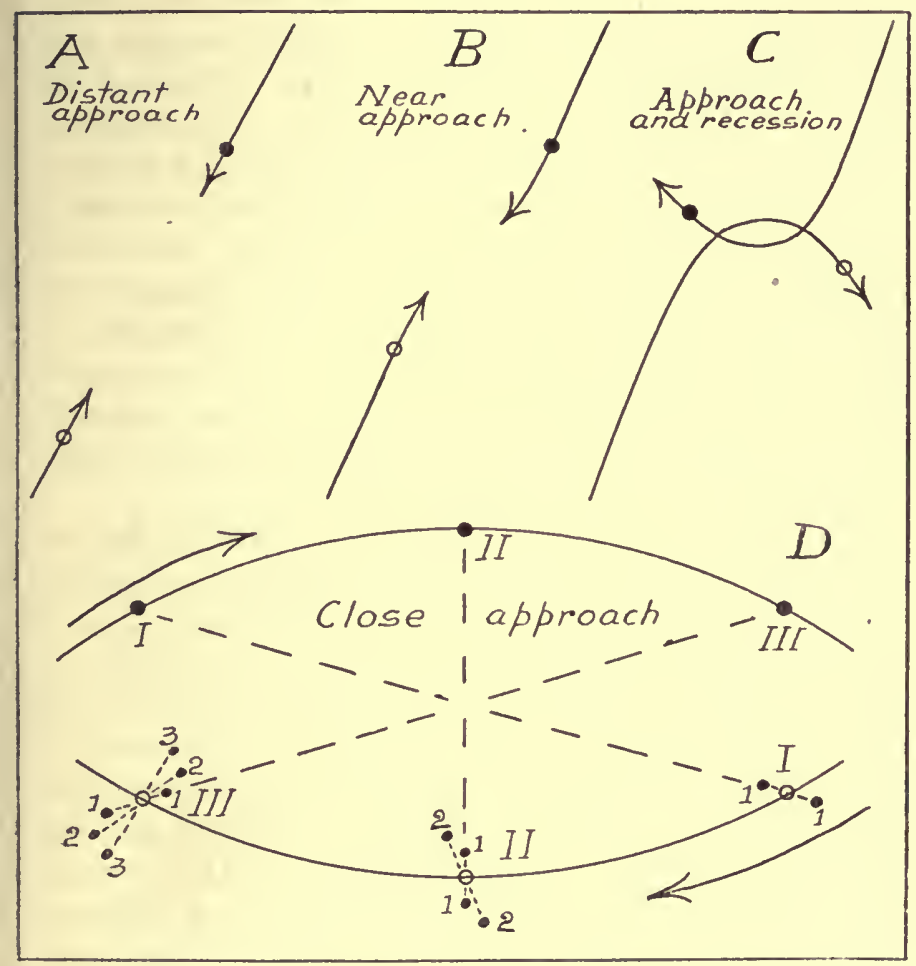

Frg. 7. Stages in the disruptive approach of two stellar bodies.

so great that the eruptive sun will become partially disintegrated. As in the case of an earthly moon-tide, there will be two protuberances, one on either side, and in the line joining the two stars, and at a certain moment each of these will be projected as an explosive "bolt." This is the condition represented by Fig. $7, \mathrm{D}, \mathrm{I}$. 
Then, as the projectile and eruptive sun swing round each other into positions II, the process will be repeated and a further pair of bolts will be projected. In the meantime the eruptive sun will have rotated on its own axis and the first pair of bolts will have swung out of line with that joining the two bodies. The result will be the disposition shown in Fig. 7, D, II. Passing on the same thing will again occur and, because of the rotation of the disruptive body, the bolts will have swung still further out of line so that, as Case III represents, the two trains of cjected matter will now have assumed the characteristic spiral arrangement. We may suppose that there were initially as many distinct bolts as there are planetary bodies in the evolving system. The first embryo form of the juvenile system will then be as Fig. 7, D, III represents. Here we have two trains of ejected matter partially wrapped round the parent sun as the two curved arms characteristic of the spiral nebular form.

Of course there will be great irregularities in the process. In general it may be expected that the nearer are the two bodies to each other the greater will be the quantities of matter ejected. While the latter are being belched out and are still within the strongly developed double gravitational field set up by the projectile and the eruptive sun, they will have gravitational tendency due to their mass. They will have a proper motion of their own due to the impetus given to them on eruption. They are sure to have some rotatory motion about their centres of gravity because of the irregularity of their ejection and the attractions of the parent stars. As a rule a considerable degree of dispersion of the ejected material may be expected so that a true nebula, in which there is the large central body and the knots, or nuclei, of condensed matter would result.

The bolts, on ejection, would have a temperature approximating to that of the eruptive sun, and they might reasonably be expected to be vaporous. But there would be such a vast expansion of this gaseous material that 
cooling would be a very rapid process, and condensation to the liquid or solid condition would soon occur except in the central parts of the nuclei. The system that would come into existence, therefore, would be (1) the central, partially disrupted sum, still in its original physical state and having lost only a rather small fraction of its mass; (2) a number of bolts arranged at first in two spiral arms but gradually settling down into regular orbital revolutionary paths round the central body; (3) a vast, widely extended cloud of wholly condensed matter in large or small fragments or particles, and also following orbital paths round the central body, or the individual knots, or the entire system. These are the planetesimal bodies. They would be cold. The nuclei or knots of the bolts would, for a time, retain much of their heat-how much, and for how long, would depend on their masses.

Such a process, if it were accessible to our observation, would perhaps be represented by the phenomena seen in a "new star." Here we can observe a very sudden increase in the luminosity of a star that was previously very faint. The latter we may suppose to have been in the physical condition of our own sun, perhaps even colder and undergoing condensation: perhaps even "skinned over" and with a solid, glowing crust. The approach of another similar star, or even of one of the cold and dark bodies that we know to exist, would initiate the series of huge eruptions suggested above and so there would be an enormous increase in the luminosity. It is characteristic of new stars that the light emitted rapidly decreases and is variable in the course of the decrease, and this is easily explained by supposing that the ejected matter quickly cools so that it forms a rather dense, nebulous mass of absorbent matter surrounding the glowing central, eruptive body and the incandescent bolts. This would be in slow rotation; it would not be uniformly wrapped about the central body and bolts, and so the absorption of light would not be uniform. 
The process of accretion.--Such may reasonably be supposed to be the genesis of the evolving planetary system. This would come to consist of a glowing central sun having a mass which would be (as in our own case) very much greater than that of all the other bodies budded off from it. Round this there would be a greatly extended. nebular cloud consisting mostly of cold and dark cosmic "dust," that is, discrete solid bodies of magnitudes varying from that of molecules perhaps up to or even greater than those of the largest meteorites that fall to the surface of the earth. In this nebula there would be a number of "nuclei," each representing a separate bolt. These planetary nuclei would be in orbital revolution about the central sun, being held by the gravitational field of force of the latter, and they would also be in rotation about their own axes.

Each of them would set up its own gravitational field and draw to itself the eosmic dust, or planetesimal bodies, that were at first in the condition of orbital revolution about the parent body. Thus each nucleus would sweep space about itself, gathering up the planetesimals and growing in mass and volume with this process. A certain condition of the evolving planet may be imagined in this preliminary phase : it would be much smaller than in the final one, but would be growing all the time. At first the infalling planetesimals would form a light, porous stratum or shell, but this would soon settle down by its own gravitation; pack together closely, and finally harden by compression as it underwent burial under the further infalls of the surrounding planetesimal matter. At first the growing planet would not be able to set up a gravitational field strong enough to hold the lighter gases: this is the stage attained by the moon, while it is perhaps the case with Mars, which appears to have an atmosphere consisting of carbonic acid gas and water vapour. The gases that now form the earth's atmosphere, or are combined with mineral matter in its crust, as well as the 
water of the oceans, must have originally been part of the nebular mass, held there by the gravitational field of the central body. But as the mass of the earth increased in consequence of the continued infall of planetesimal bodies it would, by and by, become great enough to collect the gases that now surround it. Before that, however, it would capture water vapour and this, at first, would be largely incorporated in the porous, growing, planetary substance.

Changes in rotational speed.-Given that the ejected bolt of solar matter had a certain initial, rotational speed it appears that we must postulate changes in this. Planetesimals would fall in from all sides, some overtaking the young earth and falling into it so as to communicate momentum to it, while others would meet it and so fall as to arrest its rotational speed. There might be such a distribution of the planetesimals that these effects would cancel each other, but it seems most reasonable to expect such irregularities in the nebula that the infall of matter would sometimes accelerate the terrestrial, rotational speed and sometimes retard the latter. At all events this effect may be assumed in the provisional stage of the hypothesis. It must have had momentous consequences, if it occurred.

Changes in rotational speed must, then, have affected the figure of the earth. At present the equatorial semidiameter of the earth is about 13.4 miles greater than the polar semi-diameter. Even now an increase of rotational speed would tend to increase the equatorial protuberance and accentuate the polar flattening-and viceversa. Given, then, that the primitive nebula consisted of planetesimal materials irregularly scattered along the great tracts diverging spirally from the central body, it seems likely that the accretions that the earth received would at one time increase its rotational speed and, at other times, retard it. Therefore the figure of the earth (which must also be assumed to have been more yielding in its earlier 
stages than it now is) must have oscillated and taken on greater or less oblateness from time to time.

Yield-tracts in the growing earth.-Next a " mechanism" must be assumed such as to allow the earth body to change its shape as it also changed its rate of rotation. Stresses would be set up in it as the rate changed and these would, on the whole, be greatest near the centre and least at points near the poles. They would, in general, diminish from centre to surface. Given, then, a change in the rate of rotation and a stress will be set up. In order that this stress may be relieved material must be shifted from the polar to the equatorial regions, or vice versa. If the rotational speed increased there would be a tendency to further flattening of the polar regions and so the crust there would be compressed from above downwards. At the same time the equatorial crust would tend to become more protuberant, and so it would be in a state of tension from above downward. If the rotation slackened the reverse would be the case. Somewhere between the poles and the equator there would be zones of no stress (of this kind) and the semi-diameter there would remain the same.

If the earth body were liquid, or even somewhat viscous, these stresses would be relieved by an actual transport of material, the molecules of the earth substance literally slipping on each other, or flowing in the same way that the ocean yields to the tidal generating force. We must assume, however, an earth-body that is solid and rigid in a high degree and incapable of viscous flow. Material must, therefore, be shifted in some other way. Under great mechanical pressure, assisted, it may be, by heat, tracts of "rock-flow," schistosity, or other similar conditions are established. In that kind of metamorphism seen in schistose, gneissose, or slaty rocks, planes of cleavage are , set up and the rock splits easily along these planes (which are initially perpendicular to the direction along which the pressure is exerted). Such cleavage planes are formed 
by the mechanical re-arrangement of the particles of the rock in thin sheets, or laminae, or by the re-crystallisation of the rock substance in such a way that the long axes of the platy or columnar crystals set themselves at right angle to the pressure. Then the rock yields and great masses become displaced, folded, ruptured, faulted, etc., in such ways as to relieve the stresses by actual dislocation and fracture and consequent re-arrangements of the material of the crust.

Directions of the yield-tracts. In such speculations as this some analogy suggests the form of the hypothesis. Assuming an increase of rotational speed the crust at the polar regions becomes compressed, or it may be thought about as being stretched everywhere from the pole along the meridians. A common response to stresses distributed in this way is a cracking along three lines radiating from a point at angles of $120^{\circ}$ : this gives rise to such rock forms as the familiar six-sided basaltic columns, which are due to contraction of a slowly cooling rock mass. A tentative explanation of the earth body accommodating itself to a change of rotational speed supposes, then, that a number of great yield-tracts will tend to radiate out from the poles meridionally towards the zone of no stress-the "fulcrumzone," in Chamberlin's terminology - and this we may take to be somewhere about $30^{\circ}$ in N. and S. latitudes. First we may consider a symmetrical arrangement of the yield-tracts and then consider how this is to be modified. There are, then, three meridianal lines radiating out from each pole at angles of $120^{\circ}$ apart, and terminating at $30^{\circ}$ $\mathrm{N}$. and S. latitude. There will be a difference of $60^{\circ}$ in longitude between the positions of these lines in the north and south hemispheres. Oblique lines are next drawn from the extremities of the northem meridianal ones to meet the southern meridianal lines. Thus the earth is divided up into six quadrilateral segments, each of which is bounded by parts of great circles. The reader should trace these lines on a globe. 


\section{AN INTRODUCTION TO OCEANOGRAPHY}

It has been noted that the stresses set up by changes in the rotational speed of the earth, or changes in the intensity of the tide-generating force are greatest towards the centre of the earth-body and least at the surface. Therefore, we have to consider, not only the surface of the earth, but its whole body down to the centre. The three pairs of quadrilateral areas represent, therefore, the bases of three pairs of four-sided pyramids, or wedges, having their apices touching each other at the earth's centre, their sides formed by great planes passing through the centre and their bases on the surface. These pyramids will sway on their centres, moving against each other, and it will be seen, on reflection, that this kind of segmentation lends itself to the changes in the figure of the earth that must occur as the results of the change in rotational velocity. We assume now that such a segmentation existed during the period of earth-growth by accretion and that oscillations in rotatory speed occurred, in the course of which the earth-body yielded to the changes in stress. Along the planes which bounded the quadrilateral segments, therefore, there were regions or tracts of fracture and readjustment. The yield-tracts on the surface would, then, be somewhere near the meridianal lines radiating out from the poles, and near the oblique lines crossing the equator.

Now it is clear that very many factors must have influenced the precise course of the surface yield-tracts. The latter would not be lines, so much as rather broad regions of fracture and disturbance, and it is not to be expected that they would take the symmetrical courses indicated above. They would not be straight, nor would the angles of the poles be $120^{\circ}$, but something rather more or less. What we have to expect, in general, is a rough correspondence to the ideal scheme, and also yieldtracts subsidiary to those indicated. Further, as the earthbody became more rigid, in the course of its growth and consolidation other yield-tracts must have developed. It 
will, however, be sufficient to show that there is really a rather striking correspondence between the postulated theory and the results of actual observation. This correspondence is shown in the following Figures, 8 (1) to (9). These are modified from Chamberlin's figures: the angles between the meridianal lines, and so the directions of the oblique ones depart from the theoretical scheme, but not to such an extent as might be thought necessary. The heavy continuous lines, then, represent these modified yield-tract directions; the heavy, broken lines continue them under the ocean floor, and the dotted lines are subsidiary yield-tracts not contemplated in the symmetrical scheme.

\section{The actual earth yield-tracts.}

(1) South polar region. Fig. 8 (1).-There is little doubt about our choice of the directions the tracts ought to take here. The Antarctic Continent is placed nearly symmetrically above the pole and three great land masses, S. America, Africa and Australia are placed round it in positions that approximate to equal spacing about a centre. There are indications of land connections (see Fig. 11) between the Antarctic Continent and the land regions that bound the great Southern Ocean, and so we have little difficulty in drawing the first three, basal, meridianal yield-tracts. They radiate out to Cape Horn, Cape of Good Hope and Tasmania. But obviously a subsidiary yield-tract is indicated in the position of New Zealand: this is represented by the dotted line.

(2) South Atlantic aspect. Fig. 8 (2).-The Antarctic yield-tract directed towards S. America is seen to bifurcate not far from the fulcrum-zone in about S. Lat. $30^{\circ}$. One of the oblique lines connecting it with the corresponding northern yield-tract runs along the eastern side of $S$. America, and its course underneath the tropical Atlantic is indicated by the heavy broken line. The other oblique line runs along the western borders of $\mathrm{S}$. and $\mathrm{N}$. America (see Fig. $8(3)$ ). The second meridianal line that joins 


\section{AN INTRODUCTION TO OCEANOGRAPHY}

Antarctica with Africa bifurcates into its two oblique prolongations : which embrace Africa along its eastem and western coastal regions. On the north the oblique connecting line running up the western side of Africa is

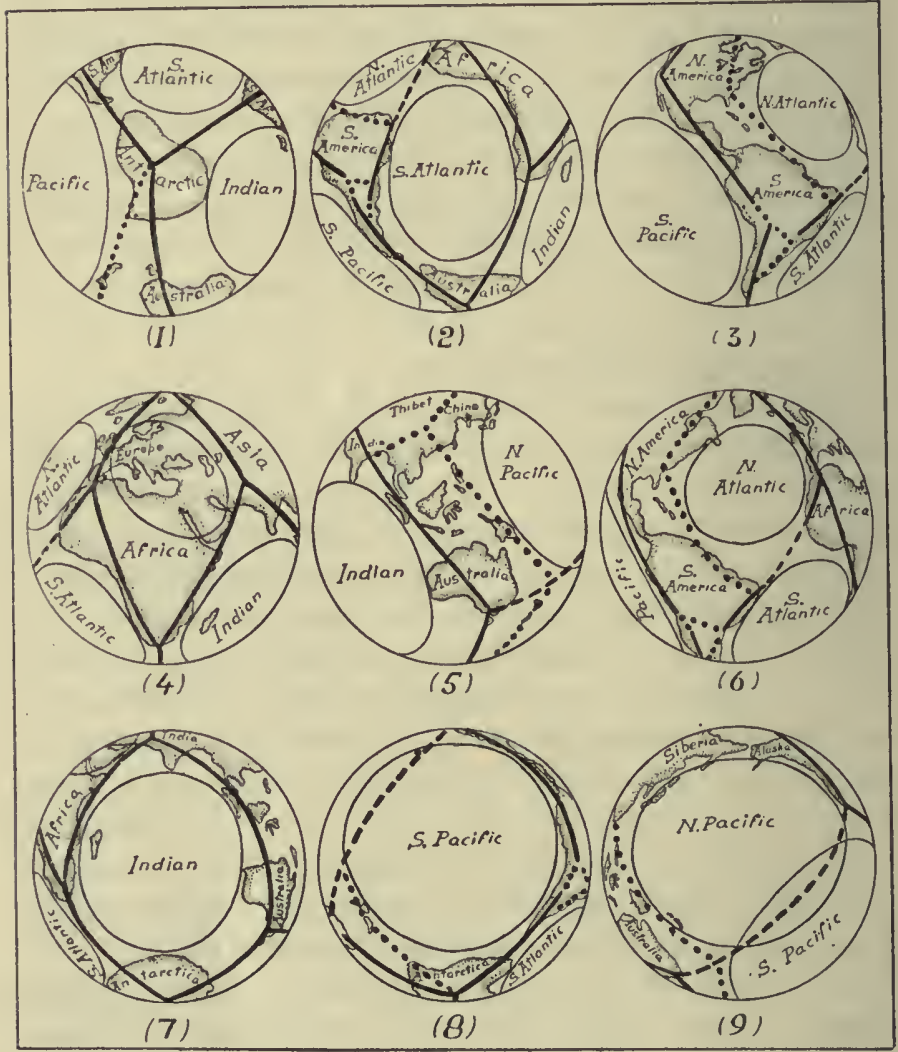

Fia. 8. The Chamberlin yield-tracts. Various views of the earth.

seen to join a radial one running down from the $\mathrm{N}$. Pole.

Antillean region. Fig. 8 (3).--Here again two of the postulated meridianal tracts in the high $\mathrm{N}$. and S. latitudes are shown, as well as the oblique one that bounds the Pacific coasts of the Americas. But two subsidiary yield- 
tracts are indicated by dotted lines: one of these is meridianal and runs down from the North Pole through the Gulf of St. Lawrence and the great American lakes towards the Floridan coast, while another is oblique and, together with the postulated line, bounds the north-east coast of S. America and the Antillean region-an area, as is well known, of great earth-disturbance.

The Eur-African Quadrilateral. Fig. 8 (4).-All the yield-tracts represented here are postulated ones, but the angles formed between them diverge (though not greatly) from the theoretical values. The Antarctic-African meridianal, the Arctic meridians embracing the W. side of Europe on the one hand, and striking down through Asia, on the other, and the two African oblique yieldtracts are shown.

East Indian yield-tracts. Fig. 8 (5).-Here we see the counterpart to the Antillean region. There are shown $(a)$ the postulated N. and S. meridianal and oblique lines, but the figure also represents the subsidiary meridianal tract striking from Antarctica through New Zealand, and a subsidiary northerly tract descending through China. These are joined together, in a regular way, by a subsidiary oblique tract. This together with the postulated one in this region include between them the East Indian areaone of evident disturbance-in the same way as postulated and subsidiary tracts embrace the Antillean area.

The western borders of the Atlantic and Pacific. Figs. $8(5)$ and (6).-These figures represent an obvious symmetry which is suggestive in a high degree. The East Indian region with its pair of parallel yield-tracts bounds the western side of the coalesced N. and S. Pacific Oceans. The West Indian region, also with its pair of parallel yieldtracts similarly bounds the western side of the coalesced N. and S. Atlantic Oceans.

The Indian Ocean region. Fig. 8 (7).-Here we again have the postulated yield-tracts: on the south, two meridianal ones joining Antarctica with Africa and 


\section{?S AN INTRODUCTION TO OCEANOGRAPHY}

Australia ; on the north, the meridianal tract striking down through Asia and, running obliquely across the Equator, the two connecting lines that frame the Indian Ocean.

The South Pacific region. Fig. 8 (8).-Both postulated and subsidiary tracts are required here. On the S. W. Antarctica and New Zealand are joined by the subsidiary south meridianal tract, and on the N. W. the broken line represents the oblique connecting line that goes under the Pacific Ocean : this is the approximate line of coalescence of $\mathrm{N}$. and S. Pacific. On the east the yield-tracts are all postulated ones.

The two Pacifics. Fig. 8 (9).- - Here the junction of the N. and S. Pacific Oceans is represented by the drowned oblique yield-tract shown by the broken heavy line. On the S. W. the border of the N. Pacific is formed by the southerly, subsidiary, meridianal yield-tract.

The reader is strongly recommended to trace these lines, as they are shown in Fig. 8, on a small globe: then he will easily see how very helpful is the Chamberlin hypothesis. He must again note what are the assumptions made:

(1) An earth growing by the accretion of solid planetesimals and with a rotational speed which oscillates because of the collisions of the infalling bodies with it ;

(2) The consequences of this-stresses set up by the tendency of the earth-body to assume spheroidal shapes corresponding with its changing rotational speeds ;

(3) The further consequences - " rock-flows" and tracts of yielding of the earth body in its adaptive changes of figure ;

(4) A possible "mechanism" permitting of this adaptive change of figure-the segmentation of the earth body by the establishment of three pairs of quadrilateral wedges extending down to the centre.

Thus a certain series of zones, meridianal and oblique (with reference to the equator) are assumed. Along these 
zones the earth-body yields to stresses (in so far as the yielding can be traced on the surface). Assume now that yielding takes place most frequently along the margins of the continents. This is indeed fairly certain, for there we find the greatest inequalities of level, the continental plateaus descending fairly steeply, to the oceanic abysses. There also we actually find regions of obvious earth disturbance, volcanic and earthquake areas and great mountain folds.

Continental and oceanic areas are, therefore, bounded by a series of zones which are mostly parts of great circles. These zones are representable by a theoretical scheme. The actual zones, in so far as they can be traced on the earth's surface, diverge somewhat from the theory, but the extent of divergence is not very great when we consider that the causes assumed are certainly far less complex than the actual ones. And quite unimportant changes in the angles assumed, with the recognition of subsidiary yieldtracts, lead to a fairly satisfactory correspondence of theory and observation.

Oceanic and Continental regions.- We find, therefore, that a series of meridianal and oblique yield-tracts divide up the surface of the earth into six great, roughly quadrilateral areas. Some of these are continental and others are occanic. The oceanic areas are arranged in pairs, North and South Atlantics, North and South Pacifics and the Indian Ocean which is southerly to a corresponding area of predominant depression occupied by the Mediterranean, Baltic, Black Sea, Caspian, Red Sea and Persian Gulf. North and South Atlantics have coalesced just as North and South Pacifics have done. There is a further symmetry with regard to the situations of each pair of oceans: the North Atlantic lies obliquely to the west with respect to the South Atlantic, and this is also the case with the North Pacific in respect to the South Pacific. The Mediterranean-Black Sea basins lie obliquely to the wast with respect to the Indian Ocean. There is 
little geological evidence of the former existence of the two Pacifics, but the forms of the Atlantics, and the markedly volcanic and seismic nature of the ocean floor along the region between the Straits of Gibraltar and the Antilles, suggest strongly that this has been a zone of yield of the earth's crust.

Some of the great areas delimited by the yicld-tracts are depressions beneath the mean earth level, and are, therefore, oceanic, while others are elevations, and, therefore, are the loci of continental plateaus. These differences are to be explained, and two new processes are invoked for this purpose: (1) the prevalent atmospheric circulation and (2) the disintegrative effect of water upon the elevated land regions. The general form of the atmospheric circulation is that of an imperfect eddy over each of the great oceans, just as in the case of the oceanic circulations themselves. Such circulations are modified to an enormous extent by the distribution of land and sea, but their prime motive forces are independent of this distribution. In general, equatorial regions must be those of high temperature and ascending movements of ocean water and atmosphere, while sub-polar regions are characterised by low temperatures and descending motions. Further, the rotation of the earth on its axis has a deflecting effect such that currents of water and air tend always to turn to the right-hand side in the northern, and the left-hand side in the southern hemispheres. We must assume that tendencies to these gyratory movements of both the ocean and the atmosphere existed in the juvenile earth during its phase of growth by the accretion of planetesimal particles.

If that is so there would be a tendency for the heavier particles to settle in the central parts of the great atmospheric eddies and, therefore, these regions of the earth's surface would be likely to come to consist of material of higher specific gravity than the surrounding ones. As soon as this became the case water vapour 
drawn to the surface of the growing earth would gather over the places where the force of gravity was greatest. Thus the loci of the primitive oceans ought to have been roughly marked out in the earlier phases of the earth's growth.

Whenever rain began to fall on the surface of the early contmental plateaus, a process of disintegration of the primitive land would begin. Weathering and solution of the rock surface would occur, and materials would be transported from the land to the seas. It is probable that this process was selective in the sense that heavier materials would be transported from the land and lighter materials left there, or on the shallow sea bottom fringing the land. Thus the difference between oceanic and continental regions - the former tending to become areas of greater, and the latter of lesser gravitation would tend to become accentuated. By some such cumulative process as this, starting from a slight initial difference that favoured the accumulation of water on some of the original areas delimited by the great yield-tracts, the oceanic and continental regions would become established. This part of the theory is, however, not very satisfactory.

Permanence of the great oceanic regions.-It is to be noted, at this stage, that the hypothesis of the origin of of the oceans outlined in the preceding pages involves the further hypothesis that the great oceanic depressions have always occupied the positions that they now do. This follows from the hypothesis of an earth-body contracting into a tetrahedral shape from a state in which it was intensely hot and also from the hypothesis of Love, according to which "harmonic deformation" occurred as the result of an earth-body rotating on a centre that was not its centre of gravity. There are other reasons for believing in the permanence of the oceanic basins, notably that of the great difference in nature of the materials forming the deep-sea deposits and those that are to be found in the series of sedimentary rocks. This we shall 
deal with in the following chapter. There is also the theory of isostatic equilibrium between continental plateaus and ocean bottoms (see Chapter IV), and this seems incompatible with the idea that an earth area that is now an oceanic abyss may, in past geological periods, have been the locus of a continental plateau. The assumption that the South Atlantic region, for instance, was at one time a continental land mass is plainly an ad hoc hypothesis designed to explain certain facts of distribution of animals and plants, facts which may be susceptible of other explanations. There is, indeed, much evidence that sedimentary rocks situated in land areas far removed from the sea, are marine in origin, but this may merely mean that shallow seas transgressed, at one time, on former land areas. This does not imply that the sites of those strata were ever covered by sea of the depth of the present oceans. The question of the permanence of the oceanic basins will, however, be discussed more fully in the last chapter.

The smallness of the effects dealt with in this chapter.It is very necessary to note that the deformations and inequalities of the earth considered in this chapter are very small indeed on the earth-scale. We shall see in the following chapters, that the oceanic depressions, as well as the continental elevations, are, in magnitude, only about $0.04 \%$ of the earth's diameter. The "tetrahedral earth," with its coigns representing continental tablelands, and its faces the oceans would, if figured on this page, be indistinguishable from a perfect sphere. Even the equatorial protuberance and the polar flattenings, which are really very large features when compared with the land and sea elevations and depressions, cause the figure of the earth to deviate from true spherical form only to the extent of about $0.3 \%$. Other deformations suspected to exist-the "pear-shape," and the "nipple" somewhere in Africa-are most difficult to detect, much more to measure precisely. 
So also with the movements that we call "yielding" of the earth-body. Such phenomena as are seen in volcanic eruptions and earthquakes are indeed gigantic and destructive when judged by their effects on human constructions, . but they are the merest sweatings and shivers when they are regarded as terrestrial effects. Ocean tides have momentous consequences to sailors and fishermen, but they only produce infinitesimal differences of sea level when they are measured on the earth-scale. Tides in the body of the earth itself are only tremors. On the cosmic scale then, the causes that are competent to elevate continents or depress ocean basins are exceedingly small ones, and so the effects we have to explain do not require the operation of factors that are necessarily very great. The earth is, in fact, a body that is exceedingly stable, and however striking its instability may be from the human point of view, it is infinitesimal from the cosmic standpoint. 


\section{CHAPTER III}

\section{THE DEPTHS OF THE OCEAN}

From the point of view of the sailor, fisherman, yachtsman or oceanographer great diversity of feature characterises the sea bottom. In respect of level they distinguish between abyssmal and shallow seas, flats, channels, gutters, deeps, shoals, ridges, bars, etc. In respect of the nature of the bottom there are equally marked differences : hard or soft, boulders and stones, gravel, sand, mud, sludge, ooze, coral, etc. These features are, however, inferred rather than seen, and the impression obtained when one - looks at extensive areas of sea bottom, laid bare by a very low spring tide, is that of monotony and sameness rather than diversity. Compared with the land there is a striking uniformity of level and the character of the materials laid down on the sea bottom may appear to differ very little over very great areas. That variety of depth which the experience of the fisherman or sailor enables him to visualise, depends rather on its utilitarian than on its absolute value. A few feet more or less in depth may make a very great difference from the point of view of the navigation of a vessel; while the nature of the bottom itself, boulders, sand, weed, or mud, may be all important to the success of a fishing operation. Even the oceanographer usually exaggerates the "bottom relief" as well as the differences in the nature of the bottom depusits. It is very important to have this influence of scale of value in mind when one is considering the morphology of the ocean floors.

The estimation of depth.--The practicable methods of finding the depth of the sea are :

(1) The traditional hand and deep-sea sounding lines. 
Here the apparatus consists of a hard, closely made, wellstretched rope of small diameter marked at various intervals by pieces of leather, cloth, etc., worked into the strands of the rope. The sinker is a heavy piece of lead (10 to $14 \mathrm{lbs}$. for a hand line of 25 fathoms and 28 to $30 \mathrm{lbs}$. for the deep-sea line of 100 fathoms). The bottom of the lead is hollowed out and the recess is filled with tallow. The hand-line is simply kept in a loose coil, but the deep-sea line is wound on a wooden reel held in a man's hands when the sounding is being made. When the line is well stretched and carefully marked the soundings obtained are usually very accurate. The technique, however, of sounding by these means is complicated and not easy to acquire.

(2) The pressure tube is used by large vessels that are compelled to make soundings while still under way. A steel rope consisting of a strand of a few wires is generally used, and this is coiled on a reel which forms part of a machine fixed to the deck of the ship. A glass tube of rather small bore, and with one end open and the other sealed up, is attached to the sounding line a little way up from the lead. The latter is thrown overboard and goes down to the bottom at an acute angle to the sea level, so that much more line is out than is represented by the depth of the water. When the sinker is felt to touch the bottom the apparatus is hauled in and the depth is estimated from the height to which the water has risen in the sealed glass tube. At the surface of the sea the pressure on the column of air in the tube is, of course, one atmosphere. Roughly 30 feet of water exert the pressure of one atmosphere and from the relation, pressure $\times$ volume $=$ constant, the depth is found. The inside wall of the tube is coated with a composition that is discoloured by contact with sea water, and when it is taken aboard the fraction, to which the original volume of air has been reduced by the pressure of the column of sea water standing on the sea bottom, is read off on a gauge calibrated for the 


\section{AN INTRODUCTION TO OCEANOGRAPHY}

particular length of tube used. If, for instance, the volume is reduced to one half, the pressure has been doubled, and was exerted by about 30 feet of water $(=5$ fathoms). If it is reduced to $1 / 4$ th of the original volume the pressure has increased to 4 atmospheres, that is $30 \times 3$ feet due to the water column and one atmosphere, due to the air pressure. The depth is, therefora, 90 feet $=15$ fathoms, and so on. The method is suitable for vessels that require only an approximate knowledge of the water depth but is not accurate enough for scientific investigations.

(3) Sounding Machines. Telegraph cable engineers and scientific workers use what is practically a deep sea line of very great length. This line is made of steel pianoforte wire of rather less than one millimetre in diameter but, nevertheless, exceedingly strong. There are various types of sounding machines, but those which are most compact and easily used are the Lucas forms. The larger machine is represented in its essentials in the figure on page 37.

The wire, which may be over six miles in length, is wound evenly on a very strong steel drum working in a triangular frame. It passes ont over a leading-wheel which is carried by a moveable arm, to the lower part of which is attached a leather brake strap bearing on the rims of the drum. When the sinker is running out its weight is carried by the leading wheel, which is therefore pulled forward. This throws back the lower part of the arm and releases the brake strap. Whenever the sinker touches the sea bottom its weight is taken off the leading wheel, the two strong springs shown are then able to pull back the arm and the lower part of the latter is thrown forward and so pulls on the brake strap. Therefore the machine stops whenever the sinker touches bottom.

At this moment, a counter, geared on to the leading wheel, is read. The revolutions of the latter have been recorded and the circumference of the leading wheel being 


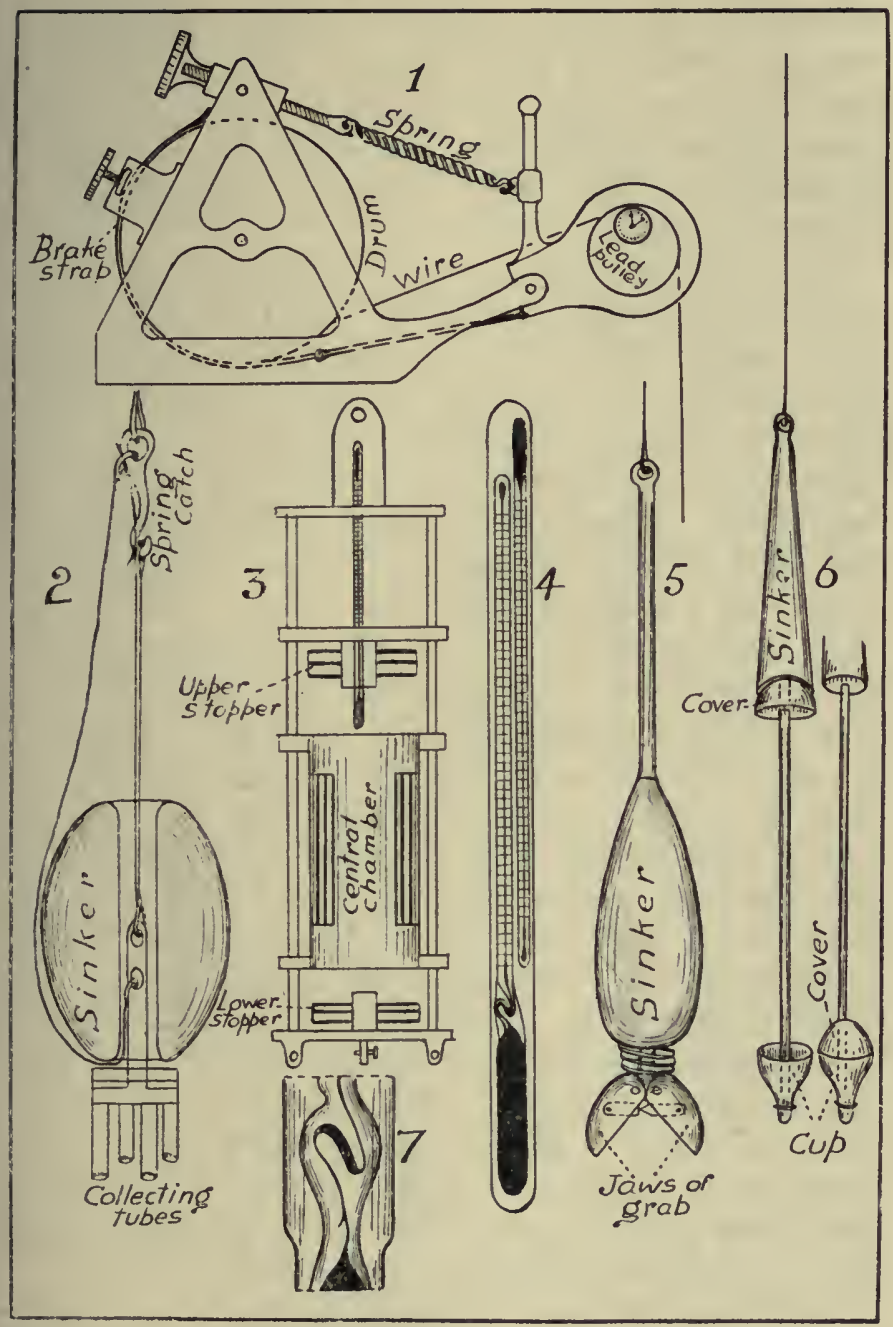

Fsu. 9. Hydrographic apparatus. (1) The Lucas deep-sea sounding machine; (2) Detachable deep-sea lead; (3) The Nansenl'ettersson water-bottle ; (4) Deep-sea reversing thermometer; (5) The Lucas bottom sampler; (6) The Hudson collecting lead. 
known the length of wire run out is found. As a matter of fact the revolution counter is directly calibrated in fathoms so that the depth is shown on it. The wire is then wound back again by a motor geared on to a pulley carried by the drum spindle, and as it comes in it is oiled to prevent rust and "laid" uniformly on the drum by a suitable mechanism.

The sinker is about 40 lbs. in weight, but in a deep sounding the weight of wire run out is also very great. In reeling-in there would, therefore, be a considerable strain on the wire-enough, perhaps, to break it-and so it is necessary to detach the sinker. Fig. 9 (2) represents the quadruple-tube sinker with its releasing mechanism. When the apparatus touches bottom the four short tubes plunge into the ooze and fill themselves, forcing up a weighted rubber washer that tends to close their upper, open ends. At the same time the steel spring shown throws off a ring from the hook attached to the wire and the apparatus turns over on its side. The sinker is now free to fall away from the sounding tube and the latter is hauled up to the surface. At the same time the rubber washer shuts down on the upper open ends of the tubes and this prevents the ooze from being removed. Sometimes a single steel sounding tube, of a foot or more in length, is used. Sometimes this contains a glass tube which is filled by the deposit. In this way any evidences of stratification of the latter can be observed. Fig. 9 (5) represents the Lucas grab. This goes down with its jaws open and when it touches bottom the pressure of the latter trips a little brass tumbling block within the jaws. The latter are thereupon closed by a powerful spring. Fig. 9 (6) represents another form of sounding tube.

In all cases the steel sounding wire itself is not directly attached to the sinker but to a fathom or two of "stray line" (strong, thin rope). The latter falls on the sea bottom but the wire is kept straight and thus kinking is avoided. 
(4) Sounding by sound waves. Since the war of 1914, methods of finding the depth of the ocean by quite a different means have been developed. An apparatus attached to the bottom of the ship makes a small, sudden explosion, thus setting up a sound wave which travels outwards along concentric, spherical fronts. On reaching the sea bottom this wave is reflected and the echo is transmitted directly back to the surface, where it affects a receiving apparatus on the ship and makes a signal. The moments of the explosion and of the receipt of the reflected wave are recorded very precisely, and half of this interval of time is that required for a sound wave to travel through a column of water of the depth in situ. The rate of transmission of a sound wave through water depends on the temperature and salinity and so corrections have to be made.

(5) Sounding by an electrical oscillator. This mechanism is referred to in connection with tidal observations.

Methods (1) to (3) are obviously rather laborious. In the time of the Challenger expedition, hemp rope was used for the sounding line, and some hours were required in order to make a single sounding. The use of steel wire has shortened the time very greatly, but still the ship has to be stopped and so manœuvred as to keep the sounding line vertical while it is running out. This makes sounding in deep water a very laborious operation, if the observations have to be made at close intervals, and the result is that there are everywhere great areas of ocean bottom which have not been sounded at all. Method (4) allows of the depth being determined while the ship is on her passage, and the last method gives a continuous record. So far, however, these latter means of deep sea soundings have not been completely developed.

The bottom gradients.-Ocean soundings have been made most frequently in rather close proximity to the landin the neighbourhood of rivers, harbours, anchorages, bays, estuaries and, in general, in waters most used by fishing, 
and other vessels. The result is that the depth of the sea is known in considerable detail, in many parts of the world at all events, where it is less than about 100 fathoms. Here there is much diversity of feature in the bottom, considerably more than where the depth is greater than about 100 fathoms. There are shoals, channels, bars, gutters, ridges, etc., and the charts representing these are always more complex than they are for the truly oceanic regions. Just now, however, we neglect this variety of feature in shallow water and consider rather the acerage gradients.

The continental shelf.-Round the margins of all continents and continental islands there is a zone of sea where the bottom slopes down on the average very slowly to somewhere about 100 fathoms. If we "smooth out" the smaller inequalities (channels, shoals, etc.) we find that the inclination downwards is very small--usually less than about $1^{\circ}$ ( $1 \mathrm{ft}$. in about $57 \mathrm{ft}$.).

The depth of 100 fathoms as the limit seawards of the continental shelf is rather arbitrary and is taken because it is a round, easily remembered number: in different continental regions it varies very greatly. The width of this zone of shallow water is also highly variable. Out from Achill Head (on the West Coast of Ireland), for instance, it is only about 30 miles wide, but due west from Land's Fnd the depth of 100 fathoms is reached only at about 200 miles. All the North Sea and most of the Irish Sea are less than 100 fathoms deep, and only in a very few places round the British Islands is the sea deeper than this.

Beyond this rather vague boundary the incliuation downward of the sea bottom becomes rather greater towards a depth of about 1,000 fathoms, and then it becomes greater still. If we join together all places where the water is 100 fathoms deep and then draw a smoothly running, irregular curve, passing as nearly as possible to all these points, we obtain the " 100 -fathom contour line." Doing the same thing with regard to the $1,000,2,000$, and $3,000-$ 
fathom soundings, we get a series of curved lines which run, very roughly, parallel to each other and to the general continental outlines. Measuring the average distances between these we then find that the 2,000-3,000-fathom contours are rather closer together than the 2,000 and 1,000 contours, and still more so than the 1,000 and 100 contour lines. On the whole, then, the gradient downwards of the sea bottom is greater just about the 1,000-fathom contour line than it is anywhere else. This part of the sea bottom is called the Continerital Slope.

The continental slope.-It is usual to represent the continental shelf and slope by means of imaginary sections taken vertically to the surface of the sea. Generally the vertical scale (of depths) is made much greater in these sections than is the horizontal one, and when this is done the figures often represent both the shelf and the slope in a striking way. But the distortion of the two scales may convey rather misleading ideas both of the relative depth of water and the bottom gradient.

In Fig. 10 the sections are drawn to the same scale of distances both horizontal and vertical : in each case one millimetre represents a mile. Further, the figures represent the curvature of the earth's surface, on approximately the same scale. Now it is by no means easy to find data on the published charts that will show the continental shelf and slope, because there is generally a great paucity of soundings outside the 100 -fathom contour line and so the inequalities of sea bottom, if they exist, must often be " averaged out" in the process of making the sections. But even when we do find data that enable us to construct a section, it is often the case that it is very difficult indeed to say where, precisely, the limits of the shelf should be, or where the steepest gradient, or continental slope, should be placed.

Fig. 10 (1) represents a section of the Atlantic Ocean taken from the West Coast of Ireland in Lat. $51^{\circ} 30^{\prime} \mathrm{N}$., at a place where there is a prolonged continental shelf. 


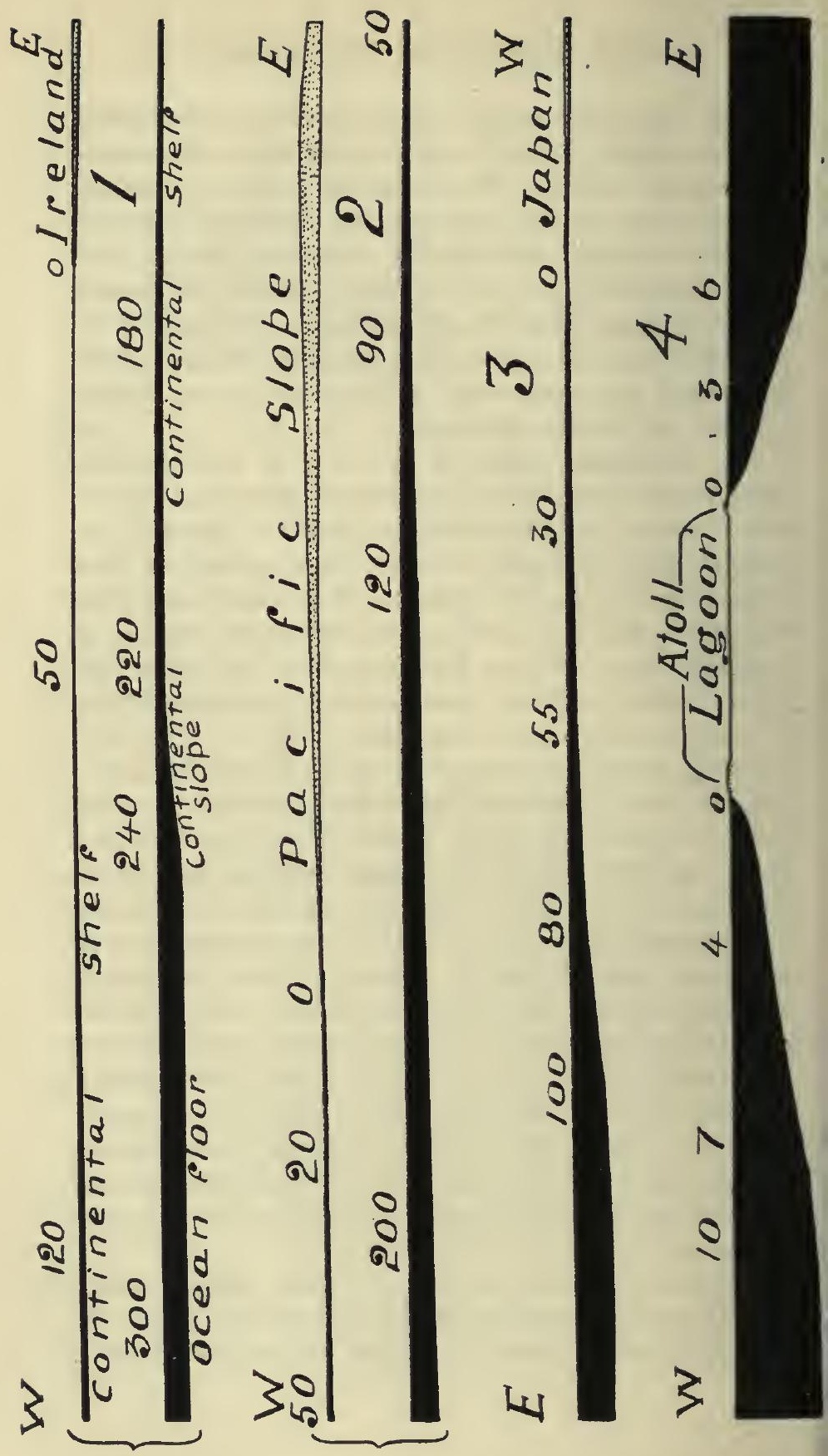


Out to 50 miles from the coast the sea does not exceed 100 fathoms in depth, but it is difficult to see any decided change in gradient at about this depth and from there out to about 220 miles from land the bottom slopes down rather gradually to about 1,000 fathoms. Between about 220 and 240 miles out there is, however, a change in gradient and this is quite noticeable on the section. Here the average inclination downward is about one in ten (an angle of $\left.5_{4}^{10}\right)$. This is the continental slope, and beyond it the depth and the average gradient do not change much. That is, at a distance of about 250 miles from land in this region the ocean "abyss" is reached.

Fig. 10 (2) represents a section taken along lat. $10^{\circ} \mathrm{S}$., that is, out from the Peruvian coast, and nearly at right angles to the general trend of the western coast of $S$. America. It also includes the adjacent land (stippled part of the section), thus passing through the Andes, where the highest altitude on the line of the section is about 15,600 feet. The section thus represents the great "Pacific geosyncline," and shows, at the best, the transition from an oceanic depression to an elevated continental region. At 20 miles seawards the depth is 50 fathoms, at 90 miles it is 1,000 , and at 200 miles we attain the Pacific oceanic abyss at a depth of about 2,500 fathomis. Now we see here that the average inclination both of the "Pacific Slope" and of the adjacent ocean floor does not appear to be particularly striking. Neither is there any place where the sea bottom is flat enough to constitute an obvious shelf, nor so much steeper than the average as to give us a pronounced continental slope.

Fig. 10 (3) is taken east from the Japanese coast in lat. $30^{\circ} 10^{\prime} \mathrm{N}$, and here one of the greatest oceanic deeps is represented. At a distance of about 30 miles from the coast we find a depth of 100 fathoms, at 55 miles 1,000 . at 80 miles 2,000, and at about 100 miles a depth of 4,000 fathoms. The inclination downwards is, so far as one can see, nearly uniform out to a depth of about 2,000 fathoms, 


\section{4

but from there the bottom descends more steeply to a depth of 4,000 fathoms. This is, however, not the typical Pacific Ocean floor but is the bottom of a "deep," a place where an exceptionally great depth, over a very limited area, has been observed. So we cannot, in this section, point to any obvious continental slope.

Fig. 10 (4) illustrates the slope and depths off an oceanic island, and represents a very different condition from that characteristic of the continental margins. The island is the Funafuti coral atoll in the Pacific Ocean, and the section is taken east and west (magnetic) across it. Going from west to east we find a depth of 500 fathoms at one mile from the rim of the atoll, 1,000 fathoms at $2 \frac{1}{2}$ miles, and the ocean floor is reached at a distance of about six miles. Here we find no indications of a shelf and, indeed, the gradient downwards appears to be steepest close up to the outside of the atoll. Within the latter the lagoon is, of course, only a few fathoms in depth.

In all these cases (Fig. 10), the section is made from the data given on the Admiralty charts. Contour lines are drawn and then the horizontal distances are taken from the latter. Because of the paucity of soundings there is always considerable difficulty in drawing the contours, and more than one way is usually possible.

The form of the ocean floor.-There is, therefore, a general slope downwards from the land to the ocean bottom. This slope is not uniform but varies in an extraordinary way thongh, looking at it in a very general manner, there is, first of all, a very gradual descent down to a limited depth which varies between about 100 and 1,000 fathoms and, next, a rather steeper gradient down to about 3,000 fathoms. The first, very gradual slope downwards may be called the continental shelf, and the second, steeper descent is the continental slope. Outside the latter the ocean bottom is, on the average, a rather flat plain presenting very little relief. The gradients are, as a rule, exceedingly small, far less than the ordinary railway ones, and they 
would, in general, be imperceptible to the eye if the ocean bed were dried up. On the great scale, however, these very small gradients give the ocean floor certain forms which we must now consider.

Terminology.-The various terms which are most commonly used are :

Continental Shelf (Plateau; Continental Schelf). The bottom out to about 100 fathons, or to any other depth after which the gradient increases.

Plateau (Plateau). A flattened, extended, submarine elevation.

Shoal (Haut fond; Grund). The most elevated parts of a plateau.

Bank (Banc; Bank). A low non-rocky submarine elevation.

Ridge (Crête: Rucke). A submarine elevation of elongated form.

Rise (Seuil; Schwelle). An extensive, gently sloping elevation of the sea bottom.

Reef (Riff; Reef). A rocky, dangerous, submarine elevation of elongated form.

Depression (Depression, Mulde). Any lowering of the sea bottom in general.

Basin (Bassin; Becke). A depression of approximately rounded form.

Trench (Fosse; G'rabe). Any marked, elongated depression of the sea bottom.

Deep (Fosse; Tiefe). The deepest part of a depression. Generally all parts of the ocean floor greater than 3,000 fathoms in depth.

Contour lines.-The data for descriptions of the forms of the ocean bottom are mainly the official charts published by the various hydrographic departments (principally Great Britain, Germany and the United States of America) and the soundings made by deep-sea expeditions. Near the land, in shallow water of less than 100 fathoms, the soundings are generally "reduced" to what they would 
be at low water of ordinary spring tides. In extreme cases, therefore, the depths of water may be some 5 or 6 fathoms greater than those marked on British Admiralty Charts. (See pp. 203-6).

Such charts are covered by a multitude of figures which are difficult to visualise as a whole. Therefore contours are drawn. On British charts these are usually drawn at $5,10,20,50$ and 100 fathoms. A contour line on a chart is usually defined as "a line joining all points where the depth is the same," but this is not quite the case. The contour passes as nearly as possible to all the points where depths of (say) 50 fathoms are marked but, as a rule, it would go near points where (say) 49 or 51 fathoms are recorded. In areas where there are few records the contour line will, so to speak, "split the differences": thus it would pass nearly midway between positions where the depths are recorded as (say) 36 and 60 fathoms, but it would be nearer to 60 than to 36 . It should be clear to the reader that contour lines are generally approximations and that two persons constructing them from the original data would not in general get quite the same results.

Further, the shape of a contour line will depend on the scale of the data: the more numerous the latter the more complex will be the shapes of the contours. In smallscale charts the contours are generally lines of sweeping curvature, and there is a tendency for the successive ones $(1,000,2,000,3,000$ fathoms, say) to "flow," so to speak, roughly parallel to each other. In large-scale charts as, for instance, those representing the sea bottom in the vicinity of an important harbour, such contours as the $5,10,20$-fathom ones are often very complex. They may interdigitate, or dovetail, and there may be numerous "islands" of shallower or deeper bottom.

Then the contours may be drawn for soundings in fathoms or metres. A fathom is nearly 2 metres and may be taken as such when we merely want a broad view of the features of the ocean bottom in depths of, say, 0 to 50 
fathoms. But when an ocean is contoured, first by 100 , $1,000,2,000$ and 3,000 fathom-lines and then by $200,2,000$, 4,000 and 6,000 metre-lines the results will not be quite the same.

The student should endeavour to think in terms both of fathoms and metres, and he should look on bathymetric contours merely as a general aid to visualising the forms of the sea bottom. He should not omit to study the uncontoured charts, trying to draw the contour lines for himself. Such work is most interesting.

We next consider small-scale charts of the various ocean bottoms.

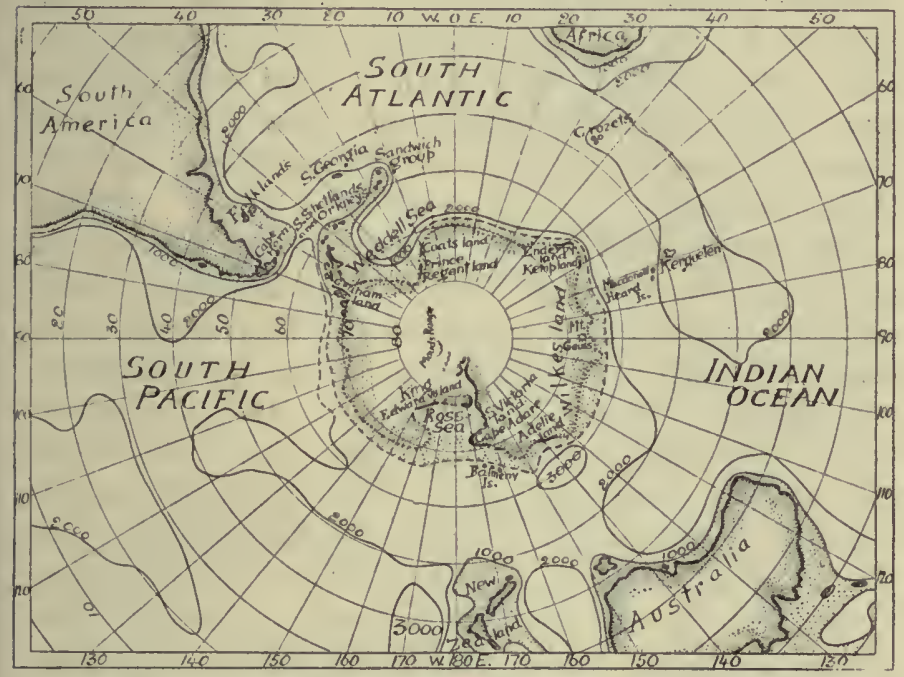

Fig. 11. The region round the South Pole. The land outline, where known, is indicated by a heavy, continuous line ; the probable land outline is shown by heavy dots. The land (known and probable) is stippled. The zone between the land outline and the 1000 -fathom contour is stippled. The soundings are in fathoms.

The Antarctic Ocean.-Fig. 11 is made from the latest Admiralty charts, but it will be seen that our knowledge of the immediate surroundings of the South Pole is still very incomplete. Obviously there is an Antarctic Continent 
which is deeply indented at two places, the Weddell Sea and the Ross Sea. The boundary of the continent, for those places where land has not actually been seen, is taken to be near the great ice-barrier. The whole continent is covered by a permanent ice-cap which projects out into the Southern Ocean and breaks away as the great tabular icebergs.

The 1,000-fathom contour line round Antarctica is very imperfectly charted because of the paucity of soundings. Where it is not well known, it is represented by a broken contour line in Fig. 11. In some places even the 2,000fathom contour is badly known. Clearly, however, our available data indicate two conditions that are very important: (1) the relatively shallow sea (between 1,000 and 2,000 fathoms) between Graham Land and Cape Horn, and (2) the relatively shallow sea (also 1,000 to 2,000 fathoms) between the Antarctic Continent and the Australian land.

The Arctic Ocean. (Fig. 12.)-The same conventional markings are employed. The land surface is left white and the continental sea margin (out to 2,000 metres in this case) is stippled. The shading represents, by its intensity; the depths. We see, then, a very extensive sea-area where the depth is everywhere less than 2,000 metres. On this are situated all the North American Islands, Greenland, Iceland, the Faeroes, the British Islands, the North Eurasian Islands, etc. Centrally to this archipelago is the North Polar Basin where depths exceeding 3,000 metres are to be found. The precise western boundaries of this basin are uncertain, for want of sufficient data, but its general form must be substantially as shown in the figure. It is clearly shut off from the Pacific by the shallow water in and near Behring Straits, both on the Arctic and Pacific sides: in the Straits themselves the sea is only 40 to 60 metres deep. It is shut off from the Norwegian Sea by water of about 800 metres in depth. The Norwegian Sea is itself a basin of at least 2,000 metres 
in depth, and in it there are two large depressions where depths of over 3,000 metres are to be found.

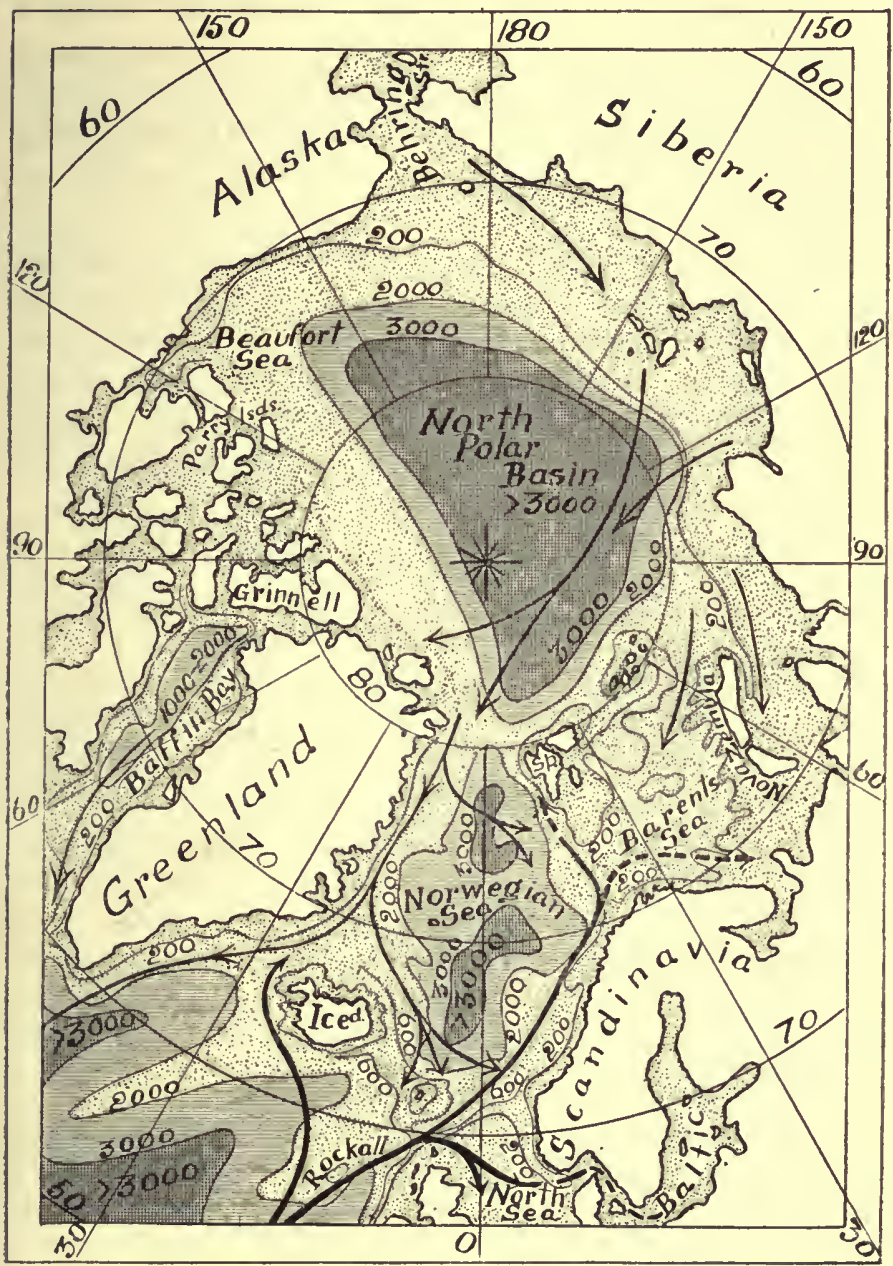

FIG. 12. The Arctic Ocean.

Between Greenland and North America there is Baffin Bay, containing a trough where the depth varies between about 1,000 and 2,000 metres. The Norwegian Sea, which E. 
interposes between Greenland and Norway is, itself, shut off from the Atlantic by the great rise which connects the British Islands with Iceland and Greenland. Along a narrow ridge joining the Shetlands, the Faeroes and Iceland the sea is only about 400-500 metres in depth. The existence of this $W^{\prime}$ yrille-Thompson Ridge has important consequences for the general circulation of water in the North Atlantic and North Polar Oceans.

The general picture of the Arctic Ocean is, therefore, the reverse of that of the Antarctic. In the former we have a nearly land-locked ocean of considerable area and depth. It is shut off, in respect of the circulation of the bottom water, by the restricted Atlantic and Pacific openings, where the sea everywhere is much less than 1,000 fathoms in depth.

The Atlantic Ocean.-Fig. 13 represents in a simplified way, the main features of the Atlantic Ocean in respect of its depths. The contours that are drawn are 2,000, 4,000, 5,000 and 6,000 metres. The land surface is left white; the region between this and the 2,000-metre contour (which we may regard as the Continental Shelf) is stippled; the region between 2,000 and 4,000 metres is lightly shaded; that between 4,000 and 6,000 metres is darkly shaded and the "deeps," that is the isolated patches where the depth is greater than 6,000 metres are cross hatched. All detail other than this is omitted because large scale charts are really necessary for its adequate representation.

Even the limited detail in Fig. 13 (which is only to be regarded as a sketch chart) shows that the Atlantic differs remarkably from the Pacific and Indian Oceans. This is due partly to the much greater amount of investigation that has been made in the Atlantic region and partly to certain structural features which we shall consider in Chapters $\mathrm{V}$ and $\mathrm{X}$. Far too little oceanographic research has been made in the Pacific and Indian Oceans, and some speculations that are quite permissible with regard to 
the Atlantic can hardly be elaborated in the cases of the two other oceans.

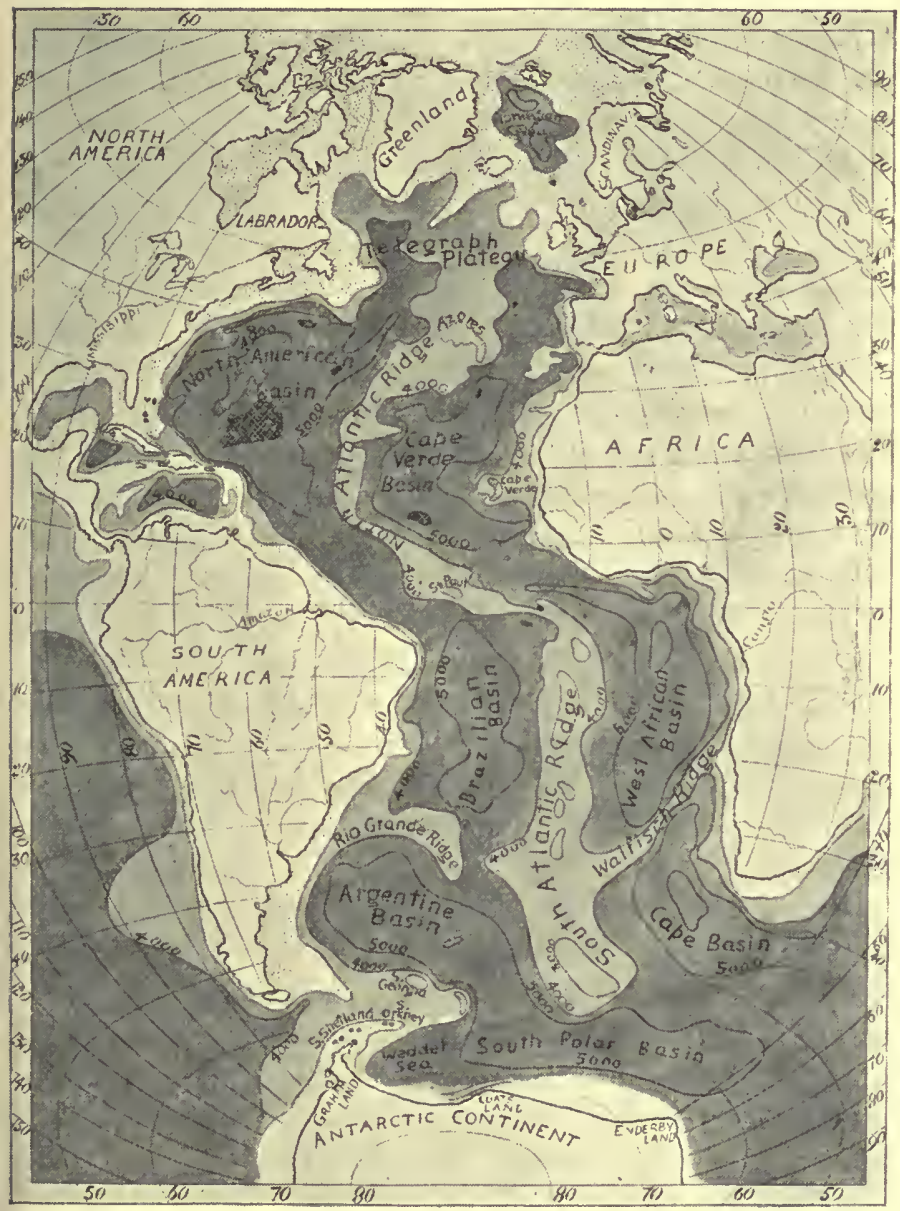

FIG. 13. The Atlantic Ocean.

The salient features of the Atlantic, with respect to its depth are as follows :

(1) The form of the Continental Shelf. 
(2) The remarkable Central Atlantic Rise or Swell.

(3) The connection of S. America with the Antarctic Continent.

(1) The Continental Shelf. The region of sea adjoining the continental land and having a depth of less than 2,000 metres (approximately 1,000 fathoins) may, hereafter, be regarded as the continental shelf. It is an area of transition between truly oceanic and truly continental regions. It may have been sea or land, and undoubtedly it has been the locus of extensive geological changes. Transgressions of the land over the sea and vice versa have very frequently occurred in this region in the past. It is seen in characteristic form all round the coast of Africa and everywhere round the coast of South America, with the exception of Patagonia. In these regions the shelf is relatively narrow. Suppose that there is a similar wide zone of land on the margins of the Continents and call this the "continental rim" - -then we see that both rim and shelf might be now sea and again land, but that the general form and extent of the continental elevations, and the adjacent oceanic depressions would still be much the same: that is in such regions as those that we have mentioned, where the shelf has the characteristic extension.

But off the coasts of North-East America and NorthWest Europe the case is quite different: here the shelf is greatly extended. Even between Florida and Newfoundland it is wider than the average, and from the northern shores of the Bay of Biscay on the one side, and from Labrador on the other, the shelf extends all the way across the North Atlantic Ocean. The two shallow inland seas, Hudson's Bay on the west of the Atlantic and the Baltic on the east, are situated on the shelf. The two deep inland seas, the Caribbean and Gulf of Mexico on the west and the Mediterranean on the east, on the other hand, contain depressions that are considerably over 1,000 fathoms : they are sea regions of quite another character. 
(2) The Central Atlantic Rise or Ridge. This is quite the most remarkable feature of the Atlantic " bottom relief." South of the continental shelf, where it bounds Greenland, Iceland, the Faeroes and the British Islands, there is an extensive area of sea bottom on which the depth is between 2,000 and 4,000 metres: this has been called the Telegraphic Plateau because it was here that the first cables were laid. This now runs nearly south to about lat. $12^{\circ} \mathrm{N}$. and then it turns to the E.S.E to about $2^{\circ}$ S. lat. where it again turns nearly due south. The Rise is variable in width and tends to spread out laterally at the north and south extremities and contract very markedly at about the middle of its length. Further, it is nearly equidistant, at all latitudes, between Europe and N. America, and Africa and S. America. And, as the westward "nose" of Africa protrudes a little northerly of the easterly protruding nose of S. America, so the Rise alters the direction to remain equidistant between NorthWest Africa and Brazil.

Most of the Atlantic Islands are situated on the Rise. To the north there is the plateau which carries the Azores. Equatorially is a similar, but smaller plateau carrying St. Paul Rocks. To the south are Ascension, Tristan d'Acunha, Gough and Bouvet Islands. St. Helena is an exception in that it rises out of the West African Basin, while the Cape Verde Islands and the Canaries lie just outside the continental shelf.

Nothing like the Central Atlantic Rise exists in the Pacific or Indian Oceans. What it means, with regard to the origin and morphology of the Atlantic Ocean is not known, but a suggestion is made at the end of Chapter X.

(3) The American-Antarctic connection. The continental shelf of the extreme S.E. Coast of S. America is widely extended and projects down to the south-east: this is the "Patagonian Shelf" and on it are situated the Falkland Islands. Then the northerly directed peninsula of the Antarctic Continent, Graham Land, is also prolonged to 
the north-east as an extended continental shelf: on this are the South Shetland, and South Orkney Islands, and beyond these, and rising out of water which is between 2,000 and 4,000 metres in depth, are the Sandwich Islands and those of South Georgia. It is not at all fanciful to see here much the same disposition as in the case of the Greater and Lesser Antilles in the West Indian region, that is a great arc of elevated sea bottom bent out from west to east. To this point, however, we return in Chapters $\mathrm{V}$ and $\mathrm{X}$. Clearly there is evidence of a former actual, or at least, potential land connection between Antarctica and S. America. This, it will be remembered, was assumed in the Chamberlin hypothesis of the origin of the great oceans.

The connections of the Central Rise with the Continental Shelf. To the north the Central Rise expands out to form the Telegraphic Plateau, and then this bathymetric region (4,000 to 2,000 metres) thins out very greatly along the Eur-African and American Atlantic margins. There is really a very narrow zone of sea of this depth along the eastern and western borders of the Atlantic, although it is greatly extended to north and south. Now just as the central rise becomes continuous with the $2,000-4,000$ zone off Labrador, on the west, and off the British Islands, on the east, so it tends to join up in a similar way in the south. Off the Rio de la Plata there is a great extension to the east of the zone of 2,000-4,000 metre bottom, and this very nearly joins the Central Rise in about lat. $35^{\circ} \mathrm{S}$. On the other side of the Atlantic, at about the latitude of Walfisch Bay, a somewhat similar tongue of $2,000-4,000$ metre bottom extends out to the S.W. and actually joins the Central Rise between latitudes $30^{\circ}$ to $40^{\circ} \mathrm{S}$. Thus there is a kind of barrier or sill extending almost uninterruptedly across the South Atlantic between the parallels of $30^{\circ}$ and $40^{\circ} \mathrm{S}$. South from this the Central Rise terminates abruptly in a broad tongue of relatively high sea bottom, and south from which again is the South Polar basin. 


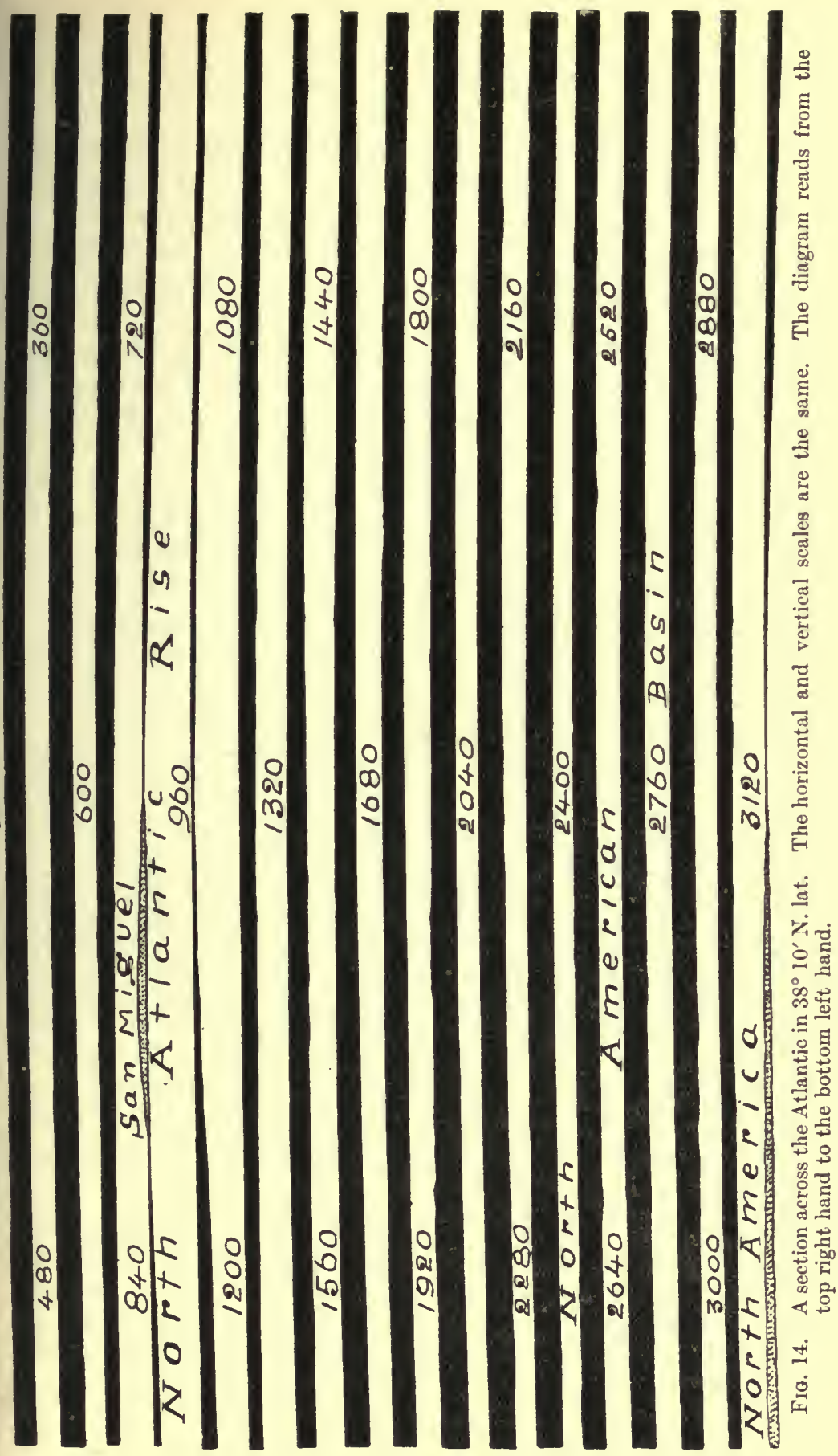




\section{AN INTRODUCTION TO OCEANOGRAPHY}

In describing these features of the Atlantic Ocean in respect of its depth, it is impossible to avoid conveying a somewhat exaggerated impression of the proportions of depth of water to distance. The sketch chart, Fig. 13, must necessarily do so, for the lateral scale is exceedingly small and the markings used to indicate the variations in depth do not suggest, in the least, the almost infinitesimal thickness of the water layer on the scale of the diagran. To correct this impression the reader must now consider Fig. 14.

In Fig. 14 the depth of water is graphed to the same scale as that of the horizontal distance. The earth is supposed to be diminished to a sphere of about 4 metres in radius and the actual curvature of this globe is represented on the diagram. On this scale (about 1 millimetre to the mile) the width of the Atlantic in the latitude chosen is about 3 metres, and so the section is broken up into segments, the left hand extremity of each joining on to the right hand of the segment just beneath. The section starts in Portugal and is so directed that it will pass through the Island of San Miguel in the Azores Archipelago. The relatively deep water off the European coast-the Cape Verde Basin-is well shown. Then comes the gradual shoaling towards the Azores Plateau on the Central Rise and the deepening again into the North American basin. The thickness of the black strip is proportional to the depth of water, and the thickness of the dotted parts at the two extremities and in the fifth segment is proportional to the height of the land above sea level. The numbers placed above the black strip represent distances in miles from the European coast.

The Pacific Ocean.-In most respects the Pacific differs remarkably from the Atlantic Ocean, and its depths do not show that approximate symmetry which is indicated in the latter region. Far less, however, is known about it, both with regard to its present condition and its geological 
history, but nevertheless the contrast with the Atlantic is very striking.

There are three evident regions (see also Fig. 58) :

(1) The South-Western Pacific. Here we have what has been called the débris of a former South Asiatic Continent.

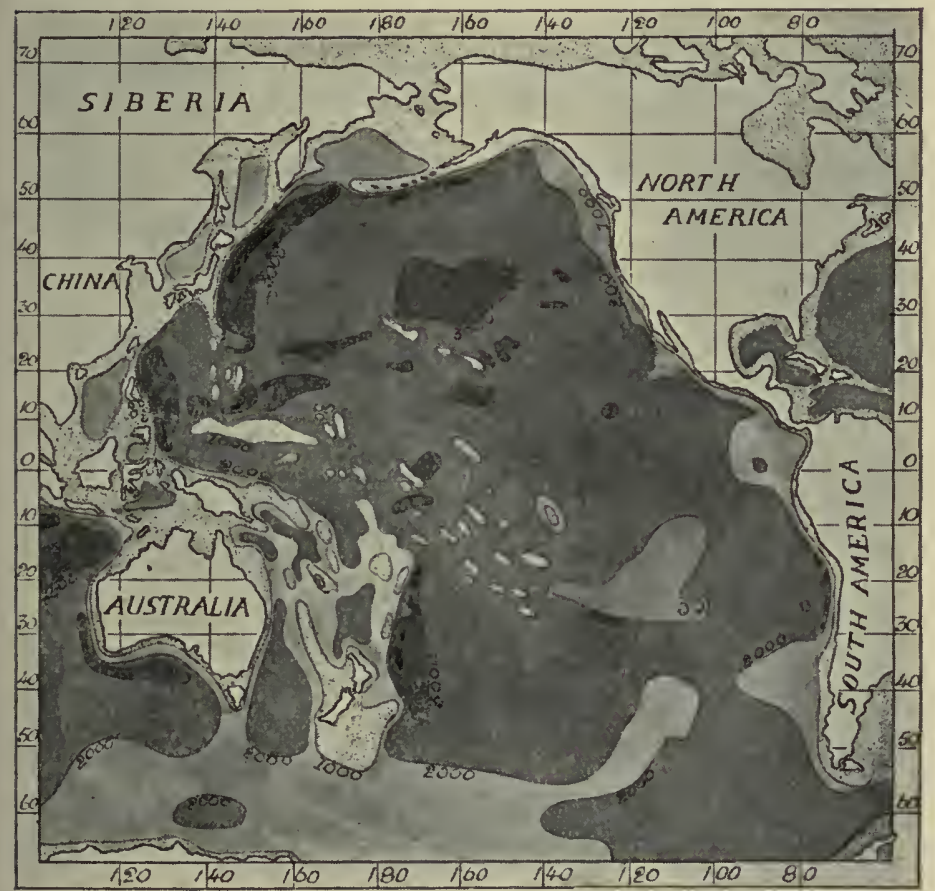

FIg. 15. Sketch Chart of the Pacrfic Ocean. The projection is a Mercator one and the depths are given in fathoms. The stippled areas represent sea bottom where the depth is less than 1000 fathoms.

Australia and all the East Indian Islands are situated on the West Pacific continental shelf. On this region of seabottom there are, indeed, a number of small depressions where the depth may exceed 2,000 fathoms, but these do not obscure the obvious relations of the Australian and 
Asiatic continental elevations. And though New Zealand is separated from Australia by a large depression of over 2,000 fathoms in depth, these Islands are also situated on a region of sea bottom with less than 1,000 fathoms of water over it, and this region is much greater in area than that of the New Zealand Islands. To the north of it are numerous outlying areas of sea with less than 1,000 fathoms of depth. Enclosing all this is the 2,000-fathom contour line which, on its south margin, passes into the continental shelf fringing the Antarctic Continent. Further, a prominent tongue of sea bottom, bounded by the 2,000 fathom contour line is thrust across and almost joins a similar tongue protruded out from the continental shelf of Western South America. A former connection with the Antarctic Continent is therefore suggested and, possibly, also one with South America.

(2) The Central Pacific. To the north and east of the vestigial (or abortive) Austral-Asiatic Continent are a number of patches of sea bottom where the water is less than 1,000 fathoms in depth, and on these are the multitudes of small islands that are so characteristic of the Pacific. These are isolated from each other and do not show that obvious continental relationship suggested by the AustralAsiatic Shelf, but there is the strong suggestion in their distribution that they are outliers of the latter and belong to the same general region in the geological sense.

(3) The North and East Pacific. To the north, east and south-east of these Central Pacific shoal regions lies deeper water. Here also are most of the "deeps" : that is, depressions in the sea bottom of over $3,000,4,000$ and even 5,000 fathoms. This region and its significance we consider further in Chapters V and X.

The Indian Ocean.-Plainly the eastern and western regions of the Indian Ocean differ from each other in somewhat the same way as in the Pacific.

(1) Near Africa, and separated from it by water which is less than 2,000 fathoms in depth, is the large island of 
Madagascar. Between this and India are a number of isolated patches of water that is less than 1,000 fathoms

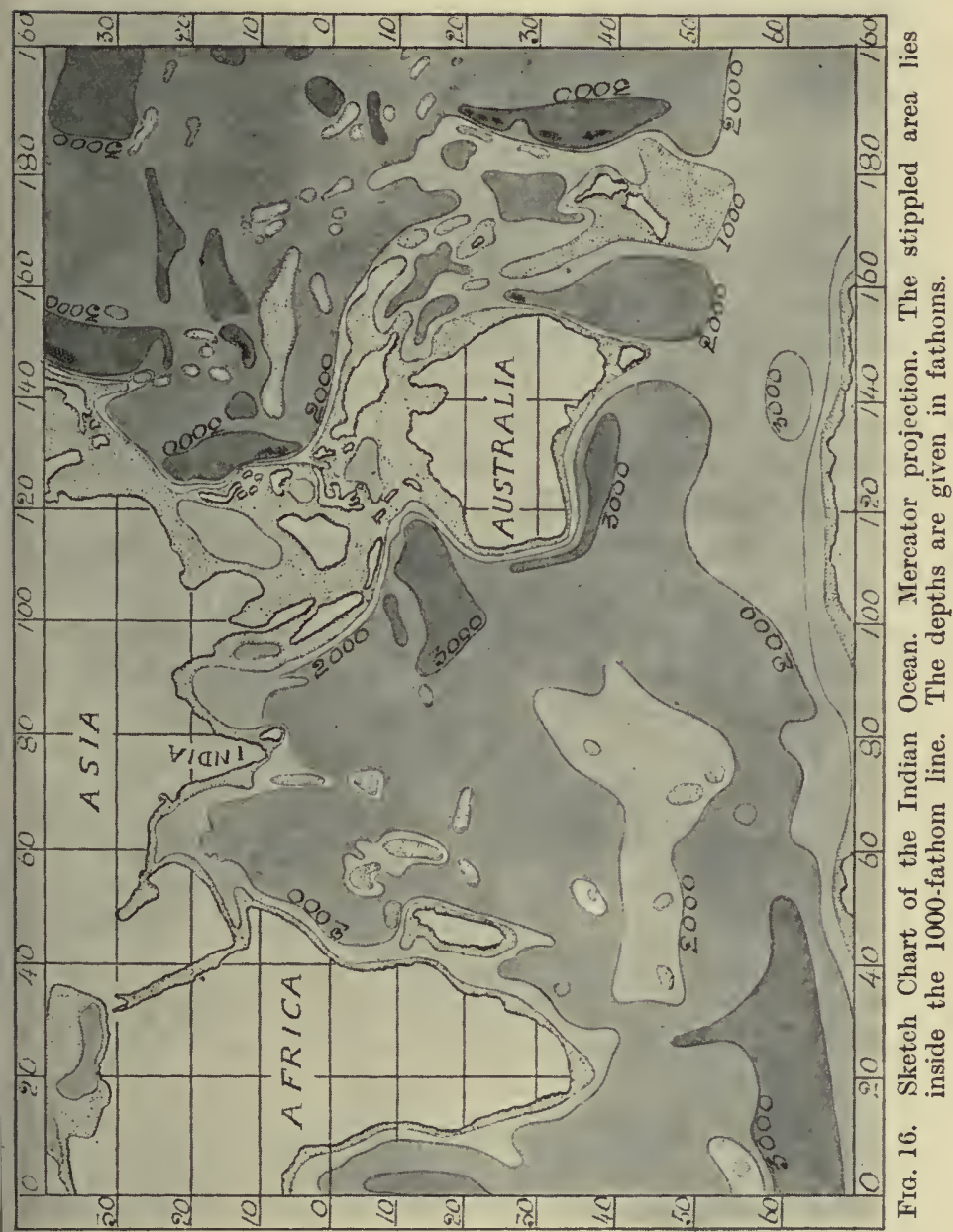

in depth. These carry numerous islands: the Seychelles, Maldives, Laccadives, etc. Here also we seem to see outliers of a truly continental region. 
(2) To the east are the deeper parts of the Indian Ocean. The eastern margin is formed by the continental shelf that bounds the Malay Peninsula, Sumatra, Java and Australia, and here the declivity into depths of over 2,000 fathoms is steeper than on the western side. Here, also, are the Indian Oceanic depressions of over 3,000 fathoms in depth.

(3) Centrally and rather to the south is an elevation of the bottom which approaches the South African continental shelf. On this are several groups of islands : the Crozets, Marions, St. Paul, Amsterdam, Kerguelen, etc. South of this again is the great Southern Ocean.

In some ways, then, there are strong suggestions of similarity between the Indian and Pacific Oceans and equally strong points of differences between both and the Atlantic. These resemblances and differences will become the more marked when we consider the kinds of continental margins that frame the oceans, as well as the general schemes of the latter. This we shall deal with in Chapters $\mathrm{V}$ and $\mathrm{X}$. 


\section{CHAPTER IV}

\section{THE SEA BOTTOM}

It is held, in this book, that the present continental elevations and oceanic depressions are "permanent" in the sense that they have occupied their present positions throughout great parts of the geological period in which the sedimentary rocks have been formed. This does not mean that the original oceanic floors, or the original continental elevations are now accessible to observation. Large tracts of the continental surfaces are covered by rocks that have certainly been deposited at the bottoms of shallow seas, and the ocean bottom in the region of the continental shelf is covered with materials of the same nature as those that are present on the continental land. There are sedimentary and "igneous" rocks that have been or are being eroded, and sediments that are in process of being consolidated into rocks like those that are exposed on the dry land.

So also the floors of the oceanic depressions are covered with deposits that conceal the original earth materials that existed there. Only about one to two feet of the depth of this layer of sea-bottom deposit is known, and that only at a very few spots. We have not even a hint, in the results of observations, as to the depth of these deposits, or as to the nature of the rock that lies underneath them. Very little is known as to the rate at which oceanic bottom deposits are being accumulated. Some few observations made by the engineers of the telegraph cable ships suggest that about one inch of deposit may be laid down in 10 years, but this is probably a maximum estimate and it is 
certain that the rate of deposition is very much less in some other places. One of the most interesting and valuable results of oceanography would be a boring of the ocean floor to a considerable depth but, at present, there does not seem to be any practicable means of doing this.

The study of sea-bottom deposits.--The methods of collection have been described at the beginning of chapter III. A deep sea sounding usually involves the collection of a sample of the sea bottom at the same time, but this is only possible when the deposit is mud, or ooze, or sand capable of being forced up into the tubes of the sinkers (Fig. $9(2)$ ). The grab (Fig. $9(5)$ ) is able to lift up small pebbles, but any objects lying on the sea bottom and bigger than what we call pebbles cannot be collected by the apparatus described. Stones, boulders, large concretions, large bones, etc., can be obtained by dredging, and small dredges have been worked at practically all depths. The process of using such apparatus is, however, very laborious, and only an exceedingly small fraction of the oceanic abysses have been explored in this way. Dredge samples include everything that lies on the bottom and, as an estimate of the area traversed by the apparatus can be made, the sample obtained is roughly quantitative. A true sample of the muddy or oozy deposit cannot, however, be obtained by a dredge, as soft and fine material is usually washed out from the apparatus to some extent while it is being hauled up to the surface. For this purpose the cup dredge, Fig. 9 (6), can be used.

Shallow seas are sampled in just the same way but with modified apparatus-usually dredges with sharp, cutting, front blades that dig into the sea bottom to a small depth, and bags made of very closely woven, thick netting that retains fine material to a certain extent. In such samples the portion in the centre of the mass that fills the net is usually taken since this is less subject to washing than the external parts. Grabs, such as that illustrated in Fig. 9 (5), 
are, however, preferably employed in water of moderate depth. The foreshore is, of course, susceptible of direct observation and the methods of collection are obvious ones.

The description of a sea-bottom deposit is that of its constituent particles. Mineral substances come from the disintegration of rocks on the land, the broken-down particles being transported by currents or wave action, or blown into the sea from the atmosphere; or they may result from the breaking down of volcanic materials ejected on to the sea bottom itself or reaching there after being water- or air-borne. Organic materials are the hard parts, or skeletons, of numerous species of plants and animals inhabiting the sea bottom itself or living in the upper layers of the ocean. The soft parts of these organisms putrefy and pass into solution, but the living or siliceous skeletons remain. Both mineral and organically formed deposits undergo chemical change when they lie for a long time on the sea bottom and so altered products, concretions, etc., are to be recognised.

The analysis of a sea bottom deposit includes, then, the identification of the constituent particles and of their mode of origin - that is, the kinds of minerals present, whether simply resulting from the disintegration of massive rocks, or chemically altered; the species of plants and animals as deduced from a knowledge of the skeletons of the living organisms and the chemical composition of the deposit, as a whole, that is, for instance, the percentage of lime, silica, alumina, iron, manganese, etc., in the dried material. In addition to this treatment mechanical analyses may be made, that is, the material may be described in relation to the prevalent sizes of its particles, as, for example, in the case of the sands that form the bulk of the shore deposits. Such a description becomes necessary when we consider the transport of fine sands, muds and oozes by the agency of moving water.

The original nature of sea-bottom deposits.

(1) Inorganic Materials. This category includes 


\section{AN INTRODUCTION TO OCEANOGRAPHY}

terrestrial, extra-terrestrial and chemically transformed substances.

Terrestrial materials are such as come from the continental land mass and are almost entirely the products of aqueous denundation carried down into the sea by rivers as muds and sands. They are shore-erosion materials resulting from wave action on the rocks of the shores and distributed mainly by tidal and wind currents; volcanic materials coming from the disintegration of lavas ejected on to the ocean floor by submarine volcanoes, pumice (either itself or in disintegrated forms) settling on the sea bottom after floating in the water, and volcanic dusts carried by winds and finally settling on the surface of the sea.

Extra-terrestrial materials are very rare though of immense interest. They are meteoritic dust coming into the earth's atmosphere from outer space. They are recognised in ocean-bottom materials as the "cosmic spherules," Fig. 19. They are microscopic, roughly spherical particles, black or bronze in colour, laminated or crystallised in texture. They usually consist of iron or of magnetic iron oxide. They are only to be found, as a rule, in those deeply-laid deposits that accumulate with exceeding slowness, and they are recognised there because of the relative scarcity of materials of other origin.

The chemically altered materials we consider later.

(2) Organic materials. Those of vegetable origin are the remains of calcareous algae such as the corallines, and broken-down coccospheres and rhabdospheres. These are relatively rare. Diaton oozes, made up of the siliceous skeletons or frustules of these minute plants, occur much more frequently.

Calcareous materials of animal origin are very much more abundant. Here we have molluscan shells, and a great variety of other calcareous skeletons. Siliceous materials of animal origin are not so abundant, but nevertheless constitute an important category of ocean-bottom deposits. 
Sea-bottom deposits : the Challenger classification.-The classification made by Murray and Renard ought to be known. It is :

$\left.\begin{array}{l}\begin{array}{l}\text { Deep-sea } \\ \text { deposits laid } \\ \text { down in water } \\ \text { over 100 } \\ \text { fathoms in } \\ \text { depth }\end{array} \\ \begin{array}{l}\text { Red clay } \\ \text { Radiolarian ooze } \\ \text { Giatom ooze } \\ \text { Pteropod ooze } \\ \text { Blue mud } \\ \text { Red mud } \\ \text { Green mud } \\ \text { Volcanic mud } \\ \text { Coral mud }\end{array}\end{array}\right\}$ Pelagic deposits

This classification considers both the immediate place of origin of the deposits and the place of deposition in respect of the depth of water. Terrigenous deposits are the results of disintegration of the rocks that occur on the land. These erosion-products are transported from the land by rivers, ice and winds, and are then distributed on the sea bottom near the land by wave-action, ocean currents, tidal streams and winds. Therefore they are not found in bulk at a very great distance from the land because of the relative feebleness of these transporting agencies. Nevertheless, very fine muds of land origin may be found at considerable distances from the shore and thus the terrigenous deposits are placed both inside and outside the 100-fathom contour line. 
The pelagic deposits, on the other hand, have their place of origin, not on the land but in the sea itself ; they consist of the remains of animals and plants that live there, and they are generally associated with masses of water of great depths. But the organisms whose skeletons form the pelagic deposits are really more abundant in relatively shallow water than they are in the ocean over great depths, and such materials as compose (say) globigerina and diatom oozes are probably laid down on quite shallow sea bottoms in much greater quantity than they are on abysmal ocean floors. In shallow water, however, they are covered up by the much greater quantities of terrigenous materials resulting from land erosion and so they are almost unrecognisable.

Here we are considering the oceanic depressions on the great scale as contrasted with the great continental elevations. Further, we are considering the continental shelf, not as any particular gradient of sea bottom, or sea floor of any particular limits of depth : it is the transition region between the oceanic depressions and the continental elevations and, during the vicissitudes of geological history, it may have been now sea bottom and again land surface. A classification of sea-bottom deposits which presents a more illuminating point of view may, therefore, be substituted for that of Murray and Renard.

Categories of sea-bottom deposits.-

$\begin{array}{ll}\text { (1) Continental deposits } & \begin{array}{l}\text { Littoral deposits } \\ \text { Shallow-water deposits } \\ \text { Terrigenous muds. }\end{array} \\ \text { (2) Neritic deposits } & \left\{\begin{array}{l}\text { Shallow-water neritic } \\ \text { deposits } \\ \text { Oceanic neritic deposits. }\end{array}\right.\end{array}$

(3) Pelagic deposits

These various categories we now consider further. Obviously the antecedent to the accumulation of very extensive shore and shallow sea-bottom deposits is the 
existence of a vast land area over which disintegration of earth materials is proceeding on the great scale. That means continental land, or at the least, extensive island land areas; great rivers with large volumes of water, fairly rapid flow and extensive catchment areas; large glaciers capable of transporting heavy materials and with notable power of erosion; desert areas from which light sand and dust may be blown by strong winds; shallow, marginal continental seas in which there are rapid tidal streams capable of shifting bottom deposits, and where wave-action may be exerted to the maximum degree-all or some of these conditions. Obviously they are not present on oceanic islands, and round these we find nothing quite like the continental shelf and the characteristic continental shallow-water deposits. Continental deposits are not defined very precisely by the depth of sea in which they are laid down or by the distance from the shore at which they are found. There will be a grading of the materials in respect of the average sizes of the constituent particles, and this will depend on the strength of the transporting agencies.

Neritic deposits are quite different in their nature. They are organic in mode of origin, consisting of the dead skeletons of marine animals and plants. There are very clear distinctions between such deposits as shelly gravels, or "coral " bottoms, on the one hand, and mud or sandbanks, on the other. The former are called "neritic" and the latter terrigenous. Neritic deposits laid down off continental shores consist predominantly of the dead and partially or wholly disintegrated skeletons of marine animals and plants which have their most favourable environment in shallow seas of relatively low salinity. They are there in abundance because of the proximity of the land. Neritic deposits off oceanic islands may be very different in their nature, again because of distance from extensive land areas. The differences between continental and oceanic neritic deposits traces back to the natural 
habits of the organisms whose dead skeletons form the materials in question.

Pelagic deposits are due to organisms which have their most favourable environment in truly oceanic regions. They are independent of the land, living and reproducing generally at or near the surface of the ocean.

The various kinds of sea-bottom deposits may now be described, premising that for details of distribution and identifications of the species of minerals and organic remains the original memoirs must be consulted.

Littoral deposits.-These are the materials present on the foreshore, that is, the region between high and low water tide-marks. Characteristically they consist of boulders, gravels, sands and muds. It will be convenient to reserve a description of them for the following chapter, where we deal with the continental margins.

Shallow-water deposits.-The most characteristic, most abundant and most widely distributed sea-bottom material is sand. In general this is the bottom material present in most shallow seas. Its main source is the shore-land itself, because the most abundant constituent of the latter is generally a quartz-containing rock of some kind. Waveaction, assisted by atmospheric agencies, hreaks down the shore materials, whether rock cliffs, boulder clay, or whatever they may be. Stones and boulders suffer attrition by being moved against each other by wave action. Disintegration of the mineral constituents occurs, and many of the latter undergo chemical alteration. The more resistant species remain and undergo grading. Of these resistant minerals the most abundant is quartz sand which is, therefore, the characteristic bottom material in shallow seas.

The grading of the shallow-water deposits is the most important question involved in our discussion, but so little adequate investigation has been made so far that little can be said. In a very general way, however, we find that the coarser materials, gravels of various grades, 
occur nearest to the foreshore; the coarser sands further out to sea and the finer sands still further away from the land. This is what is to be expected when we consider the transporting agencies. The effect of the waves is felt most strongly on the beach itself, then on the foreshore and, finally, on the shallow sea bottom just off the land. To what degree wave-action diminishes with increasing depth of water is not precisely known, but in a sea of over 50 fathoms in depth the effect becomes slight. Tidal streams are most rapid in shallow water near the land, and particularly in bays and narrow estuaries, and they diminish in velocity very greatly as the distance from the land and the depth of water increase. Wind currents are also most pronounced in water that is very shallow. In general, then, the power of the movements of the sea to shift and transport stones, gravels and sands decreases with distance from the land. Further there is a resultant effect of all these agencies. The general pounding action of waves will take place at a certain angle to the shore line and this angle will depend on local conditions. Tidal streams reverse themselves in direction with every high and low water change, but not completely, so that they tend to transport materials along certain resultant paths. Wind currents, too, have prevalent seasonal directions, and it must generally happen that they also have a resultant effect, taking the whole year into consideration, on each part of a coast line.

Therefore, waves, tidal streams, wind currents, and the marine channels of rivers transport the materials of the shallow sea bottom; so that they roll stones, gravels, sands and muds in this way and that but, on the whole, in a certain general direction dependent on the sum of all the local conditions. The general directions will vary from place to place, although they may, to some extent, be seasonal. The same particles will be moved more rapidly near the coast than off shore. Coarser particles will in general, tend to remain on or near the beach and foreshore, 
and finer ones will tend to be transported into deeper water.

Large inequalities of the coast line, that is bold promontories or headlands shaping out bays and estuaries, influence the directions and velocities of the tidal streams. Thus "tidal races" or local rapidly-running streams, or slack ones, or eddies are established. On the sea bottom beneath rapidly running tidal streams there will generally only be rock, or boulders, or stones, or gravel, while beneath large tidal eddies fine sand and mud will tend to accumulate. Again unperiodic changes occur. Exceptional spates, or freshets, or melting snow-falls may greatly increase the volume and velocities of river streams in their estuarine portions, and so sand-banks, embankments, etc., may be temporarily breached and lead to changing river and tidal channels. These react on the directions of the tidal. streanis and so on the places in which coarser and finer bottom materials tend to accumulate.

A grading into accumulations of coarse and fine gravels, sands and muds occurs, then, as the result of the disintegrating and transporting agencies which we have very briefly mentioned. The distribution of the shallowwater deposits in a particular sea area is, therefore, the result not only of the nature of the rocks composing the coast line, but also of the average effect of the transporting agencies. The processes involved will be, as a rule, exceeding complex, and their investigation must always be difficult and laborious in the extreme.

The composition of a shallow-water deposit is studied by identification of the rock fragments or mineral particles contained in it. Quantitative separation of the species of mineral particles may often be effected by the use of heavy liquids of suitable densities; by the use of an electromagnet where magnetic particles are concerned; by chemical analyses, etc. Grading of particles which are mineralogically similar is effected by the use of metallic sieves with apertures of known size (where the particles 
are large) or by elutriation in water currents of known velocities (when the particles are small ones).

The Terrigenous Muds-Muds are, in general, deposits in which the particles are very small and rather heterogeneous in respect of their chemical composition. Very fine sands, with minute particles, are distinguishable from muds and silts in that they consist predominantly of quartz particles. In muds and silts alumina is present to a much greater extent than in sands: this and the smallness of the particles is, perhaps, the only notable character in which they differ. Clays are finer still than muds and " bind" to a greater degree in drying. It must be noted, however, that there are no satisfactory class-characters that can generally be utilised in distinguishing between muds, silts and clays.

Deposits that are variously coloured, very fine in respect of the sizes of their particles, that remain easily in suspension in sea water and discolour the latter, occur very generally on the foreshore and at the bottoms of deep and shallow seas. Neglecting the foreshore, in the meantime, we consider the muds of the off-shore regions. Their origin is, in general, the disintegration of continental and volcanic rock, both sedimentary and plutonic. The condition for their occurrence on the sea bottom is relatively still water: still because of great depth, the absence of a current or tidal stream, or the presence of an eddy, in the central portion of which fine suspended particles settle to the sea bottom. But there are no precise boundaries, as a rule, to a mud patch and the transition between a typical mud and a clean, angular, or rounded sand may be a very gradual one. Both on and off the foreshore muddy sands and silts, of very indefinite compositions as regards the fineness of the particles and the proportions of the various grades present, may occur. In shallow bays and estuaries muddy water, during times of rough sea, or when strong spring tidal streams are running, is familiar to every one. This is the result of a natural process of levigation, 


\section{2}

the lighter particles of the rather heterogeneous sea bottom being borne by the motion of the water. The process would, of course, lead to an ultimate grading of the sea bottom in respect of the sizes of the particles were it not that the heterogeneity along the coastal sea bottom is continually maintained by the disintegration of more earth materials.

Off the mouths of rivers, mud is also formed by a process of physical agglutination. Fresh water entering the sea in rivers contains colloidal "clay," that is the aluminous particles are in a state which is not that of mere physical suspension. They are too small to fall to the bottom as sediments but they are not in a state of true solution. When this river water mixes with that of the sea, containing ionised sodium chloride in solution (see Chap. VI) electrical changes occur and the colloidal clay passes into the form of a true suspension. The particles of the latter then sink as a sediment and the water becomes " muddy" until the sedimentation is complete.

Outside the region of "shallow" water, where wave motion becomes very feeble at sufficient depths and where the tidal streams have very small velocities, fine particles in suspension finally sink to the sea-bottom. There is, then, a "mud line" round the continents and this we may take to be somewhere outside the 100 -fathom contour-where exactly will vary to a great extent. As a rough approximation we may put it near the outer margin of the zones of "terrigenous" deposits on Figures 17 and 18 , but it must be noted that observations on the distribution of sea-bottom deposits near the land are far too few to enable us to chart the mud line in detail in any sea area. However, somewhere towards the 1,000-fathom line the gravels, sands and silts of the zone of terrigenous deposits disappear and are replaced by the various muds of the table on p. 65. But, in exceptional cases the terrigenous muds may be found at far greater depths than 1,000 fathoms. 
Blue Muds. These are fine muds that are black or bluish-black in colour. Their limits of depth are so variable that nothing more precise can be said than that they occur towards the edges of the continental shelves. Their origin is as we have stated above - that is, they are the finer detritus resulting from the disintegration of the shore materials or they are the result of the distribution seawards of the colloidal clay brought to the sea by river water. The colour is due to a process of chemical reduction leading to the formation of ferrous sulphide. The typical blue muds are very widely distributed.

Green Muds. These are only varieties of the general deep-sea. mud fringing the continental shelves. The colour (which is rarely strikingly "green ") is due to the presence of the interesting mineral called glauconite. This is a hydrated silicate of aluminium, iron and potassium but its chemical constitution is not satisfactorily established. As a rule it occurs as casts filling the cavities of the shells of foraminifera (see fig. 19) and thus in rather small particles. Its mode of origin is not well understood but it is very probable that it results from a process of organic putrefaction followed by a chemical synthesis. It has much significance inasmuch as it points to the way in which potassium compounds are withdrawn from solution in the sea. It is rather rare, far more than the typical blue muds, but its distribution is wide. It is known to occur off the Cape of Good Hope, off Eastern Australia, off Japan, off the Atlantic coasts of the United States of America and in the Ceylon Seas. In general it is said (by Murray) to occur on the Continental slopes off high and bold coasts where there is a seasonal alteration in the strength of the ocean currents.

Red Muds. These are simply a variety of the general continental slope mud coloured reddish by iron oxide. Typical localities are the Yellow Sea and the continental shelf off the coast of Brazil. Relatively to the blue-black muds, the red variety is rare. 


\section{AN INTRODUCTION TO OCEANOGRAPHY}

Volcanic Muds. The characteristic minerals in these deposits are those arising from the disintegration of volcanic rocks-thus there are liparite, basaltic minerals, andesite, volcanic glass, broken down pumice, etc. Where volcanic rocks occur on the coasts the weathering of these produces volcanic sands and muds in the immediate vicinity. So also the loci of submarine volcanoes are also those of volcanic muds. But plutonic materials are very widely distributed on the sea bottom. Dust is ejected into the atmosphere during eruptions and may settle everywhere on the surface of the sea. Pumice may float on the sea for prolonged periods before becoming water-logged and sinking to the bottom to disintegrate.

Neritic Deposits-The sea-bottom deposits considered so far are mainly inorganic in nature: they consist of land detritus, the disintegration products of "clastic" agencies. They are transported from the land by rivers and are distributed on the sea bottom by movements of the ocean. The distributing agencies grade the deposits to a certain extent.

Nevertheless almost any sample of sand or mud taken from the foreshore or the adjacent shallow sea is sure to contain materials that are organic in their origin and do not come from the detritus of the land. Almost any such sample will contain, perhaps, a few per cent. of calcium carbonate, and microscopic examination will show, as a rule, fragments or particles which can often be identified as broken down shells or skeletons of various animals and plants. Such mineral matter of organic origin may be briefly mentioned :-

Molluscan shells and their fragments;

The limy plates and spines of starfishes, sea-urchins, ophiurids and crinoids;

The calcareous tests, or skeletons, of alcyonaria, polyzoa, gorgonids, etc. ;

The limy tubes of marine worms;

The calcareous tests of foraminifera; 
The limy spicules of sponges, alcyonaria and tunicates ; The calcareous exoskeletons, or carapaces, of crustacea ; Teeth, earbones, etc., of whales and sharks.

On a great scale-the calcareous skeletons of solitary and reef-building corals.

The above are animal remains, and they consist of calcium carbonate in the form of aragonite or calcite.

Siliceous animal remains are:-

The skeletons of radiolaria;

The spicules of sponges.

There are also calcareous plant remains. These are :-

Calcareous skeletons of algae-the "corallines";

Coccospheres and rhabdospheres with their disintegrated products-the coccoliths and rhabdoliths. (These are also calcareous algae).

The siliceous plant remains are:-

The skeletons or frustules of diatoms.

These materials are not restricted to any particular sea bottom, with respect to depth: they occur both in continental or pelagic deposits. In shallow water in particular and, in general, on the continental shelf they are smothered by the huge quantities of sand and mud laid down at the same time.

In certain places, and on practically all coasts, however, there are deposits which consist predominantly of some of the kinds of organic remains mentioned above. This is even the case with the deposits of the foreshore, but we consider these in the next chapter. The accumulations of calcareous materials of organic origin that we find here and there on the sea bottom near the land are-

The Shallow-Water Neritic Deposits. The principal deposits of this kind are the shelly gravels and sands that are to be found at the sea bottom in depths out to (say) 50 fathoms. The characteristic remains in such are the whole or broken valves of bivalve and univalve shellfish.

It is, of course, very rarely that a neritic deposit will consist entirely of such materials and when this is the case 
there is sure to have been some process of segregation at work. To the same category of deposits belong shelly sands which are the result of the attrition of shelly gravels.

Nullipore gravels and sands. Nullipores are calcareous algae, that is, plants like the ordinary seaweeds but having the soft plant tissues impregnated with calcium carbonate to the degree that the plant body has become stony in texture. The two principal forms in British waters are Lithothamnium and the ordinary nulliporeCorallina.

Polyzoan gravels and sands. Polyzoa are colonial animals of small size which have much the same external appearance as the zoophytes. As a rule they form incrustations on the surface of stones, gravels and even coarse sands. They are never very abundant in a shallowwater deposit in point of mass, but they may be very noticeable because of the way in which they form thin crusts on the surface of truly terrigenous materials.

The distribution of the shallow-water neritic deposits. This is not arbitrary. Just as the distribution of the various grades of gravel, sand and mud on the continental shelf depends on the nature of the adjacent land, and on the prevalent currents, tidal streams, winds, etc., so there are factors which rule the distribution of the neritic deposits. These are called the "ecological factors." There is something in the geological nature of the inorganic materials of the sea bottom; or in that of the adjacent land; some particular set of currents or tidal streams that carry food materials; some favourable admixture of fresh and salt water; some particular materials in solution in the rivers entering the sea in the neighbourhood; a particular annual range of temperature, or winter minimal, or summer maximal values of the latter; some set of currents or tidal streams that carries eggs or larvae to a certain part of the sea. All or some of these conditions may lead to the establishment, throughout a great number of years, of colonies of molluscs, nullipores, echinoids, etc., on 
restricted parts of the sea bottom. In course of time their skeletons accumulate to form a neritic deposit-one which does not come from the materials of the land but which is, to a predominant degree, conditioned by the local peculiarities of the adjacent land.

The study of such ecological conditions has become one of the most attractive departments of biology. The methods are the ordinary ones of the field naturalist, but they include rather specialised apparatus for collecting the living animals and the deposits from the sea bottom. The use of the fisherman's trawl-net (but with a very thick foot-rope which will bump over stones and rough ground), or of the old fashioned naturalists' dredge gives us qualitative information as to the kinds of organisms that inhabit the sea bottom. Quantitative estimates are made by means of the Petersen "bottom-grab," an apparatus that scoops up a given patch of soft sea bottom, say one-quarter square metre. The deposits so obtained are then examined at leisure and the mineral and organic materials present are identified, measured, counted, etc. Most of the animals and plants living on the sea bottom (demersal species) at some early stage in their life-history live swimming or passively drifting in the water and usually near the surface-this is their pelagic or planktonic stage-and they are collected by using a small conical net made of fine (miller's) boltingsilk cloth. Such nets are towed slowly from boats, and either at the surface of the sea, or at any convenient depth down to the bottom. They can be so constructed as to give approximately the volume of water that passes through their meshes and the individual animals or plants caught by them can be identified and counted. Finally the physical conditions of the sea can be studied: the directions of tidal streams by means of floats, etc., the temperature of the water at the surface and various depths by means of specially constructed thermometers; the salinity of the water and its composition in respect 
of substances necessary for life (see Chapter VI), are determined by chemical analysis. All such investigations are seasonal ones since the conditions are always changing.

Thus the investigation of marine animal and plant communities comes into relation with the study of the neritic deposits now forming on the sea bottom. From the results of such studies (which have not, so far, been very extensively made) it becomes possible to reconstruct the ecological conditions that prevailed in the past when neritic deposits, such as may be found in the fossil form, were being laid down.

Oceanic Neritic Deposits.--These occur in the neighbourhood of oceanic islands. The main character of the latter, from one point of view, is that they have no continental shelf-that is no flat, or relatively flat margin of sea bottom round them. As a rule the sea in the immediate vicinity of an oceanic island sinks down more steeply towards the ocean bottom than does that along a continental margin. The slope is never "precipitous" to the oceanic abyss but it may often be 1 in 10 and rarely as steep as $1 \mathrm{in} 1$. The islands themselves are usually of volcanic origin; they are small; there is no great surface exposed to subaerial or submarine erosion and great rivers are absent. Their material, therefore, makes but a small contribution to the sea bottom in the neighbourhood, and the latter is what we term neritic. There are volcanic sands and muds, and along with these materials are the remains of organisms that live in the water of the ocean and have much the same general biological characters as those that contribute to the formation of the deep sea oozes. In fact what we have in the neighbourhood of an oceanic island is an oceanicinsular, rather than a continental-terrigenous, inorganic sea bottom, along with a pelagic deposit. The pelagic constituents are not, as a rule, disintegrated to the same extent as are those that we find at the bottom of the deep 
oceans. The shells and other remains are usually cleaner and more nearly entire and there is less muddy or clayey constituents. Such sea-bottom materials in the immediate vicinity of oceanic islands are, therefore, mixtures in various proportions, of volcanic and coral sands.

Coral Formations.--True corals, as apart from the "corals" that are often marked on the official charts, or the deposits so named by fishermen (which are often nullipores or polyzoan remains) are animals belonging to the group called Hydrozoa. They are often solitary, living on the sea bottom as units. Mostly the hydrozoa are the common "zoophytes," that is, colonial groups. The individuals or zooids, or polyps, are connected together by a common fleshy material and are arranged in variously formed communities simulating plant forms. The common, fleshy, connecting material, and the greater parts of the bodies of the polyps are invested by a stiff, flexible cuticle formed of chitin. The colonies are rooted to stones on the sea bottom. Zoophytes are an important group of animals in shallow water. Because of the perishable nature of the chitinous investing skeleton they leave little or no remains, to contribute to the formation of the deep or shallow-water deposits.

Instead of a chitinous cuticle many of these animals secrete a calcareous one (just as many marine algae, or polyzoa do). These are the calcareous corals. A number of them form very massive colonial skeletons which grow to form the typical reefs.

Reef-building corals have rather a limited distribution, as will be seen by consulting Figures 17 and 18 at the end of this chapter. They are quite absent over the greater part of the Atlantic, being found only in the West Indian region and off Bermuda. They are highly characteristic of the Australian Seas and of what we have called the Central parts of the Pacific and Indian Ocean. Figs. 17 and 18 give only their general distribution : on a larger scale chart very numerous patches of coral sea bottom would be 
marked. But, in broad terms, coral reef formations are characteristic of the Central and Western regions of the Pacific and Indian Oceans and curiously deficient in the Eastern regions. They are quite absent in the Northern and Southern latitudes. This distribution is bound up with that of oceanic temperature as we shall see in Chapter VII.

Coral Reefs. These are to be regarded rather as great geological features than neritic bottom formations, nevertheless their nature is described by the latter term. Massive coral reefs are present in the gigantic scale as the Great Australian Barrier Reef. This runs for 1,200 miles along the north-eastern coast of Australia at an average distance of about 20-30 miles from the continental land. Inside the Barrier there is a channel with a general depth of about 15 to 20 fathoms, and within this again, and forming its continental margin are a line of inner reefs. Between the inner reefs and the land are shoal channels.

Fringing Reefs have much the same characters represented on a much smaller scale than the great Barrier Reefs. They may be placed on a foundation of sedimentary or plutonic rock, or on a basis of old coral rock. Abrasion of the foundation by wave action results in the formation of a very shallow submarine flat bounded shoreward by a low flat beach often terminated by cliffs which may be undercut. On the outer edge of the submarine flat the fringing reef is built up by the polyps. As it is formed it becomes broken down by wave action and fragments of the dead coral rock fall down into the sea to form what is called a "talus." Often this seaward slope of the fringing reef is called a "coral precipice," but the terms "talus" and "precipice" ought not to suggest the land features to which they were originally applied. The actual slopes of the "talus " and " precipice" (when these can really be stated numerically) are, as a rule, far less than the corresponding land ones. Such a slope as that formed by loose stones and earth lying at their 
" angles of repose" on a hillside can hardly exist in the sea, for wave action will break up and distribute the materials of the "talus" and spread them out over the sea bottom at an angle which may be a rather small one. Precipices on the land may be actually vertical, but such features are exceedingly rare on the margins of continents and oceanic islands.

Between the fringing reef and the land the submarine flat is usually deepened to the extent that it forms a shallow channel navigable by small boats. Just how this deepening occurs is not quite clear. It is ascribed to slow disintegration of the old coral rock foundation, with the formation of coral mud. When there are tidal streams these run with increased velocity, along the submarine flat inside the fringing reef-the latter, it may be stated, is usually broken down here and there so that there is access of the sea to the shallow region inside the reef. The disintegrated coral mud may, therefore, be scoured away by rapid tidal stream, or even removed in solution.

On the outside of the reef the coral polyps continue to live and build fresh material because there is a plentiful supply of food and oxygen-more than there is on the inside margin. The deposition of new coral rock will keep pace with the destruction of the material of the reef by wave action. Abraded rock falls down the seaward "talus," continually adding to the latter, and evidently the reef will tend both to increase in mass and to grow seaward from the land. Thus the barrier form of reef comes into existence. But when the formation becomes sufficiently great its character must alter. The boat channel between the fringing reef and the land will deepen as coral mud is removed, and tend to become a passage for oceanic water, and new reef building corals will tend to establish themselves so that the inner reefs become formed.

Atolls are reefs of roughly circular, crescentic, or arcuate form. The profile of a typical coral atoll, that of Funafuti, 
is represented, in section, in Fig. 10,4. The gradient on the outer margin of the reef is relatively steep, more so at the extreme margin than off shore and, as a rule, a depth of over 1,000 fathoms occurs on the convex side of the atoll at a distance of a mile or morre. On the concave side, that is, within the encircling reef, the slope is slight and the depth is only a few fathoms. Inside the lagoon so formed the bottom consists predominantly of living corals, but outside there is the usual "talus" formed by the disintegration of the reef by wave action. This is covered by coral sands containing the remains of pelagic organisms.

Modes of Origin of Coral Reefs-The well-known hypotheses of the mode of origin of coral reefs in general are (1) that of Charles Darwin and (2) the Murray-Semper one. According to Darwin's hypothesis reefs are built up on ocean bottoms that are undergoing depression. The usually cited case is that of a volcanic cone which is slowly being submerged. Round the margin of the cone reef-building polyps are living and are raising the shallow sea-bottom to near the surface and as the cone keeps on sinking the growing reefs keep pace with it and maintain their level at a fathom or two beneath the surface. Wave action leads to disintegration and fragments of coral rock are piled up to form a beach. Inside the latter a shallow flat forms and this becomes a channel in the way that we have indicated above. Thus a fringing reef is established but with continued subsidence of the enclosed cone the fringing reef becomes an atoll encircling a shallow lagoon. It is not clear why the growing corals do not gradually fill up the latter: to explain this we have to assume death of the enclosed corals, disintegration of their calcareous matrix and removal of coral mud either by scour, or by solution, or by both processes. The hypothesis involves a general depression of an enormous region of the Central and Western Pacific, but the assumption fits in with the general idea formed from a broad survey of 
the ocean depths-that in this region we see the "débris of a drowned continental elevation " and so also, perhaps, with the other great coral sea, that between Madagascar and India. Clear evidence is, however, still wanting that such is actually the case. In the Fiji Islands of the Pacific it is, however, probable that extensive submarine flats on which coral reefs are situated have actually been formed by a downward tilting of the ocean floor.

The Semper-Murray hypothesis dispenses with the assumption of subsidence of the ocean floor in the regions where reefs are being formed. Let there be an elevation of the latter to begin with : the dead skeletons of pelagic organisms rain down on this and, in time, raise its level near to the surface. This assumes, be it noted, a general elevation of an ocean floor on which the skeletons of pelagic organisms subside but, given a local elevated region there will be a tendency for such remains to accumulate there more rapidly than in the adjacent deeper water, where they will dissolve to a greater extent than in the relatively shallow water over the elevation. But an apparently fatal objection to the hypothesis is contained in the now established theory of isostatic equilibrium of oceanic depressions and continental elevations. The weighting of the ocean floor (whether over a local elevation or elsewhere) by the accumulation of pelagic deposits ought to lead to subsidence. (See the following chapter).

The theory of isostasy, however, was not formulated when the Semper-Murray hypothesis of coral reefs was in general acceptance. Let, then, the accumulation of pelagic deposits gradually raise the level of a submarine elevation : by and by the latter will come so near to the surface that coral polyps become able to establish themselves and build encircling or fringing reefs. To account for the existence of the lagoon, or shallow channel, it is assumed that solution of the lime of the reefs occurs; that there is less food and oxygen in these still enclosed 


\section{AN INTRODUCTION TO OCEANOGRAPHY}

waters and that abrasion and removal of disintegrated material proceeds. Here again the results of recent research cause difficulties :- in such enclosed waters as those inside a fringing reef or atol deposition of lime, rather than solution and removal, ought to occur.

$\rightarrow$ Are Coral reefs formed on subsiding regions? This is the main problem and it is one for geological investigation. Where such investigation has been most successful it seems to be established that reef areas are also, in general, areas of subsidence of the ocean floor? In the West Indies, for instance, there are satisfactory evidences of depression or downward tilting of a large area of sea bottom in the seaward direction: there are deeply indented bays and valleys, steeply sloping sea bottoms, drowned escarpments and submerged peat deposits. Most important of all, there is geological evidence (from the West Indies and Southern United States) that fossil reefs occur and that these rest unconformably on eroded submarine platforms. There is also evidence that this is the case with living reefs. Coral reefs appear, therefore, to become established on submerged rock platforms. This is the case with fringing and barrier reefs and also with atolls. There is no evidence that these grow up round subsiding cones, but rather that they are based on submarine flat summits.

The Glacial Control hypothesis of Coral Reefs. There ought, therefore, to be a flat platform underneath reefs, whether barriers, fringing reefs or atolls and this should show signs of erosion. How to account for the formation of these submerged platforms which existed prior to the deposition of reefs upon them, is a problem that must be solved before constructing a general theory. According to Daly, Andrews, Humphreys and others the formation of the platforms, and the subsequent growth of reefs on them, are due to changes in water level rather than actual movements of the earth crust relative to the earth as - a whole. During periods of extensive glaciation enormous volumes of water have been withdrawn from 
the ocean and deposited on the continental elevations as the great ice-caps. This, and the consequent gravitative effect of the increased continental masses, has been estimated to lower the ocean level by as much as 36 fathoms. At the same time the ocean temperature became lowered and the conditions for coral growth may have become unfavourable except in a narrow equatorial zone. Land surfaces unprotected by growing reefs were thus exposed to wave action and wide and flat terraces were cut out round continental lands and large islands, while the tops of smaller islands were planed down to a general level. On the melting of the ice-caps the sea temperature was probably raised as the result of the reversal of operation of whatever causes led to the glaciation and, at the same time, the water level became raised by the melting of the accumulated ice. Corals then began to build on the edges of the terraces and flat submerged island summits. In the former cases fringing and barrier reefs became formed and in the latter, atolls. In the channels between the fringes and barriers and the land, and in the spaces encircled by the atolls, conditions for coral growth must have been rather less favourable, nevertheless it goes on there, and both channels and lagoons are assumed to be filling up rather than being deepened by scouring and solution.

Ecology of Coral organisms. The problem is, therefore, one for geology on the one hand, and marine biology on the other. Coral polyps are plankton-feeders, capturing and ingesting minute pelagic organisms in the usual way, but they have also the holophytic mode of nutrition. That is, they contain in their fleshy tissues green cells, which are really symbiotic algae with which the polyps become infected at certain stages in their development. These symbiotic algae are able, by reason of the chlorophyll that they contain, to take up carbon dioxide from its solution in the sea water and then to synthesise carbohydrate from this in essentially the same way as 
the ordinary green plant does. Obviously this manner of feeding must be reckoned with in any discussion as to the conditions in which corals thrive-best.

As to the general depths at which the polyps live, reproduce and build: we must distinguish between the deep and shallow species. The former may be found in water of 50 fathoms or over, but the massive reef builders live best in water of 27 fathoms or less. They prefer water which is free from sediment although they have limited powers of removing sediment from their exposed parts. They can only settle on a hard sea bottom. The most favourable temperature is about $18^{\circ} \mathrm{C}$. and the salinity that appears to be most suitable is about 27 to 30 per mille (see Chap. VI). This is a fairly wide range and must include a variety of hydrographic conditions.

A rather brisk circulation of the sea water is favourable, as in the case of all sessile, marine animals. A fairly strong light is favourable and in the complete absence of sunlight many, but not all, corals die. The importance of light is obvious when we consider the rôle of the symbiotic algae in the tissues of the polyps, for the chlorophyll of these can only function in the presence of light above a minimum intensity. At a depth of 50 fathoms the lighting is favourable. The red is still present, though weak, and the blue and ultraviolet constituents are still powerful.

In the lagoons and shallow channels within fringing reefs, the conditions must be rather less favourable than on the seaward sides of the reefs. The water circulation is less brisk so that nutritive matter may be more scanty than on the outside margins. There must be a tendency for the withdrawal of carbon dioxide from solution, not only by the green plants present but also by the algal cells of the coral polyps. There may be increased evaporation where the water is still. There will be a higher temperature. 
Now the shallow water in such regions is usually saturated-with lime. This does not exist in the form of calcium carbonate (which is sparingly soluble) but in the form of the hydrogen calcium carbonate (which is much more soluble). There is an equilibrium between the $\mathrm{CO}_{2}$ in the atmosphere and that in solution in the sea water. The latter is not present so much in ordinary solution as in combination with calcium carbonate to form the acid salt, $\mathrm{CaH}_{2}\left(\mathrm{CO}_{3}\right)_{2}$, or some such compound. If the sea takes up $\mathrm{CO}_{2}$ from the atmosphere, there will be a tendency for solution of ordinary limestone so as to form more of the hydrogen calcium salt. If, on the other hand, $\mathrm{CO}_{2}$ is withdrawn from the water in any way some of the bicarbonate will dissociate and normal calcium carbonate will be precipitated. Also if the alkalinity of the sea water (see p. 148) is increased, the same precipitation must occur. In the lagoons and shallow channels there may be enormous numbers of denitrifying bacteria. Certain ordinary bacteria can reduce proteid matter (arising from decomposed animal and plant substance) to nitrate and nitrite, and it is in such forms that inorganic nitrogen usually exists in solution in sea water. The denitrifying bacteria are able to reduce nitrates to nitrites, nitrites to ammonia and ammonia to elementary nitrogen which then returns to the atmosphere. But there will be a tendency for the ammonia, as soon as it is formed, to combine with $\mathrm{CO}_{2}$ in solution in the sea water. Then the calcium bicarbonate will dissociate into $\mathrm{CO}_{2}$ and calcium carbonate $\left(\mathrm{CaCO}_{3}\right)$ which will be precipitated as minute balls of aragonite.

In lagoons and on the leeward sides of reefs there will therefore, be a tendency to the deposition of calcium carbonate precipitates. This will cause sediments and lead to the result that reproduction and growth of the reef-building corals will be less active there than on the outside margins of channels and lagoons. The net effect will be-not solution and deepening of the 
lagoons and channels-but deposition of sediments and filling up.

The processes in operation are, however, very numerous and complex, and far too little is known about them to utilise in the elaboration of a satisfactory theory of coral formation.

The Pelagic Deposits.-Categories of marine organisms. From our present point of view it is convenient to arrange all marine organisms-plants and animals - in three groups: the Benthos, Nekton and Plankton. To the Benthos belong all rooted, sessile, sedentary or semisedentary organisms. These include the rooted shore and sea bottom algae, the zoophytes, corals (massive reef-building and solitary species), the alcyonarians, sea-anemones, sponges, polyzoa, all starfishes, sea-urchins and crinoids, nearly all the molluscan shellfish, most of the larger crustacea, all the barnacles and very many of the marine worms. These animals live, either attached to hard objects on the sea bottom, or burrowing on the sand and mud, or moving freely on the sea bottom though incapable of making long journeys. Many of them, as we have seen, have calcareous or siliceous skeletons which accumulate to form the neritic deposits.

To the Nekton belong the whales, other marine mammals, all the adult fishes, some of the cephalopods (the larger squids) and some of the crustacea. They are animals that have well-developed locomotory organs and they can make long migrations. They mostly have calcareous skeletons and they contribute both to the neritic and pelagic deposits.

To the Plankton belong nearly all the unicellular plants and animals (the Infusoria, Flagellate Protozoa, Peridinians, Diatoms, etc.), all the smaller Crustacea (Copepods, Ostracods, Schizopods, Amphipods, etc.), many marine worms, some of the Coelenterates (the Medusae, Siphonophores, etc.), many molluscs (the Heteropods, Pteropods and some of the Cephalopods) and nearly all 
the eggs and larvae of the Benthos and Nekton. These organisms contribute to the pelagic sea bottom deposits.

Density of life in the Sea. The most prolific region is that of the shallow water just beyond the littoral zone and extending out to about 50 fathoms. The littoral zone itself teems with life (sand and mud-living molluses, sea-weeds, barnacles, etc.). The littoral and shallow water regions contain most of the algae and it is exceptional for these to inhabit deeper water. In the case of the greater Laminarians, however, marine algae may grow up towards the surface from water that is as deep as 50 fathoms. The characteristic region of the Benthos is the sea between the foreshore and the 50 fathom contour line, but the general abundance of life there depends largely on the nature of the sea bottom and that of the adjacent land; upon the sea temperature ; upon the nature and origin of the neighbouring ocean currents and tidal streams and upon the presence of fresh water coming down from the land. This region is that of the greatest abundance of fishes and also of the planktonic organisms.

Beyond the 50 fathom contour-line demersal (or bottomliving) algae rapidly diminish in abundance because of the great diminution in the intensity of light which reaches the sea bottom. Many benthonic and nektonic animals are herbivorous and so depend directly upon plant organisms for their nutrition. Carnivorous animals feed on other animals, whether herbivores or carnivores, but obviously all animal life must depend directly or indirectly on plant substance. There is, then, a poverty of plant life on the sea bottom which is deeper than 50 fathoms, and this density of plant life becomes less as the water becomes deeper and has a lower degree of illumination. Benthonic animal life therefore decreases in much the same ratio.

The Abysmal life. In the greatest depths (or, in general, everywhere outside the continental shelves) life of all kinds becomes very scanty on the sea bottom. There is 
no plant life at all, because of the darkness. All the principal groups of animal life are represented in the abysmal fauna, but the prevalent species of fishes, crustacea, echinoderms, molluscs, worms, and sponges are different from those that inhabit shallow water. So far, however, as their evolution can be traced they are closely related to the shallow-water species and have, in all probability, come from the shore areas originally and have become adapted to the abysmal conditions.

In all cases the mode of nutrition differs from that of the shallow-water species. Abysmal animals subsist largely by eating the bottom deposits; at the very low temperature (see p. 191) of the water on the oceanic floors putrefaction becoming greatly retarded. Pelagic animals living in the surface layers of the ocean die and fall down to the sea bottom. There the fleshy parts decompose slowly-so slowly that they form the only renewable source of food for the abysmal animals. This poverty of food material is the principal reason for postulating a very low density of demersal life in the great ocean.

Categories of planktonic life. A description of the organisms that make up the oceanic plankton cannot be given here and only the main groups that contribute to the sea-bottom deposits can be mentioned. The planktonic plants are, of course, holophytic in their mode of nutrition: they synthesise starch and sugar from the $\mathrm{CO}_{2}$ in solution in the water. Their nitrogen is obtained from nitrates, nitrites and ammonia (also in solution). Lime and silica and other inorganic constituents have the same source. In all respects their condition of life is pelagic, appertaining to oceanic conditions and not depending, except remotely, on the land.

The Heteropods and Pteropods are small, pelagic molluses which drift about with oceanic and wind currents at the surface of the sea. They have delicate calcareous shells. They exist in enormous shoals and furnish one of the 
principal sources of food of the whalebone whales. The Foraminifera are protozoa, the protoplasmic cell bodies of which are enclosed in thin calcareous "tests" or chambered cells. They are holozoic in their mode of nutrition, that is they ingest the organic substances of other planktonic animals and plants, or they may perhaps be saprozoic or saprophytic, that is, they may absorb organic food materials from solution in the sea water.

The Peridinians are unicellular organisms which are animal-like in their structure. But they contain chlorophyll and have the same mode of nutrition (holophytic) as have the typical green plants. They have cellulose tests impregnated with silica.

The Diatoms are unicellular plants which are, of course, holophytic as regards their nutrition. They have siliceous shells, or frustules.

The Copepods are minute crustacea which are (as are all the above groups of organisms) extraordinarily abundant in the sea.

Density and Distribution of the Marine plankton. In general all the planktonic groups are more abundant in shallow water near the land than in the truly oceanic regions far out at sea, and this is because of the more abundant food materials brought down into the sea by rivers. It is because of this wealth of planktonic life in shallow water and the nutritive influence of the rivers, that the ordinary life of the shallow seas is more abundant than that of the deep oceans. The plankton is much more abundant in cold polar, subpolar and temperate sea zones than it is in the warmer tropical and subtropical oceanic zone. This is because the denitrifying bacteria are more abundant, and function more rapidly in warmer than in colder seas. The effect of these organisms is to break down nitrates, nitrites and ammonia into elementary nitrogen. Thus these materials, which are the indispensable sources of nutriment for all marine plants 
and animals, are destroyed to a much greater extent in the warmer than in the colder seas.

Finally the plankton inhabits the upper, illuminated strata of the ocean.

The reader is now prepared to consider the various deep sea oozes.

Pteropod Ooze.-This material is characterised by the presence of the entire and broken shells of Pteropod molluscs. Of all the deep-sea oozes it is the least abundant. It exists in two or three small patches in the Western and Central Pacific; in a few larger (but still relatively small) patches in the Atlantic, mainly on or near to the Central Rise, and in the Mediterranean. Generally it is found in relatively shallow water of about 400 to 1,500 fathoms in depth far from the land, and therefore on low elevations of the sea bottom. On these places the temperature of the water is fairly high and has a restricted annual range. The deposit is not an individualised one and easily passes into some form of globigerina ooze. In it about 35 species of Pteropods and 32 species of Heteropods have been found. When dried it is a coarse white powder containing about $90 \%$ of calcium carbonate. See Fig. 19 for the appearance of this and other deposits and Figs. 17 and 18 for their approximate regions of distribution.

Globigerina Ooze.-This deposit is, as a rule, a dirty white, rather coherent powder when dried. About a half to two-thirds of its weight is due to calcium carbonate, mainly present in the form of detritus. When the finer materials are washed away a coarsely granular residue is left, and this is the "ooze" that is usually represented in figures (as, for instance, in our Fig. 19). From one half to a third of the substance is insoluble in acid and one or two per cent. of this consists of the siliceous skeletons of radiolarians and diatoms. Recognisable minerals, such as quartz particles, volcanic glass, plaglioclase, augite, magnetite, mica, etc., are 


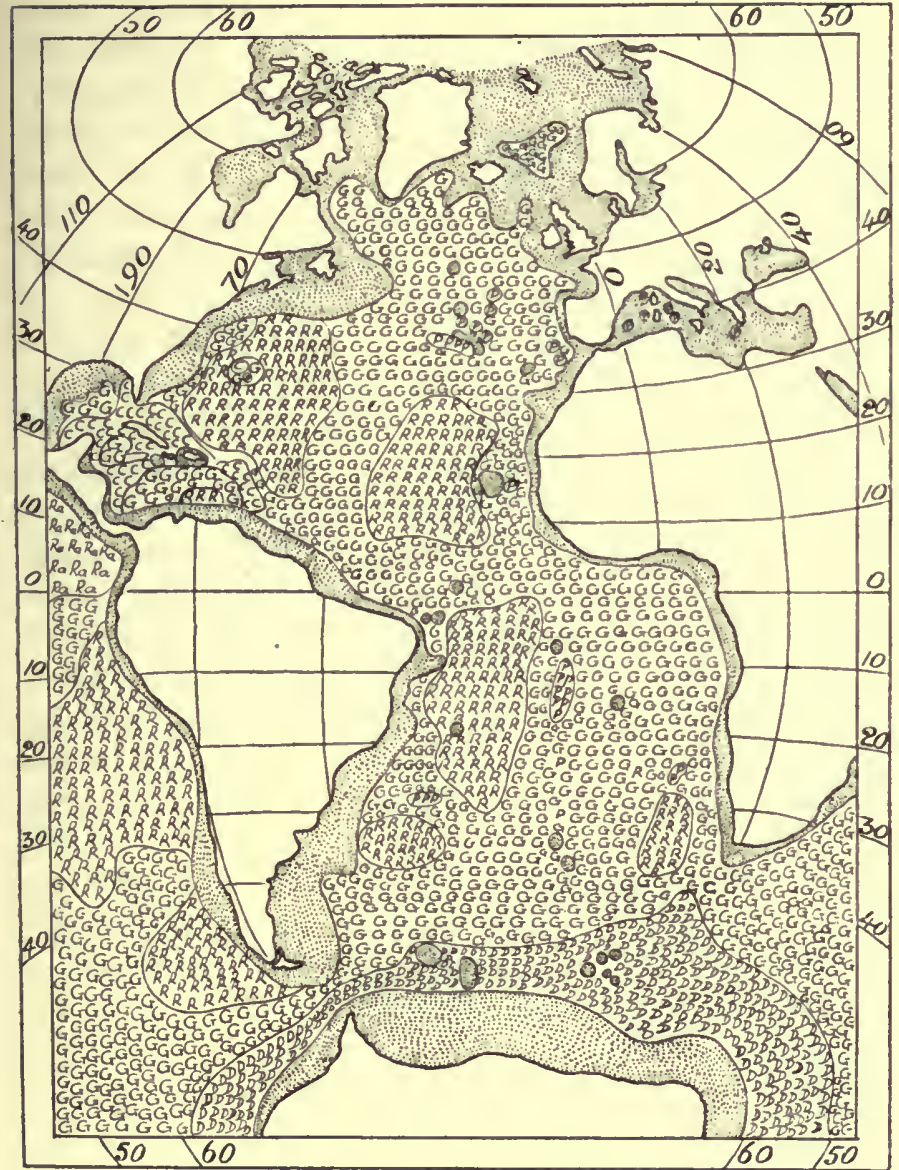

Fig. 17. The deposits on the bottom of the Atlantic Ocean. The area of terrigenous deposits is stippled. Elsewhere $\mathrm{G}=$ globigerina ooze; $\mathbf{P}=$ pteropod ooze ; $\mathbf{R}=$ red clay; $\mathbf{R a}=$ radiolarian ooze; $\mathrm{D}=$ diatom ooze and $\mathrm{C}=$ coral formations. 
usually present in very small quantity. The rest of the material is fine amorphous clay.

Globigerina ooze has a very wide distribution, being found in all the oceans but particularly in the Atlantic. Pelagic Foraminifera are, in fact, of universal occurrence, though they are least abundant, and the number of species is also least, in polar waters. In equatorial zones about a couple of dozen species have been recognised. The ooze occurs all over the Atlantic, close up to the Eastern and Western continental shelf deposits of mud. It. extends, in the Atlantic region to about $72^{\circ} \mathrm{N}$. lat. and to about $60^{\circ} \mathrm{S}$. lat. a difference which is due to the European Stream circulation and the consequent higher sea temperature in the North. It occurs to a limited extent in the deposits of the deeper part of the Norwegian Sea. It is, however, nearly absent in the Antarctic south of $50^{\circ}$ to $60^{\circ}$. It occurs all over the Indian Ocean except on the eastern margin opposite to the Asiatic-Australian continental shelf. It is present in the Pacific but again mainly on the eastern side. The southern limit of its distribution in the Pacific is about $60^{\circ}$ but in the Indian Ocean it does not occur in quantity much below about $43^{\circ}$ to $45^{\circ}$.

Its vertical range extends from about 400 to about 3,000 fathoms. In the Atlantic it is even found at 3,500 fathoms, but 2,800 to 2,900 represents the extreme limits in the Indian and Pacific Oceans. Typically, however, Globigerina ooze is a deposit characteristic of sea bottoms that lie between about 1,200 to 2,200 fathoms in depth.

Radiolarian Ooze.-This deposit is characterised by the presence of the siliceous skeletons of the protozoan organisms called Radiolarians. It is a dirty grey powder drying to a very coherent clay-like substance. It always contains much clay and the siliceous remains, even when the diatom and sponge skeletons are considered, are not so predominant as are the foraminiferal tests in Globigerina ooze. It contains silica and calcium carbonate, but the 


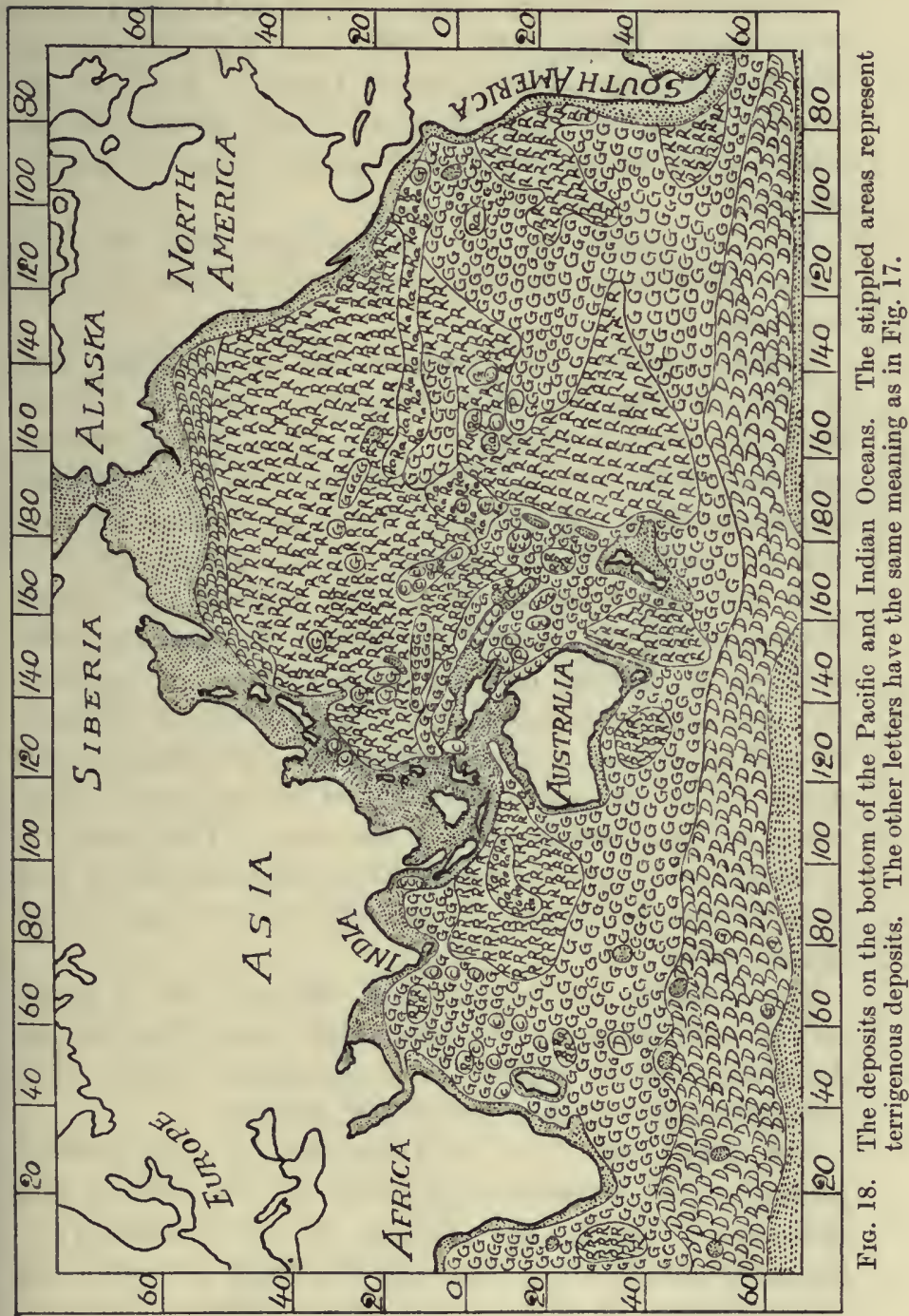


proportions vary remarkably in samples taken from various ocean bottoms. No typical Radiolarian oozes occur in the Atlantic and there is only a small patch on the eastern side of the Indian Ocean. Even in the Pacific, where it is most abundant, it only occurs centrally and as a belt on the eastern side between about $5^{\circ}$ and $15^{\circ}$ N. lat.

It is not known to occur in sea bottoms of less than about 2,000 fathoms in depth and it may go down to 5,000 fathoms.

Diatom Ooze.-The characteristic of Diatom ooze is the presence, in great abundance, of the siliceous frustules of pelagic diatoms. It is a fine, white, coherent powder when dried. With the diatom remains are numerous sponge spicules and some radiolarian skeletons and the inevitable, amorphous, clayey constituents.

It does not occur at all in the Atlantic and Indian Oceans, nor in the North Polar basin. Along the extreme north of the Pacific, between latitude about $40^{\circ}$ to about $55^{\circ}$, there is a broad band of diatom ooze sloping northerly from West to East and just outside the zone of continental muds. It is highly characteristic of the Antarctic Ocean, where a broad band encircles the earth. This band has a maximum breadth of about $20^{\circ}$ in longitude $20^{\circ} \mathrm{E}$. and it is estimated to have an area of about $10 \frac{1}{2}$ millions of square miles.

The extreme vertical range of diatom ooze is about 600 to 4,000 fathoms, the lower limit being found in the Antarctic and the higher one in the North Pacific. The usual range of depths is $600-2,000$ fathoms.

Red Clay.-Red Clay is, when dried, a firm coherent powder which is usually red-brown in the Atlantic and chocolate-brown in the Pacific. It is, chemically, a hydrated aluminium silicate and its origin is mainly the decomposition of pumice and other volcanic minerals. Lime is always very scarce, and in red clays derived from the deepest sea bottoms lime may be totally absent. 


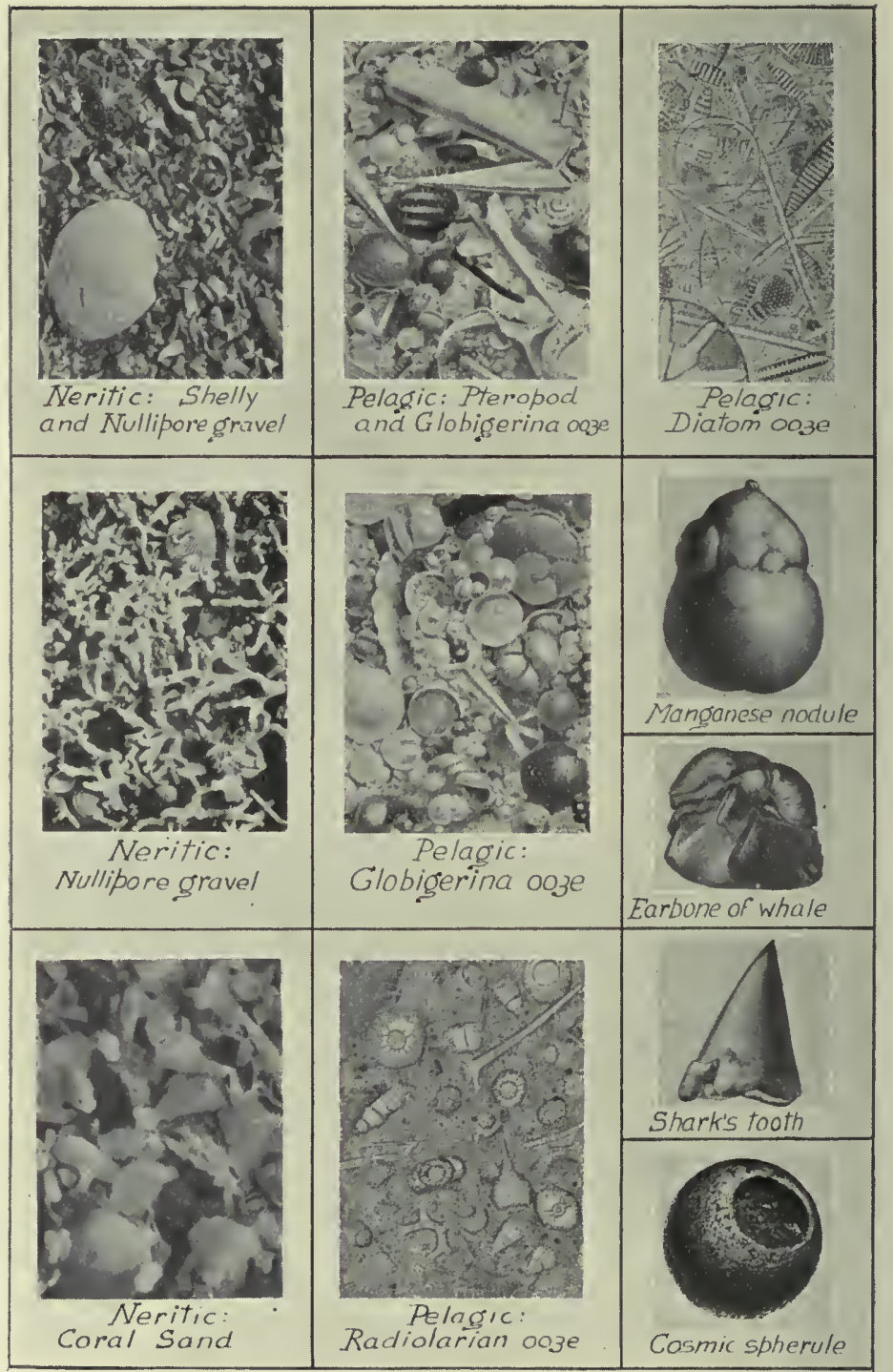

FIG. 19. Typical deep-sea and shallow-water deposits. The shelly and nullipore gravels are reduced; the coral sand, pteropod and globigerina oozes are noderately magnified; the radiolarian and diatom oozes are highly magnificd. The cosmic spherule is highly magnified while the manganese nodule, the whale earbone and the shark's tooth are slightly reduced. 
Red clay is essentially a residue-the end product of a series of solutions and decompositions.

It is characteristic in that it contains the rare sea bottom materials - the earbones of whales, the teeth of sharks, synthetic minerals like phillipsite, manganese-iron nodules and the very peculiar cosmic spherules. The earbones of whales, like the teeth of sharks, consist of very hard, highly resistant materials and they are "common" in red clay (relatively to the other deep sea oozes) because the rate of formation of red clay is so much slower than that of any other deposit. This is also the case with regard to the cosmic spherules: these can hardly be found in any of the other oozes but may be expected in the red clay. Phillipsite and the other synthetic products (the peculiar manganese nodules, for instance) are probably to be associated with the long series of decompositions of which red clay itself is a terminus.

It is the most widely distributed of all the deep sea bottom deposits, being found in all the oceans. It occurs on both sides of the Atlantic between latitudes of $40^{\circ} \mathrm{N}$. and S. It is widely distributed over the Pacific and Indian Oceans but mainly on the eastern sides. Something like it occurs in the North Polar Basin but it is shut off from the Antarctic Continental area by the broad band of Diatom ooze which extends close up to the outer margin of the continental terrigenous deposits. It occurs, in general, everywhere at depths greater than about 2,700 fathoms and it is present at the bottoms of the "deeps." To this statement there are, of course, exceptions and it is often difficult to distinguish between a Radiolarian ooze and a Red clay.

The Pelagic Oozes in general.-The two sketch charts Figs. 17 and 18 give only the very broadest idea of the distribution of the deep sea oozes. Of necessity the latter are regarded as being quite distinct from each other, but this is not really the case. Pteropod ooze passes gradually into the surrounding Globigerina ooze and samples may 


\section{8 - AN INTRODUCTION TO OCEANOGRAPHY}

be examined which it is impossible to place with certainty in either category. Radiolarian ooze shades off into Red Clay and so on. The hard contours drawn in Figs. 17 and 18 are therefore quite artificial and are intended to represent. only the general distributional features.

The vertical range is equally vague. In general terms the serial arrangement is Pteropod ooze (on the shallower bottoms), Diatom ooze, Globigerina ooze, Radiolarian ooze and Red Clay on the deepest bottoms). To some extent the vertical distribution depends on solution of the materials. If the ratios to each other of Pteropods, Foraminfera, Diatoms, Radiolarian and volcanic debris at the superficial strata of the ocean were everywhere the same, then a sorting out of these materials would occur as they sank slowly to the bottom. The fragile shells of the Pteropods would dissolve first of all, then those of the Foraminifera, then the Diatom frustules and lastly the Radiolarian skeletons. That means that lime becomes the less abundant the deeper is the sea bottom, for its solution is apparently accelerated by increasing water pressure. At a certain rough limit of depth, then, no lime will be found and this is actually the case. Then the siliceous skeletons of the Radiolaria, Diatoms and Sponge also dissolve with great depth and so they disappear completely, as organically formed structures, in the very deep ocean basins. In the Red Clay we have the insoluble residues of the calcareous and siliceous skeletons, as well as the end-products of the volcanic materials and the synthetic products for which a low temperature, a high pressure and, no doubt, some other conditions are essential.

The distribution at the surface of the ocean, of Pteropods, Foraminifera, Diatoms, Radiolaria, etc., is not, however, everywhere the same for the ecological conditions there vary from region to region. So also the differences that we know do obtain in the ocean with respect to the vertical and horizontal water movements affect the paths along which these organic remains fall towards 
the bottom. The result is irregularity of distribution such as is not representable on small-scale charts. Also the observations at our disposal are far too few to justify us in drawing the contours limiting the regions of deposition in any other way than very roughly.

Finally we may again remind the reader that the figures of deep sea oozes given in the books are usually representations of the characteristic organic remains rather than of the oozes themselves as they come from the sounding tubes. What one sees in the latter is a mass of general detritus resulting from the attrition of the characteristic shells, etc. This contains fragmented shells, tests, frustules, spicules, etc., some of them entire and it is from the presence of these that the deposit is identified. 


\section{CHAPTER V}

\section{THE OCEANIC MARGINS}

On any ordinary small-scale map there appears to be a very distinct boundary line between the land and the sea. On a large-scale chart, however, this line of demarcation may disappear completely, revealing a region of transition which is sea at one time and land at another.

On p. 101 we have three representations of the same area, Morecambe Bay, on the West Coast of England, but on different scales. $(\mathrm{I})$ is a reproduction in line of the ordinary small-scale map and we see that a quite distinct boundary line apparently separates the water from the adjacent land area. The Bay is here depicted as a sea-area. (II), however, represents a small part of the same region on a much bigger scale and the markings are those that we find on an Admiralty Chart. The approximate boundary is the line which is marked "L.W.O.S.," that is, low water of ordinary spring tides, and this is the average limit of the sea during one day or so in each fortnight. A little distance landward of this line would be another (not usually marked on the Admiralty Charts) giving the limit, low water of ordinary neap tides, and this would be the average limit of the sea on one day (or thereabout) every fortnight and intermediate between the days of highest spring tides (see p. 101).

Near the arbitrary line representing the "shore" on the Chart ought to be another pair of boundary linesthe high water marks of ordinary spring and neap tides. The water of the sea, then, may be anywhere between the high and low water tide marks in normal conditions. At certain times, twice or so during the year, however, the high water marks are higher than usual while the 100 
low water marks are lower than usual. This occurs regularly during the periods of "equinoctial tides," but it also occurs exceptionally at other times when unusual gales of wind may raise or lower the expected heights of the tides.
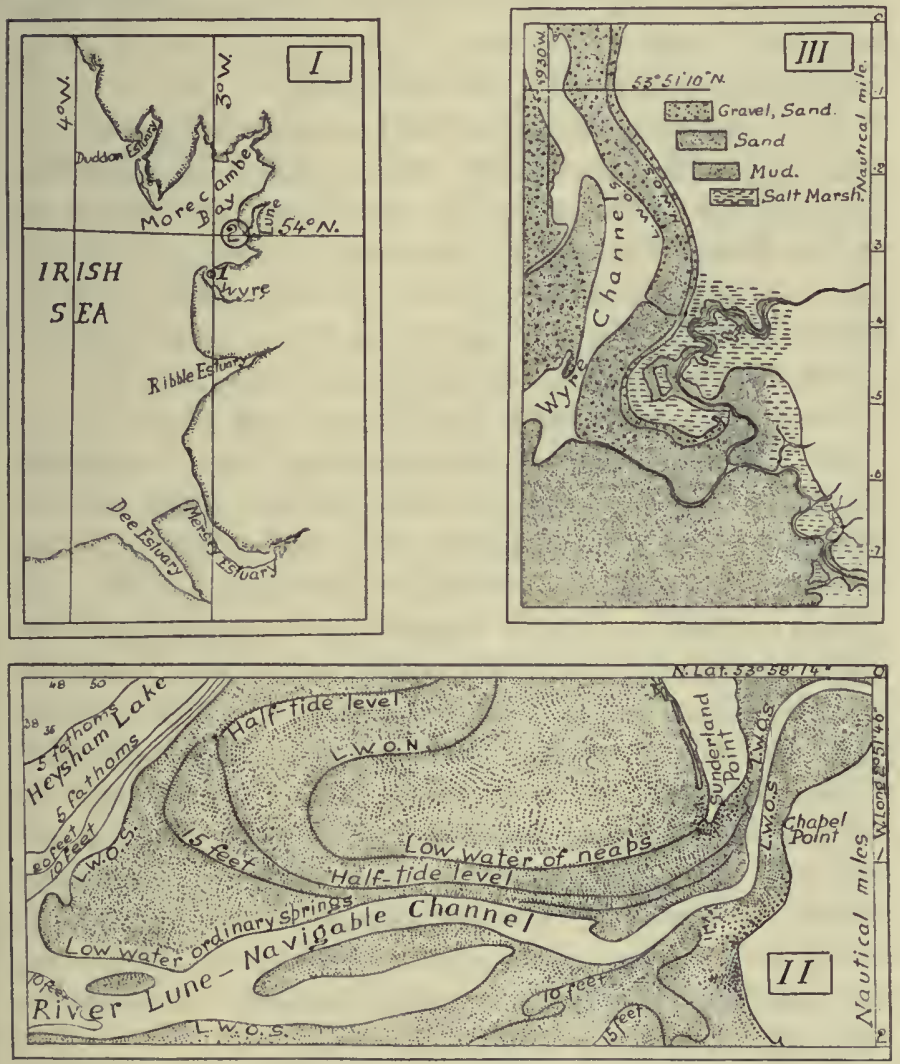

Fig. 20. I is a small-scale map of the West Coast of England ; II is a sketch copy of the Admiralty chart representing the part of I marked by circle 2; III is also a copy of the Admiralty large-scale chart marked in I by the circle 1.

In addition to this broader region of shifting of the water level, the coast line may still be more indefinite 


\section{AN INTRODUCTION TO OCEANOGRAPHY}

Fig. 20 (III) represents a "salt-marsh" from the same general area. We see here that the shore is cut up in a most complex manner by a multitude of small, sinuous channels up which ordinary flood tides penetrate. At very high spring tides most of these channels are obliterated and the sea covers much of the area represented by them and the miniature islands, capes, straits, etc., of the vegetation-covered part of the marsh.

This indefiniteness of the land boundary is characteristic of a large part of the world: wherever there is a significant rise and fall of the tides. In some parts (Liverpool and in the Bristol Channel, for instance) this extreme rise and fall may be about 30 to 40 feet. In other places (as in the Firth of Clyde) the rise and fall may not exceed 10 feet. In the Mediterranean it is only two or three feet.

Further, a very little observation will show that on many parts of the coast the average high water tide markings are not constant-even in the space of time throughout which one person may observe them. That is, there is significant erosion of the coast line in some places or filling up by the deposition of material elsewhere. Such changes are quite noticeable when maps, made at various times during a century or two, are compared: they are due to erosion, or deposition of land materials. Channels, ports and river courses may become silted up, or new channels may be eroded out. Such changes may be slow, progressive ones, or they may be catastrophic (when, for instance, they are caused by very exceptional tides, or floods in rivers entering estuaries). They may be variable, reversing themselves because of conditions that are exceedingly difficult to trace.

Finally, when we consider the changes of land and sea that occur in those periods of time which we call geological ones we see that they occur on a great scale, altering the outlines of the continents themselves. We have now to do with earth movements of enormous magnitude and acting very slowly but with huge effects. 
The Foreshore.-On most parts of the oceanic margins there is, then, a zone situated between the tide-marks. The latter are conventional, being taken to be the junctions of land and sea at the moments of mean high and mean low water at intervals of approximately 15 days. The levels to which the tides rise and fall at these fortnightly intervals are variable and so the marks "L.W.O.S.T." on the Admiralty charts represent the average water levels. (To this matter we return in Chapter VIII). The zone between high and low water marks is called the Foreshore, or sometimes the Strand. Below it, in this country, is the legally conventional "sea." Above the average level to which the tide rises once a fortnight, at springs, is the legally conventional "land." The foreshore is a kind of no-man's land regarded as the property of the Crown, unless there are immemorial, prescriptive, or manorial titles to its partial monopoly for some purpose or another.

The area of the foreshore depends not only on the vertical range of the tides but also on the shore gradients. The vertical range of the tides can only be given an average value for it changes from day to day. The area of foreshore, therefore, undergoes a continuous change : (1) daily, being greatest at low water ; (2) fortnightly, being greater still at low water of spring tides; and (3) six-monthly, being greatest at low water of the highest equinoctial spring tides. It is least at the corresponding high waters of the above tidal conditions. It depends also on the shore gradients, vanishing altogether on those coasts formed by rocky cliffs. There the vertical change of tide is marked in various ways on the face of the cliff but there may be no change at all in the sea area of such coasts. On those coasts, then, where the land is flat and low and easily eroded, and where there is a large tidal range, the extent of the foreshore may be very great. In Morecambe Bay it amounts to about 100 square miles.

High water tide-marks are nearly always recognisable on such flat coasts by lines of debris (sea-weeds, etc.) on 


\section{AN INTRODUCTION TO OCEANOGRAPHY}

the foreshore. On falling tides, that is, during the few days following the highest springs, several such temporary tide-marks can be seen, each showing the level to which the sea rose on a particular day. The levels of the highest tides of all are usually indicated by some fairly permanent markings, such as low sand-hills, deposits of shingle, low earthy cliffs, etc.

Low water tide-marks are not so easily recognised, though they call often be indicated by the presence of typical animals and plants. Thus the large Laminarian sea-weeds mark the approximate levels (on suitable shores, of course) of the lowest tides.

The Foreshore Gradients.-On a rocky coast the land surface immediately adjacent to the sea is usually a low plateau bounded seaward by a cliff. The latter may be the typical, precipitous wall of rock, usually inclined backward at a small angle to the perpendicular; rarely overhanging or undercut but often with caves due to wave action. At its base, and exposed by low tides, there is often a rocky shelf (though as often, perhaps, the cliff may be continued below the sea level), or there may be a terrace of shingle or boulders or gravel. The cliff may be of softer material than rock: boulder clay deposits, for instance, and then there is often a terrace at its foot, partly above and partly below high water level. This terrace corresponds to the talus at the foot of an escarpment on the land, but here its materials have been disintegrated and spread out horizontally by waves and tidal streams. We may find, then, on coasts of these, or similar materials a rather steep, or even an approximately vertical slope from the land plateau to the upper limit of the foreshore.

Even where the land is flat and low and composed of easily eroded materials, something similar to this rather steep gradient may exist. The coastal substance is disintegrated by wave action, but the stones, shingle, etc., which are separated out tend to become piled up on the 


\section{AN INTRODUCTION TO OCEANOGRAPHY}

upper margin of the foreshore as a low rise, rather than a cliff. The rest of the shore materials become abraded; muds are removed by the tidal streams and deposited elsewhere, and quartz sand is spread out on the lower levels of the foreshore or on the sea bottom adjacent to the latter. But even when the land is exceedingly easily eroded and stones and boulders resulting therefrom are rare, the loose sand at the upper margin of the foreshore becomes blown by winds on to the land and then compacted together here and there by vegetation. Such wind-blown sand may even accumulate behind a foreshore consisting of shingle or boulders, the latter being left behind after the separation of the sand by wind action. Thus there arise the low sand-hills so characteristic of many coasts. These give to the shore-line a fairly large gradient down to the foreshore.

The latter has, itself, a gradient which is always slight but is variable with a host of conditions. It will depend, for instance, on the nature of the land, the tidal range, the velocity of the tidal streams, the amount of shelter from heavy seas, etc. We must, however, remember that it is an average gradient. There are "features" on the foreshore: shallow channels and gutters through which land water drains; "lakes" which depend in some way upon scouring eddies; patches of raised stones or boulders covered by sea-weed. There are soft parts or "quicksands": these are generally found near to the land and not often far down the foreshore, and they appear to depend on land water oozing up through the sand on to the surface of the latter. Thus there is considerable diversity of feature on the foreshore as we see from Fig. 20, or almost any large-scale Admiralty chart of a coastal area where there is a considerable rise and fall of the tide.

The Shallow-Water Bottom Gradient.-At the lower margin of the foreshore the gradient again increases slightly: that is, the sea usually deepens rather rapidly at first and then more slowly. Then there is the gradient 
of the upper part of the continental shelf: this upper part may be taken as the sea bottom where the water is less than 100 fathoms in depth. Beyond that it is usually said that the gradient again increases, though there are remarkably few good series of soundings that illustrate this point. We must note particularly now that the gradient of the upper, shallow part of the continental shelf must also be thought about as an average one. In reality there is, here again, very considerable diversity of bottom relief. Particularly in shallow bays and estuaries do we find this variety : sinuous channels, sand-banks, bars, ridges, etc. It is all on a very small scale when compared with those features of ocean bottom which we considered in Chapter III, but it is interesting, and of immense practical importance for navigation and fishery. It may be illustrated by almost any Admiralty chart of the sea in the immediate neighbourhood of an important harbour. There the soundings are usually very numerous so that the natural detail is all represented.

This variety of feature that the shallow-water seas exhibit contrasts strongly with the bottom relief of the ocean basins. But we must always remember that the soundings on the latter regions are very few indeed when compared with those that have been made on the sea bottom within the 100 fathom line. Even, however, when we bear this in mind, and entertain the possibility that more detailed examination of the oceanic abysses might reveal a greater variety than is known so far, it is, nevertheless, probable that the latter regions are monotonous in their flatness.

The Marginal Seas.-All the region of sea bottom within the 1,000-fathom, or the 2,000-metre contour lines (for the limit of depth cannot be precisely stated) we are regarding as the continental shelf. This corresponds roughly with the zone of continental sea-bottom deposits and there are structural reasons why we regard it as belonging rather to the areas of earth-elevation than to those of earth-depres- 


\section{AN INTRODUCTION TO OCEANOGRAPHY}

sion on the big scale. On this continental shelf margin, then, are situated a number of smaller seas. Some of these are partially land-encircled; others are partially separated from the oceanic basins by chains of continental islands while others again are depressions of the shelf itself, areas of the latter where the depths exceed those roughly limiting ones that we have mentioned. These water areas have been called the Marginal Seas and there are several categories of them.

The Epeiric Seas. These are the smaller sea-areas that have, as a rule, very limited depths (not much exceeding 100 fathoms and usually a great deal less) and which present the characters of great gulfs or bays with relatively narrow communications with the ocean. Examples from the Atlantic region are Hudson's Bay, the Gulf of St. Lawrence, Baffins Bay, the Baltic, the North Sea and the White Sea. It is difficult to differentiate them always from the great bays or straits such as, for instances, the Bay of Biscay or the Irish Sea, and some of their individuality must be traced to economic or historical reasons. They are mostly very shallow seaareas with depths of 50 to 100 fathoms. They are also characterised by a low salinity and large temperature ranges, on the physical side, and with marked faunal features, from the biological side. Their presence is rather characteristic of the North Atlantic region.

The Epi-Continental Seas. Just as the Epeiric seas characterise the Atlantic margins so do the Epi-continental seas seem to belong typically to the Pacific. They are the Behring Sea, partially enclosed by the Aleutian Islands and the Kamschatka Peninsula; the Sea of Okhotsk, between Siberia, Kamschatka and Sakhalin and bounded towards the Pacific by the Kurile Islands; the Sea of Japan; the Yellow Sea, which is a great gulf with a shoaling of the bottom emerging to form the arc of the Lu Chu Islands, across its opening; the China Sea, partially enclosed towards the Pacific by 
the Philippines and Formosa; the Celebes Sea, between Borneo, Celebes and the Philippines, and the Banda Sea, between Celebes, New Guinea and Australia (See Figs. 58-9, Chap. X). Fairly well-marked characters distinguish the Epi-continental Seas : depths which, in places, exceed 1,000 fathoms and boundaries towards the ocean formed by chains of islands arranged in arcs with their convexities outwards from the continental land. Doubtless there are physical and biological characters, but as to these much detail is not yet available.

The Epi-continental seas are rather characteristic of the Western sides of the Pacific and Atlantic Oceans. On the Eastern side of the former there is no example except the untypical one of the Gulf of California. This Eastern side of the Pacific, has, we shall see, an altogether different structure. Nor is there anything in the Indian Ocean quite like them, and the only examples in the Atlantic are the Caribbean Sea and the Gulf of Mexico. The Norwegian Basin may, perhaps, be regarded as such a sea bounded to the south by Iceland, the Faeroes and Northern British Islands, but the peculiar arcuate boundary with its concavity facing continental land is wanting in this case.

The Mediterraneans and Relict Seas.-These may be mentioned here although they do not belong to the general category of marginal seas.

The Mediterraneans are the Roman Mediterranean and the North Polar Basin. The Classical MediterraneanBlack Sea region is almost completely enclosed, for the communication through the Straits of Gibraltar is very restricted and permits of only a very peculiar water circulation. The Caribbean and Gulf of Mexico basins have been called a Mediterranean Sea but, obviously, they are separated from the Atlantic in the same way as are the Epi-continental Pacific Seas-that is by an arc of numerous islands, the Greater and Lesser Antilles. The North Polar Mediterranean has been called the "Arctic Ocean" 


\section{AN INTRODUCTION TO OCEANOGRAPHY}

for so long that it is difficult to think about it by another name: it is, however, separated from the Pacific in the same way as the Roman Mediterranean is separated from the Atlantic and it is separated from the Atlantic by an extensive region of continental shelf. The Mediterraneans have depths that belong to the order of the truly oceanic abysses and their bottom deposits may have the pelagic character. Further, there are indications that they have belonged in the past, to the oceanic earth-depression regions rather than to those of elevation-which latter character distinguishes the Epeiric and Epi-continental Seas. The latter we consider to be of the same nature as the seas that have transgressed on the land during the geological periods: their loci have alternately been land and sea. The Mediterraneans, on the other hand, share with the great oceans the character of relative permanence.

The Relict Seas are vestigial sea-areas that have lost their connection with the ocean and have become landlocked, or nearly so. The Epeirics, Epi-continentals and Mediterraneans which have been mentioned are, it should be noted, in working communication with the ocean and have some importance when the general circulation of the latter is concerned: Relicts have no such influence on the water circulation of the ocean. They are the remains of seas that have transgressed upon the continental land during periods of depression of the latter and have then become isolated from the ocean as the result of subsequent continental elevation.

They are the Black Sea, Caspian, Sea of Aral, Lake Ontario, Lake Champlain, probably Lake Tanganyika, Lough Neagh (in Ireland) and doubtless many other smaller lake areas. In all these cases the water is fresh because the salt has been removed by drainage. In the Northern part of the Baltic, for instance, the water has a very low salinity: there is little evaporation, much inflow from rivers and a deficient inflow from the North Sea area. Isolation of the Baltic by elevation across the 
Sound and Belts would therefore leave a relict sea that would speedily become fresh. Salt water land-locked areas-as for instance, the American Great Salt Lake, the Bitter Lake in the Suez Canal, the Dead Sea, etc., are not necessarily relicts because of their high salinity but simply terminal basins suffering removal of water by evaporation and continuous addition of saline materials in solution.

Indications of the original nature of the Relicts are the geological history of their general land areas, as in the case of the Black Sea; elevated beaches with marine fossils (Lake Champlain); the relict marine fauna (squids in Lake Onondaga, which was a tributary to Ontario); the fishes of the Caspian (sturgeon, salmon, herring); sponges in Lake Tanganyika, etc.

The Marginal Sea-bottom Deposits.-In general these are the sea-bottom deposits of the Continental shelf, that is, Murray's terrigenous deposits and the shallow-water neritic materials. This region of sea-bottom is that on which the greater mass of the sedimentary rocks of the earth's crust has been deposited, and on which future sedimentaries are, of coursa, now forming. The general limits of depth of the marginal deposits we may take to be those of the Continental shelf, but this is necessarily a rough approximation. Muds of land origin may be carried much further out to sea before they subside to the bottom: thus blue muds may be found at 2,0003,000 fathoms. In general, however, the two limitsthat of the Continental shelf in about 1,000 fathoms, and that of the oceanic distribution of continental seabottom deposits will be much the same.

The Foreshore Terrigenous Deposits. For the most part the material lying on the foreshore is quartz sand, but even a very limited degree of observation will show many other kinds of deposit. In the neighbourhood of rock shores the intertidal zone may be clean, or nearly clean rock covered with weed; off boulder-clay cliffs 


\section{AN INTRODUCTION TO OCEANOGRAPHY}

there will be rounded water-worn stones of all sizes passing into quartz sand; elsewhere there may be sand and mud, or mud alone. The conditions are obviously the nature of the adjacent land, the strength and direction of the tidal streams, the volumes of rivers and streams entering the sea, the configuration of the coast line-as in bays of different forms, estuaries, straits, etc. Obviously the variety of these conditions will be very great.

The Foreshore Neritic Deposits. Quite different materials may, however, be seen in the deposits due to molluscan shells, nullipores, the sandy tubes of marine worms ; remains of polyzoa, etc. '(See Fig. 19). Coral materials driven on to the intertidal zone, or beyond this, by wave action we have already considered. Shelly gravels and sands are very common, but such accumulations on the foreshore, or on the adjacent shallow sea bottom are, as a rule, not the results of the growth of mollusca in situ. Wave action, assisted by peculiarities in the local tidal streams and in the form of the coast line, drive the dead shells of molluses living beyond the low water marks on to the foreshore (as one sees by examining the débris of the tide marks). Even in a clean sandy foreshore thickly populated by cockles we do not usually find many dead shells in the sand. As a rule foreshore shell deposits, then, have originated elsewhere in the neighbourhood of the locality where they are seen. On the other hand, highly characteristic foreshore neritic deposits formed in situ-are the sandy tubes of the worm Sabellaria: here we have true "Annelid Reefs" of quite a massive kind.

Shallow Water Neritic Deposits. It would more commonly be the case that the extensive deposits of molluscan shells found on sea bottoms less than 50 fathoms in depth had originated in situ from animals living and dying there. Possibly examination of the shell fragments from a neritic deposit would indicate whether the accumulation had been made on the region inhabited by the living animals or had been transported on the sea bottom, or 
driven by wave action on to the foreshore. Evidence of wear by rubbing among stones and sand on the beach, or rolling gently on the sea bottom, the marks of corrosion by solution, or those of boring by marine molluses or sponges might indicate deposition in situ. But there is need for prolonged and careful observations on these matters.

Neritic shallow-water deposits will, of course, vary in nature according to the local faunas. Thus the gravels and sands composed characteristically of the tests of Foraminifera (Orbulites) or of calcareous algae (Halimeda, for instance) are typical of some tropical sea bottoms - as off Ceylon. Here too, we may mention such limy deposits as may be found on the continental shelf in the West Indian Seas. These may be very largely the result of precipitation of calcium carbonate from solution in the sea water, and they are neritic only in the sense that they are, to a great extent, due to the action of certain species of marine bacteria.

The deposits of the foreshore and the shallow water immediately adjacent to this are, then, exceedingly varied - far more so than those laid down in the oceanic abysses. But terrigenous materials of continental origin must always predominate except, of course, on those marginal areas (as on the North-East coast of Australia) where coral formations on the great scale occur. By studying the ways in which shallow water neritic deposits form and are transported, much useful data might become available for elucidating the conditions in which many marine sedimentary rocks have been formed.

The Continental Margins.-We may now neglect the great variety of feature which is exhibited by the bottom deposits in the transitional zone between the continental elevations and the oceanic depressions. On a chart showing whole oceans and continents this transitional zone is, after all, a very narrow one, and what one looks at are the great continental and oceanic regions 


\section{AN INTRODUCTION TO OCEANOGRAPHY}

of the earth's surface. Something, then, must be said as to the general nature of this continental-oceanic margin on the great scale and from the point of view taken in Chapter II-the origin of the oceanic abysses and their assumed permanence as great earth features. It is assumed that the general positions on the earth of the oceanic depressions and continental elevations were marked out quite early in the history of the planet and that the continental margins represent zones of weakness in the superficial earth layers. These margins have always been, and still remain zones of weakness because movements of the earth body as a whole still continue. There are causes that lead to instability of these surface layers : strains set up by the tide-generating force in an earth body which is not perfectly rigid; loss of heat which has been locally generated; erosion of the continental areas; deposition on the sea bottom and possibly other factors. Therefore, there is instability and this has led, and still leads to alterations in the shapes of the continents as marked out by the land-sea margin, by the surface relief of the land and by its elevation above sea level. This means that extensive areas of the submarine continental shelf have, at various times in the past, been dry land, while far more extensive areas of the present continental regions have been shallow sea bottoms. It does not follow, however, that correspondingly large areas of the present oceanic regions have ever been dry land. There is geological evidence that the greater part of the North American Continent, for instance, has been submerged beneath shallow seas, but evidence of the uplifting of a truly oceanic basin is not nearly so strong.

The physical condition of the interior of the Earth.As a whole the evidence indicates that the interior of the earth, generally, is not highly heated. There are local regions of high temperature but these are probably superficial in their situation and the heat is locally generated. The temperature gradients are very irregular 
and the observations apply only to a very restricted depth. The conclusion that has been made from these observations: that a high temperature exists towards the earth's centre is unjustifiable because it involves extrapolation from the data of the surface temperature gradients and this extrapolation itself involves an hypothesis-that the rate of increase of temperature continues. The main reason for the assumption of a very high internal temperature is, of course, the postulation of a gaseous-molten origin for the earth, and this we have no good reasons for accepting. We take it, then, that the whole interior mass of the earth body, down to the centre, is not, as a whole, highly heated.

The Density of the Earth. The mean density of the earth as a whole is about $5 \cdot 6$ times that of water-this result depends on gravity measurements. But the most superficial layer of earth substance-the atmosphere-is very much less in density than water. The next layer-the ocean (or hydrosphere)-is very little greater in density than water (the ratio is about 1.03 to 1.00 ). Then comes the rocky part of the earth (the lithosphere) and the density of this is about 2.7 times that of water. Since the density of the earth as a whole is about $5 \cdot 6$, it follows that the nuclear part (the centrosphere) must have a density that is greater than the mean: it has been taken to be anything from about 7 to 11 .

The Rigidity of the Earth. The rigidity is the measure of the resistance which the earth body opposes to external causes which would lead to its deformation. Obviously the atmosphere opposes very little such resistance since it is greatly deformed (in changes of barometric pressure and winds) by relatively small causes. Nor is the ocean rigid in a marked degree, for tidal deformations are conspicuous features in its form. The lithosphere is obviously deformed in the processes by which great masses of stratified rocks are crumpled, or even folded into mountain ranges. There remains the (presumably metallic) centrosphere, and this 


\section{AN INTRODUCTION TO OCEANOGRAPHY}

is also susceptible of deformation but to a degree which is almost infinitesimal when compared with that of the lithosphere-to say nothing of the hydrosphere.

That the earth body (that is the metallic centrosphere as distinguished from its envelopes, the rocky lithosphere, the watery hydrosphere and the gaseous atmosphere) is actually deformed is proved by (1) the wandering of the axis of rotation. The poles trace roughly circular paths on the earth's surface, with a period of about 14 months and a range of about 10 metres. If the earth body were perfectly rigid the period can be shown to be 10 months. (2) The experiments of Hecker, Orloff and Michelson. Hecker and Orloff used horizontal pendulums, and Michelson made use of horizontal water columns 500 feet long and sunk to a depth of 6 feet in the ground. The descriptions and interpretations of these experiments are difficult but their results are clear. The earth body does respond by changes in shape to the tide-generating force but to an excessively small degree. It responds to a significantly greater extent in a North-South direction than in an East-West one. But the amount of deformation produced by the tide-generating force is no greater than if the earth were composed of tempered steel.

The Changes towards the Earth's Centre. The outer envelope-the atmosphere-is highly compressible. The hydrosphere is very much less compressible (see p. 166) but is viscous in that it flows. The character of the lithosphere is a certain "viscosity"-not, however, quite the same thing as physical viscosity. There is "flowage," or "rock-creeping" rather than semi-liquid "flow." Compressibility and viscosity are infinitesimal in the centrosphere but this is, to some extent, elastic as is shown by the propagation of earthquake waves. The latter can be thought about as set up in the earth in much the same way as vibrations would be set up in, say, an anvil when the latter is given a sharp tap with a hammer. When an earthquake shock is made, three series of waves 
are established and are propagated outward through the earth body.

(1) The first precursors, or first preliminary tremors: these are long waves of compression (longitudinal, like sound waves) and they travel through the earth in paths which are chords to the surface. (2) The second precursors, or 2nd preliminary tremors : these also travel through the earth body in chordal or curved paths. They are transverse waves and they cannot exist in a liquid medium. (3) The main waves, that is the destructive ones. These are rocking waves that travel on the earth's surface.

The velocity of the preliminary waves is greater than that of the superficial ones. Since they take approximately the shortest paths through the earth body, they may pass through any parts from the surface layer down to the centre. Their paths can be deduced from a knowledge of their points of origin and receipt, because they go straight, or nearly so, through the earth from the one point to the other. Now the deeper is their path (down to a certain distance from the centre) the greater is their velocity. Down to about 2,450 kilometres from the surface the velocity increases then it decreases rather suddenly at a depth of about 2,900 kilometres and finally increases again towards the centre. The velocity depends on the ratio of elasticity of earth material to density, so that either or both of these properties change down to a certain depth, then remain approximately constant and finally change again towards the centre. But everywhere below about 1,200 kilometres the ratio is high relatively to its value above that level.

The Theory of Isostasy.-The intensity of gravity is not the same everywhere on the surface of the earth, and this is due to the spheroidal shape of the latter : a point near the pole is about $13 \frac{1}{2}$ miles nearer to the earth's centre than is a point on the equator. The gravitational field is therefore more intense at the latter point. This variability in the intensity of gravity is measured, on the 


\section{AN INTRODUCTION TO OCEANOGRAPHY}

land, by observing the times of swing of a pendulum of invariable length and, on the sea, by measuring the atmospheric pressure by a barometer and, at the same time, finding the temperature at which water boils. The height of the barometer depends not only on the air pressure but also on the intensity of gravity, and the boiling point depends only on the air pressure. The two observations, taken simultaneously, therefore give us the intensity of gravity, which depends on the earth's mass beneath the point where the observations are made. This value depends again, on the density of the subjacent earth substance and on its quantity, that is the distance from the centre of earth to the place where the experiments are made.

Over the deep oceans the intensity of gravity is everywhere the same though the depth may vary, say between three miles and two miles. In the latter case we have an earth column which is greater in depth by one mile and a water column which is less in depth by one mile, but the intensity of gravity is the same as at the place where the earth column is one mile less in depth, and the water column one mile greater. The density of the earth column cannot, therefore, be the same at the two places and must be less where the water is less deep than where it is more deep.

The intensity of gravity is measured on the continents by observing the time of swing of a seconds pendulum. On the top of a mountain the intensity will be rather greater than at the base, but we can imagine the inequalities of a continental land area to be smoothed down, that is, the materials that constitute the mountains can be imagined as being removed to the extent that they are necessary to fill up the valleys. Then we have the continental plateau, or mean plane. The latter can be calculated from the data of surveys so that an estimate can be always made as to the vertical distance of any place above or below the mean plane. Corrections to the observed 
values of the intensity of gravity are then made so that the latter is reduced to what it would be at the mean plane level. If the station of observation is above the latter a certain deduction has to be made, if below an additive correction is made.

Then it is found that the intensity of gravity is the same for places on a continental plateau as it is for places on an oceanic depression (in the same latitude of course). This means that the total mass of a column of earth beneath a certain area on a continental plateau is the same as that beneath the same area on an ocean bed. Yet the difference in the heights of the two columns may be (say) four miles The conclusion is that the earth material beneath the continental area is less dense than that beneath the oceanic area. There is other evidence leading to the same conclusion : thus the Himalayas, and other mountain ranges, are less attractive than they ought to be if they were composed of the material that is found at their margins. So their interior parts must be formed of less dense rock than that which is observable.

The Isostatic Earth Layer. Rock materials have certain "strengths," varying between about $\frac{1}{4}$ ton and 4 tons per square inch : when the strain exceeds the limit of strength of any particular rock material the latter is crushed or disintegrated. Now the general density of the substance of the continental plateaus is such that the weight of a column of rock three to five miles high would crush the materials at the base of the column. In general, then, the continental elevations are so high above the oceanic depressions that at the level of the latter the rocks beneath the continents must be self-crushed.

Somewhere beneath the ocean beds and continental plateaus, then, there must be an earth layer which is unstable because it consists of crushed materials. This is, nevertheless, a zone of very rigid rock and it is only potentially unstable or crushable. It will yield easily to a change of stress which would be resisted by an un- 


\section{AN INTRODUCTION TO OCEANOGRAPHY}

crushed rock. In this zone there will be "rock flow"not the flow of a viscous material such as solid pitch but a transference of material by solid solution, particle by particle, by shearing of crystals, molecular re-arrangements, etc. The materials will, in general, be in such a state owing to the superincumbent weight, that they will slowly yield to stresses in appropriate directions.

This zone of yield is the isostatic earth layer. It has been estimated as being placed at about a depth of about 122 kilometres beneath the mean earth level, but recent observations tend to reduce this depth by about one-half. Below it the earth material is rigid in the geological sense, but in it the material is " plastic "-when sufficient length of time is allowed for the process of rock-flowage indicated above.

Above the isostatic level there is " isostatic equilibrium," that is, higher earth regions, such as the continental plateaus, are balanced against the lower earth regions, such as the oceanic depressions. The equilibrium will be essentially the same as that to be seen in the two limbs of a U-tube, one of which contains sea water and the other distilled water. The liquids will stand at different levels in the two limbs and the difference of level will depend on that of their densities.

The great features of the earth's surface are balanced in this way, that is, the lighter materials of the higherstanding continents are balanced against the heavier materials of the lower-standing ocean beds, the balancing. occurring in the layer of earth about 29 to 122 kilometres in depth. Small features, say mountains and valleys of magnitude equivalent to mountains, may exist in virtue of the rigidity of the earth's crust, and need not be balanced in the isostatic way. Such features as are, perhaps, over one square mile in area but less than one square degree, may exist unbalanced just because of their own rigidity and that of the supporting earth crust. The picture of the earth that we now make is as follows:- 
(1) A nearly rigid centrosphere occupying at least $\frac{3}{4}$ ths of the earth's diameter. Stresses due to tidegenerating force distort this centrosphere in a very small degree.

(2) An isostatic layer some 100 kilometres thick. This yields slowly to stresses due to the tide-generating force or to the increased weight of materials deposited on it, or to lightening due to the removal of materials from it. "Materials" here are rock removed by erosion, or sands, gravels, muds and oozes deposited by geological transporting agencies, or snow or ice deposited or removed by meteorological agencies.

(3) A superficial layer some 30 to 130 kilometres in thickness. This is the part of the lithosphere represented by the ocean beds and continental elevations. It may be deformed by tidal action. It is the locus of subaerial and submarine denudation.

(4) The envelopes-ocean and atmosphere. These are mobile and easily deformed by tidal action.

Movements of the Continental masses with respect to the theory of Isostasy. - We have now to consider in what ways these notions of earth-structure on the great scale enable us to understand the relations of continental and oceanic regions-premising that the theory is still too incomplete, and the data of observation too meagre to do more than join together descriptions of earth-features which would otherwise have little scientific interest.

The Shield-lands. First then, it is to be noted that each of the continental elevations contains several ancient, nuclear, land-masses called "shields." The situations of of these are roughly indicated in Fig. 64. In the Eastern Hemisphere there are (1) Baltica, the ScandinavianRussian region; (2) Angara, Northern Asia and Siberia; (3) Ethiopia, the greater part of Africa; (4) and (5) Lemuria, Madagascar across to India; (6) Australia, the western part of that continent. In the Western Hemisphere there are (1) Canadia, Canada and Greenland; 


\section{AN INTRODUCTION TO OCEANOGRAPHY}

(2) Columbia, Mexico ; (3) Antillia, the West Indian Islands and Central America; (4) Amazonia, Brazil and N.W. North America; (5) Archiplata, Patagonia and possibly across the Southern Ocean to Antarctica. See further, in Chapter X.

The Oceanic Abysses. Opposed to the shield-lands are their "opposite numbers," the oceanic abysses. These great areas of depression have been supposed to have originated (like the original elevations now represented by the shields) in the primitive movements of depression and elevation following the maturing of the earth after its period of growth by the accretion of planetesimal matter. Thus they may have existed since Archean times.

The General Continental Regions. These (including the nuclear lands to some extent) we know to have had a degree of elevation above the mean earth level that has certainly been variable: that is, the continental land has alternately been elevated and then lowered by denudation and erosion from the shore inwards. They may have always been elevated relatively to the oceanic abysses.

The Oceanic-Continental Margins. Here are the loci of greatest geological change. Both erosion and deposition proceed at the maximal rates in these zones.

Interchange between Continental and Continental Shelf Regions. We can attempt now to trace in what ways the interchange of earth materials goes on between land and sea. First of all, it may be noted that the interchange between the land and the sea bottom under the great oceans is indirect and one sided. Lime, silica and (to a much less degree) iron, manganese and potassium are taken from the land and pass into solution in sea water. Then these materials are separated from the sea by pelagic plants and animals and are finally deposited on the ocean bottom as the calcareous and siliceous oozes, as glauconite (containing the potassium) and as concretions which contain the iron and manganese. On the whole, the specific 
gravity of such deposits is greater than that of the siliceous sands and clays which are laid down on the continental shelf; also there is no return of these deep-sea deposits to the continental regions. With the exception of a very few eases (which may be accounted for quite satisfactorily) there is no evidence of sedimentary rocks of such a nature that they can be supposed to have been laid down at the bottom of a deep ocean. Lastly the deposition of material on the oceanic bottoms is exceedingly slow, when compared with the corresponding process on the bottom of the marginal seas-but it has been continuous throughout very protracted periods. The conclusion is that the sea bottom outside the limit of the continental sea-bottom deposits is heavier than the remainder of the earth's crust. It spreads out, flattening itself, so to speak, under its own weight on the plastic isostatic layer undemeath. Hence the flat oceanic floors.

Between the continents and the zone of continental shelf, however, the interchange is much greater and more rapid. It must be regarded as a highly significant fact for structural geology, that by far the greater part of the material derived from the waste of the land is deposited on the continental shelf in relatively shallow water as sandstones, mud-stones and limestones. Further, a glance at Figs. 13 to 16 will show how very restricted, in comparison with the areas of the continents and oceans, this region of greatest deposition is. When one remembers, then, how great a thickness of strata $(25,000$ feet or more' is represented in some series of sedimentary rocks it is easy to see that space for such accumulated material on the continental shelf can only be obtained in a vertical direction. That is to say, as these deposits accumulatein shallow water, it must be remembered-they must subside, pressing down into the plastic isostatic layer of the earth's crust.

But beneath this again, and not deeper than about 30 to 60 miles, lies the rigid unyielding centrosphere. 


\section{AN INTRODUCTION TO OCEANOGRAPHY}

The material on the shelf region, then, must spread out laterally as it accumulates from above. The flatness of the ocean floor, seawards from the continental slope, suggests (but see pp. 128-9) that it does not spread out laterally in a seaward direction and so we conclude that the materials deposited on the shelf sink down deeply, are metamorphosed by pressure and "flow" inwards beneath the continental elevations. This is how isostatic balancing of heavier ocean beds and lighter continental core-materials occur. On the ocean beds there is continual slow deposition and so there is time for vertical subsidence into the plastic isostatic layer. The latter, but not the upper, relatively rigid ocean floor, spreads out laterally in the only possible direction, that is towards the region of continental shelf. But there a much more rapid deposition of material occurs and there is still greater loading on the isostatic layer. The only region of yield, then, is underneath the shelf itself, or uncierneath the continental plateaus. Material "flows," in the ways suggested already, and so there is uplift of the oceanic-continental margins, or of the continental plateaus themselves.

The great features of the Oceanic-Continental Margins.Next we may consider (but quite shortly, in the meantime) how the present forms of the oceanic-continental margins fit in with the ideas that come from the theory of isostasy, leaving a more detailed discussion for the last chapter. Fig. 60 represents the best known regionthat of the Atlantic and the Eastern side of the Pacific. Now, in many ways the Atlantic differs strikingly from the Pacific, and some of these we notice now, deferring further consideration of the facts until Chapter X.

Two main kinds of margins are indicated. The longitudinal coasts and the transverse coasts. The former are represented in the most typical manner by the Pacific Coast of South America. Here the great ranges of the Andes run near the ocean and everywhere parallel to the shore. This is a longitudinal coast in the most obvious 
form. So also the Pacific Coast of North America shows the same great features in the Sierras and Rocky mountains, also bordering the land and forming the land rampart of the continental slope. All these ranges of mountains are recent earth folds; great masses of strata crumpled and bent in complicated ways but in general with the folds lying parallel to the oceanic margins. There are no recent longitudinal earth-folds on the Atlantic Margins, but inland from the coast of Brazil there are ancient foldings. Also on the Scandinavian Coast there are similar old earth-folds and these are continued outwards across the North Sea as the Scottish mountains striking to the S.E. On the Scandinavian-Atlantic Margin, then, we have an old longitudinal coast. This is also the case on the Western North Atlantic Margin: here we have the old Appalachian earth-folds which run longitudinally on the North American Atlantic coast between about latitudes $30^{\circ}$ to $45^{\circ} \mathrm{N}$.

Elsewhere on the Atlantic Margin we have transverse coasts, rias and fiords with " fractured margins of horsts and fractured table lands." Thus in New Brunswick and Cape Breton Island folded Archean and Paleozoic rocks run about N.E. out into the Atlantic and are continued over to Newfoundland. These folds slope down seawards and are finally submerged, leaving the drowned valleys sloping down into the sea as the rias. They also occur on the North and South sides of the Bay of Biscay and elsewhere.

Fiords occur in typical form on the Norwegian coast, and in less typical forms on the West Coast of Scotland, in Greenland and elswhere. These features, rias and fiords, characterise the greater part of the European Atlantic Margin, the Newfoundland and Canadian coasts and the Eastern Coast of Greenland. Here old earthfolds, partially submerged and much eroded, run into the ocean either perpendicularly, or at some other angle to the general direction of the coasts. Between them are 


\section{AN INTRODUCTION TO OCEANOGRAPHY}

submerged valleys. In other places the continental land inwards from the Atlantic Coast tends to form horsts (which are great blocks of land, left elevated while the adjacent land has sunk down by systems of faultings). These are broken and eroded. The shields we may regard as worn and fractured table-lands.

All this suggests that the Atlantic oceanic-continental margins represent a phase of decadence. Turn now to the Pacific margins and on the eastern side of that ocean we see a young formation-a series of recent folds rising high above sea level, continuing parallel to the oceanic margin over immense distances and lying landward to relatively steep continental slopes down into deep water. This represents the continental margin in its growing, or mature phase.

The normal condition of a continental region we may take to be one of moderate elevation, a low table-land (when its average features are considered) rather than a great region bearing extensive and high mountain systems. It is the locus of extensive denudation-atmospheric and fluviatile. The result is the transport of eroded material into the sea on a great scale and the deposition of this on the continental shelf. Remembering the limited area of the latter, we see that long continued continental erosion and deposition must ultimately lead to the accumulation of immense thicknesses of strata on the shelf region. Seaward from this is the ocean bed beneath deep water. Here also there is long continued deposition of material, and our hypothesis is that the oceanic region is a relatively stable one. It has been there for a relatively long time as an area of depression; it has thus received pelagic deposits for periods that are much longer than those during which the continental regions suffer the change of which we are about to speak; these pelagic deposits are relatively heavy and, in addition, the ocean bed is loaded by the two to three miles of water standing on it. It is, therefore, an area of stability and beneath it the 
yielding isostatic earth layer must also be in a condition of relative stability.

Loading, then, of the restricted region of the shelf must cause yielding of the isostatic layer and then rock flowage. What direction will the latter take? Not underneath the ocean bed, we may expect, for that is loaded to a greater degree, as we have seen. Further, the deposition thins out on the oceanic margin of the continental slope, so that there must be a region there where the underlying strata are not self-crushed and are relatively rigid. The shelf deposits are, in a way, buttressed towards the oceanic margin, and the flowage due to self-crushing will probably tend to occur on the continental margin. After long continued erosion and shelf-deposition, therefore, there will be a tendency for the transference of material, from underneath the continental shelf region to underneath the continental region. By this time the general elevation of the latter has been reduced; the load on its underlying isostatic layer has also been reduced, and so the lateral pressure from the margins towards the central parts of the continental regions must increase. The result will be renewed elevation.

But that again must lead to lateral or horizontal thrust towards the oceanic margins. The outer regions of the shelf are, we have seen, buttressed and resist the thrust from the continental interior. So the shelf strata are subjected to lateral compression and are folded. Such would appear to be the origin of the great Pacific geosyncline formed by the Andes and Rockies. With this process of continental uplift and marginal folding, the conditions again become favourable for renewed erosion on a great scale.

Quite other phases are represented by the Atlantic margins and that of the Western Pacific, but these we consider in Chapter X.

The Continental displacement hypothesis.-The hypothesis of displacement formulated during recent years 


\section{AN INTRODUCTION TO OCEANOGRAPHY}

by Wegener states that the great continental plateaus are moveable on the earth's surface. The equatorial bulging and the polar flattenings are features of such magnitude that, relative to them and to the centrosphere, the plane of the equator, and the axis of the earth are invariable except for the very small cyclic movements mentioned on pp. 13,14. The lithosphere itself is, however, to be regarded as a film on the centrosphere, and between it and the latter is the yielding isostatic layer. Represent the continental plateaus by paper shapes fastened on to the surface of a small sphere with wet glue: we might then easily shift each paper continent bodily on the globe, sliding it on its wet glue surface (which would then represent the yielding isostatic layer). Thus the symmetry of the globe-its axis of rotation, its equatorial plane, its lines of latitude and longitude-would remain invariant (or nearly so) but the continents themselves would change relatively to this fixed frame of reference.

The shapes of the continental elevations lend themselves to this hypothesis (just as they do-in a way-to the tetrahedral one). The Atlantic margins of the old and new world give the most plausible case. Translate the Eur-African land mass across the ocean and it will nearly fit into the American one: the Cape Verde protuberance of Africa fitting into the great Central American Bight; the Cape San Roque American protuberance fitting into the Gulf of Guinea Bight and so on. On the north there will be a gap which can be filled up by Greenland. On the south there will also be a gap to be filled in, perhaps, by Antarctica. If, further, Antarctica and Australia are bent up to the north, being pivoted on Cape Horn, the Indian Ocean will be filled up. Then we should have one great continental land mass completely surrounded by ocean. It is assumed that such a single land mass did originally exist and that it broke apart, so to speak. The Americas drifted away westward from Eur-Africa, and the Antarctic-Australian lands drifted southerly from 
Asia. These movements led to crumpling and folding of strata. The Andes rolled up, so to speak, in front of the sliding American continent. There would have been a general movement from North towards the Equator, and so we can account for the tendency to form the great transverse foldings-the Himalaya-Alps one. On each side of the regions of rupture (the Atlantic, for instance) there ought to be corresponding features. Thus we can suppose the old Appalachian and Caledonian foldings (in North America and Northern Europe respectively) to have been continuous before the two Americas broke away from Eur-Africa-and so on.

Thus the hypothesis claims to have support in the facts of structural geology, but, without considerable space, the latter cannot be summarised here. It also claims support from the records of paleontology. The present distribution of many species of animals is undoubtedly puzzling, and to account for it land " bridges," or communications between the continents, are assumed to have existed in the past-Gondwana, for instance, an ancient continent joining Africa and America. Some of these assumed land connections are made probable by the facts of structural geology, but others seem to be ad hoc hypotheses designed to account for the observed distribution of species of animals. Possibly as much is to be said for the Wegener ad hoc hypothesis, in so far as it accounts for the facts of biological distribution, as is to be said for the others which had the same goal. Their weakness is their special object-one which biological research may yet render unnecessary, for it does not yet seem certain that convergence of animal characters may not explain some, at all events, of the problems of distribution.

So far as the displacement hypothesis is understood at present (for it is in process of revision) it would appear that the continental plateaus "float" on the present sea beds. But the limit of isostatic compensation must be put at a depth much greater than this-at 122 kilometres. 


\section{AN INTRODUCTION TO OCEANOGRAPHY}

Below this level the centrosphere is rigid and unyielding. except in so far as it "trembles" to earthquake shocks and to the changes in the tide-generating force. Thus both the ocean-bed and the continental plateaus rest on a yielding stratum. It must, then, be shown that the latter do actually yield, or tend to yield, more to forces of translation than do the oceanic plateaus-which must have a considerable thickness. Forces, or stresses, competent. to set up such movements must be found. Finally, astronomical evidence is quite essential to the hypothesis : that is, non-cyclical variations of latitude and longitude must be traced. 


\section{CHAPTER VI}

\section{THE CHEMISTRY OF SEA WATER}

The volume of the oceans and seas of the earth is about $324,000,000$ cubic miles, which is about 15 times the volume of the part of the earth above sea level. If surface inequalities of the earth were smoothed out, the higher parts of the continental elevations being deposited in the lower parts of the oceanic depressions, water would cover the entire globe to a depth of nearly two miles.

Such figures are impressive but they must not give the reader a false impression of the mass of the oceanic water relatively to that of the earth body. A two-mile deep ocean is only a sheet of water about 1/4000th part of the earth's diameter in thickness. Represent the globe by a rubber ball of 4 inches in diameter: then the ocean would be represented by a film of water 1/1000 inch in thickness. Such a film would cling to the rubber ball by capillary attraction. It might, quite easily, be sweated out from a ball of this size composed of suitable material. The analogy has some importance.

The origin of oceanic water.-We considered the possible modes of origin of the oceanic earth-depressions in Chapter II, and found that these depended upon the particular hypothesis of the origin of the earth itself that is assumed. This must also be the case with regard to the origin of the water, and the saline matter which this holds in solution. On the gaseous-molten hypothesis the problem is quite a simple one: the original earth-nebula contained the materials of the present gaseous and liquid envelopes, which formed part of an original atmosphere. When the solid earth-body had cooled sufficiently the water of the primitive atmos- 


\section{AN INTRODUCTION TO OCEANOGRAPHY}

phere condensed on it to form the ocean, accumulating in the depressions of the crust.

A difficulty is now encountered: there is apparently too little water on the earth. It is known that the molten lavas, or volcanic magmas of the present earth's crust contain considerable quantities of water and even crystallised rock materials are known to contain water inclusions. If, then, the rocky earth crust, or lithosphere, resulting from the solidification of an originally molten earth had a considerable thickness it must have contained quite a large quantity of water. In addition to this absorbed water present in the rocky lithosphere there was that assumed by the hypothesis, to be present in the primitive atmosphere. Now during the great crustal movements that have always proceeded, most (or at least very much) of the original crust must have been brought to the surface from time to time and have suffered disintegration. In the course of this the contained water-or very much of it-must have been sweated out, so to speak. If we assume reasonable data for the amount of this included water, it would appear that the total volume that has come from an earth solidifying from a gaseous-molten stage would probably be greater than the volume of the earth-film now represented by the ocean. It may be, of course, that the process of "sweating-out" is still going on and that the volume of the ocean is increasing and has always been increasing throughout geological time. And, indeed, there are suggestions in geological history that this is sothat, for instance, the ocean was much less in volume in Permian time, than it is now.

Far less difficulty is encountered if we adopt the planetesimal hypothesis of the origin of the earth. We may admit that the original bolt of gaseous-molten matter ejected by the eruptive sun contained a very large quantity of water-as much as one likes to assume. But the earth, in this embryo stage was small and so its gravitational field was, for a long time, insufficient to retain water- 
vapour as an atmosphere; and it is doubtful whether Mars can do so. Therefore, as the juvenile earth solidified and squeezed out water the latter would escape from its atmosphere, and not until it had grown to near its present size, by planetesimal accretions, would its gravitational field be intense enough to prevent water from evaporating and escaping from the atmosphere into outer space.

Probably, then, the ocean has not had its origin in a primitive atmosphere surrounding a hot earth body slowly solidifying from a gaseous-molten phase. It is far more likely that it has come from the water absorbed by the planetesimal dust, or chemically combined in the materials of the latter. As this solidified and then became disintegrated, the water would be liberated. At first it would escape, but when the earth grew big enough by the accretion of new planetesimal material the water would be retained. With its present mass it is even possible that the earth continually captures water molecules from outer space, and it is also probable that the water included in the last planetesimal accretions is still being sweated out. On this view, then, the ocean is very slowly increasing in volume.

The Chemistry of Sea Water.-Sea water is a complex solution of very many substances and the origin of this saline material must also be considered. On the gaseousmolten hypothesis, the question is a very simple one. The earth solidified and water which was approximately "fresh" accumulated in the depressions, or on those areas where the gravitational force was greatest. Evaporation, and subsequent precipitation as rain on the dry land, led to denudation of the materials of the latter. Soluble constituents, sodium chloride, for instance, were thus "leached" out and the originally fresh ocean became salt by degrees. On the planetesimal hypothesis it is difficult to see why it was not salt from the beginning since water which was squeezed out from a loosely compacted porous material must have exercised 


\section{AN INTRODUCTION TO OCEANOGRAPHY}

its solvent action all the time. To this question we return later in the present chapter, for it will be more convenient to deal now with the actual composition of sea water.

Water is almost an universal solvent, and there are few substances which are not soluble in it to some extent. In the conditions that have existed-prolonged periods of time; occasional high temperature and pressure and favourable conditions of percolation through, and over rock materials in all stages of disintegration - the solvent action of water upon the earth-materials has been facilitated. Therefore, a great number of elements can be found in solution in the sea.

This solution, even in the case of the most abundant substance sodium chloride, is a dilute one and for most of the detectable substances it is very dilute. What exists in sea water are not, then, simply the salts, sodium chloride, calcium sulphate, sodium carbonate, etc., but the dissociation products of these. In most cases the dissociation will be nearly complete; that is, for instance, it is not sodium chloride that is present but sodium and chlorine ions, with sodium chloride molecules, the whole forming an equilibrium which varies with the temperature. Even the water itself is dissociated to some extent, there being hydrogen and hydroxyl ions in the solution (see p. 149). What we regard as the substances present in sea water are, therefore, the ions mentioned in the following pages. It is true that we can isolate common salt, as a pure chemical, in the dry, crystalline form, from the sea, but in the sea it exists mostly as sodium and chlorine ions.

The substances present. These are, roughly in order of abundance, Chlorine, Sodium, Sulphur (as $\mathrm{SO}_{4}$ ), Magnesium, Calcium, Bromine, Carbon (as $\mathrm{CO}_{3}$ ), Silicon (as $\mathrm{SiO}_{2}$ ), Phosphorus (as $\mathrm{PO}_{4}$ ), Nitrogen (as $\mathrm{NH}_{4}$ and $\mathrm{NO}_{3}$ ), Iron, Aluminium and Rhubidium. All these elements can easily be found, in weighable quantities, either in the sea water, or in the dry salts obtained by evaporating the latter. 
In addition to them the following elements have been detected by chemical and spectroscopic methods even if their amounts, in some cases, cannot be.precisely estimated :-Iodine, Fluorine, Arsenic, Boron, Lithium, Caesium, Barium, Strontium, Manganese, Nickel, Cobalt, Copper, Zinc, Lead, Silver, Gold and Radium. Some of these elements can be traced in the dried salts, others in the ash of various plants or animals and others again in concretionary bodies on the sea bottom. "Radium" is, of course, the assumed cause of the observed radio-activity of oceanic salts and sediments, but it may be due to other elements. In the case of most of the substances present the concentration is too small for precise measurement, but the total quantities present in the ocean must be very great. It is curious to note, for instance, that there are certainly thousands of millions of tons of gold in solution and even a minimum estimate of the quantity of Radium present is taken to be about 1,400 tons.

The composition of Sea-Salt. Some of the rarer substances have extraordinary importance and we consider them later (pp. 156-60). "Sea-Salt" is the saline residue obtained when sea water is slowly evaporated to dryness, and this is the substance of which the composition is given below. A very great number of analyses have been made but only the later ones are considered here, and of them only a few are quoted. Seasalt, then, has the typical compositions given on p. 136.

The numbers given are percentages of the weight of the dry salts taken.

The localities are :-

(1) All the oceans: means of 77 samples taken by the "Challenger." The salinity was $33 \cdot 01$ to $37 \cdot 37$.

(2) The Atlantic: mean of 22 samples. Salinity $=36 \cdot 31$.

(3) The Baltic: Salinity $=7 \cdot 21$.

(4) The Mediterranean: Salinity $=38.97$.

(5) The Red Sea: Salinity $=39 \cdot 76$. 


\section{AN INTRODUCTION TO OCEANOGRAPHY}

(6) The Indian Ocean: Salinity $=35 \cdot 53$ to $36 \cdot 68$. (See pp. 137-146 for "Salinity").

A glance over these analyses will show how very uniform in composition is sea-salts taken from the most varied localities. Some of the differences in the results quoted are not much greater than the magnitude of the errors to be expected. Even in the cases of the Baltic (with only about $0.7 \%$ of dissolved solids) and the Red Sea (with nearly $4 \%$ ) the ratios to each other of the ions present are nearly the same. Where we do get significant

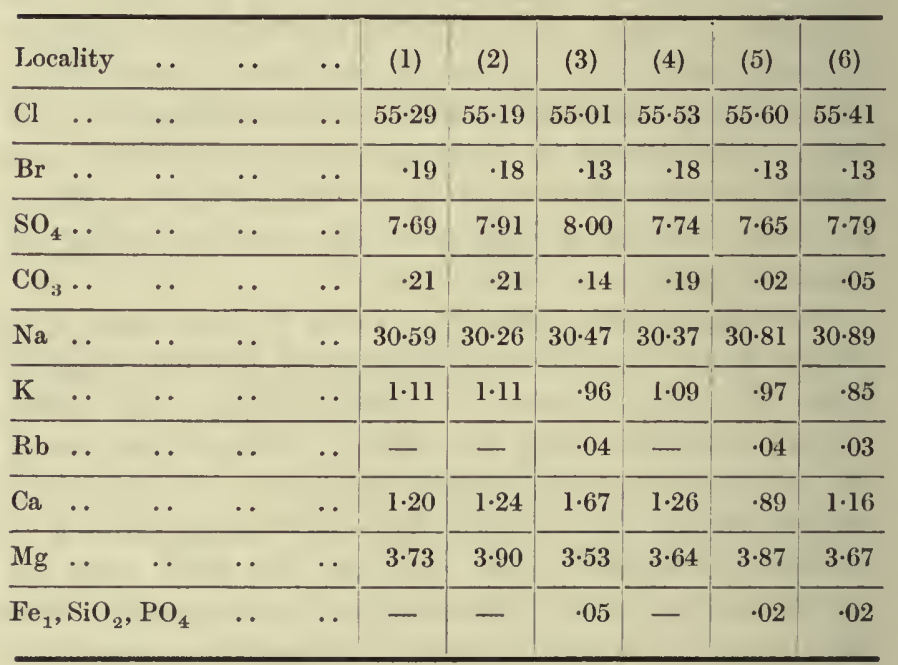

differences is in the neighbourhood of great rivers, and this is because the saline matter in solution in river water is rather different from that in the sea. Differences in the ratio of lime to sodium are also noticeable where there is a rapid removal of this element by marine organisms.

In general, however, the movements of the sea due to wave action, currents and tidal streams lead to a very thorough mixture of the water of different origins and this cause, which is in constant operation, has resulted in the 
very remarkable uniformity of composition indicated in the analytical results.

The Salinity.-What varies in a notable degree is the actual quantity of solid matter present per unit volume of water. This is the result of several causes: dilution by river water in the neighbourhood of continental lands, or by rainfall in the tropical zones of the oceans, or by the melting of ice, or concentration in the regions of high temperature and strong winds. Thus the salinity varies from one or two parts per thousand (in the Baltic) to nearly 40 per 1000 (in the Red Sea).

Salinity is (arbitrarily) defined as the total weight in grams of solid matter present in 1,000 grams of sea water where (1) the Bromine and Iodine are replaced by Chlorine; (2) the carbonates are reduced to oxides, and (3) the organic matter is ignited. It is estimated in various ways.

(1) By titration with standard silver nitrate solution. This method depends on the condition that the ratio of chlorine to the total salts present is so very nearly constant that the error involved in assuming that it is absolutely constant may be neglected. An empirical formula (obtained by Martin Knudsen) shows that Salinity $=0.03$ +1.805 Chlorine so that the estimation of the latter element enables us to calculate the salinity. Special burettes and pipettes are used so as to make the estimation rapid and accurate. The graduations on the stem of the burette are so arranged as to give the actual quantities of chlorine contained in 1,000 c.cs. of the water, of which 15 c.cs. are taken, as a sample for the titration and the concentration of the silver nitrate solution is made such that this is nearly the case. The sample is contained in a porcelain evaporating basin; a few drops of sodium chromate are added to it. Then the silver nitrate solution is added slowly from the burette until a very faint red colour appears: this happens when all the chlorine is precipitated as silver chloride and the next drop of solution throws down a ruby-red precipitate of silver chromate. 


\section{AN INTRODUCTION TO OCEANOGRAPHY}

There are of course many precautions which are not mentioned here. It is generally impossible to make, and preserve, a solution of silver nitrate of precisely the strength theoretically required, and so the approximate solution made is titrated against a sample of "standard sea water," the chlorine concentration of which is known accurately. Tables are then used to obtain the correction which is to be made to the burette reading.

(2) The electrical resistance of the sea-water sample is determined. Reference to tables then gives the salinity.

(3) An " interference method" has lately been developed.

In practical work the chlorine titration method is used. It is easy and accurate enough for most purposes, giving results correct to about 0.02 per mille. Usually this will suffice, but in the cases of samples taken from mid-ocean and at considerable depths the salinity variations are so very small that a higher degree of accuracy may be necessary. Then the interference method seems to be the only one that is refined enough for the purpose.

The variations in salinity.-Movements of the ocean which we shall consider in greater detail in the following chapters lead to a very thorough mixture of the water. These movements are the tidal streams which everywhere surge backwards and forwards in the neighbourhood of the land; slow currents and drifts which transport water from equatorial to polar regions and vice versa, and vertical movements of the ocean which lift up water from the bottom to the surface in some regions and cause surface water to sink to the bottom elsewhere. The effect of this mixing is to give the water a nearly uniform composition in respect of the ratios to one another of the various substances in solution, and the data quoted on pp. 136 will show how very nearly constant are these ratios. Long-continued mixing, due to the movements of the ocean would lead, of course, to an absolute uniformity in composition were not other factors in operation. Everywhere the salinity would be the same. 
Then other factors lead to diversity. In the equatorial regions there are zones of heavy rainfall which dilutes the surface water and so leads to an appreciable reduction of salinity. North and south of this intra-tropical zone of calms, high temperature and heavy rainfall are the zones of high temperature and strong N.W. and S.E. trade winds. These blow strongly throughout the year and lead to great evaporation of the surface water, raising the salinity of the latter to a marked degree. Movements of this surface water then lead to its transport into high northerly and southerly latitudes, and so the salinity which is normal to the temperate zones is increased by the entrance of denser water. At the same time an upward movement occurs : the surface water in the tropical zone becomes expanded by the high temperature and stands at a higher level than the normal one. Therefore it flows away to north and south and colder and lighter water rises up from the lower strata of ocean to take its place.

In the polar and subpolar regions there is an excessive amount of precipitation of water from the atmosphere in the form of snow. This accumulates on the land and solidifies to the form of ice. The ice is pressed down towards the sea as glaciers and the latter break away as icebergs which drift to south and north and slowly melt as they move towards the temperate latitudes. Melting there, they dilute the water of the ocean and so reduce the salinity.

There are smaller regions of high temperature and increased evaporation. The Mediterranean, for instance, is such a region and so are the Gulf of Mexico and the Red Sea. The salinity in these areas rises to much above the average value and the temperature also increases. The effect is an outflow of highly saline water which raises the salinity of the ocean in the regions into which such an outflow occurs. Thus the sea in the Bay of Biscay, and even at the entrance to the English Channel, is denser than normal because of the highly saline water 


\section{AN INTRODUCTION TO OCEANOGRAPHY}

flowing out into the Atlantic from the Mediterranean Sea. So also the South-West Atlantic, in the neighbourhood of the Gulf Stream outflow from the Straits of Florida, has an increased salinity.

In other places just the reverse change occurs. Thus the sea in the neighbourhood of the Amazon, Congo, Mississippi and other great rivers is much less saline than normal because of the entrance into it of great volumes of fresh water, and the reduction of salinity is a general feature of the ocean in the vicinity of continental land.

General variation of Salinity. Thus there is a general variation of salinity according to latitude and this is approximately as follows :--

$\begin{array}{clllll}\text { Zone of latitude } & \ldots & 70-55 \mathrm{~N} & 55-40 \mathrm{~N} & 40-15 \mathrm{~N} . & 15 \mathrm{~N} .-10 \mathrm{~S} . \\ \text { Salinity . } & \ldots & 30-31 & 33 \cdot 34 & 35 \cdot 36 & 34 \cdot 5-35 \\ \text { Zone of latitude } & \ldots & 10-30 \mathrm{~S} . & 30-50 \mathrm{~S} . & 50-70 \mathrm{~S} . & \\ \text { Salinity .. } & \ldots & 35-36 & 34-35 & 33-34 & \end{array}$

That is, roughly, low salinity in the equatorial zone; high salinity in two belts north and south; low salinity in the temperate zones; minimal salinity in the subpolar zones.

The Salinity Charts. Let a great number of observations of the value of the salinity of the surface water be made simultaneously: by "simultaneously" is meant, say, during the same month, for the values will not change greatly during that period and it is impracticable to attempt to deal with a shorter interval. The values are written down on a chart at the places where the observations were made and then a smoothly running line is drawn through all the points which have the same numerical value, say $35.5 \% \%^{*}$ This is done for each grade, say $31,32,33,34,35,36,37$ and 38 . The $35 \cdot 5$ contour line will not necessarily pass through all the points $35 \cdot 5$, say, but will go as nearly as possible to all of them and will change in curvature as gradually as possible. These lines are called Isohatines, and they are contours which are to be regarded as the average boundaries of

* The sign, \%o, means "per thousand." 
areas of water of the same ranges of salinity : thus the contours 35 and 36 enclose an area within which the water varies in salinity between those limiting values.

On large-scale charts, and when the observations are numerous, the isohalines represent very closely the distribution of the salinity. Such will be the case for such small areas as the North Sea, where there have been many investigations in progress. For much larger areas, say, the Atlantic Ocean, the courses of the isohalines must be much less precise because the observations must necessarily be made at places much further apart. In the case of the small areas the courses of the isohalines will generally be rather complex when compared with those of the large areas. Further, there are rather considerable changes in the contours from month to month, and even from day to day in the case of a small sea-area, and so the chart of isohaline contours must always be taken to represent the approximate conditions only. Remembering, then, that the actual distribution of salinity at any moment must always be more complex than that represented by the average distribution for a period of several weeks, and that it will be more complex on the small, than on the large scale, we may consider Figs. 22 and 23.

Far more attention has been paid to the Atlantic than to any of the other oceans, and the distribution of water of different degrees of salinity is fairly well known, both on the surface and in the lower strata. The chart shows, first of all, the general variation summarised on p. 140 . Rather to the north of the equator, that is roughly in the zone $0^{\circ}$ to $10^{\circ} \mathrm{N}$., the salinity is low varying between 33 and 36 . Then there are two regions of higher salinity north and south of the $0^{\circ}$ to $10^{\circ} \mathrm{N}$. zone but these are not so much belts as large, roughly elliptical areas centred round smaller regions where the salinity rises to over $37.5 \%$. The northern region has its centre roughly about $25^{\circ} \mathrm{N}$.Lat. and $40^{\circ} \mathrm{W}$.Long. while the southern one is about $15^{\circ} \mathrm{N}$.Lat. and $25^{\circ} \mathrm{W}$.Long. Round these central areas the salinity 


\section{AN INTRODUCTION TO OCEANOGRAPHY}

decreases, in the ways represented by the contours, towards the value $35 \%$, which we may regard as characteristic of the higher temperate latitudes, both North and South.

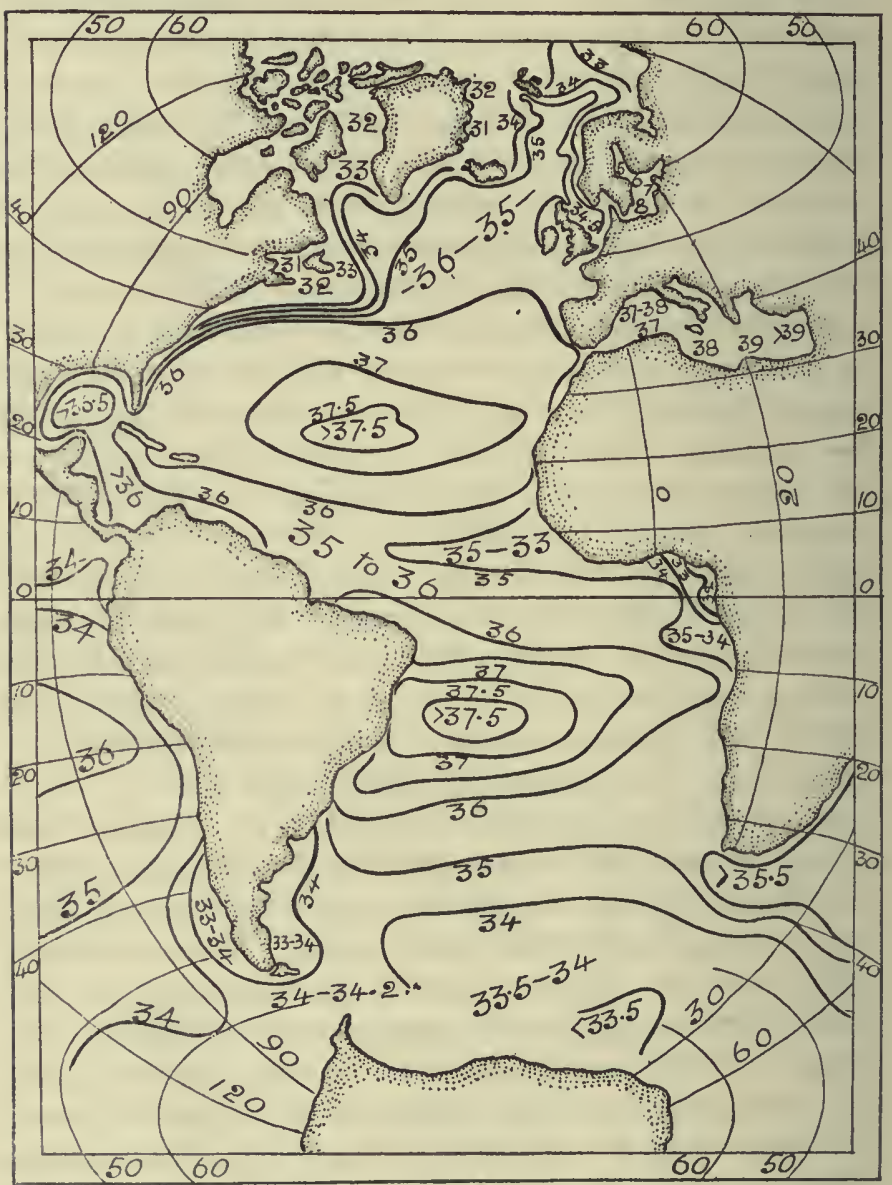

FIG. 22. The average distribution of salinity in the surface water of the Atlantic Ocean.

There is, therefore, an evident asymmetry in the distribution of the salinity of the Atlantic, inasmuch as the 
values do not decrease at the same rate to north and south of the equator, and the latter does not represent the central part of the zone of low salinity but lies about $10^{\circ}$ to the south of the latter. Further, we see that there is a tendency in the South Atlantic for the isohalines $37,36,35$ and 34 , to run roughly parallel to the equator while this is not the case in the North. There the isohalines are pressed up to the north-west, so to speak, against the coast of North America. Also the extension to the north of the 35 contour is very noticeable. We find water of 35 to $36 \%$ salinity round the S. and $\mathrm{E}$. of Iceland, up close to Spitzbergen and well to the north of North Cape, thus higher up than the 70th parallel of latitude. In the South Atlantic, on the other hand, the 40th parallel is, roughly speaking, the southern boundary of water which has a salinity of $35 \%$ or more. Again, we see that the more highly saline water is to be found in the north, on the eastern side of the Atlantic: thus the British Islands. in latitudes $50^{\circ}$ to $55^{\circ} \mathrm{N}$. are bathed by water of 35 to $35.5 \%$, while on the western side the Labrador Peninsula. is fringed by relatively fresh water between 31 and $33^{\circ} \%$. In the South Atlantic, on the other hand, the heavier water is found on the west, and the fresher water on the east borders of the ocean. Close up to Brazil we find the $37 \%$ contour line while, nearly opposite, in the Gulf of Guinea we get water which is only from 32 to $35 \%$. Finally, the toe of South America is surrounded by a rather wide zone of water which is also relatively fresh, that is, from 33 to $34^{\circ} \%$.

Next look at the "seas" that are situated on the continental margins. The two true "Mediterraneans," that is, the classical Mediterranean and the Gulf of Mexico, show high salinity values. In the former the water may attain a salinity of over $39 \%$ while in the latter the corresponding value is over $36.5 \%$. The shallow epi-continental seas, the Baltic, North Sea, and Gulf of St. Lawrence and Hudson's Bay, on the other hand, are filled with water 


\section{AN INTRODUCTION TO OCEANOGRAPHY}

which is relatively fresh, although this is much more noticeable on the West than on the East.

The figure is on far too small a scale to show the variations in salinity due to fresh water entering the ocean from the great rivers. Thus one could, by inspection of this chart, hardly deduce the situation of the openings of the Amazon, Rio Grande or Mississippi, although these would be indicated by the course of the isohalines in large scale charts. The low salinities in the Gulf of Guinea are evidently not due to the presence of water poured into the Atlantic from the Congo-we find just the same presence of low salinity water, and the great extension of this to the west as a long narrow tongue, in the Pacific Ocean.

The main features that Fig. 22 exhibits, with respect to the distribution of salinity, are due primarily to the equatorial dilution referred to on p. 140, and to the concentrating effect of the North-East and South-West trade winds. These causes would lead to the arrangement of the isohalines parallel to the equator. But the general trend of the great currents leads to the distortion of the isohalines in a way that we may the better study in Chapter IX. The low salinity on the extreme N.W. is due to the inflow of water from the Arctic regions, and that in the region situated off the Gulf of Guinea is the result of the upwelling of relatively cold and light water from the deeper parts of the ocean.

The conditions in the Indian and Pacific Oceans are represented in Fig. 23, which is drawn on a much smaller scale because the observations there are much less numerous than they are in the Atlantic. But, considering the ways in which these oceans are bounded, it is evident that we have to deal with essentially a similar kind of distribution.

Thus the equatorial zone of water, that is, the ocean between about $0^{\circ}$ and $10^{\circ} \mathrm{N}$. has lower values for the salinity than the zones to the north and south. There are two roughly elliptical regions, in about $20^{\circ} \mathrm{N}$. and 
S. Lats. where the salinity is high, over $36 \%$, though it is not so high as in the corresponding Atlantic areas. Smaller "islands" of water which is over $36 \%$ are situated to the north-east, east and west of Australia.

On the whole the tendency of the isohalines is to run more nearly parallel to the equator than in the Atlantic. The great diversity of land and sea, and of oceanic depths in the Australasian area, however, introduces a host of complications which are still more apparent when the contours are plotted on a larger scale chart. The epi-continental

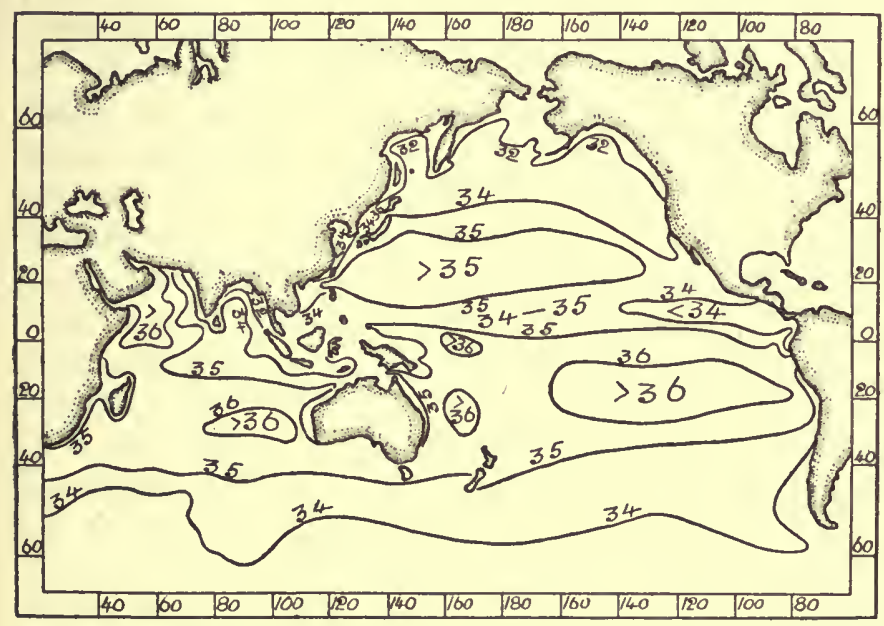

FIG. 23. The variation of salinity in the surface waters of the Indian and Pacific Oceans.

seas are, as in the Atlantic area, distinguished by their lower salinity. The influence of the Red Sea and Persian Gulf areas is indicated in the region of high salinity (over $36^{\circ} \%$ ) in the North-Easterly part of the Indian Ocean, and the evident influx of water from the Arctic is shown by the low salinity south of the Behring Sea. Just the same easterly projecting tongue of low-salinity water is shown in the eastern side in the equatorial latitudes and this, as in the case of the Atlantic, is due to the upwelling 


\section{AN INTRODUCTION TO OCEANOGRAPHY}

of cold and relatively light water from the lower levels of the Pacific.

We return to a consideration of the distribution of water of varying salinity in Chapter IX, for the origin and courses of ocean currents and drifts are, to a very great extent, traced by a consideration of the course of the isohalines.

The Gases of Sea Water.-In addition to the saline substances mentioned on pp. 134-6, the water of the ocean contains gases in solution. These are nitrogen (with argon), oxygen, carbonic acid gas, and, in exceptional places, sulphuretted hydrogen. The nitrogen and oxygen are mainly taken up from the atmosphere either by sea water itself, or by fresh water entering the ocean from rivers. This, to a great extent, is also the source of the carbon dioxide. In other ways, however, the sea receives gases: carbon dioxide may be liberated from solution in the water of submarine volcanic springs and as the result of putrefactive processes in the sea; oxygen is formed in the process of carbon-assimilation by plants; and nitrogen may be set free from organic matter as the result of the activity of certain species of marine bacteria. In other ways the sea loses the gases held in solution : oxygen is removed as the result of the respiration of marine animals and in processes of putrefaction of organic matter; carbon dioxide is removed in the process of carbon-assimilation ; and nitrogen is certainly removed by the nitrogen-fixing bacteria and locked up as nitrites and nitrates. These gains and losses probably balance each other during long periods of time.

For the greater part, however, the interchanges of nitrogen, oxygen and carbon dioxide take place between the sea and the atmosphere. Distilled water dissolves all the gases mentioned, and we shall consider the solution to be "dissolved air." The quantity of any gas that can be taken up by water depends on the temperature, on the partial pressure of the gas and on a chemical constant. 
Thus $Q=T . k / p, k$ being a constant depending on the chemical nature of the gas, and on the units adopted, $p$ being the partial pressure of the gas in the atmospheric mixture and $T$ being the absolute temperature of the water.

In the case of sea water the expression given above will contain an additional constant which depends on the salinity. At $0^{\circ} \mathrm{C}$. and $760 \mathrm{~mm}$. pressure, a litre of distilled water will take up about 19.5 c.cs. of nitrogen and about 10 c.cs. of oxygen-thus this "dissolved air" will contain about $34 \%$ of oxygen whereas the atmosphere contains only about $21 \%$. The gases mentioned are, however, less soluble in sea water then in distilled water: thus sea water of ordinary ( 35 to $36 \%$ ) salinity will dissolve about 10.5 c.cs. of nitrogen and about 5.3 c.cs. of oxygen at the temperature of $20^{\circ} \mathrm{C}$. and so this "dissolved air" will contain a little more oxygen than does the mixture dissolved in pure water. This percentage will remain nearly the same even if the temperature varies.

There is a continual tendency towards equilibrium between the gases dissolved in the sea and those contained in the atmosphere. This equilibrium would exist in the case of a dish of sterilised sea water exposed to the air. If the temperature decreases more gases will be dissolved by the water and if it rises gases will be liberated from solution into the air. Any change of atmospheric pressure will also affect the condition of equilibrium. To some extent this is the case with the ocean and atmosphere, but the equilibrium will be an average one which is continually being disturbed. The facilities for solution of air by the ocean are evidently very great. Winds blowing strongly bring repeated quantities of air in intimate contact with the water surface and the latter becomes enormously increased by breaking wave and spray. The tidal streams, currents and vertical movements of the sea continually change the water that is exposed at the surface. Thus the interchange is facilitated. 


\section{AN INTRODUCTION TO OCEANOGRAPHY}

Nevertheless the equilibrium changes from time to time and place to place. A cold current flowing into a place where the temperature of sea and atmosphere is higher must also rise in temperature and, the solubility of gases being diminished, some of these dissolved must be liberated into the air. 'The reverse reaction will occur when a warm current flows into a colder region, or when cold bottom water wells up to the surface of the sea. Change of winds will act in the same ways : a cold wind blowing off the land will chill the surface layers of water and then the latter will take up more air: on the other hand a warm wind will heat the surface and deprive it of some gas. Changes in atmospheric pressure will obviously produce similar effects. Finally, the activities of animals and plants in the sea lead to very marked local changes in the concentrations of all the dissolved gases.

The dissolved carbonic acid gas. The conditions regulating the interchange of $\mathrm{CO}_{2}$ between sea and atmosphere are much more complex than in the case of oxygen and nitrogen. First, the partial pressure of carbon dioxide in the air is much less than that of the other principal gases: its proportion is only about $0.04 \%$ as compared with about 79 and 21 in the case of nitrogen and oxygen respectively. If, then, we calculate the quantity contained in a litre of sea water from the expression on p. 147 we shall find it to be about 0.5 c.cs. whereas sea water usually contains about 50 c.cs. Thus sea water dissolves far more $\mathrm{CO}_{2}$ than if it were a saline solution strictly neutral in its reaction.

The Alkalinity of Sea Water.-Here we must consider why sea water can take up this relatively enormous quantity of $\mathrm{CO}_{2}$ and, first, we must make it clear what is meant by the "alkalinity." When an alcoholic solution of phenol-phthalein is added to sea water a pink coloration may be produced, and this is the indication of an alkaline reaction. To destroy the pink colour, acid 
must be added, and one or two c.cs. of centi-normal hydrochloric acid are usually required. This quantity of standard acid that is necessary in order to make sea water neutral to phenol-phthalein as an indicator is a convenient, though rough measure of the alkalinity.*

The hydrogen-ion-concentration is, however, a much more precise measurement of the reaction of the water. The purest water obtainable by repeated distillation in insoluble glass vessels may be regarded as neutral in reaction. It is dissociated to a very small degree, that is some water molecules, $\mathrm{H}_{2} \mathrm{O}$, are split up into their ions, hydrogen-ion, or $\mathrm{H}^{*}$, and hydroxyl-ion, or $\mathrm{HO}^{\prime}$, and the symbol ${ }^{{ }^{\mathrm{P}}}{ }_{\mathrm{H}}$ is used to represent the potential, or concentration of the hydrogen-ion. ${ }^{P_{H}}$ for pure water has the value $10^{-7}$, or $1 / 10^{7}$, and this represents the quantity of hydrogen-ion, measured in grams, contained in a litre of water : obviously it is exceedingly small. Since every hydrogen-ion corresponds to an hydroxyl-ion the concentration of the latter is represented by the same value: that is ${ }^{{ }} \mathrm{OH}=10^{-7}$.

Pure water, then, contains as many $\mathrm{H}$-ions as it does $\mathrm{OH}$-ions and so its reaction is neutral. If there is an excess of $\mathrm{H}$-ions the water becomes acid and if $\mathrm{OH}$-ions are in excess the reaction is alkaline. Now, since sea water usually has a distinctly alkaline reaction the $\mathrm{OH}$-ions must be in excess.

To what substances in the state of dissociation is the excess of $\mathrm{OH}$-ions due? This is a very difficult problem and the matter is not yet fully understood, yet the discussion turns on the dissociation of the carbonates present in solution and we conveniently consider it in connection with the question of the $\mathrm{CO}_{2}$ in solution. Now although sea water contains some 40 to 60 c.cs. of $\mathrm{CO}_{2}$ per litre (that is, that volume of the gas can be extracted from a litre of sea water, the quantity of $\mathrm{CO}_{2}$ dissolved,

* The alkalinity may be negative. One or more c.cs. of N/10 alkali may have to be added to sea-water in order to produce the colour change in phenol-phthalein. 


\section{AN INTRODUCTION TO OCEANOGRAPHY}

in the "free" condition (like the nitrogen is dissolved,) is only a few tenths of a c.c. The rest exists in combination with normal carbonates of magnesium and calcium, forming the hydrogen, or acid carbonates $\mathrm{MgH}_{2}\left(\mathrm{CO}_{3}\right)_{2}$ and $\mathrm{CaH}_{2}\left(\mathrm{CO}_{3}\right)_{2}$. These are much more soluble in sea water than are the normal salts, $\mathrm{MgCO}_{3}$ and $\mathrm{CaCO}_{3}$, yet the solution is not so simple as the above sentences indicate : in the water the various substances are ionised to an extent that depends on the dilution. Not only have we (say) the hydrogen calcium salt, but also the normal salt, the Ca-ions, the bicarbonate-ion, $\mathrm{HCO}_{3}$, hydrogen-ion and the free $\mathrm{CO}_{2}$. The state of equilibrium, that is the relative quantities of the various undissociated salts and ions present, varies with the physical and chemical conditions.

If the equilibrium is disturbed, the reaction of the solution will change also. If, for any reason, lime is removed, say by absorption by calcareous organisms, such as corals, or molluscs, or algae, then $\mathrm{HCO}_{3}$-ion will be increased and the alkalinity will decrease (or the acidity increase). If the $\mathrm{CO}_{2}$ be removed-as by the carbon-assimilation of marine plants-then $\mathrm{OH}$-ion will be increased. The plant cannot usually get enough $\mathrm{CO}_{2}$ simply from that which exists in simple solution as such, but as fast as this is removed $\mathrm{HCO}_{3}$ dissociates into $\mathrm{CO}_{2}$ and $\mathrm{OH}$-ion and the increase of the latter is the reason for the increased alkalinity. As fast as the $\mathrm{HCO}_{3}$ dissociates $\mathrm{CaH}_{2}\left(\mathrm{CO}_{3}\right)_{2}$ will also dissociate into $\mathrm{CaCO}_{3}$ and $\mathrm{HCO}_{3}$ in the effort to maintain the equilibrium. Thus carbon-assimilation by green plants first removes the free $\mathrm{CO}_{2}$, then leads to dissociation of $\mathrm{HCO}_{3}$ and lastly to dissociation of the hydrogen calcium salt. The end phase must be $\mathrm{CaCO}_{3}$ and $\mathrm{OH}$-ions. The water becomes the more strongly alkaline. Now the equilibrium is never attained in actuality. Pure water, we have seen has a ${ }^{P_{H}}$ value $=10^{-7}$ and ordinary sea water has the values $10^{-8}$ to $10^{-8 \cdot 5}$ As the dissociations due to carbon-assimilation proceed the 
reaction tends towards the value about $10^{-8}$.

(Note that these also mean $\frac{1}{10^{7}} \frac{1}{10^{8}}$ and $\frac{1}{10^{9}}$ in terms of $\mathrm{H}$-ions.) Thus the proportion of $\mathrm{H}$-ion in a volume of water decreases, or the quantity of $\mathrm{OH}$-ion increases and so the alkalinity, as measured say by the number of c.cs. of centi-normal acid necessary for neutralisation, increases.

Photosynthesis and Carbon dioxide. An enormous quantity of $\mathrm{CO}_{2}$ is annually withdrawn from solution in the sea. In the process of carbon-assimilation $\mathrm{CO}_{2}$ and $\mathrm{H}_{2} \mathrm{O}$ are taken into the tissues of a green plant and are synthesised to form a carbohydrate. The free energy of the latter substance is much greater than that of the $\mathrm{CO}_{2}$ and $\mathrm{OH}_{2}$ and so there must be an absorption of energy during the synthesis. It is known now that this is obtained from sunlight and that it is utilised to activate the $\mathrm{CO}_{2}$ and $\mathrm{OH}_{2}$ molecules which therefore enter into combination. The pigments of the green plant act as catalysts, intercepting and transforming the incident sunlight. For some reasons not yet understood, either the sunlight has a greater energising power during the months March to May, or there are necessary substances in sea water, other than $\mathrm{CO}_{2}$, which are more abundant in those months than at other seasons, or there is a rhythm of constructive activity inherent in the plant organisms. Anyhow, photosynthesis-that is the production of carbohydrate by green plants-is far more active, in the sea, during the spring months than it is at any other time during the year.

During those months, then, there will be a tendency to upset the average $\mathrm{CO}_{2}$ equilibrium. As the activity of the marine plants-the Algae, Diatoms and Peridiniansbecomes the more intense, first the "free" $\mathrm{CO}_{2}$ will be used up, then $\mathrm{HCO}_{3}$-ions will dissociate and lastly the acid magnesium and calcium salts will also dissociate, approaching the phase in which all the magnesium and calcium are contained in the form of the normal salts. 


\section{AN INTRODUCTION TO OCEANOGRAPHY}

But before that occurs the conditions for continued intense photosynthesis will have become rather unfavourable, or the other necessary substances will be used up to a significant extent and will not have been regenerated. The process of intense reproduction of the green plants will thus tend to its normal rate. But the alkalinity of the sea will have increased. It is difficult to believe that this increase of alkalinity is the reason why the rate of reproduction of the Diatoms (say) falls off so rapidly during the late spring, or early summer months and it is very probable that we must assume a rhythm of reproduction which is nearly independent of external conditions. There are arguments for this conclusion.

Experimental work shows that photosynthesis by marine algae tends towards cessation as the ${ }^{\mathrm{P}_{\mathrm{H}} \text {-value of }}$ the sea water approached $10^{-9}$. Take the normal value as about $10^{-8}$ and there are data for rough calculations as to the quantity of $\mathrm{CO}_{2}$ that may be withdrawn from solution in the sea and incorporated into the living tissues of marine organisms. Even a reasonably minimal estimate gives about 8.8 milligrams of carbon taken from the water, per litre of volume, during the months December to May. Expanding this we find a total production of carbohydrate of the order of magnitude of 10 tons of wet vegetable tissue per acre of sea surface. The complexity introduced into the conditions of chemical and biological equilibria in the sea by this change are easy to indicate but quite impossible to specify, even approximately.

Variations in $\mathrm{H}$-ion Concentration in the Sea. Lately the estimation 'of the ${ }^{{ }^{P}} \mathrm{H}$ values of sea water has been practised in a routine way as part of systematic hydrographic investigations. So far the results are not of great importance either from the biological or physical side and the method promises more when applied to very localised problems than to the study of a large sea area. Nevertheless some of the more recent results may be quoted here. The variable that is estimated is ${ }^{P_{\text {II }}}$ and 
for convenience we may express it as the logarithm of the reciprocal of the $\mathrm{H}$-ion concentration. The latter is, we have seen $\frac{1}{10^{7}}$ gram per litre for pure water and so ${ }^{P_{H}}$ is the index of 10 , that is 7 . The following data are those obtained in a study of the conditions in the neighbouraood of the Plymouth Laboratory of the Marine Biological Association.

(1) In the open sea at the mouth of the English Channel ${ }^{P_{H}}$ had the mean value, 8.20 (the full expression is $\left.\frac{1}{10^{8 \cdot 20}}\right)$. The variations were roughly, $8 \cdot 27$ to $8 \cdot 14$.

(2) Round Lands End, into the mouth of the Bristol Channel, the values ranged from $8 \cdot 18$ to $8 \cdot 14$. The mean was about $8 \cdot 16$. Here we see the influence of proximity to the land.

(3) In Plymouth Sound ${ }^{P_{H}}$ varied between about 8 and 8.2 the mean may be taken as $8 \cdot 10$. There was a decrease between high water and low water of about 0.05 . The conditions on the foreshore and in shallow water-that is, a greater quantity of marine life and an amount of contamination due to decomposing organic matter increases the $\mathrm{CO}_{2}$, and therefore the acidity-or conversely the alkalinity is diminished.

(4) In the Aquarium tanks. Here the water is much less alkaline. The ordinary $\mathbf{P}_{\mathrm{H}}$ value is $7 \cdot 6$. Plant activity is decreased while respiration by animals tends to increase of $\mathrm{CO}_{2}$-there is relatively much organic matter in solution and this decomposes by the activity of micro-organisms, again increasing the acidity-the quantity of $\mathrm{CO}_{2}$-ion. At $\mathrm{P}_{\mathrm{H}}=7 \cdot 6$ $\mathrm{CO}_{2}$ is abnormally in excess. At $\mathrm{P}_{\mathrm{H}}=7 \cdot 3$ fishes show signs of respiratory distress, for $\mathrm{CO}_{2}$ is much in excess.

At $7 \cdot 1$ the water is foul and smells badly. 


\section{AN INTRODUCTION TO OCEANOGRAPHY}

(5) In a jar of sea water without circulation and renewal, decomposition processes proceed to their limit-that is, to the resolution, by bacterial activity, of the carbohydrates into $\mathrm{CO}_{2}$ and $\mathrm{OH}_{2}$. The $\mathrm{P}_{\mathrm{H}}$ values approach the extreme figure of about 6.4 . The water is definitely unfit for animal life. Nevertheless strong agitation by a current of air will remove the

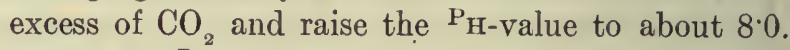

Variations in $\mathrm{P}_{\mathrm{H}}$ indicate, then, the varying balance between the processes of photosynthesis by plant life, respiration hy animal life and decomposition of organic matter by micro-organisms. Add to these renewal of the $\mathrm{CO}_{2}$ or its removal by agitation of the sea water.

Distribution of dissolved gases in the ocean.-The general distribution only is known and that alone with respect to oxygen (which is more easily estimated then $\mathrm{CO}_{2}$ or nitrogen). From what has been said above, the reader will be prepared for the following rough statement, which refers to the Atlantic Ocean. It is not very precise but the local variations are probably so great that no precise statement is possible.

The average quantities of oxygen are given for the various zones of latitude and depth as cubic centimetres per litre of sea water in situ.

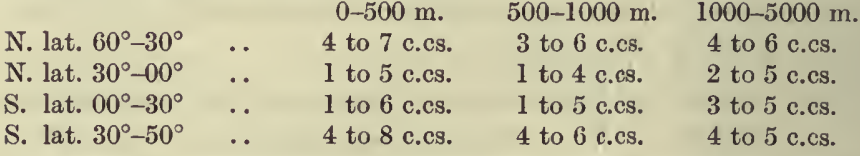

Thus the water at the surface generally contains more oxygen than the water at the bottom. This is because it is exposed to the air. If, however, the water at the bottom were within access of oxygen it would contain more because, at a lower temperature, it could hold more in solution.

Also the water near the poles contains more oxygen than that near the equator. This is because of the much lower temperature of the sub-polar seas. 
In general, sea water contains less oxygen than it might hold in solution in the given conditions-that is, it is undersaturated. The deficiency from saturation is, in genesal, less at the surface than at the bottom. But it may easily become saturated in experimental conditions, or in localised regions where intense photosynthesis by maine plants goes on. It does actually become supersaturated in the sea, exceptionally, it is true. Supersacuration with oxygen is known to give rise to a definite frm of disease in fishes inhabiting fresh water. There the water receives so much oxygen from plants that, should a sudden rise of temperature occur, the state of upersaturation would follow and the gas would tend to pecome liberated from solution. A fish has the same temperature as that of the water which it inhabits, and its intake of oxygen will depend to some extent on the concentration of the gas in the water. With supersaturated water an unusually large quantity of oxygen may be absorbed by the blood and then the latter, itself, may become saturated at a given temperature. Should this rise significantly, oxygen may be liberated from the blood, forming visible bubbles, or gas-embolisms in the vessels.

Deficiency of oxygen, that is, a defect well below the quantity to be expected from such a general statement as that of p. 154, may easily occur as the result of a lack of circulation in the water. Such a defective circulation occurs, on a small scale, in some of the Norwegian fiords and, on a large scale, in the Black Sea. In both cases the communication with the ocean is restricted by submarine elevations resembling dock sills. At the entrance to the fiords the water is often very shallow, while it is relatively deep at the inner parts. The Black Sea is moderately deep but its entrance (the Sea of Marmora) is stallow. In both cases, then, there is stagnant water near the bottom. The oxyzen is used up in a variety of ways and is not renewed, and sulphuretted hydrogen, resuling from organic decomposition, takes its place. 


\section{AN INTRODUCTION TO OCEANOGRAPHY}

Nitrogen will be distributed in the same general way as oxygen, that is, the quantity in solution is a function of the temperature and pressure, and will, on the vhole, be less at the surface and in the equatorial regions, than at the bottom and in the sub-polar and polar regons. The gas, however, is chemically inert and it can only be withdrawn from solution by the activity of nitrogen-fixing bacteria. We have no good data as to the distribution and intensity of action of these organisms. Nitrog?n is present in solution in something like the order of 10 to 12 c.cs. per litre of sea water. The latter is nearl always saturated with nitrogen at the surface and, therefore, a large mass of water falling from the surface to a bottor stratum of much colder water must become super-saturated with this gas.

The indispensable food substances ; vital production in the sea.-Certain chemical compounds in solution in sea water are of extraordinary significance with respect to marine life. These are carbon dioxide, salts of ammonia, salts of nitrous and nitric acid, "albuminoid substances" (that is amino-acids), organic carbon compounds (volatile and other acids and basic substances), silicic acid, and salts of phosphoric acid. All these are indispensible to life. All of them, except $\mathrm{CO}_{2}$, occur in extremely small quantities and are variable in abundance from place to place and season to season. Their estimation in sea water is extraordinarily difficult, and far too little work, in this direction, has yet been done. It is, however, essential that the general nature of the results so frr obtained should be indicated here.

Vital production in the sea. Animal life in the sea and on the land depends absciutely on the supply of food substances in the forms of proteids, carbohydjates and fats. Such materials can only be obtained rom the bodies of plants and animals. Animal life, therfore, subsists on animal and plant life. The limit to vhich animal processes tend is the utilisation of the avalable 
energy of the food substances mentioned, and the ultimate reduction of these materials to the stages of carbon dioxide, water and amino-acids. The aminoacids are then further reduced, by micro-organisms, to the stage of nitrates. When this limit (organic matter to $\mathrm{CO}_{2}, \mathrm{OH}_{2}$ and nitrates) is attained the food-materials can no longer be utilised by animals and are thrown out of circulation, so far as these organisms are concerned. The general process of animal metabolism is one of energydissipation. The substances involved are chemically degraded, and pass into their most stable conditions, while the energy involved becomes unavailable. Physically the processes lead to augmentation of entropy. The animals are, therefore, the "consumers" of the sea.

Plant life in the sea tends to reverse the processes indicated above, since it can utilise the chemical substances $\left(\mathrm{CO}_{2}, \mathrm{OH}_{2}\right.$, nitrates, etc.) that are no longer available as food for the animals. So far as we know the typical, green, unicellular or multicellular plant cannot utilise energy in the form in which it is unavailable for the animals. Possibly micro-organisms may do so by making use of the Brownian movement of small particles. Thus synthesis of carbohydrates can be effected, in the absence of visible radiation, by certain bacteria. The plant can, however, arrest the process of dissipation of solar energy by using the latter to activate the $\mathrm{CO}_{2}$ and $\mathrm{OH}_{2}$ molecules. Otherwise inert, these molecules can now enter into combination, with the result that formaldehyde and then carbohydrates are synthesised. Somewhat similar syntheses must occur so as to form amino-acids from nitrates and other mineral nitrogen compounds, together with the synthetic carbohydrates.

In the ordinary course of events, then, marine plants (that is, the large algae and the minute Diatoms, Peridinians, etc.) arrest the process of dissipation of solar energy. The latter tends, in the absence of light, to transform into low temperature heat, which becomes 


\section{AN INTRODUCTION TO OCEANOGRAPHY}

unavailable inasmuch as it is uniformly distributed. In photosynthetic plant metabolism, the dissipating solar energy becomes stored, in the potential form, as the carbohydrates and proteids of plant tissues. This is vital production.

For its continuance there must be, in the sea, the various substances mentioned at the head of this section.

We have already considered the carbon dioxide. Its abundance in the sea is limited by an equilibrium between sea and air. The equilibrium is always being locally and temporarily disturbed. When $\mathrm{CO}_{2}$ is in excess (as in sea water containing decomposing organic matter) it becomes returned to the atmosphere. When it is deficient (as when photosynthesis, in the spring and in shallow shore pools proceeds at an unusally rapid rate) $\mathrm{CO}_{2}$ is absorbed from the atmosphere. Now the supply in the latter and in the open sea is practically unlimited when all the conditions are taken into account. It must vary throughout geological periods. Excessive emergence of the land means a more rapid rate of weathering of rocks, the decomposition of silicates and the removal of $\mathrm{CO}_{2}$ from the air. Converse conditions will occur when the land is, on the average, low and when subaerial denudation is minimal. Such conditions have alternated in the past and so has the quantity of $\mathrm{CO}_{2}$ in the air (and by consequence, in the sea). Upon these alternations in quantity of $\mathrm{CO}_{2}$ may depend climatic changes, because of the heat-absorbing property of the gas.

The Nitrogen compounds. These are salts of ammonia and salts of nitrous and nitric acids, with "albuminoid ammonia." Their origin is partly the decomposition of proteid matter arising from dead bodies, or the excretions of marine organisms, and partly substances of the same nature draining down into the sea from the land. In addition to these sources of mineral nitrogen, some comes from the atmosphere where it is formed from elementary nitrogen and oxygen combined by electric discharges. 
Some also comes from the activity of nitrogen-fixing bacteria on the shallow sea bottoms. These organisms are able to oxidise elementary nitrogen, first to nitrous, and then to nitric acids. As the result of all these processes there is an excessively small quantity of mineral nitrogen compounds in any volume of sea water, say a litre, that can conveniently be submitted to analysis. The nitrates are the stable forms and are rather more abundant than the albuminoid ammonia, which is a temporary stage in the breaking down of proteid matter. Ammonia, as such, is much less abundant than either of the other two kinds of nitrogenous material.

The quantities are very small and are expressed as parts per million (milligrams per litre) of sea water. The following data are rough means from many estimations :-

Water from the Antarctic contained about 0.5 part per million;

Water from the Indian Ocean contained about $0.05-$ 0.02 part per million;

Water from the Equatorial Seas contained about 0.1 part per million;

Water from the Mediterranean region contained about $0 \cdot 2$ part per million;

Water from the North Atlantic contained about 0.15 part per million ;

of nitrogen in the form of nitrite, nitrate, ammonia and albuminoid ammonia. On the whole it appears to be greatest in the Antarctic Seas, where the temperature is minimal; more abundant in the North Atlantic, where the temperature varied between about $5^{\circ}$ to $10^{\circ} \mathrm{C}$. and was least in the equatorial seas where the temperature was over $28^{\circ} \mathrm{C}$. To this relation between temperature and quantity of inorganic nitrogen, we return later.

There is also a seasonal variation which, however, is not very distinct. The results of a great number of 
analyses made in the Baltic and North Seas by the German fishery investigators give the following results :--

\begin{tabular}{|c|c|c|c|c|c|c|c|}
\hline & & Feb. & Mar. & April & May & June & July \\
\hline Nitrate $\quad \cdots \quad .$. &. & 135 & 200 & 125 & 136 & 160 & \\
\hline Albuminoid Ammonia & .. & - & 92 & 71 & 134 & 161 & 112 \\
\hline Ammonia $\quad . . \quad \ldots$ & .. & 62 & 34 & 21 & 66 & 42 & 50 \\
\hline & & . & Aug. & $\begin{array}{l}\text { Sept. } \\
1666\end{array}$ & $\begin{array}{l}\text { Oct. } \\
105\end{array}$ & Nov. & $\begin{array}{l}\text { Dec. } \\
138\end{array}$ \\
\hline Albuminoid Ammonia & & $\therefore$ & - & 156 & 118 & 110 & 130 \\
\hline Ammonia & & .. & 63 & 63 & 43 & 60 & 43 \\
\hline
\end{tabular}

The numbers represent parts of the substances in 1000 million parts of sea water, or grams per cubic metre of water. The range of variation of the total nitrogen represented in the same way as is the salinity of sea water is from $0.00038 \%$ to $0.00015 \%$. Upon these excessively small quantities of combined nitrogen depends all vegetable life in the sea. Looking at the results in the most general way we see a tendency for the quantity of combined $\mathrm{N}$ to attain a maximum in the winter and spring and to fall to a minimum in the summer and autumn. The seasonal variation is, however, indicated rather than definitely demonstrated by the data at our disposal.

The Silicic Acid. Sea water contains exceedingly small quantities of colloidal silica in solution. The origin of this substance is the silica brought down from the land in the water of rivers, but it may also result from bacterial action on the fine particles of silicates suspended in the water. A series of analyses carried out by the German oceanographers give the following results :-

Feb. Mar. April May June Aug. Sept. Oct. Nov. $\begin{array}{lllllllll}796 & 683 & 650 & 659 & 915 & 794 & 905 & 1000 & 942\end{array}$

Those are parts per 1000 million parts of sea water. Expressed in the same way as the salinity of the water we get the range of variation, 0.001 to $0.00065 \%$.

The origin of the Oceanic Salts. - Why has the ocean its present saline composition and concentration? To this question no satisfactory answer can be given so long as the problem of the origin of the earth itself remains unsolved. Obviously the assumption of either of the two 
main alternative hypotheses - the gaseous-molten and the planetesimal ones-will lead to modes of treatment of our question that must be very different.

Further, the problem is bound up with that of the age of the ocean-carrying earth itself and that is a question that seems to become more difficult as the investigation is pressed. The moderate estimate of 40 to 100 millions of years, based by Sir William Thomson on an assumed original temperature for a molten earth crust and a certain mean rate of cooling, has now been definitely abandoned. Recent methods based on the study of the residues of radio-active substance in the earth's crust promised well for a time, but the serious discrepancies between the estimates of the quantities of helium and lead in the rocks make this method also an unsatisfactory one. No value more definite than a "small multiple of a thousand million years" seems to have been obtained from the line of investigation.

Joly's estimate, based on the quantity of sodium in the ocean is of interest in relation to the subject of this book. The total quantity of sodium in the ocean can be found approximately: it is about $15,000 \times 10^{12}$ tons. The quantity of sodium entering the sea via the rivers can also be estimated: this is about 157 millions of tons annually. Joly assumed that the primitive ocean contained about $14 \%$ of the sodium now present in it and that this was originally precipitated with the water of the first atmosphere. Some of the salt entering the ocean from the rivers is cyclical : that is, it is removed from the sea by winds carrying surface spray on to the land, or it may become imprisoned in sediments forming on the sea bottom. When these become continental land and suffer denudation, the salt is returned to the ocean.

Assuming, then, that the ocean obtained its salt (with the above qualifications) from sodium chloride dissolved out from the rocks of an original earth-crust formed by solidification of an originally liquid earth-body, we get 


\section{AN INTRODUCTION TO OCEANOGRAPHY}

an age for the ocean of about 90 millions of years. There are various sources of error which may make it necessary to quadruple this estimate, but these need not be considered. The much greater (though strikingly divergent) values deduced from the study of radio-activity puts the whole matter on another plane. In any case our cosmogony is still too undeveloped to permit of a discussion that would be very useful.

Obviously there are two main hypotheses of the origin of the salts of the ocean: (1) that these were there from the beginning, being dissolved out from the planetesimal materials that cohered to form the nuclear-earth by the first accumulations of water. It is known that meteoritic materials do contain chlorides and it is possible, then that, we have here an origin for the saline matter in solution in the sea. (2) The salts came partly from condensation of saline materials in the original heavy atmosphere that remained behind after solidification of earth-crust from a molten condition and partly from the slow addition of salts dissolved out from the land surface by rain and then brought down to the sea by rivers.

But either the materials thus reaching the sea were different in the past than they now are or there have been processes at work that have made the composition of ocean salts different from that of river salts. At present the two dissolved mixtures are not the same: in the ocean we have

$$
\mathrm{Cl}>\mathrm{SO}_{4}>\mathrm{CO}_{3} \text { and } \mathrm{Na}>\mathrm{Mg}>\mathrm{Ca}
$$

while just the opposite distribution exists with regard to the salts of river water, that is,

$$
\mathrm{CO}_{3}>\mathrm{SO}_{4}>\mathrm{Cl} \text { and } \mathrm{Ca}>\mathrm{Mg}>\mathrm{Na}
$$

Something, then happens in the sea to change the ratios of abundance of the various substances that are added to it by river water.

Certainly calcium is, and has been, removed from solution in all parts of the ocean except at the greatest 
depths. It accumulates as deep-sea oozes formed by the tests of Foraminifera and the shells of molluses; as massive coral reefs ; as the very abundant neritic deposits of the past and present (molluscan shells, Echinoderm exoskeletons, polyzoan skeletons, etc.); and as chemical precipitates. Magnesium is removed from solution in much the same way. Silica goes out of solution to form radiolarian and diatom tests and the spicules of sponges, and accumulates as bottom-oozes, flints, etc. Iron and manganese go to form concretions, and iron becomes locked up as a coating over quartz-sand particles. Potassium has perhaps accumulated in this way. Potassium has also since it goes out of solution as the synthetic mineral glauconite and it appears also to be removed from the sea in certain clayey sediments. In the course of time enormous quantities of nitrogen and carbon compounds must have entered the sea in the form of organic matter resulting from the decomposition of the tissues of plants and animals, and yet the quantity of these substances in solution is exceedingly small while they do not accumulate as insoluble deposits. The nitrogenous organic matter is sooner or later oxidised by bacterial agents to the form of nitrate, but some part of this is always being reduced to nitrates, ammonia and finally elementary nitrogen by denitrifying organisms. The gas then escapes into the atmosphere. Organic carbon compounds are also broken down by bacteria, with the appearence of $\mathrm{CO}_{2}$ as the end product. This also can escape into the atmosphere. Sulphur can also reduce to $\mathrm{SH}_{2}$ which can escape from solution. Thus we can account for most of the elements present in solution in the sea : they either pass into insoluble compounds and so form deposits, or they may assume the gaseous state and be liberated into the air. They are continually being added to the sea, but it seems probable that a condition of equilibrium has been established or at all events, that the composition of sea-salts change, very slowly indeed. Only the sodium is difficult to account for, and it seems 


\section{AN INTRODUCTION TO OCEANOGRAPHY}

likely that this element is also being removed from solution in some way not yet known, for the tendency of modern investigation is greatly to lengthen the period estimated by Joly as that of the duration of the ocean. If, as seems probable, these increased estimates of the age of the sea will be confirmed by future work, it can hardly be doubted that sodium is being removed in some way for we have no reason to doubt that the present rate of addition of salt to the sea by river water has been maintained during past geological time. 


\section{CHAPTER VII}

\section{THE PHYSICAL CHARACTERS OF SEA WATER}

The movements of the ocean, that is, the tides and tidal streams; convection currents; surface currents and drifts due to heating, concentration and dilution of the sea water, etc., are considered in Chapters VIII and IX and here we have to deal with those other physical characters with regard to which the sea differs from ordinary water examined in such masses as can be handled in the usual laboratory operations. In considering any volume of sea water in situ we have to take account of several variables: the hydrostatic pressure, the temperature and the salinity. The pressure may be that due to the weight of a column of saline solution varying between 0 and about 10,000 metres in height; the temperature may be any between $0^{\circ} \mathrm{C}$. and $28^{\circ} \mathrm{C}$. and the saline solution may be one containing from 0 to $3 \frac{1}{2} \%$ of dissolved substance. Any physical characteristic of water, when applied to the sea, is in general, a function of these three variables. Its pressure, viscosity, electrical conductivity, sound conductivity, density, colour, surface tension, vapour pressure, osmotic pressure, freezing point, expansion, etc., depend, in general, upon the hydrostatic pressure, the temperature and the salinity. The whole subject is exceedingly complex and the experimental research necessary is by no means complete. As a general rule empirical, or interpolation formulae, based on values of the various functions obtained experimentally, have been devised and these, with tables, are given in the literature of oceanography.

The Pressure.-At any point in the sea the pressure is that due to the weight of the column resting on the surface of unit area, say a square $\mathrm{cm}$. To this must be 


\section{AN INTRODUCTION TO OCEANOGRAPHY}

added the weight of the column of air of the same cross section resting on the surface of the sea. The weight of a water column of the same height and cross section will vary according to the place on the earth's surface considered, being, in general, greatest at the equator and least at the poles. We assume that this water columr has everywhere the same salinity and temperature but this is, of course, not the case. The salinity may be approximately 0 or 38 or any intermediate value and the temperature may be anything between $0^{\circ} \mathrm{C}$. and $28^{\circ} \mathrm{C}$. The mass, then, of a column of sea water of certain dimensions varies with its chemical and physical configurations, and the weight of this column of specified dimensions and physico-chemical configuration varies with its position in latitude on the earth's surface.

Given a mean salinity and temperature and a specified latitude the pressure at any required depth cannot be calculated simply from the depth itself. Distilled water is compressible, though the amount of contraction of volume with increased pressure is very small. It is, nevertheless, great enough to be of much significance in hydrographic investigations and it becomes a factor of importance when such questions as the conductivity of sound waves, or the density of water at any specified depth are considered. How significant it is when we take account of the actual depth of the ocean may be grasped when we note that the sudden annihilation of the property of slight compressibility of sea water would increase the volume of the sea by about 11 millions of cubic kilometres and raise its level by about 30 metres. Such a rise of mean sea level of 15 fathoms would alter the outlines of the land surface in a noticeable degree.

The compressibility coefficient of sea water is a number showing what is the diminution of volume when the hydrostatic pressure has a certain value. For a mean salinity and temperature the contraction of volume is given, for the pressure due to a water-column of one metre 
height, by the fraction $0 \cdot 00000466$. That is to say, the volume of, say, 1 litre of water at the depth $m$ metres would be $1-0.0000466 \mathrm{~m}$.

The pressures at the bottoms of deep oceans are therefore very great. Roughly they are given by rather over a ton, per square inch of surface exposed, for each 1000 fathoms.

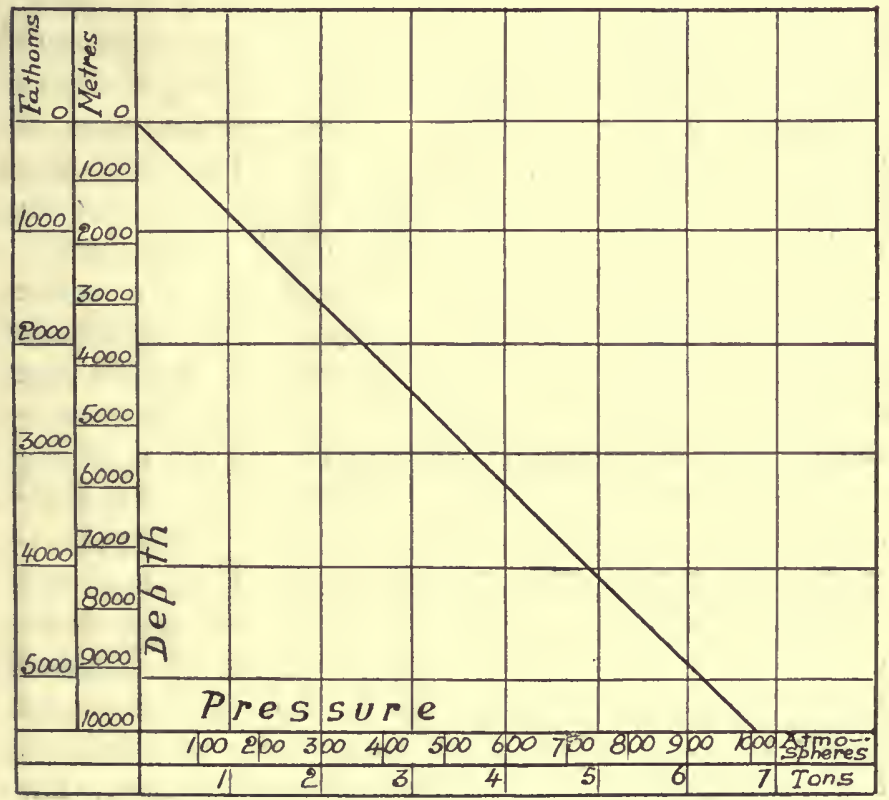

Fic. 24. Graph of the hydrostatic pressure of sea water at the depths 0 to 10,000 metres.

The Temperature.-The temperature of the sea is due almost entirely to solar radiation. Even if we assume a very high temperature in the deep interior of the earth, it appears to be the case that whatever quantity of heat would be transmitted from this store, through the lithosphere, to the overlying ocean is negligible. It is known that the bottom deposits are slightly radio-active and must, therefore, generate heat, but this also may be neglected. In the absence of solar radiation the ocean 


\section{AN INTRODUCTION TO OCEANOGRAPHY}

would freeze and its temperature everywhere on the earth would be that of cosmic space-only a degree or two above absolute zero. As it is the temperature of the unfrozen water varies between about $-1 \cdot 3^{\circ} \mathrm{C}$, at the bottom of polar seas, to about $28^{\circ} \mathrm{C}$. in the tropics.

Estimation of the oceanic temperature. At the "surface" there is no difficulty, for a sample of water is simply withdrawn by a bucket and its temperature is read by a thermometer graduated in tenths of a degree centigrade. By the "surface" is meant the stratum of water to a depth of about a foot: we shall see later that there may be a considerable temperature-difference even in the upper stratum of sea to the depth of one foot.

In the deep sea the estimation of temperature is a matter of much greater difficulty and many forms of apparatus have been devised for this purpose. Nowadays the estimation is always made either by a reversing thermometer, or by an insulated water-bottle. In the reversing thermometer there is an S-shaped bend in the capillary tube just above the bulb and somewhere in the neighbourhood of this bend there is a constriction. The instrument is enclosed vertically in a frame, with its bulb downward, and when the frame has been lowered to the required depth a weight is allowed to slide down the wire rope and release a catch, whereupon the frame turns upside down. The mercury column in the thermometer has meanwhile contracted or expanded, as the case may be, but when it is turned upside down the thread breaks away from the mercury in the bulb at the constriction in the stem. The latter is graduated from the top downwards, and from the volume of the column broken off the temperature is denuced. Several corrections have to be made.

The insulating water bottle now generally used consists essentially of a central chamber of about 300 c.cs in capacity. The walls of this chamber are formed by several concentric cylinders of zinc and ebonite with annular spaces of about $\frac{1}{2} \mathrm{~cm}$. in thickness. The vessel is represented in diagram, 
in Fig. 9, (3), and it will be seen that when it is close the central chamber containing the water sample is insulated by three concentric shells of water of the same temperature and by three water partitions at top and bottom. The thermometer is so placed that its bulb is immersed in the water of the central chamber so that it assumes the temporature of the latter. The apparatus is lowered to the required depth, and then a weight is allowed to slide down the wire and on reaching the bottle a catch is released and the ends shut down into the top and bottom of the multiple cylinder, closing the water sample chamber and the insulating water-shells. During the time when the apparatus is being hauled up to the surface there is no significant conduction of heat into the water sample from a warmer sea outside, nor any conduction of heat from the sample to a colder sea outside. The temperature is read on the thermometer and then the water contained in the central chamber is run down into a bottle and is preserved for analysis.

At considerable depths the water which is enclosed within the chambers of the bottle is under pressure and is compressed. When the apparatus is lifted to the surface the pressure diminishes from, it may be, several hundreds to one atmosphere and the water in the central and insulating chambers expands. So also does the material of the apparatus. This expansion involves cooling of the expanding materials of the bottle and of the water sample itself, but the latter is heat-isolated. The expansion is therefore adiabatic and so the temperature read on the thermometer is lower than that of the water sample when it was in situ. At moderate depths, down to, say, 1000 metres the reduction in temperature due to adiabatic expansion of the water sample may usually be neglected. In the case, however, of water brought up from the greatest depths the reduction may be as much as $1.3^{\circ}$ to $1.4^{\circ} \mathrm{C}$.

At ordinary depths the pressure is so great that the apparatus used must be constructed so as to resist it. 


\section{0}

Ordinary thermometers, such as are used for taking surface temperatures, may be crushed to fine powder when lowered to depths of much over 1,000 fathoms. In any case the thin-walled bulbs must be protected. The thermometer itself is always enclosed in a glass tube which has thick and strong walls and hermetically sealed ends. This is evacuated of air so that the insulation of the stem may be as complete as possible. The section of the enclosing tube containing the thermometer bulb is shut off from the rest and contains some mercury which conducts heat through the space between jacket and bulb.

The temperature variations. Suppose that the earth were to revolve round the sun in the plane of its equator, that is, suppose the ecliptic and equinoctial planes were coincident. Suppose also that the ocean were to cover the earth everywhere to an uniform depth. The precession of the poles may be neglected for we can assume that the earth's axis remains parallel to itself throughout any period of time that we need consider. In these very simple conditions the temperature of the ocean would vary in a very regular way: it would be greatest at the equator, where the sun's rays fall perpendicularly on the surface of the sea, and it would be least at the poles, where they would fall most obliquely. At the equator all the solar radiation would either penetrate, or be absorbed by the atmosphere, but somewhere between equator and poles a certain fraction would be reflected by the upper layers of the atmosphere. This fraction would be greatest at the poles. Everywhere, then, the temperature of the ocean would be a function of the latitude decreasing regularly from equator to poles. The isotherms would be parallel to the lines of latitude.

In fact the equinoctial is inclined at an angle of $23 \frac{1}{2}^{\circ}$ to the plane of the ecliptic. That means that the sun's declination varies throughout the year so that he may be overhead at the equator, or at latitude $23 \frac{1}{2}^{\circ} \mathrm{S}$. or N. At any one place, then, the declination varies and so the 
amount of solar radiation received per unit of area of the ocean also varies. This means that there will be an annual period of temperature variations, the maximum occurring about the time when the sun's declination is greatest and the minimum occurring about the time when it is least. There would be, of course, a lag, the change of temperature following the change of declination.

There would be also a variation in the temperature in the course of the year at any particular place beneath the surface: as the temperature at the surface varies so do those at various depths beneath-though the range of variation there may be very much smaller than it is on the surface. Water is a very bad conductor of heat, but differences of temperature between the equatorial, and the zones of higher latitude set up convection currents and the intensity of these at any one zone would undergo an annual variation. To this matter of convection currents we return in the next chapter.

So far we have assumed that the depth of the ocean is uniform and that it covers the earth everywhere. In fact the highly irregular distribution of land and water introduces irregularities of a very complicated nature. So does the variable depth of the ocean. The result is that the isothermal lines nowhere run parallel to those of latitude though we can see an approximation to this postulated parallelism in the Pacific and Southern Oceans. Neither is there any very regular variation of temperature according to depth, because of the way in which the convection currents are modified by the irregular depths and the distribution of the land masses.

Thus there are periodic annual changes of temperature both at the surface and in the depths and these are to be traced to the variations in declination of the sun, with, of course, changes in the distance of the earth from the sun. At present the earth is in perihelion (is nearest to the sun) in the northern winter and ought to receive more heat then. The effect of varying declination at any one place 


\section{AN INTRODUCTION TO OCEANOGRAPHY}

is, however, greater than that of varying distance between earth and sun.

That there are periodic changes of greater frequency than one year is evident from the common experience that the minima and maxima of sea temperature are not of the same value from year to year nor do they occur at the same times in every year. As to the causes of these long periodic variations there is much difficulty. It appears to be certain that the sun is a variable star, and it is made probable, by a study of the frequency of occurrence of sunspots, that the period is somewhere in the neighbourhood of eleven years. If the same causes that lead to the outbreak of sunspots lead also to changes in the intensity of solar radiation, it would follow that there would be an eleven-year periodicity in ocean temperature.

The establishment of such a periodicity is very difficult because the effect of change in the intensity of solar radiation is not exhibited directly in change of ocean temperature. Of the total heat incident on the earth a certain fraction (about $40 \%$ ) is reflected away into outer space from the atmosphere and of the remainder only about $33 \%$ penetrates to the ocean or land-the rest is absorbed by the atmosphere. This heat taken up by the air sets the latter in motion, and the cyclonic storms and winds so caused then lead to variations in ocean temperature. Thus the connection between changes in solar radiation and changes in ocean temperature are of a very indirect kind and are to be traced only with great difficultv.

Other changes are competent to set up long periodic variations in ocean temperature. Thus the presence of dust in the atmosphere, as the result of long continued periods of volcanic eruptions, must by its absorptive effects reduce the quantity of heat directly received by the sea. The same effect would follow a significant increase in the quantity of carbon dioxide contained in the atmosphere since this also has a heat-absorbing effect. Such 
an increase in the $\mathrm{CO}_{2}$ of the atmosphere would result from the transgression of the sea on the land, thus leading to a smaller surface of rocks subject to subaerial denudation: there would be less decomposition of alkaline silicates by the $\mathrm{CO}_{2}$ of the air and so the proportion of the latter would increase. If the latter proportion were largely to increase, would it be absorbed by the ocean ? It is doubtful, because the latter is already saturated, in the ordinary physical sense, by $\mathrm{CO}_{2}$ and a larger quantity could only be held were the carbonates of calcium and magnesium in solution in sea water to increase.

If some such cause, an increase in the quantity of heatabsorbing material in the atmosphere, were to continue to operate over a considerable period of years, such conditions as were represented in the various ice-ages would be set up. Even a fall of only a very few degrees in the average temperature of the atmosphere overlying the ocean would have momentous effects in that it would lead to a great increase in the precipitation of water, as rain and snow, on the land, or frozen sea, in higher latitudes. Thus the sea level would be lowered to a significant extent and the outlines of the continental land would be changed. The courses and velocities of oceanic currents would probably be changed and these changes would react on the meteorological conditions of the lands that come under their influence. The effects we have indicated would, most probably, be cumulative, leading to all the conditions that characterise periods of extensive glaciation. They might co-operate with, or tend to cancel the effects of astronomical changes.

Thus the well-known hypothesis of the cause of the ice-ages, due to Croll and Geikie, makes use of the periodic change known as the precession of the equinoxes. The planes of the ecliptic and equinoctial are not absolutely fixed in relation to each other. They cut each other at two points such that the earth is at one of them at the time of the vernal equinox and at the other at the time 


\section{AN INTRODUCTION TO OCEANOGRAPHY}

of the autumnal equinox. These points are not fixed with relation to the stars but move round the earth's orbit in a direction retrograde to that of the earth's path. At present they are so placed that the winter solstice (position of least solar declination in the northern hemisphere) occurs when the earth is nearest to the sun. In the course of a period of about 30,000 years the vernal equinox will move completely round the ecliptic, and so such a configuration of earth and sun must occur that the winter solstice will occur when the earth is furthest from the sun. Then the conditions must be such as will lead to a reduction of temperature in the northern hemisphere and an increase in the south. The hypothesis would be competent to explain the succession of ice-ages, if it could be shown that the latter occurred strictly periodically and about the time when the astronomical events referred to above had happened. Now the ice-ages are not periodic in this sense. It will be seen, however, that the other cause of variation in the average quantity of heat received upon the sea during the year may so operate as sometimes to co-operate with, and at other times to counteract the effects of the astronomical causes.

The oceanic Isotherms. Let a great number of observations of the temperature of the sea, at the surface, be made simultaneously over a large area, say the Atlantic Ocean: by "simultaneously" we may mean during the same month. These observations are marked on a chart and then all the points on the latter, where the temperature was, say, $10^{\circ} \mathrm{C}$. are joined by straight lines. The latter are next replaced by a curved line drawn freehand as near as possible to all the points and having as few changes of curvature as possible. It would be allowable to take points of (say) $9.5^{\circ}$ or $10.5^{\circ}$ as representing $10^{\circ}$. (But this process of "smoothing" would depend on the scales adopted, the number of observations and their probable accuracy). In this way a mean curve is obtained. The same process is repeated for the 


\section{PHYSICAL CHARACTERS OF SEA WATER 175}

other temperatures, say $9^{\circ}, 8^{\circ}$, etc. Such lines are isotherms, or lines of equal temperature.

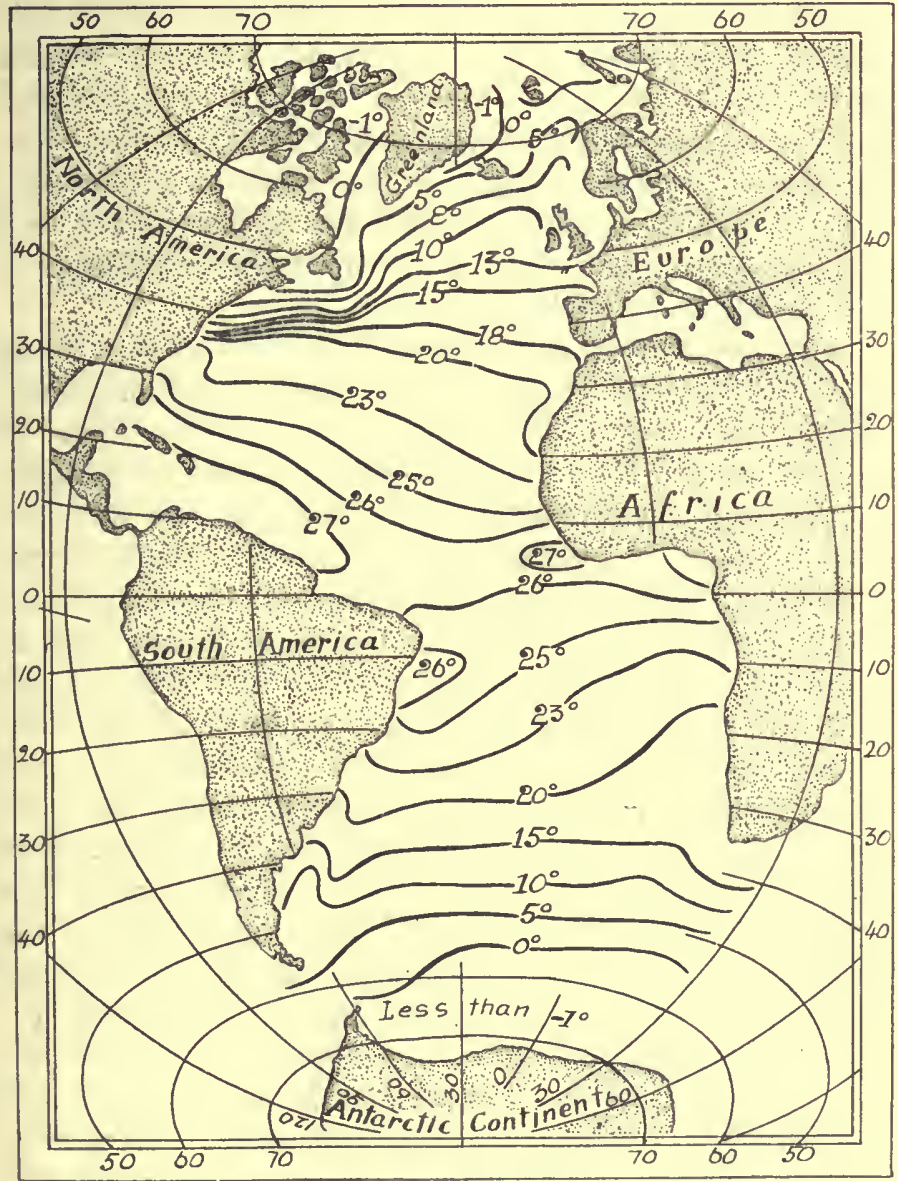

Fig. 25. Chart of the Atlantic Ocean showing the summer isotherms at the surface.

Premising that we can only deal with them in a very general way and that any amount of detail could be given for various seas, we may now consider how they exhibit 


\section{AN INTRODUCTION TO OCEANOGRAPHY}

the variations of sea temperature on the surface of the ocean.

First we notice that the extreme range of temperature is about $-1^{\circ} \mathrm{C}$. to about $27^{\circ} \mathrm{C}$.; that the maximum is in a zone lying from about $5^{\circ}$ to $10^{\circ} \mathrm{N}$. lat. ; that the minima are in the Arctic and Antarctic Oceans, where the temperature at the surface approximates to zero on the centigrade scale and may sink to $-1^{\circ} \mathrm{C}$. below the surface and, lastly, that the isotherms do not run parallel to the lines of latitude, though there is a very rough parallelism at about $40^{\circ}$ to $50^{\circ} \mathrm{S}$. latitudes.

Each isotherm is a boundary, delimiting an area where the temperature has a certain mean range of values. Within the curved line marked $27^{\circ}$ and the coast of Africa, on the East, and within that marked $27^{\circ}$ and the coasts of Central America and Brazil, on the West, the temperature is $27^{\circ}$ and over that value. The two isotherms marked $26^{\circ}$ and $25^{\circ}$ bound an area where the temperature varies between $25^{\circ}$ and $26^{\circ}$. This is, of course, only an approximation, or rather an average expression of the range of temperature variation. In each of the areas mentioned there are certainly small patches of sea where the temperature, during the summer months may fall below, or rise above the limits indicated by the isotherms.

Further, there is a certain trend of the isothermal lines up to the North-West in the North Atlantic tropical and sub-tropical zones as far as about $30^{\circ} \mathrm{N}$. Lat. Higher than that they trend in a most marked way towards the North-East. About $40^{\circ} \mathrm{N}$. the isotherms $5^{\circ}$ to $20^{\circ}$ are crowded together in a very remarkable way and then they diverge outwards in a fan-like manner. This peculiar arrangement, we shall see, is to be explained by the way in which the relatively warm water of the Equatorial Streams is deflected northerly as it approaches the American coast, and is then dispersed to the North-East as the Gulf Stream Current and Drift. Also, the isotherms in the South Atlantic are deflected to the South-West in the zone 
$0^{\circ}$ to $30^{\circ} \mathrm{S}$. Lat. and for the same reason-the direction of the South Equatorial Stream. In the South, however, there is nothing quite corresponding to the strongly marked Gulf-Stream circulation of the North Atlantic although the general features of the water movement, as a whole, are the same in both oceans.

The asymmetry of the two oceans in regard to the distribution of temperature is very noticeable. Thus the $5^{\circ}$ isotherm reaches the latitude of $70^{\circ}$ in the North but it runs nearly along the 50th parallel in the South. Nearly everywhere there is a considerable difference in temperature on the East and West sides of the Atlantic: thus the sea off Labrador, in latitudes $50^{\circ}$ to $60^{\circ} \mathrm{N}$. is at, or little above $0^{\circ} \mathrm{C}$. while in latitudes $50^{\circ}$ to $60^{\circ} \mathrm{N}$. on the European side the temperature of the sea in summer varies between about $9^{\circ}$ and $13^{\circ} \mathrm{C}$. This particular difference is due to the Gulf Stream circulation which bathes the coasts of Europe on the East, and to the Labrador Current which flows down the coast of $\mathrm{N}$. America, on the West. In general (with the exceptions of the regions affected by the Gulf Stream drift) and for the same range of latitudes, the sea temperature is higher on the western side of all the oceans than it is on the eastern sides, and this is because the directions of the Equatorial Streams are as they are because the Earth rotates from West to East. Because water flows, on the surface, from East to West it must be replaced by water which rises up from the lower strata and this, we shall see, is always colder than that on the surface.

Finally the conditions in the Mediterraneans and marginal seas may be noticed. In the Roman Mediterranean we find temperatures of $18^{\circ} \mathrm{C}$. to $21^{\circ} \mathrm{C}$, while those of the Atlantic in the same zone of latitude vary between $15^{\circ}$ and $18^{\circ}$. The Caribbean Sea and Gulf of Mexico exhibit temperatures of $25^{\circ} \mathrm{C}$. to $27^{\circ} \mathrm{C}$. in contrast with a range of about $23^{\circ}$ to $27^{\circ}$ outside. On the other hand the two epi-continental seas, the Baltic and Hudson's Bay, are colder than the adjacent Atlantic, the Baltic being about 


\section{AN INTRODUCTION TO OCEANOGRAPHY}

$2^{\circ} \mathrm{C}$. to $10^{\circ} \mathrm{C}$.; Hudson's Bay being about zero while the Atlantic is, in general, ahout $5^{\circ}$ to $10^{\circ} \mathrm{C}$. between the two seas.

The general courses of the isotherms in the Pacific and Indian Oceans are represented in Fig. 26.

In the above figures the isotherms are drawn for temperature-intervals of $5^{\circ} \mathrm{C}$. except in the equatorial zones where the differences are more noticeable. Both in this and the last chart only the most general representations of the variation in temperature are attempted. Even

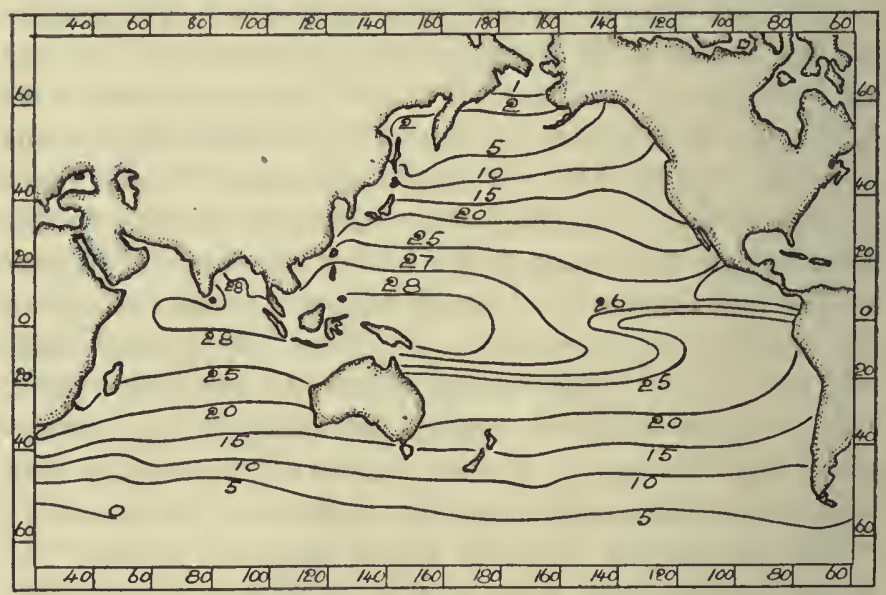

FIG. 26. The distribution of surface temperature in the Pacific and Indian Oceans during the summer months.

with the data that we possess the amount of detail that could be dealt with is enormous, and this increases still further whenever we consider the conditions in the shallow seas in the temperate zones, where variability both in space and time is much greater than it is in the open ocean. Looking at Fig. 26 we see, then, that there is a closer approximation to parallelism of the isotherms with the lines of latitude than can be observed in the Atlantic regions: this is particularly the case in the southern ocean South of Australia but it can also be seen in the 
North Pacific. Even here, however, there is a tendency for the isotherms to become bent up from $\mathrm{S}$. to $\mathrm{N}$. and from $W$. to $E$. and this is because the water circulation of the North Pacific is fundamentally the same as that of the North Atlantic, although the movements are less exaggerated, so to speak, in the former ocean.

In general the temperature tends to be higher in the West Pacific than in the East. Thus there is a large area of sea in the Austral-Asiatic region where the temperature rises to over $28^{\circ} \mathrm{C}$.

We leave the more detailed study of the spatial variations of temperature to the student who has access to largescale charts of the various oceans at different times throughout the year. Without these, and some general idea in mind, the subject is one that is full of interminable detail of little interest. But the main conditions that lead to temperature differences may be briefly noticed. First of all there is the relation between such variations and the currents and ocean drifts. If water flows from a region of higher intensity of solar radiation to one of lower intensity there will be a transference of heat: thus the Gulf Stream drift in the North Atlantic carries water that has been strongly heated in the region of the equatorial streams up to temperate, and even Arctic latitudes. Therefore, the temperature in the latter regions is higher than it would be if there were no Gulf Stream circulation. So, also, the Labrador Current carries water from regions where the sea is cooled by melting ice down to latitudes where the temperature normal to those zones would be much higher were there no southerly-flowing cold Arctic streams, Again, the westerly-flowing equatorial streams transfer warm water towards the West and pile this up, so to speak against the American shores of the mid-Atlantic, against the Austral-Asiatic Islands in the Pacific, and against the East coast of Africa.

Then we have the very strong effect of winds. These, impinging on the surface of the sea actually propel the 


\section{AN INTRODUCTION TO OCEANOGRAPHY}

superficial layers of water in the directions towards which they blow: that, for instance, is why the temperature in the Caribbean Sea and in the Gulf of Mexico is higher than it is in the Mid-Atlantic of the same range of latitudes. But here we have to do, really, with the condition mentioned above, the transfer of heated water by ocean currents: the North-East and South-East Trades are the propulsive forces of the North and South Equatorial streams. Irregularities in the distribution of temperature, that is the local and seasonal deviations from the colurses of the isotherms of Figs. 25 and 26 , which can always be seen when we look at large-scale charts, are due to local winds or to series of cyclonic storms.

Upwelling of water from the deeper parts of the sea is a cause of variation in surface temperature. Thus water is actually driven from East to West in the tropical Atlantic by the trade winds, and it follows that this water must be replaced. It is so replaced to a considerable extent, by water which rises up from below, off the West Coast of Africa. This water is colder than that which would be present at the surface of the sea were there no upward movement.

Obviously the lands present barriers to the progress of currents or drifts of ocean water, and this is also the case with shallow sea bottoms. Currents always tend to flow along depressions on the floor of the ocean, and shoals impede them to a marked extent, or even arrest them entirely. So do straits which are relatively wide: thus the Gulf Stream drift flows round to the North of the Shetland Islands into the North Sea, but not through the Pentland Firth, and only to a very small degree through the Straits of Dover. One sees here how intimately the phenomena of variations of temperature from place to place are related to those of ocean drifts and currents : thus those smaller local irregularities that are so apparent in charts which represent the courses of the isotherms in shallow inshore seas are due in a large measure to the tidal streams. 
Periodic temperature changes at the same place. First, there is a small daily variation of temperature at a fixed spot (say at a light vessel). This may be fairly large in a shallow sea area near the land (say two or more degrees centigrade) and it is due to the tidal streams. If there are considerable areas of foreshore alternately covered and laid bare by the tides, there is a periodic heating effect in the summer and a cooling effect in the winter months. The extensive areas of sand-banks become hotter than the adjacent sea during the summer and so the water that covers them when the tide flows is heated to over the average temperature of the region. When this water flows out to sea on the next ebb-tide it is warmer than the water in situ would be were there no tidal streams. If the in-going and out-going streams had exactly the same directions the effect would not be so noticeable, but it generally happens that the water flowing into a bay or estuary from the open sea does not return to exactly the same place when it ebbs out again. In the winter months the sand-banks are cooled, on exposure, to below the temperature normal for the sea-region off shore and so the effects mentioned above are reversed.

Further, the in-going and out-going tidal streams are more rapid at springs than at neaps and the areas of foreshore exposed are also greater. There will, then, be a fortnightly variation of temperature at stations chosen so as to be affected by the tidal streams.

In the open ocean, tides can have no such effect, of course, but there a small daily temperature variation can be observed. This is usually less than about $0.5^{\circ} \mathrm{C}$. It is due to the heating effect of the sun on the superficial stratum of water.

The annual temperature change is, of course, the most noticeable variation and it is due to the change in the sun's declination. That is to say, the quantity of heat received by the ocean at any one place is variable, reaching its maximum and minimum values some time after the 
summer and winter solstices. This annual range of sea temperature varies greatly from place to place. Looking at the ocean as a whole, we have the following general distribution of temperature ranges :-

- (1) The polar regions : the mean temperature is lowest and the annual temperature range is also low. In the North this region of minimal mean temperature and minimal range is, roughly speaking, the Arctic Ocean (excepting the sea between Greenland, Spitzbergen and Norway). The extreme range is from about $2^{\circ} \mathrm{C}$. to $10^{\circ} \mathrm{C}$. but the mean annual range is only about $6^{\circ} \mathrm{C}$. In the South the region lies between the pole and about $50^{\circ} \mathrm{S}$. latitude.

(2) The tropical regions: these comprise the ocean between about $20^{\circ} \mathrm{N}$. and $\mathrm{S}$. latitudes but extending to about $30^{\circ} \mathrm{S}$. lat. in the Central Pacific. The extreme temperature range is from about $21^{\circ} \mathrm{C}$. to $32^{\circ} \mathrm{C}$. but the mean range is only about $6^{\circ} \mathrm{C}$. This is a region of maximal temperature and minimal annual temperature range.

(3) The temperate regions: these lie round about $40^{\circ} \mathrm{N}$. and S. latitude but they extend along the North-West Pacific and the North-East Atlantic to about $20^{\circ} \mathrm{S}$. and $70^{\circ} \mathrm{N}$. The extreme temperature ranges are very variable but lie intermediate between those characterising polar and equatorial regions. The mean annual ranges for limited areas in the North-West Atlantic South of Nova Scotia and in the North-West Pacific, in the Sea of Japan, may exceed $28^{\circ} \mathrm{C}$. and elsewhere it is, in general, between about $11^{\circ} \mathrm{C}$. and $22^{\circ} \mathrm{C}$. Here, then, we have regions of moderate temperature and maximal annual temperature range.

In the shallow epi-continental seas the ranges may be very variable, even in places which are near to each other. In shallow bays and estuaries where there are extensive areas of foreshore and much fresh water entering the sea from rivers, the annual range may be exceptionally great. Reversals in the directions of winds may also increase 
the range. In general the latter is greater close to the land than it is at considerable distances out to sea.

If we observe the sea temperature taken at the same place at regular intervals (say every day) throughout the year, the form of the annual variation can be studied. Neglecting the small diurnal variation, we find that the graph of the observations (temperature plotted against time) may be very irregular. At inshore stations the disturbing effects of the tides may sometimes be recognised, but more important are the effects of the winds which not only heat or cool the surface waters above or below the temperature that would be observed were there no variable and violent winds, but also lead to actual transport of water from regions of higher to regions of lower temperature (and vice versa) and, further, to the upwelling of water from lower strata, where the temperature may be lower. If the observations taken daily be reduced to means (say of 10-daily periods), the graph becomes more regular but even then we can see the influence of the "weather," that is of the succession of cyclonic and anticyclonic disturbance of the atmosphere. If the observations be reduced to monthly averages and if the latter be taken over (say) 10 to 20 years the graph of annual temperature variation approaches a limiting form, that of an harmonic curve. This expresses the effect of the generalised heating effect on the sea of solar radiation, at the particular place under observation, apart from the other cause of variability mentioned above, and apart also from the change, from year to year, in the intensity of solar radiation.

Change of temperature is certainly the biggest factor in leading to change in the nature and abundance of marine life. Looking at this matter in a very general way we see that the facts of temperature distribution outlined on p. 182 can easily be correlated with biological phenomena. The intra-tropical zone of high temperature and minimal temperature range is, thus, the region 


\section{AN INTRODUCTION TO OCEANOGRAPHY}

of great and characteristic coral-reef formation. Here the secretion of lime from its solution in the sea is displayed on the great scale, not only in the massive reef deposits but also in the large-shelled molluses and the pelagic foraminifera and other calcareous organisms. In the temperate zones secretion of lime by organisms is far less pronounced, and it is minimal in the polar regions.

In the intra-tropical seas there is a great wealth of species of animals as compared with individuals. Animals are, on the whole, bigger (though the whales are an exception as they are more characteristic of polar than of equatorial seas). Colouring is more vivid and patterns, both of form and colour, are more diversified. On the other hand, the polar and temperate seas are characterised by an extraordinary wealth of individuals (both pelagic and benthonic). Thus the great fisheries of the world are in the higher temperate latitudes; the abundance of plankton in the Arctic and Antarctic Seas is surprising when the latter are compared, in this respect, with the tropics. Even the land fauna, as exemplified by the Antarctic penguin ' rookeries, or the seal fisheries in the higher latitudes, is seen to be very abundant. But in the polar and temperate seas there is a poverty of species as compared with the intra-tropical regions.

In localised regions, and in small ways, the same importance of sea-temperature change, as an agency leading to great changes in the distribution of marine life, can be verified. But the subject cannot be discussed here as it carries us too far away from the limits set out in the planning of this book.

Ice in the Sea. When distilled water is progressively cooled it contracts until the temperature reaches the well-known limit, $4^{\circ} \mathrm{C}$. At that point water has a maximum density, and as it continues to cool to temperatures lower than $4^{\circ} \mathrm{C}$. it expands. At $0^{\circ} \mathrm{C}$. it freezes and the ice that is formed is, therefore, lighter than the unmelted water in its neighbourhood of temper- 
ature and so floats at the surface. Fresh water at $4^{\circ} \mathrm{C}$. will, therefore, be denser than liquid water at any other temperature and will sink from the surface where it has been cooled, but newly-formed ice will, should it form at the bottom, rise to the surface and float there. It will, to some extent; insulate the remainder of the body of cooling water from the atmosphere, not only preventing the abstraction of heat by contact of water with cold winds, but also hindering convection currents.

When sea water is progressively cooled it continues to contract until the freezing point is attained, and at that temperature sea water exhibits its maximum density. The freezing point is not a constant one but depends on the quantity of dissolved solids. In the case of a solution of pure sodium chloride in distilled water there is a regular series of phases of the system ice and solution at each temperature. The quantity of ice formed increases, the quantity of sodium chloride crystals formed also increases and the concentration of the solution remaining unfrozen increases. Finally, the whole mass of salts, ice-crystals and solution, becomes solid: this is the eutectic phase. The ice formed at each stage varies in composition, it may be $\mathrm{H}_{2} \mathrm{O}, 2\left(\mathrm{H}_{2} \mathrm{O}\right)$, or $3\left(\mathrm{H}_{2} \mathrm{O}\right)$ and the solid crystals of sodium chloride that are formed also vary with regard to the quantities of water that they contain as water of crystallisation.

The process, even when we start with a solution of pure salt of known concentration, is thus very complex, but it is much more so when we deal with sea water. This is a solution of many substances and its concentration varies from place to place in the ocean and from time to time. The freezing-point varies with the salinity, becoming lower as the latter increases, and the reduction cannot be calculated but must be found empirically. It is graphed in Fig. 27.

The freezing-point of sea water, then, is depressed from 0 , when the salinity is 0 (or the water is "fresh") to 


\section{AN INTRODUCTION TO OCEANOGRAPHY}

about $-2^{\circ} \mathrm{C}$. when the salinity is about $35 \%$. The behaviour on freezing is quite different from that of fresh water inasmuch as the liquid continues to contract until the freezing-point is attained. The ice formed from sea water will, therefore, be slightly heavier than the unfrozen water from which it has been formed and it would sink below the surface (or place of lowest temperature) but

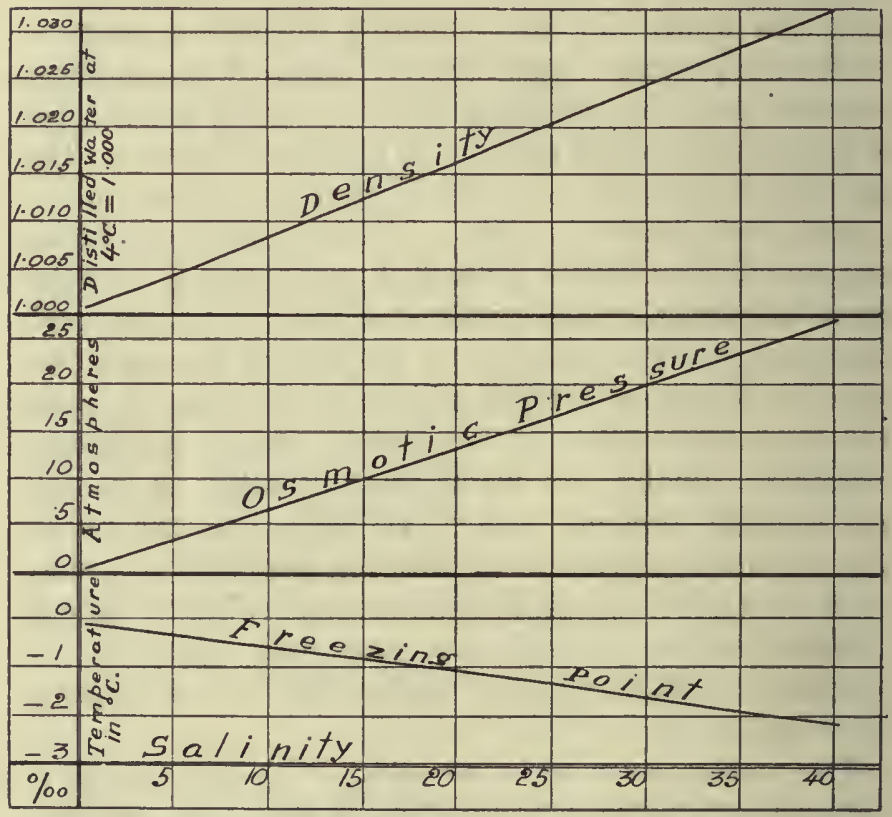

FIG. 27. Various physical characters of sea water graphed for the range of salinities 0 to $40^{\circ} \%$.

for the condition that in the process of freezing the part of the water that remains unfrozen increases in density. In a pure solution of $\mathrm{NaCl}$ in distilled water this would occur, as we have noted, and the solution would become more and more concentrated as the eutectic point is approached. In sea water, however, the conditions are much more complex. 
The solution, we have seen, cannot be regarded as one of $\mathrm{NaCl}, \mathrm{MgCl}_{2}, \mathrm{CaSO}_{4}$, etc. What we have is water which is itself slightly dissociated and is so a mixture of $\mathrm{H}_{2} \mathrm{O}$ molecules, $2\left(\mathrm{H}_{2} \mathrm{O}\right)$ molecules, $\mathrm{H}$ and $\mathrm{OH}$-ions. Each of the salts is dissociated, thus instead of $\mathrm{NaCl}, \mathrm{MgCl}_{2}$ and $\mathrm{CaSO}_{4}$ we have $\mathrm{Na}$ and Cl-ions, $\mathrm{Mg}$ and $\mathrm{Cl}$-ions, $\mathrm{Ca}$ and $\mathrm{SO}_{4}$-ions, with the undissociated salts, the concentrations of all these substances depending on the total quantities in solution and on the temperature. The smaller the total quantity of $\mathrm{Na}$ and $\mathrm{Cl}$-ions present the greater will be the ratio $\mathrm{Na}$-ion and $\mathrm{Cl}$-ion to $\mathrm{NaCl}$, and so with each of the other substances. The solubility of the various salts, $\mathrm{NaCl}, \mathrm{MgCl}_{2}, \mathrm{CaSO}_{4}$, etc., varies, and also varies in a different way with change of temperature. Thus the composition of the solid ice (that is the solid form of $\mathrm{H}_{2} \mathrm{O}$ and the solid crystals of the salts separated out on freezing) will be different at each temperature-stage and so also will be the composition of the remaining mother-liquor. In ordinary sea water the solubility of calcium carbonate, $\mathrm{CaCO}_{3}$, is very small and so ordinary lime will separate out at once when the temperature falls significantly. Calcium sulphate, $\mathrm{CaSO}_{4}$, will not separate out as such but there is a possible re-arrangement of the ions such that the $\mathrm{Na}$ and $\mathrm{SO}_{4}$ can combine to form $\mathrm{NaSO}_{4}$. The eutectic point of this salt is only about $-0.7^{\circ} \mathrm{C}$., that of $\mathrm{KCl}$ is about $-11 \cdot 1^{\circ}, \mathrm{NaCl}$ is about $-21 \cdot 9^{\circ}, \mathrm{MgCl}_{2}$ is about $-33 \cdot 6^{\circ}$ and $\mathrm{CaCl}_{2}$ is about $-55^{\circ} \mathrm{C}$. Thus the last substance to separate out from the mother-liquor would be calcium chloride at a very low temperature, seldom, or never attained in the sea. Among the first substances to separate out would be sodium sulphate, because of its high eutectic temperature, and so we find that the unfrozen motherliquor in freezing sea water becomes less and less concentrated, as regards $\mathrm{SO}_{4}$, as the temperature falls. But the behaviour of actual sea water in these respects is not precisely the same as that of pure solutions of the various salts since the presence of each in the mixed solution 


\section{AN INTRODUCTION TO OCEANOGRAPHY}

affects all the others. Enough, with regard to this very difficult subject, has been said to show the reader what a very complicated process, from the physico-chemical point of view, the freezing of sea water is.

As a result, however, we have the formation of an ice containing crystals of salts in its substance along with polymerised water crystals, $\mathrm{H}_{2} \mathrm{O}, 2\left(\mathrm{H}_{2} \mathrm{O}\right), 3\left(\mathrm{H}_{2} \mathrm{O}\right)$, and floating upon a solution which has become rather denser by reason of concentration, and rather different in composition by reason of selective crystallisation.

The forms of Ice in the Sea. These are (1) land ice brought down by rivers, that is ice resulting from the freezing of fresh water in lakes and rivers and subsequently dislodged and carried down into the sea. (2) Land ice is broken away from glaciers as these approach the sea, or broken off from the great ice caps resting on Greenland, the Antarctic continent and elsewhere. This is the mode of origin of icebergs. (3) There is, lastly, the ice resulting from the freezing of sea water in situ and this assumes a great variety of forms according to the conditions under which the freezing occurs, or the subsequent treatment to which the ice is subjected. Descriptions of sea ice-pack ice, floes, bankice, hummocks, pancake-ice, etc., etc.-are very common and are probably sufficiently well known to most readers.

The vertical distribution of sea temperature. There is usually a marked variation of sea temperature with increasing depth such that, in general, the surface waters are warmer than those at the bottom. We shall have occasion to refer to many specific instances of this temperature variation when we deal with ocean currents, and so only the main features of the vertical distribution of temperature need be mentioned here.

The surface water is heated in two ways: (1) by direct solar radiation, and (2) by contact with warm winds. It is cooled by direct radiation and by contact with cold winds. In the latter cases-the heating or cooling effects 
of winds-the results are usually very complex since not only does the wind warm or cool the surface water but it. also propels the latter in the direction towards which the air current moves. On approaching land this warm current becomes deflected in a variety of ways and is often driven beneath the surface thus heating the lower strata of water to an extent that would not be exhibited in the absence of strong winds. Barriers to the flow of surface water, whether these be lands or merely submarine elevations of the ocean floor, thus lead to marked variations in the temperature of the sea beneath the surface. The winds themselves are variable, changing from season to season, and the combinatious of these conditions lead to very complicated effects.

Generally, however, the sea is warmest at the surface in the tropical and temperate regions and then the temperature decreases with depth, attaining minimal values on the ocean floors. To this general statement there are some important exceptions which we shall notice in Chapter IX.

In calm seas the heating effect of the sun may be very marked indeed, but in the ocean absolute stillness of the surface water is very exceptional. In small lakes the condition of entire calm is more often observed, and there the temperature gradient immediately beneath the surface is quite steep : this is illustrated by the graph that follows.

Fig. 28, B, is a graph of the temperature of the surface water of a lake as determined at intervals of depth of $1 \mathrm{~cm}$. or less beneath the surface. In this case the thermometer bulb is a glass tube of $1 \mathrm{~mm}$. in cross section and about $10 \mathrm{cms}$. in length. The stem is bent at right angles to the bulb and so the latter can be lowered to depths varying by a few millimetres, the elongated tubular bulb of the thermometer being horizontal and the stem vertical. From graduations on the stem, which is held perpendicular to the surface of the water, the depth to which the horizontal bulb has been lowered can be measured very exactly. 


\section{AN INTRODUCTION TO OCEANOGRAPHY}

At the surface, then, the temperature was about $15^{\circ} \mathrm{C}$. and this decreased rather quickly throughout the upper $4 \mathrm{cms}$. of water, to about $10^{\circ} \mathrm{C}$ - - a range of $5^{\circ} \mathrm{C}$. in $4 \mathrm{cms}$. of depth. Then the temperature fell much more slowly down to about $9.5^{\circ}$, a range of about $1_{2}^{1}{ }^{\circ}$ in the succeeding $8 \mathrm{cms}$. From that stratum the rate of decrease would remain nearly the same down to the bottom of the lake, or at all events, to relatively considerable depths. Thus

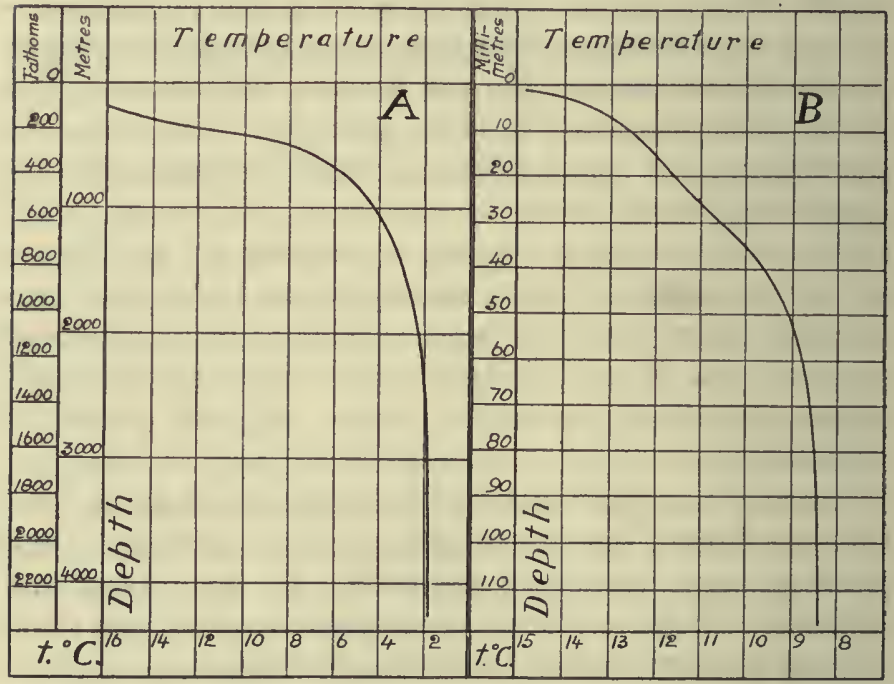

FIG. 28. (A) The general temperature gradient in the ocean as deduced from a very great number of observations in all parts.

(B) The temperature gradient in the upper $11 \mathrm{cms}$. of a freshwater lake.

there is a very steep temperature gradient given the favourable conditions, an absolutely calm surface and a strong sun. In water which is disturbed, even to a slight extent, mixing of the warm surface water and the cooler strata beneath occurs very rapidly, for wave motion is accompanied by both vertical and horizontal movements of the water particles, even if the mean place of these particles is constant. With wave motion there is, 
however, always some wind and this leads to a translation of the surface water film in the direction towards which the wind blows. At the same time a new surface is exposed to the heating action and so mixing down to many $\mathrm{cms}$. of depth must be a very rapid process. The consequence is that, in ordinary conditions the temperature in the upper metre layer of the sea, or in a lake, is uniform, or very nearly so. The observations referred to above are interesting because they show how the surface layers of the sea become heated and the heat distributed to lower layers apart from the processes of condition and connection.

Fig. 28, A, is a graph of the average temperature of the ocean in all latitudes, and at the depths recorded, as deduced from the "Challenger" observations. The upper layer (at 100 fathoms) has a temperature of about $16^{\circ} \mathrm{C}$. and then this falls relatively rapidly down to about $4^{\circ} \mathrm{C}$., at about 600 fathoms. From that depth downwards it falls much more rapidly to about $2^{\circ} \mathrm{C}$. at a depth of 2,000 fathoms.

In general, the bottom temperature everywhere in the ocean abysses is little above freezing-point of fresh water. At the bottoms of the icebound regions of the Arctic and Antarctic Oceans the temperature falls to below $-1^{\circ} \mathrm{C}$. Over the whole of the Antarctic and Southern Oceans, most of the Indian Ocean and parts of the Atlantic and Pacific the bottom temperature varies between about $-1^{\circ} \mathrm{C}$. and $2^{\circ} \mathrm{C}$. while over the bottom of most of the Atlantic and Pacific the temperature lies between about $2^{\circ}$ and $4.5 \mathrm{C}^{\circ}$. The North Atlantic floor, however, has a temperature which is about $2^{\circ} \mathrm{C}$. higher than that at the bottom of the South Atlantic and Pacific and this is because of the position of the thermal equator well to the North of the geographical equator. Thus the South Equatorial stream sends large volumes of warm water into the North Atlantic, and sooner or later this becomes denser than the water which would lie at the surface were the conditions not asymmetrical in the way indicated. 


\section{AN INTRODUCTION TO OCEANOGRAPHY}

So it sinks, and raises the average temperature of the bottom water.

Conditions may be very different in the epi-continental seas, but to these matters we return in Chapter IX.

Seasonal changes in the temperature at the lower levels. Those changes in the temperature of the surface water that we noted on pp. 174-8 become less and less as the depth increases, until at a level of about 100 fathoms they are very difficult to observe with certainty. At about that stratum of the ocean, then, the heating and cooling effects traceable to the changes in the sun's declination become nil, or nearly so, and the temperature there may be regarded as approximating to the mean annual surface temperature. It is probable that some slight seasonal changes, due mainly to seasonal changes in the circulation of water between the surface and the lower strata, occur during the year but these are very small.

The Density of the Water.-The density of a liquid is, in general, the ratio of the weight of a certain volume to that of a similar volume of distilled water, both being at the same temperature. The latter is usually taken as $4^{\circ} \mathrm{C}$. for at that point distilled water has its maximum density. In the case of sea water, however, the expression is much less simple for it is really the density at the temperature and pressure of the stratum from which the sample was taken that is of importance in oceanographical investigation. The actual estimation must, however, usually be made at some convenient arbitrary temperature, and this is generally that of the atmosphere on the deck of a ship at sea, or in a laboratory ashore. The pressure is always that of one atmosphere. To obtain the density of the water sample in situ corrections to the experimental value must, then, be made and these corrections involve a knowledge of the temperature and pressure in situ. The temperature will have been found in the process of collecting the water sample, and the pressure is calculated from the depth and the salinity. 
Determination of the Density. This can be obtained in various ways :-

(1) By a pycnometer. This is a U-tube with capillary side stems which have marks on them. The tube is weighed empty and dry, then filled to the marks with distilled water at a convenient temperature and lastly with sea water from the sample, at the same temperature. The ratio between the weight of the sea water and that of the distilled water is the density at the temperature of the experiment and at the pressure of one atmosphere.

(2) By a hydrometer. This method can give only a rough result. The stem of the instrument clings to the surface film of water and this effect varies with the condition of the glass. It can be avoided by using a "total-immersion" hydrometer but here again there are sources of error. Further corrections must be applied according to the kind of glass from which the instrument is made.

(3) By the Petterssen specific gravity balances. The water sample is contained in a glass vessel consisting of a narrow tube enlarged at its upper end. A closed silica bulb floats in the enlarged end and the lower end of this bulb has attached to it a very fine gold chain, which lies partly heaped up at the bottom of the tube. The vessel is filled with the water and then the bulb with its attached chain is placed in it. The bulb rises in denser, and sinks in lighter water dragging as much of the gold chain as will keep it at a certain level. From the length of chain uncoiled from the heap at the bottom the density is estimated by means of empirically prepared tables.

A U-tube may be used in such a way that a certain column of sea water in one limb is in equilibrium with a longer column of distilled water in the other limb. From the difference in the heights of the columns the density is estimated.

(4) By a chlorine titration. It has been stated (see p. 136) that the ratio of chlorine to total dissolved solids is the same everywhere in the ocean. This is not absolutely true, for water of very low density in the neighbourhood 


\section{AN INTRODUCTION TO OCEANOGRAPHY.}

of great rivers may differ in composition from that in the open sea. Nevertheless, the uniformity of composition is so very nearly perfect that no significant error is involved in the assumption upon which the method depends. The relation between chlorine and total dissolved solids has been found by Knudsen over a considerable range of values of the latter, and an interpolation formula has been obtained. This is :-

Density at $0^{\circ} \mathrm{C} .=-0.069+1.4708 \mathrm{Cl}-0.00157 \mathrm{Cl}^{2}+0.00004 \mathrm{Cl}^{: 3}$

The results are tabulated, so that from the chlorine value the total dissolved solids can be found. Thus the salinity (see p. 137) can be obtained from the results of the chlorine titrations. This is the method of obtaining density that is now generally adopted.

The salinity has been defined as the weight of total dissolved solids (given certain qualifications) measured in grams and contained in 1,000 grams of the sea water in question. The temperature will not matter. But the density will vary with the temperature, for this function is the ratio of a certain volume of sea water at $t^{\circ}$ to an equal volume of distilled water at $4^{\circ}$ and the same volume of the former will contain more dissolved solids (and so be heavier) when its temperature is lower than when it is higher, because of the expansion or contraction of volume with change of temperature.

Density varies with salinity in the way shown by the "density" graph in Fig. 27 (p. 186). Here again the actual ratios have been found experimentally; an interpolation formula has been made and the results are tabulated for a large range of chlorine titrations.

There are two main expressions for the density of sea water :-

(1) The weight of unit volume of sea water at $0^{\circ} \mathrm{C}$. $=\sigma$

(2) The weight of unit volume of sea water at $t^{\circ} \mathrm{C}$. $=\sigma t$

Given, then, the temperature of the water sample in situ, 
with the results of the chlorine titration and the density at $0^{\circ} \mathrm{C}$., that is, $\sigma_{o}$ can be found from tables. In a similar way $\sigma_{t}$ can be found from the value of $\sigma_{o}$.

There remains the correction for the compressibility of sea water. The depth from which the sample was taken is known and from this the hydrostatic pressure can be found (given an approximate value for the salinity in situ for this does not affect the compressibility to a very marked extent). At a depth of one metre, say, the volume of a litre of sea water will be diminished to $c$ litres, $c$ being the coefficient of compressibility for a water column of 1 metre in height. Call the density at the temperature in situ and at atmospheric pressure $\sigma_{t}$ then the density in situ will be $n c \sigma_{t}, n$ being the depth in metres. This expression for the density is of importance in hydrodynamic investigations. Finally the density is usually expressed in an abbreviated form: unity is subtracted from the number representing it and the result is multiplied by 1,000. Thus the numbers on the vertical scale in Fig. 27 are usually written $30,25,20,15,10$ and 5 instead of $1 \cdot 030,1 \cdot 025,1 \cdot 020$, etc.

Other physical functions of Sea Water.-The Osmotic pressure. Suppose a small quantity of sea water to be contained in a vessel, the walls of which are semi-permeable, that is, they allow water molecules to pass through but prevent the passage of the molecules of the dissolved salts. Suppose the vessel to be closed; to be immersed in distilled water, and to be provided with a. manometer so that the pressure of the liquid against the walls may be observed. Water will pass into it from outside, diluting the saline solution, and in a short time a very considerable pressure will be established within the closed vessel. For water of the same temperature this osmotic pressure will increase as the salinity increases, and its rate of variation is given by the graph in Fig. 27. These values have not been observed experimentally but are calculated from observations of the depression of the 


\section{AN INTRODUCTION TO OCEANOGRAPHY}

freezing-point with increasing salinity. The importance of this character is mainly theoretical.

The boiling point. This is higher than that of distilled water. For the same atmospheric pressure it increases as the salinity increases. The vapour pressure varies in the same way. The viscosity or internal friction of sea water is mainly a function of the temperature but depends also on the salinity. It has little practical importance in oceanographical investigation though it has been correlated with the forms of marine Diatoms, Peridinians, Radiolarians, etc. In equatorial regions, where the temperature is relatively high, the viscosity is decreased and many micro-organisms appear to exhibit adaptations of form such as will tend to a slower rate of sinking through the water. The electrical conductivity varies both with the temperature and salinity. Distilled water is a very poor conductor of electricity since it is dissociated to a very small extent. Dissociation means the formation of ions, which then carry the current. With increase in salinity up to a certain limit (of course), there is increase in the quantity of salt molecules dissociated, increase in the numbers of ions present per unit volume of water and so increase in the conductivity. Obviously the salinity might be found from a determination of the conductivity, and apparatus has been devised whereby the conductivity of the water in situ can be estimated. The apparatus is lowered down into the sea at the end of an insulated cable and the electrical resistance of a known column of the water is read on the instruments on board the ship. The method is not always practicable, and it has not the degree of accuracy given by a chlorine titration.

The optical characters of sea water. The refractive index is greater than that of distilled water and depends on the temperature and salinity: the function has little significance in oceanography. The penetrating power of light in sea water is very much more important as upon the energy of solar radiation depends the 
ability of plant organisms to synthesise carbohydrate from $\mathrm{CO}_{2}$ and water. The penetrating power depends mainly on the presence of fine particles in suspension in the sea. This turbidity due to detritus is very small in the water far away from land, but photosynthesis is far less intense there than in shallow inshore seas, and so the occurrence of finely divided suspended matter in the water has much general importance. Where there are rapid tidal streams near the land there is always much matter in suspension, and sunlight does not penetrate to much below 10 to 20 fathoms in such turbid seas.

The transparency of the sea has been estimated by lowering a white enamelled disc of about two feet in diameter to such a distance that it just ceases to be visible. This depth may not exceed one or two fathoms in muddy water off the mouth of an estuary but it may be as much as twenty fathoms or more in the open sea far from the land and in bright sunlight. When the tidal streams have little velocity off a coast where there are no big rivers and with a bottom of hard sand, the sea is always more transparent than in lakes. This is because of the precipitating effect of the ions in sea water on colloidal clay entering the sea.

Even in water far from the land and containing little or no mineral particles in suspension, there are always plankton organisms in the surface layers, and these absorb the light falling through the sea, altering the colour of the water. As a liquid, however, and apart altogether from the presence of solid particles, mineral or organic, the sea water absorbs the solar radiation. This effect has been studied by observation of photographic plates exposed to the light at various depths. The plates are contained in a carrier with glass covers shielding them from contact with the water and the carrier is covered by a metal case. When it reaches the required depth, a weight is allowed to slide down the wire rope carrying the instrument, and this releases a catch which allows the 


\section{AN INTRODUCTION TO OCEANOGRAPHY}

plate carrier to slide out of the case. The plates are then exposed for a definite time, when a second weight is lowered and this closes the carrier again. The apparatus is then hauled up to the surface and the plates are developed. Colour filters can be used. Highly sensitive panchromatic photographic plates are employed.

Such plates, then, are affected by the radiation at a depth of 1,000 metres, but are certainly not affected at a depth of 1,700 metres. Thus some light penetrates to a depth of over 500 fathoms. Plates screened with blue filters require 6 times, and those screened with green filters 18 times the exposure of unscreened plates.

The composition of the radiation alters rapidly with the depth. At even a few centimetres below the surface the infra-red heat rays are absorbed; then follows a disappearance of the red waves and last of all the blue and violet ones. At about 100 metres all the wave lengths are still present, but at 500 metres the red has almost disappeared while blue is still present.

The colour of sea water varies between green and blue. Distilled water prepared very carefully has a pure, clear blue colour when seen in some depth. Near the land and off muddy estuaries the colour of the sea is often that of the suspended mineral particles, but when the latter are very few in number the colour is green or yellowgreen. Within a zone between $30^{\circ} \mathrm{N}$. and $\mathrm{S}$. latitudes the colour is ultramarine changing to indigo in the Southern Ocean and then to olive-green in the Antarctic. The general blueness is due, of course, to the absorption of most other wave lengths before the blue ones disappear, and the green colour of the Antarctic is attributed to the abundance of diatoms in those waters. Dissolved chemical substances affect the colour: thus in the neighbourhood of coral reefs there is much calcium carbonate in solution and this gives the water a blue colour. 


\section{CHAPTER VIII}

\section{THE TIDES}

It is quite impossible to do more in this Chapter than deal with the outlines of our knowledge of the tides. The dynamical theory of tidal movements is still very incomplete and it is necessarily treated in such a way as to be quite unintelligible to all those students who do not possess the mathematical technique of the investigator. Bound up with this is the problem of the prediction of the tides and this, also, is exceedingly technical and probably quite impossible, in its later phases at least, to anyone who does not attempt actually to work out examples. Here, then, we deal only with such parts of the subject as are capable of exposition without mathematical symbolism. We take, first, the tides as they are to be studied by ordinary observation and measurements; then we consider the principal celestial phenomena associated with tidal changes and lastly we say something about the methods of prediction.

The tides from ordinary observation.-At most places on the sea coast there is a periodic rise and fall in the level of the sea. This can easily be studied by watching the rise of the water on the foreshore or on the vertical face of a cliff, dock wall, breakwater, etc. The extent of the rise and fall varies greatly and it may even be non-apparent in some exceptional localities.

The rise and fall of the tides. In the ocean, far from land and over deep water, the tidal rise and fall can hardly be observed, much less precisely measured. On the shores of oceanic islands, however, it can be seen to be only a very few feet. In inland seas, such as the Mediterranean it is small-only two or three feet or less-and in great 


\section{AN INTRODUCTION TO OCEANOGRAPHY}

lakes it does not exist in the typical form but is replaced by peculiar water movements called Seiches. In shallow seas, such as the North Sea, English Channel, or Irish Sea, it is moderately large and it is maximal in large shallow bays, estuaries and tidal rivers.

Associated with the vertical rise and fall of water level is a horizontal streaming movement: this we consider presently.

There are remarkable differences, even at stations no great distance apart, in the extent of rise and fall of the sea level and here we consider some typical place on the coast of a shallow sea, but not in an estuary. Beginning with the lowest level of the water on any chosen day-low water-we find that for an appreciable time, say half an hour or more, there is no apparent change in the sea level. Then the sea begins to rise very slowly, then more quickly and finally more and more slowly until it appears to cease. For an appreciable time there is again no apparent change in water-level and high water occurs. During the time of rise the tide is said to be flowing, or it is flood-tide and during the time of fall the tide is said to be $e b b i n g$, or it is ebb-tide.

Tidal gauges. The rate, and extent of rise and fall can be estimated very precisely by observations of a tidegauge. In its simplest form this consists of a plank set up vertically on the outer side of a dock-wall or in some other suitable place. The plank is marked in feet and half-, and quarter-feet. At regular intervals of time the height of the water is read off on the scale.

Automatic tide gauges are now generally set up by harbour authorities. As a rule a deep well, lined by brickwork, is sunk to such a depth that there is always water in it no matter how low the tide may be. The well is connected, by a pipe, with a part of the sea below the lowest water observed. A float in the well rises and falls with the water level and this is connected with a mechanism which reduces the rise of fall, in some convenient ratio, 
say an inch to the foot. The mechanism records the rise and fall by tracing a curve on a sheet of paper wound on a drum. The paper is marked by a time-recording mechanism and the heights of the curve are measured at the time-intervals required.

Lately tide-gauges have been constructed on entirely different principles. The water pressure at any spot on the sea bottom depends on the height of the tide and the varying pressure is made to affect a Bourdon pressure gauge or to actuate a system of electric oscillators contained in a water-tight vessel lying near the sea-bottom. In this way the change in pressure from moment to moment can be transmitted to a suitable recording station and registered as such. The recording mechanism is calibrated so that the head of water is read instead of hydrostatic pressure.

From the graphs obtained in these ways the times and levels of low and high water can be estimated with considerable accuracy and the rates of rise and fall can be deduced from the form of the graphs.

Chart data, ordnance data and mean sea level. Some fixed level is adopted at each place where tidal observations are made and, as a rule, this is an arbitrary mark on some part of the foreshore which is generally accessible to observation. The mark is chosen so that the tide will not often fall below it, or it has been chosen for some practical reason. The original tide datum at Liverpool was the level of the old Dock Sill : this was a practical level mark for the height of the tide above it was an indication of value to vessels preparing to enter or leave the Dock. The Dock does not now exist but the datum is preserved in the form of a mark cut on the river face of the centre pier of Canning Half-Tide Dock. All land surveys in Great Britain are referred (as to level) to the Ordnance Datum and this is taken to be a level of 4.67 feet above that of the old Dock Sill at Liverpool. Elsewhere the heights of the tides are referred to some local datum mark which is specified on the local charts. The tidal heights 


\section{AN INTRODUCTION TO OCEANOGRAPHY}

are given in feet and tenths above such marks unless in the cases of exceptional tides, when they may fall below the mark, then the distances below the datum are measured.

In nearly all places the tide, then, rises to variable heights above some arbitrary level and exceptionally falls below the latter. If the sea level is measured with respect to this arbitrary mark and if the mean of a great number of measurements, made at equal intervals of time, be taken the result is mean sea level, stated with reference to the datum mark.*

If a long series of measurements be made of the height of the tide at low water and high water, and if the mean of these be calculated the result is mean tide level. This is not quite the same as mean sea level because the tide seldom rises at the same rate as it falls. Mean tide level is also referred to the local datum mark.

The range of the tide is the difference between high and low water levels: it varies from tide to tide. The rise of the tide is the difference between the datum mark and high water level: this also varies from tide to tide. The height of the tide is the difference between the datum mark and the water level: it varies from moment to moment.

Periodicity of the tides. Ordinary observation shows that high and low waters occur alternately and about twice a day: the interval between two successive high waters being nearly $12 \frac{1}{2}$ hours : thus the rise and fall of the tide is approximately semi-diurnal. But it may also be noticed that one of the two tides that occur each day is bigger than the other one: thus there is a diurnal periodicity in the change of water level as well as a semidiurnal variation, the interval between two higher high waters being approximately $24 \frac{3}{4}$ hours.

Spring and Neap tides. For several days during every fortnight the high waters are higher than usual and the

* The question of "mean sea level" is inuch too complex to be discussed here. Differences in level due to meteorological causes have much importance in marine biology. 
low waters are lower than usual: these are the spring tides and they occur a few days after the moon is new and full. Also the highest springs occur, at any place, at nearly the same time in the day. For a few days also, during each fortnight, the high waters are lower than usual and the low waters are higher than usual: these are the neap tides and they occur about a few days after the moon is in her first and last quarters. Like the spring tides the lowest neaps also occur, at any place, at very nearly the same time of day. Since the high and low waters are about three-quarters of an hour later every day it follows that, at any given place, they may occur at any hour during the twenty-four, but for any one place the highest spring tide occurs at very approximately the same time in the day. There is thus a fortnightly periodicity in the tides as well as half-daily and daily periodicities.

Twice a year, also, the spring tides are rather higher than usual: this occurs about the times of the vernal and autumnal equinoxes. These extra ligh tides are the equinoctial springs.

The range of the tides. Thus the rise of the tide has a daily, fortnightly and six-monthly periodicity: these are not the only periodicities but they are those that are most easily apparent to ordinary observation. If now we consider different places on the sea coast we shall find quite notable differences in the range of the tides: that is, between the levels, say, of ordinary springs. This is so even with places that are not very far apart-say Liverpool, where the range of ordinary spring tides is about 30 feet and Greenock, where it is only about 10 feet. Some examples of this geographical difference are given in Fig. 29 which shows, for the same month, the rise and fall of the tide for the ports of Avonmouth, Heligoland and Gibraltar.

It will be noticed that though the extreme range varies from about 49 feet (for Avonmouth) to about $3 \frac{1}{2}$ feet (for Gibraltar) we see the same sequence of springs and neaps 


\section{AN INTRODUCTION TO OCEANOGRAPHY}

and also that the spring-tides occur in each case at nearly the same time.

Types of tidal rise and fall. Our usual experience in Great Britain is that of a semi-diurnal tide: that is a succession of high waters occurring at intervals of half a day. We see, however, that one of the two half-daily tides is usually bigger than the other, so that we may regard the whole tidal undulation as consisting of at least

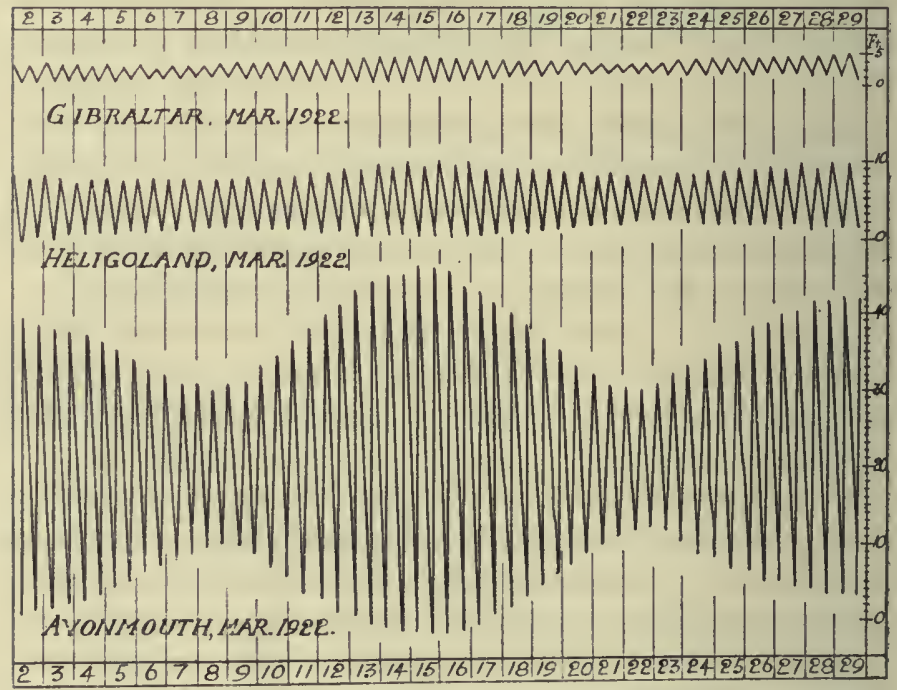

Fig. 29. Graphs of the rise and fall of the tides for the ports of Avonmouth, Heligoland and Gibraltar during the month of March, 1922. The data are the predictions taken from the Admiralty Tide Tables.

two parts: the predominant one (in the Atlantic Ocean) being half-daily and the other (much less noticeable) one being daily in their recurrence. In other parts of the world, however, the opposite is the case: the daily part of the tide is the more prominent and the half-daily part is much less noticeable. This is illustrated by the graphs of Fig. 30 .

Here we see tides consisting almost entirely of a halfdaily part in the case of Dover. In the other case the 
main part of the tide is daily in periodicity, but there is a small half-daily part which adds a hump to the daily curve. We may regard this hump as sometimes occurring on the ascending part, and again on the descending part of the daily curve.

Exceptional forms of tide occur in the British Seas. Thus there are places on the South Coast of England, between Portsmouth and Southampton where there are double high waters, or double low waters, in every halfdaily period of $12 \frac{1}{2}$ hours. There are also places in the North Sea and elsewhere where there is no tidal rise and

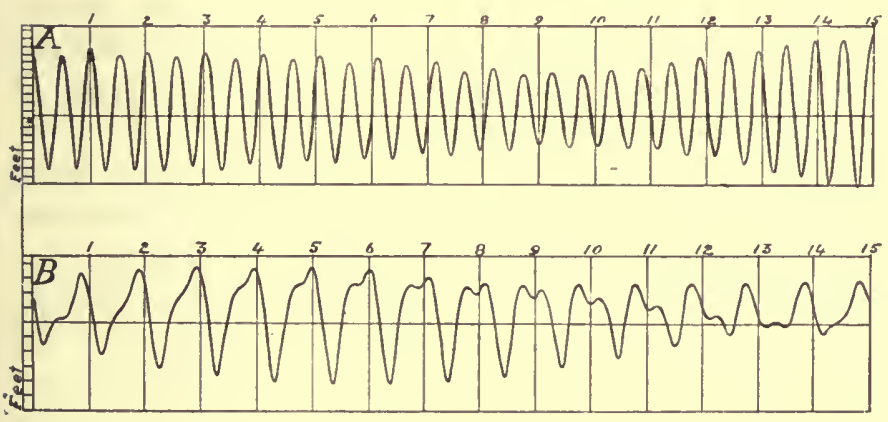

Fic. 30. (a) Fifteen days' tides at Dover and (b) fifteen days' tides at Victoria, British Columbia. The data are the predicted times and heights in each case.

fall. These are called " amphidromic points," and round these exceptional conditions occur.

Summarising we find :-

Semi-diurnal tides characteristic of the North Atlantic region. These recur at intervals of $12 \frac{1}{2}$ hours.

Diurnal tides exceptional for the Atlantic but common in the Pacific. These recur at intervals of $24 \frac{3}{4}$ hours. Quarter-diurnal tides exist but they are very exceptional. Spring tides recur once a fortnight.

Neap tides recur once a fortnight.

Equinoctial spring tides recur at intervals of 6 months. 


\section{AN INTRODUCTION TO OCEANOGRAPHY}

The tidal streams.-Associated with the rise and fall of sea level due to tides there are generally horizontal movements which often reverse themselves at about the same times as the change of level. These horizontal movements are the tidal streams. They are moderately small (that is, from the seaman's point of view) in shallow sea areas like the North Sea, English Channel and Irish Sea, they are large in shallow bays, and they are maximal in estuaries which shoal and contract in width as we pass upwards from the sea. Neither the tidal rise, nor the streaming, have much practical significance in open shallow seas, except that the rise and fall must be taken into account in making use of soundings. In narrow waters, straits, estuaries, shallow bays, tidal rivers and harbours the rise and fall as well as the tidal streams have immense practical importance.

The tidal undulation approaches the land from the ocean as a wave of approximately harmonic form. As it enters shallow water its energy tends to remain constant (apart from dissipation of course), but its wave length shortens and its amplitude (vertical height) increases. Also the wave ceases to be harmonic (or approximately so) and becomes steeper on the advancing than on the trailing side. Wind waves or "seas" break in such circumstances but the tidal oscillation seldom breaks. In such circumstances the vertical displacement motion is far less striking to ordinary observation than the horizontal one.

In general the stream will tend to flow in the same direction as that in which the tidal wave advances. But, coming into shallow water, the direction and velocity are modified in a host of ways according to the conformation of the land and the depth of the sea. Tidal streams tend to flow parallel to the coast in the fairways of channels, along gutters, or elongated depressions of the sea bottom, through straits and along the courses of estuaries or tidal rivers. They will strike across the mouths of small bays but there is generally an indraught into wide bays. Their 
velocities are also exceedingly variable being, perhaps, half a knot to one knot (a knot is a nautical mile per hour) in an open shallow sea at some distance from the land, and as much as 7 knots in narrow estuaries.

Very often the duration and direction of the tidal stream are the same as those of the tidal wave front. Near the time when high water and low water occur the directions of the stream usually reverse and when this reversal occurs within an hour or so before or after high or low water it is customary to speak of the Flood-stream as that one which runs while the tide is rising, and of the Ebb-stream as the one which runs while the tide is falling. In tidal rivers and estuaries, however, the rise of the tide is not generally synchronous with the flood stream nor is its fall with the ebb-stream. The water may continue to rise for nearly the normal period of six hours but after three hours flood the stream may reverse. Thus it is often said that the tide may flow in a tidal river for a period of 3 to 5 hours, and ebb for 7 to 9 hours, but the water level may really continue to rise although the tidal stream has reversed in direction. So in reference to channels, fairways and estuaries it is customary to speak of ingoing and outgoing rather than flood and ebb streams.

When the change of direction of the stream occurs in an open shallow sea at some distance from the land, it. usually does so in a certain way. Fig. 31 shows graphically the results of a series of estimations of the direction and velocity of the current at Ling Bank, in the North Sea, on 7th and 8th August, 1906.

A small object floating on the surface of the sea is affected far more by a moderately strong wind than by a tide-way, but a large and heavy object, such as a big. ship at anchor rides to the tide and is affected by the latter more than by a moderate breeze. When the tide is slack the ship will be "wind-rode," but when the stream begins again she will rotate on her anchor as a pivot in the same direction as the hands of a watch turn. This is the 


\section{AN INTRODUCTION TO OCEANOGRAPHY}

normal condition in the northern hemisphere: in the southern one the rotation will occur in the opposite direction to the movement of a watch hand.

In seas immediately off a coastline with prominent headlands, bays, islands, etc., and with much variety in depths the tidal streams become very complicated. Islands will split them and, on reuniting, the streams may reinforce or almost nullify each other, or form small turbulent eddies, or very large ones with areas of slack

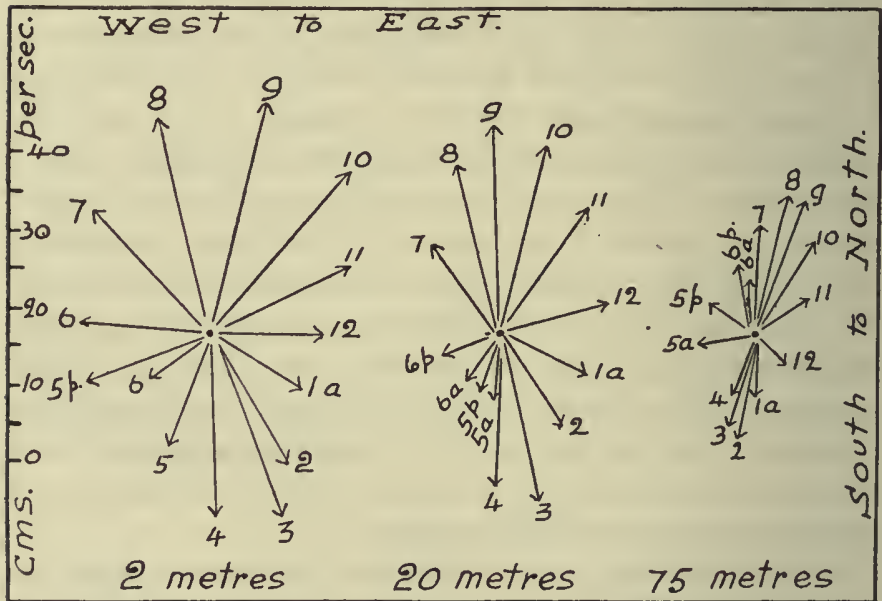

Fig. 31. Graphs of a series of readings of a current-meter at depths of 2,20 and $75 \mathrm{~m}$. The lengths of the arrows are proportional to the velocities of the stream and the directions are as shown in the figure, North Sea.

water in the centre and comfortable anchorages. In large bays and estuaries where there are numerous sandbanks and channels and where a prominent river current enters the sea the conditions may be extremely complicated. The Admiralty Charts usually record the main directions and velocities of the tidal streams, but much of this information is very old and dates back from observations made about 1848 and which do not appear to have been repeated since then. (Lately, however, extensive observa- 
tions have been made in the North Sea). The conditions in shallow, inshore waters are well known to fishermen, pilots, coasting sailors and harbour engineers, but extensive surveys of this kind do not appear often to have been made-certainly there is little published information.

Obstructions to the tidal streams lead to change in direction and velocity. Rocks, or bold sand banks on the sea bottom, divert the stream upwards and in narrow channels (such as in the Menai Straits between the Tubular and Suspension Bridges), overfalls may be very prominent during certain states of the tides: these are peculiar boilings-up of the water which may be dangerous to small vessels. Very bold headlands also divert the streams and increase their velocities. Round such headlands there may be a narrow zone close inshore, where the sea is calm, but off this the tidal stream may run very strongly, and when a strong wind is blowing in the opposite direction a very violent sea may result. This is a tidal race and good examples exist round the Mulls of Cantyre and Galloway, on the coast of Scotland.

When a well-marked tide runs up an estuary which shoals and narrows the wave becomes higher and departs still further from the symmetrical harmonic form. Finally it may become steep on the advancing front so that the tide enters the narrower part of the estuary as a breast of water several feet high. This may break, and be succeeded by several smaller waves which may not break. Such a tide is known as a Bore, and good examples exist in the Severn and Solway in Great Britain and in some of the Chinese rivers.

When the tide enters a very large and shallow bay (Morecambe Bay, on the West Coast of England, for instance) it may appear to rise very slowly at first. The upper part of the foreshore may be nearly flat and may be very extensive. A time comes (it may be at about half tide, when the rate of rise is maximal) when the advancing tide spills over the front of the bay and then rushes up the 


\section{AN INTRODUCTION TO OCEANOGRAPHY}

shallow flat part as a stream deepening very quickly. In a very short time vast areas of foreshore are covered by the sea.

So much for the more obvious characteristics of the tides, we next consider

The tide-generating force.-In the theory of universal gravitation, so far as it is applied to planetary movements, the whole of the mass of a cosmic body is supposed to be collected at its centre. The gravitational force between two such bodies is directly proportional to the product of the masses and inversely proportional to the square of the distances between them. The bodies themselves are regarded as being perfectly rigid.

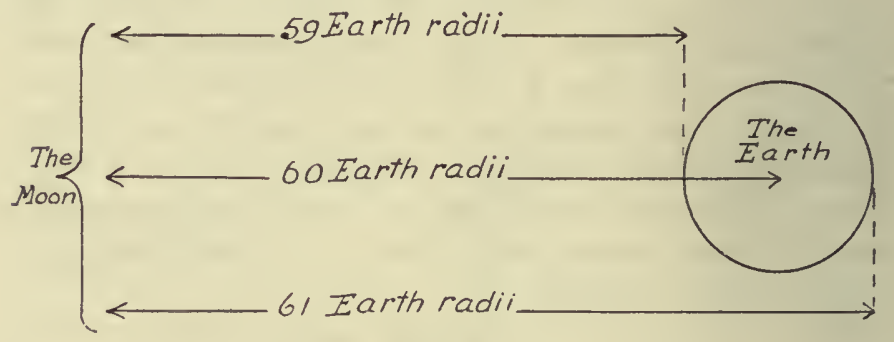

FIG. 32.

Let $E$ be the earth and let the horizontal straight lines lie in the direction of the moon's gravitative force. At $E$ the latter may be represented by $\frac{1}{60^{2}} C$ where $C$ is a constant depending on the masses of the two bodies and on the units adopted. At $A$ it is given by $\frac{1}{59^{2}} C$ and at B. by $\frac{1}{61^{2}} C$. Between the two places represented by the extremities of a diameter lying in the direction of the tide-generating force there is therefore a difference in potential of $\left(\frac{1}{61^{2}}-\frac{1}{59^{2}}\right) C$.

The earth-body itself is not quite rigid and it can be shown that the tide-generating force does actually deform 
it because it must act with greater effect on a place near $A$ than on a place near $B$. The deformation, however, is extremely small. But the envelopes of the earth are not rigid and they are easily deformed. We need not consider the atmospheric envelope, though tidal effects are said to have been detected in it. The other envelope, the ocean, is subject to a sensible deformation and this latter is the tide.

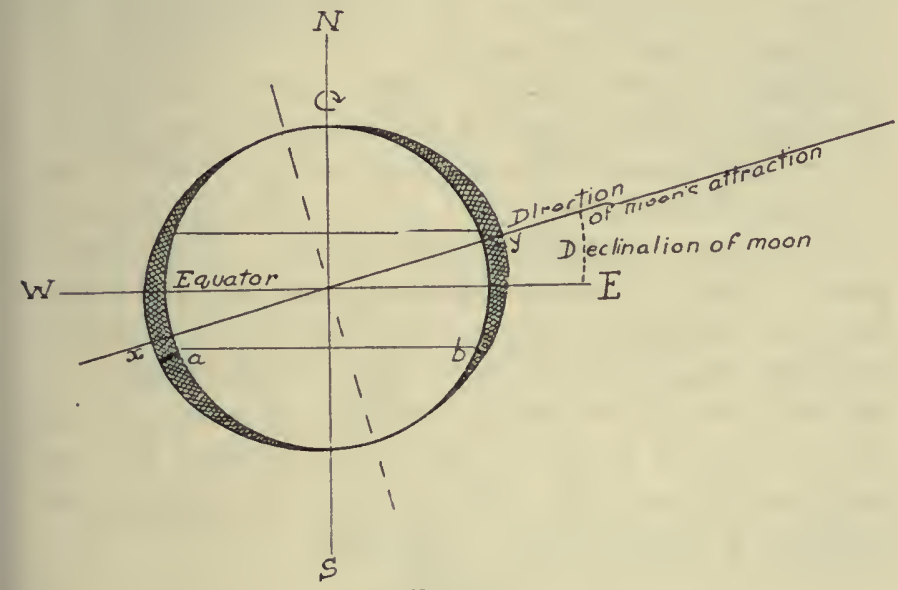

Fra. 33.

Let the circle represent the earth and the inclined line the direction of the attractional force: it can be shown that the latter is inversely proportional to the cube of the distance between the generating body and the place on the earth considered. It is easy to see, by general reasoning, that the tide-generating effect will be greatest at the points $x$ and $y$ where the lines of force of the gravitational field cut the ocean surfaces normal to the latter. It will be zero at the ends of the broken line and will diminish from $x$ and $y$ towards points on the earth's surface $90^{\circ}$ distant. All this follows very precisely from a trigonometric discussion which is, however, not necessary for our present purpose. Therefore the effect of the tide- 


\section{AN INTRODUCTION TO OCEANOGRAPHY}

generating force is a heaping-up of the water of the ocean round two places on the extremities of a diameter of the earth which is in line with the direction of the tidegenerating force. The heaping up, in such an ideal earth, uniformly covered by ocean as we are now considering will amount only to a foot or two at the most.

Suppose now that the earth rotates (very slowly and without friction) round its axis $N S$, which we take to be inclined to the direction of the tide-generating force. The tidal protuberances remain where they are, and the earth slips round beneath them so that a wave will appear to travel round it in a period of half a day (because there are two protuberances). But a glance at Fig. 33 shows that one of the latter is highor (it is $h h^{\prime}$ ) at the point $a$ than it is at the point $b$ (where its height is $h^{\prime \prime} h^{\prime \prime}$ ). Therefore the place $a$, when it has moved through $180^{\circ}$ of longitude and comes to position $b$, will not only have experienced two half-daily tides but one of the latter will be greater than the other so that we have a semi-diurnal change of water level as well as a diurnal one. The condition of this is that the tide-generating body is not on the earth's equator but is on a plane inclined to the latter.

Next we have to consider the

Variations in direction and intensity of the tide-generating force. Every body in the solar system attracts the earth, or contributes to the gravitational field in which the latter is placed. The distances and masses of the other planets are, however, not competent to produce significant effects and so we need only consider the sun and moon. The gravitational force due to the sun is a little less than half of that due to the moon. The field, however, is a combined one and its force varies continually with the relative positions of the earth, moon and sun while the tidal elevation at any place on the earth's surface undergoes corresponding fluctuations. We now deal with the principal limiting configurations of the system and this leads us to consider the motions of sun and moon in relation to the earth. 
These are very complex and we can only deal with a few of them. The reader must, therefore, understand that we only mention such of the motions that will illustrate the means of studying the variations in the tide-generating force.

(1) The moon in syzygy. That is, the earth, moon and sun are most nearly in line. Let the horizontal straight line represent the plane of the ecliptic (that of the earth's orbit round the sun). Then (neglecting declination) we have the principal configurations of the moon in opposition and in conjunction :-

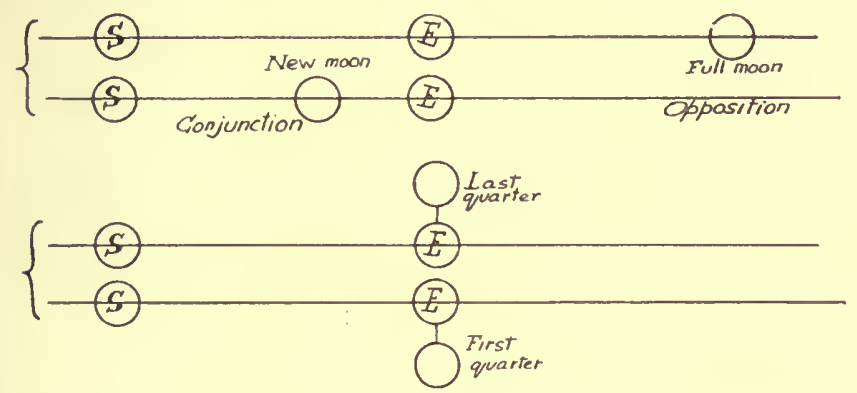

Fig. 34.

These are the conditions for spring tides because the directions of the tide-generating forces due to the moon and sun are most nearly similar.

(2) The moon in quadrature. That is, the lines joining the centres of the three bodies are most nearly at right angles to each other. We have the two cases of Fig. 34 .

These are the conditions for neap tides. The effect of the sun's gravitational field is to produce high water at that place on the earth's surface where the effect of the moon's gravitational field is to produce low water and vice versa. But since the moon's effect is to the sun's effect as $5: 2$ there will always be a residual high water due to the moon.

The principal variations in the heights of the tides, therefore, occur in correlation with the positions of the 


\section{AN INTRODUCTION TO OCEANOGRAPHY}

moon in conjunction, opposition, first and last quarters. Spring and neap tides follow the moon in her orbit round the earth.

The effect of varying declination. Next consider declination (when the conditions become much more complicated). The plane of the earth's equator is inclined, at an angle of $23 \frac{1}{2}^{\circ}$, to the plane of the ecliptic and the plane of the moon's orbit round the earth is inclined at an angle of $5^{\circ}$ to the plane of the ecliptic. In the figure the angles and sizes of the cosmic bodies are exaggerated.

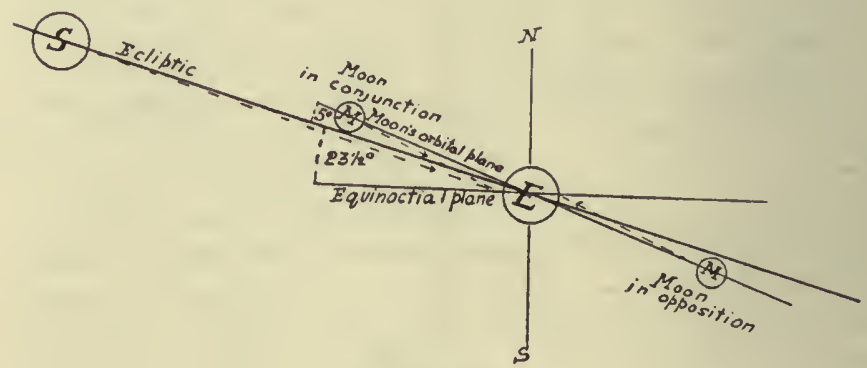

Fra. 35.

Thus the attractional forces due to the moon and sun are not normal to the surface of the sea at a place on the earth's equator: these directions are indicated in the Figure by the dotted lines with arrows.

Place the moon on the left of the earth leaving all the angles as they are and we have the conditions while the moon is in conjunction.

Place the sun on the left of the earth, leaving all the rest of the figure as it is and we have the conditions at the winter solstice. The moon may be on the right and left giving the positions of conjunction and opposition while the sun is at its position in the winter solstice.

Thus when the moon is in syzyzy we have spring tides, and when she is in quadrature we have neap tides. In the 
cases considered in Fig. 35 these conditions are accompanied with the condition of maximum declination of the sun and moon. This, by giving a less direct effect of the tidegenerating force, sets up the conditions of ordinary spring tides.

Declination: the sun at the equinoxes. It is necessary to

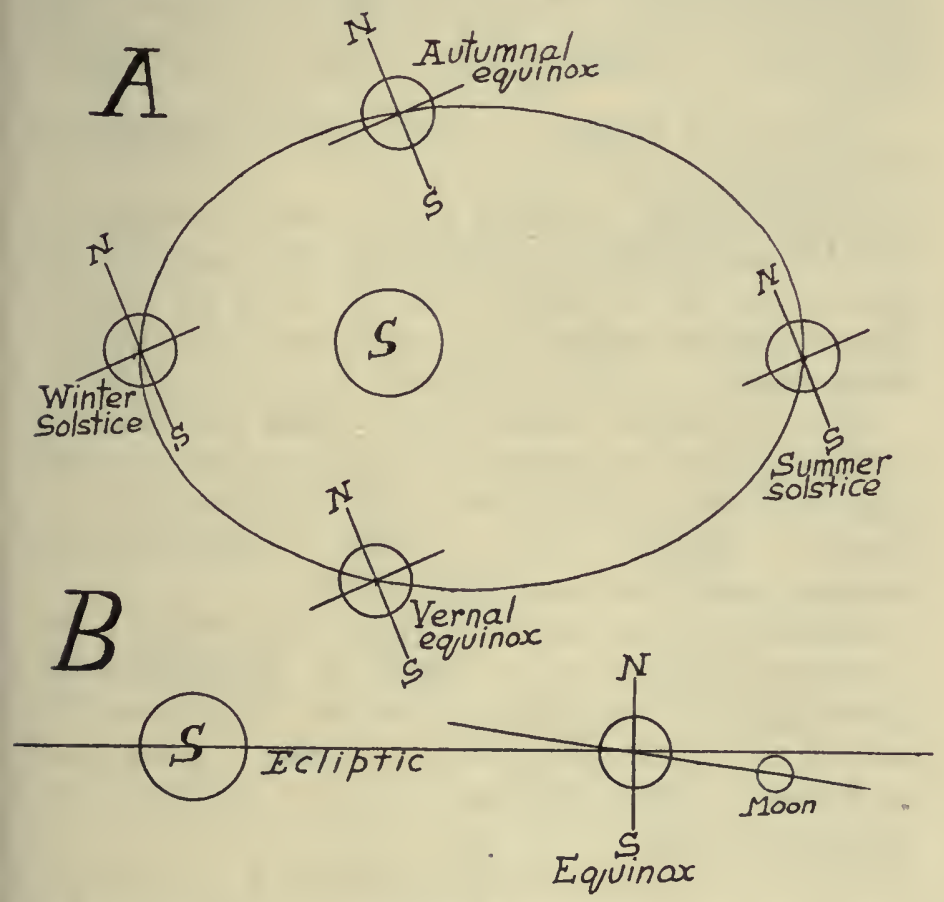

FIG. 36.

visualise the configuration at the vernal and autumnal equinoxes. This is represented at A, Fig. 36.

Now regard the configuration as seen from the side of the diagram. This is represented at B, Fig. 36 .

For several days, about the times of the equinoxes, the sun will be very nearly on the equator as the earth rotates on its axis and so its declination will be zero, or nearly so. 


\section{AN INTRODUCTION TO OCEANOGRAPHY}

For a day or two in every fortnight the moon is also nearly on the equator. Therefore, about the time of each of the equinoxes, there will be a short period when the declination of the sun and moon will both be zero, or nearly so. At such periods the combined gravitational field of both the tide-generating bodies will most directly affect a place on the earth's equator. When this configuration occurs while the moon is in syzygy we have high or equinoctial spring tides.

The moon in perigee and apogee; the sun in perihelion and aphelion.

When the moon is nearest to the earth (in perigee) her tide-generating force is greater than the mean and vice versa when she is furthest from the earth (in apogee). These periods of perigee and apogee occur twice during the lunar month.

When the sun is nearest to the earth (the latter in perihelion) his tide-generating force is above the mean and vice versa when he is furthest away from the earth (the latter in aphelion). These periods of perihelion and aphelion occur twice during the solar year.

Perigee or apogee may occur at any time relative to the occurrence of new or full moon, or of the moon in quadrature; or with reference to the times when the earth is in perihelion, or aphelion; or relative to the times of greatest or least declination of one or other of the tidegenerating bodies.

Thus the intensity of the tide-generating force must vary from moment to moment at a place on the equator. But if we take any other place on the earth's surface the same conclusion follows. The various motions of sun, moon and earth, upon which the above, and other configurations depend are strictly periodic, are known and so the configurations can be predicted. We may now summarise the principal tidal cycles with reference to the various astronomical phenomena with which they can be associated. 
Tidal period Associated astronomical phenomena

Half-daily . The rotation of the earth.

Daily . . The rotation of the earth and the declination of the sun and moon.

Fortnightly - The revolution of the moon in her orbit; syzygy and quadrature; declination of the moon.

Monthly . The revolution of the moon; perigee and apogee.

Half-yearly . The revolution of the earth in its orbit; the sun's varying declination.

Yearly . The revolution of the earth; the earth in perihelion and aphelion.

Long periodic variations in the tide-generating force. In addition to the periodic variations indicated above there
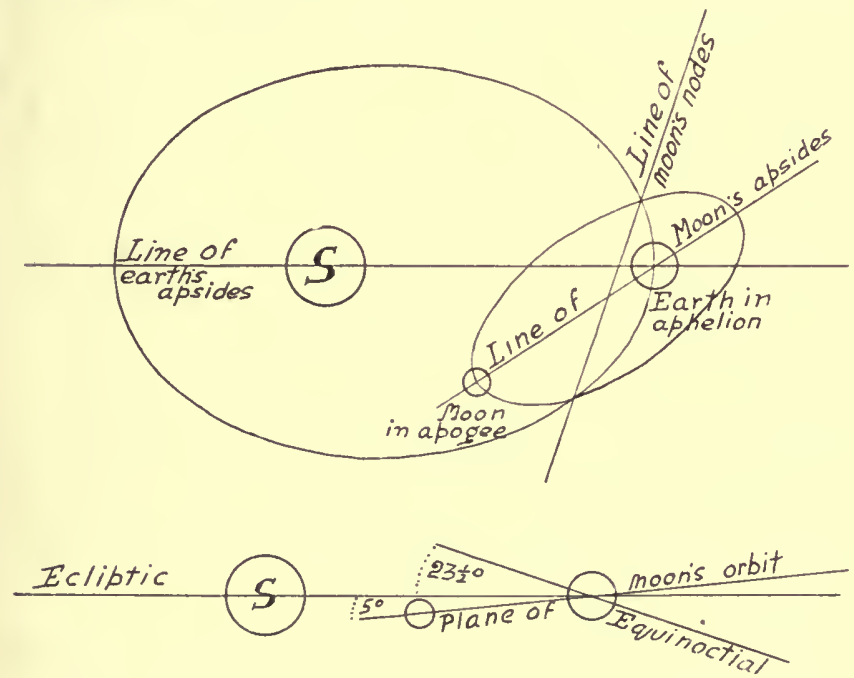

FIG. 37.

are, of course, others. Some are small and we do not refer to them. Others occur after prolonged intervals of time and have much general interest. 


\section{AN INTRODUCTION TO OCEANOGRAPHY}

The plane of the earth's equator prolonged out into space (the equinoctial) is inclined to the plane of the earth's orbit round the sun (the ecliptic) at an angle of $23 \frac{1}{2}^{\circ}$. The inclination varies but we need not consider this here.

Fig. 37, A, represents the orbits of the earth and moon as seen on the flat. Each of them is an ellipse (though the eccentricity of the latter has been greatly exaggerated in the figure) and the straight lines forming their major axes are the lines of apsides. The line of apsides of the earth's

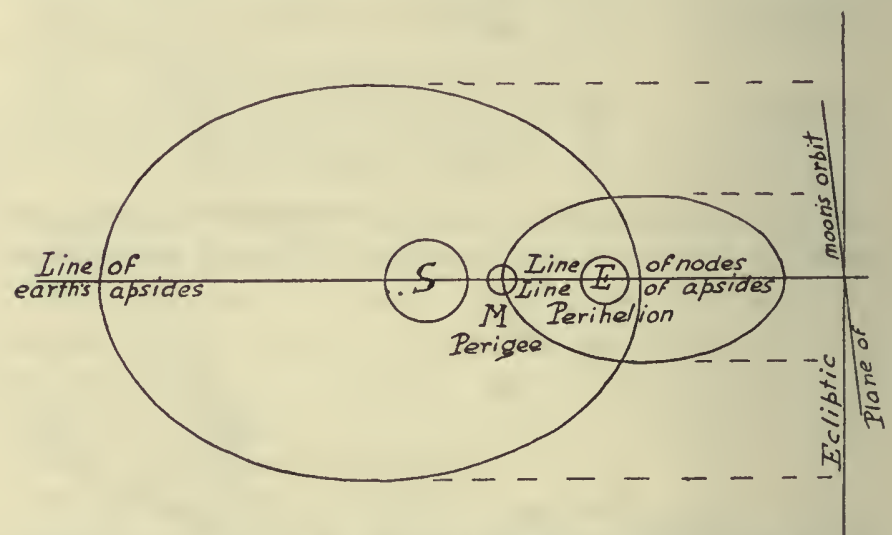

Fig. 38. The line of the earth's apsides, the line of the moon's apsides, and the line of nodes will coincide. This is the configuration for an absolute maximum.

orbit rotates, but so slowly that we need not consider its motion. The line of apsides in the moon's orbit also rotates with a period of about 8.8 years. The planes of the two orbits intersect each other in a straight line called the line of modes and this rotates with a period of about $18 \cdot 6$ years:

The result of these various motions is that at intervals of about 1,600 years a certain configuration of the three bodies and the plane of their orbits arises:

It is shown in Fig. 38 where the projection of the planes of the orbits at the side should make the configuration clear. The motions that result in the latter are rather slow 
so that, for some time, it will remain. During this phase there will be times when the earth is in perihelion, the moon in perigee, the sun and moon in conjunction or in opposition and both on or near the equator. Then we shall have absolute maxima in the potential of the tide-generating force.

The dates of such absolute maxima are calculable: they occurred in 3500 B.c., 1900 B.C., 250 B.C., 1433 A.D., and the next maximum will occur in 3300 A.D. About these times there must have been series of high spring tides when there were very high tidal ranges (see further at pp. 251-3). Subsidiary maxima to this one (that recurs at intervals of about 1600 years) recur at intervals of $4 \frac{1}{2}$, 9,19 and from 84 to 93 years.

Theories of the tides. Thus the moon and sun establish a tide generating force which varies in intensity from moment to moment passing through phases of maxima and minima which depend on the relative motions of the three bodies.

Suppose now that the earth does not rotate and that sea-water is a perfect fluid without viscosity and moving on the sea bottom without friction. We imagine the ocean water "to have lost its inertia without losing its gravitational properties." Suppose also the earth to be covered by ocean to an uniform depth everywhere.

Then the surface of the ocean would assume a figure of equilibrium in response to the tide-generating force. It would become heaped up under the gravitation of the generating body as two nearly spherical surfaces of revolution with their axes passing through the centres of the earth and the tide-generating body, as shown, in an exaggerated degree, in Fig. 33. Directly in line with the moon (say) the elevation would be maximal and it would decrease to zero at distances of $90^{\circ}$ along great circles passing through the position of maximal elevation.

Suppose now the earth to rotate so that the tidal elevations slipped on its solid surface without external and 


\section{AN INTRODUCTION TO OCEANOGRAPHY}

internal friction. Then a tidal wave, with two crests at a distance of $180^{\circ}$, would be formed and would appear to travel round the earth with a period of half a day. This is the principle of equilibrium. The modifications of this simple, theoretical scheme made necessary by the motions of the moon and sun relatively to the earth can easily be traced. Neap and spring tides, with their variations according to declination, etc., can be deduced. Given the hypothetical conditions indicated, then mathematical investigation can find all the cases that arise. Such, in short, is the ordinary "explanation" of the tides given in the older text books.

Limitations of the equilibrium theory. The most obvious limitation is that the ocean is not a perfect fluid but one which moves on the earth's surface with considerable external and internal friction. Next the depth of the ocean is about 5 miles at the greatest and has an average value of only two to three miles. This means that a wave travelling freely would take much longer than the theoretical time to run round the earth. However the tidal wave is not free but is forced. It receives what may be regarded as a periodically repeated impulse and so it travels, as a forced oscillation, round the earth with the same period as, but lagging behind the generating body.

Next; the earth is not covered completely by the ocean. The water and land surfaces exhibit a complicated figure which, almost everywhere, obstructs the passage of a wave round the earth. Also the depth of the ocean varies in a highly irregular way.

The progressive wave theory. Taking account of these qualifications a theory that makes an approach to considering actuality has been elaborated. In the Antarctic Ocean we have a zone of earth completely covered by ocean. This zone, it is true, contracts in width to some 600 miles between the Antarctic Continent and Cape Horn, but let that be regarded as offering a sufficient water way for a tidal wave. The latter, then, 
sweep round the Southern Ocean as a forced oscillation, kept going, so to speak, by the continual impetus of the tide-generating force. Its main constituents have periods of about $12 \frac{1}{2}$ and $24 \frac{3}{4}$ hours. It lags behind the impetus so that, for instance, low water may occur at a place when the equilibsium principle would make high water. The tidal waves have, however, the same periodicities as the tide-generating forces.

The Atlantic, Pacific and Indian Oceans, we have seen, may be regarded as gulfs opening out from the Southern Ocean. Near the equator the Atlantic coasts tend to east and west so that there is an obstruction there which does not exist in the other two oceans. The forced wave, then, which sweeps round the earth in the zone of Southern Ocean initiates free waves as it passes across the mouths of the oceanic gulfs. These free waves then travel up the Pacific and Indian Dceans. One travels up the South Atlantic, becomes obstructed near the equatorial latitudes and initiates a new free wave in the North Atlantic.

These "free" waves 'ravel, in the main, from south to north, undergoing dissipation of energy, but all the time causing tidal phenomena. They are, however, not quite free, for tidal waves are set up in the North and South Atlantic basins, in the Parific and in the Indian Ocean and these are forced in a peiodic way just as is the forced generating wave in the Southern Ocean. Thus the periodic impetus given by the latter to the subsidiary waves becomes greatly modified. Any tidal wave in the Atlantic Ocean, say, thus originates in the Antarctic and travels progressively up to high nortiern latitudes. There must, then, be a series of fronts as the wave advances: the latter is in different latitudes at different times. These fronts are represented by the dder figures of cotidal lines which showed how the wave progressed as it passed from south to north.

To go into some illustrativ detail: the tidal wave front was said to approach the British Islands from the 


\section{AN INTRODUCTION TO OCEANOGRAPHY}

south west, or thereabouts, and to split off the scuth of Ireland. A subsidiary wave thus enters the English Channel (where the configuration of the coast line plays all sorts of tricks with it) and goes on into the North Sea. Another wave enters the Irish Sea through Sc. George's Channel, and a third enters the same area chrough the Channel between Ireland and Scotland. The parent wave makes tides on the West coasts of Great Britain and Ireland and then passes round the North of Scotlandinto the North Sea. The older figures of cotidal lines showed these progressive waves very beautifully. The newer figures do not. The "age" of the tide represented the time that had elapsed since its origin in the Southern Ocean.

Finally, whatever difficulties in this conception of the tides are not explained can be accountzd for very plausibly by ascribing them to the influence o. the land outlines or to the great irregularities of depth of the oceans. Since deviations in the progress of a free wave could hardly be deduced a priori from a knowledse of these irregularities such explanations cannot be questioned.

The stationary wave theory. If a small shallow vessel containing water, say an ordinary "developing" tray, be gently tilted a wave of a special kind will be established. The body of water will vibrate as a whole, the level rising on one side and falling on the other while the level at the middle part remains stationary. A single impulse will set up a series of stationary waves of this kind and these will rapidly disappear by dissipation of their energy. If a regular timed impulse be given by rocking the dish with a periodicity which can easily be found by watching the oscillations of the water the latter can be maintained. If, while the dish is rocking from end to end the tilting movements be suddenly stopped and then the dish rocked from side to side the wave will be turned through a right angle. If the dish be rocked successively from side to side, corner to corner and end to end waves having these directions will be set up. The direction will change as the rocking 
motion changes. The central part of the water will remain approximately level.

The recent work on the theory of the tides looks upou the phenomena in something like this manner and the same kind of treatment applies to each ocean or sea region considered as a unit. What we have is a system-the solid earth and the water on it--that is made to oscillate. The oscillations are established by the periodically repeated tide-generating force set up by the gravitational field of the sun and moon, and the intensity of this force changes as the relative positions of the earth, sun and moon change. These relative positions, and thus the variations in intensity of the tide-generating force, can be traced with considerable accuracy.

The material that oscillates is the water of the oceans and seas. The solid matter of the earth itself can also be shown to oscillate but the effect is extremely small and need not be considered here.

The oscillations of the water are forced by the periodically repeated impulses of the tide-generating force. But the masses of water considered, say the North Atlantic Ocean, or the North Sea, have certain shapes and depths and there are tributary seas, bays, straits, \&c., in open connections with them. There are also capes, islands, \&c., in the way of the forced waves, obstructing them. The depths of the water varies from place to place. Further, and very important, the whole mass of water considered is in rotation with respect to the earth's axis, therefore it has properties analogous to those of the rotating material of a gyroscope.

In each ocean or sea basin, then, we have a system such as is represented, in miniature, by the rocking developing dish. In the centre of the ocean, or sea, there will be a nodal point (an amphidromic point) where the water streams but does not rise or fall. Usually there will be several such nodal points according to the configuration of the basin and its relations with other basins. Suppose, 


\section{AN INTRODUCTION TO OCEANOGRAPHY}

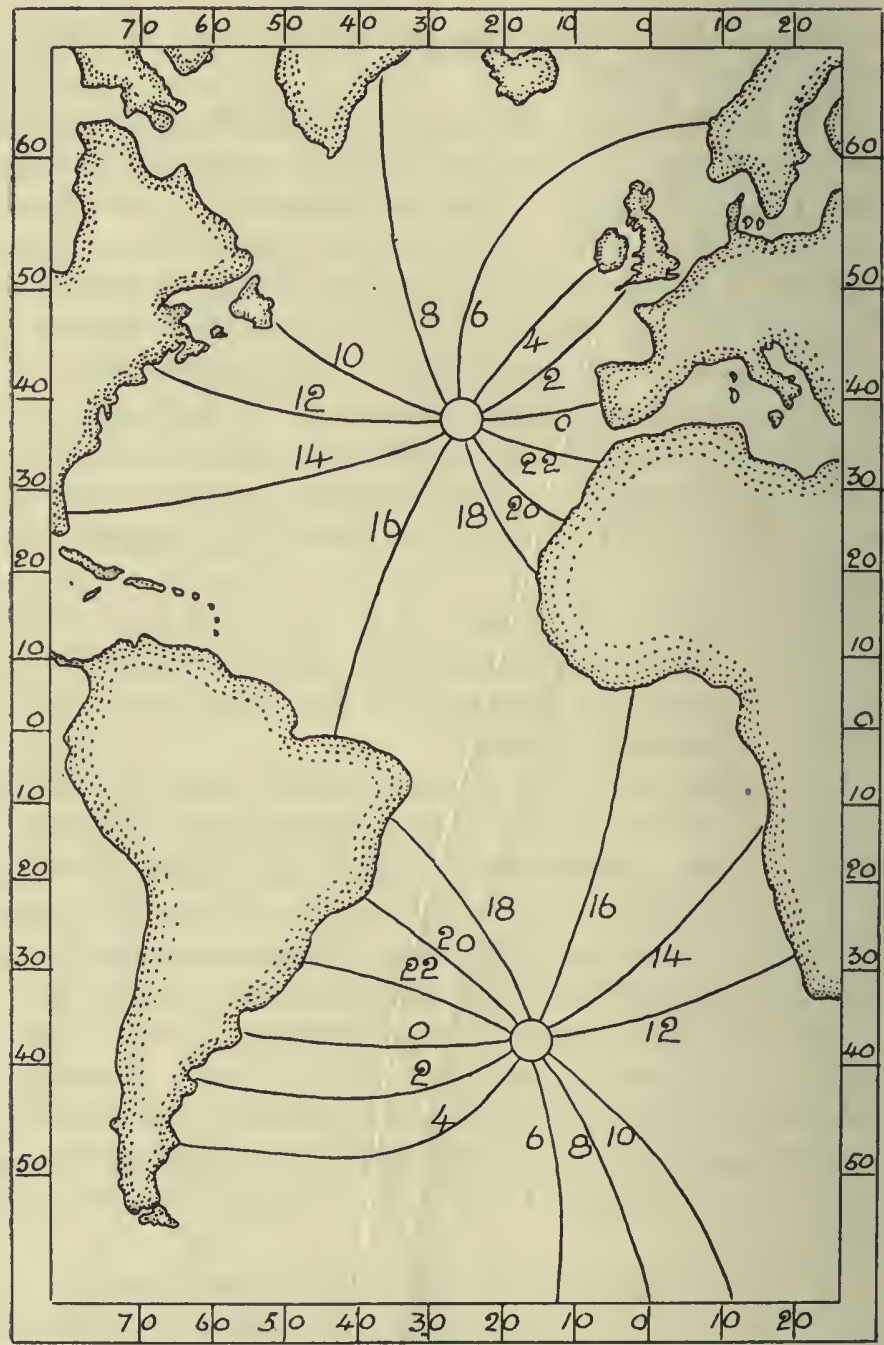

Fia. 39. The co-tidal lines in the Atlantic Ocean. The small circles are the amphidromic points. The radial lines mark the successive positions of the forced wave that swings round the nodal points. The numbers on the radii give the hours when the crest of the wave has the positions marked by these radii. The amplitude of the wave is zero at the nodal point and maximal at the other extremity of a radius. 
for simplicity, that there is only one amphidromic point, then, along radii from this the water will rise and fall. The oscillations will swing round the nodal point in a certain direction.

This short explanation will, it is hoped, give the reader some idea of the properties of a tidal system, treated in the modern way. Further investigation is, of course, exceedingly technical.

Tidal predictions. - It is not difficult to see how the times and heights of the tides, in the British seas at all events, can be predicted with a degree of approximation that is near enough for rough navigational requirements. Such predictions would, of course, be entirely empirical ones and must have been made, in the days before tidetables, by many old experienced sailors and fishermen who were entirely illiterate. Doubtless they are still so made.

To begin with, it must have been noticed that spring tides were highest at a certain interval of time after the moon was full and new. Then the rise and fall of the water level must have been observed with considerable accuracy because it was seen, not on a vertically standing tide-gauge scale, but on a foreshore of very gentle slope, when even an inch or two of rise makes a very noticeable difference in the appearance of the beach. The tidemarks made by shore débris also provide very exact measures of the rise of the highest tides. Further the correct estimation of the depth of the sea over sand banks, bars, and in narrow channels is a matter of practice upon which everything in fishing in inshore waters depends. The time also can be estimated with considerable accuracy by men who are able to note exactly the southing of the sun at midday.

The highest of the spring tides must then have been observed to occur at the same time during a certain day after that on which the moon was full or new. Then it would be noticed that the tides would "take off" for 


\section{AN INTRODUCTION TO OCEANOGRAPHY}

about a week by which time they would rise to a minimum height, also at a definite time in the day. Then they would "make" for a similar period and would again reach the maximum height at the same time of day as they did on the occasion of the last springs. It would be noticed that there was a certain rough alternation of higher and lower spring tides and that twice a year, about the times when day and night were about equal, extra high springs would happen. There would be an average rise and fall of the height of the tides and variations from this would be expected. It would be very apparent, of course, that high water was a little later (by an interval of time easily approximable) each day. It would be noticed then, as it is now, that winds blowing in certain directions tended to raise or "cut" the tides, or hasten or slacken the ebbs. Such knowledge, all coming in the course of the day's work would be little inferior in point of practical value than that obtained from the use of a modern tidetable.

First of all there is a basis of observation : the heights and times of high and low water have been recorded by a tide gauge and it is assumed that this is available for a period of at least a year and a quarter. As a rule longer periods than this are used. There are then two principal methods by which the observations are reduced.

(1) Empirical (non-harmonic) methods. These are the methods by which the British Tide-Tables have been calculated in the past and they can only be briefly indicated. The Table on p. 228 may be taken to represent the observations. They are really the predictions but the difference between them and the results, as given by the tide-gauges, may be neglected so far as our present purpose is concerned. Three months are chosen : January, March and July, and in addition to the figures taken from the Admiralty Tables some other astronomical data are quoted. To save space only the first few lines of one 
Table are actually given. The reader can complete them from the Admiralty Tide Tables and Nautical Almanac.

Col. (1) gives the day of the month; (2) gives the times of high and low waters and the heights above the datum mark.* In general there are two high and two low waters in each day but occasionally there is only one. The heights are in feet and tenths and the times are "standard." 00 hrs. is midnight; 12 hrs. is noon ; hrs. less than 12 are a.m., more than 12, p.m. Col. (3) gives the times and heights of the low waters. Col. (4) gives the times of the moon's transit across the meridian (also in standard time). The "upper" transit is that which occurs on the meridian above the horizon; the "lower" one occurs half a lunar day later, below the horizon. Col. (5) we explain presently. Cols. (6) and (7) give the declinations of the moon and sun at apparent noon at Greenwich. These are the distances in degrees and minutes $\mathrm{N}$. or S. of the body from the equator. Col. (8) gives the phases of the moon and the dates of her positions furthest north or south of the equator, as well as her positions in perigee and apogee. The moon's transits are taken from the Admiralty Tide-Tables and the declinations, phases, etc., are taken from the Nautical Almanac. If the data for the transits and declinations are to be used for any other place than Greenwich they must be corrected for longitude. This, however, is most conveniently done by a change in the scale when the dates are graphed.

The times and heights of high and low waters must next be related to the times when the moon is on the meridian at the place of observation. These are given in Col. (4). We take them one by one and look for the time of high water of the tide immediately following a transit. Thus on January 2, the moon crossed the meridian at $2 \mathrm{hrs}$. 57 mins. (her lower passage). The H.W. immediately following this was that of January 2 at $13 \mathrm{hrs.} 41$ mins.

* When an asterisk is prefixed to a height it means that the latter is really a distance below the datum. 


\section{AN INTRODUCTION TO OCEANOGRAPHY}

We subtract 2 hrs. 57 mins. from 13 hrs. 41 mins. and get 10 hrs. 44 mins.- the entry in Col. (5) opposite the time of high water on January 2 at 13 hrs. 41 mins. Again the moon crossed the meridian above the horizon on January 2

Tides and associated celestial phenomena. Liverpool, January, 1922.

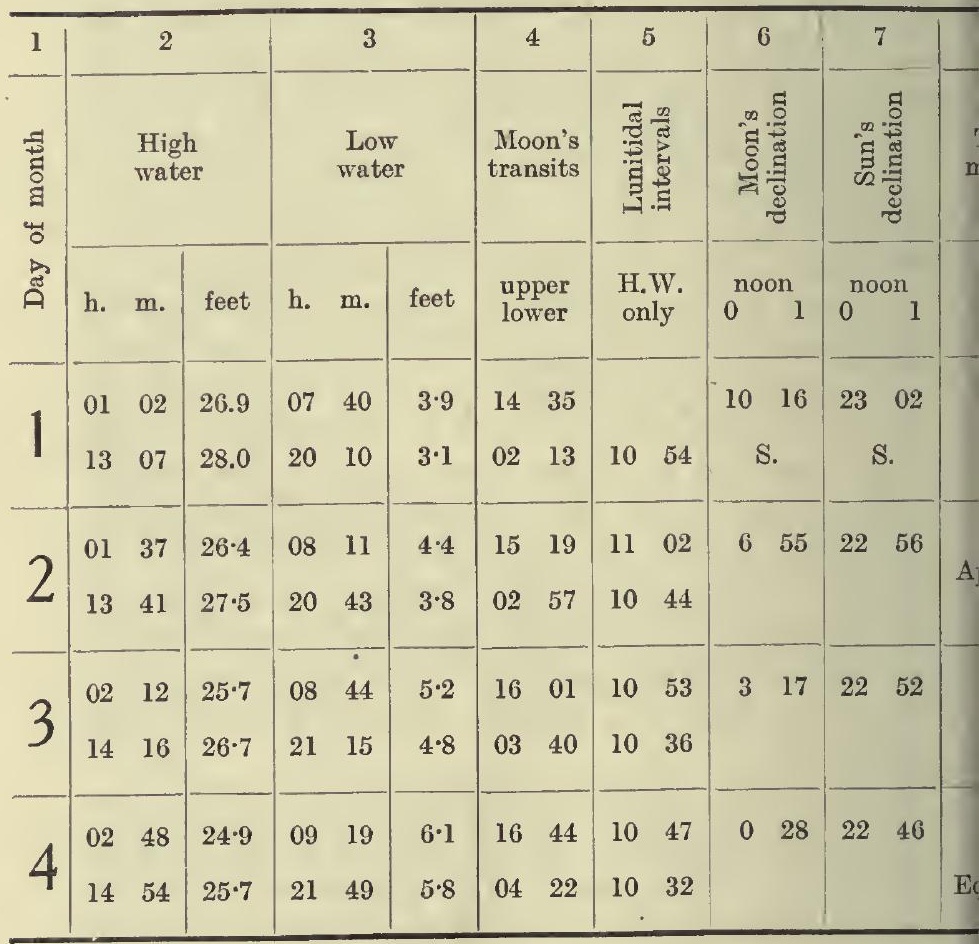

at $15 \mathrm{hrs.} 19$ mins. and the high water immediately following this was that occurring on January 3 at 02 hrs. 12 mins. Take 15 hrs. 19 mins. from 24 hrs. and add 2 hrs. 12 mins. to the result: we get $10 \mathrm{hrs} .53 \mathrm{mins}$. as the interval that elapsed between the moon's transit on 2 January at 15 hrs. 
19 mins. and the high water immediately following on 3 January at 2 hrs. 12 mins.

Thus the "Lunitidal intervals" in Col. (5) give the periods that elapsed between the times of high water (on the same line) and the times of the preceding transits of the moon. It will be seen that high water (at Liverpool) follows a transit of the moon after an interval of from $10 \frac{1}{2}$ to $12 \frac{1}{4}$ hours. The same calculations can be applied to the times of low water but the applications to times of high water will illustrate the method well enough.

Imagine that the moon were to revolve round the earth in the plane of the equinoctial, and with a period of 24 solar hours, and that there were no sun. There would be a series of high waters, all of precisely the same height and occurring at a certain constant time (the lunitidal interval) after the moon had crossed the meridian of the place. One observation of the time of transit, the time of high water and the height of high water would enable us to predict the times and heights of H.W. at any time in the future.

Imagine now that the sun were to revolve round the earth in the plane of the equinoctial and with the same period as the moon, and further that it were to cross the meridian at the same times. The tide caused by the sun would now be added to that caused by the moon, but the times of H.W. would remain the same. This would also be the case if the sun crossed the meridian 12 hrs. exactly after the moon.

If, however, the sun were to cross the meridian 6 hours before or after the transit of the moon the tide caused by him would have to be subtracted from the tide caused by the moon : this follows from pp. 213-4. The times of H.W. would still be the same.

Still suppose that the moon and sun to revolve round the earth in the plane of the equinoctial but give these two bodies each its real period. Let the sun cross the 


\section{AN INTRODUCTION TO OCEANOGRAPHY}

meridian at intervals of 24 hours and the moon at intervals of $24 \mathrm{hrs} .51$ mins. There will now be a variable, angular distance between the two tide-generating bodies. At new moon and full moon they are both on the meridian at the same time and the angle is zero: the two tides are now to be added together. About 7 days later, the moon is in quadrature, the angular distance between her and the sun is about $90^{\circ}$ : the solar tide must now be subtracted from the lunar tide.

Therefore, in the course of a synodic month, the Iunar and solar tides reinforce each other at new and full moon and we have springs. Halfway between these times the solar tide diminishes the total one and we have neaps. There is thus a continual variation in the height of the tide and this has to be predicted. The predictions must give the times of high and low water, and the height of the compound tide generated by both the bodies.

The establishment of the port. From the (completed) Tables of p. 228 we might take all the moon's transits, upper and lower, occurring within the twelve groups of intervals, thus :-

0 hour to 1 hour, 1 hour to 2 hours, etc...11 hours to 12 hours. and $11,, 13,13,, 14, \quad, \ldots 23$, , , 24 ,

Opposite each transit we place the heights of high water and low water of the tide that immediately follows, and also the lunitidal interval. Thus, from the tables we get that on p. 231.

Thus the mean time of transit is $0 \mathrm{hr} .31 \mathrm{mins}$. (If a sufficiently large number of data had been taken this would have been $0 \mathrm{hr} .30 \mathrm{mins}$.) The mean height of high waters following the transits of $0 \mathrm{hr}$. to $1 \mathrm{hr}$. and $12 \mathrm{hr}$. to $13 \mathrm{hr}$. is 28.7 feet, and the mean lunitidal interval between the transits and the following high waters is $11 \mathrm{hr} .21$ mins. 
Moon's transits occurring between 0 hour and 1 hour and 12 and 13 hours.

\begin{tabular}{|c|c|c|c|c|}
\hline \multicolumn{2}{|c|}{ Times of transits. } & \multirow{2}{*}{$\begin{array}{l}\text { Heights of the tides } \\
\text { following the } \\
\text { preceding transits. } \\
\text { FEET. }\end{array}$} & \multicolumn{2}{|c|}{$\begin{array}{l}\text { Lunitidal intervals } \\
\text { between the transits } \\
\text { and the following tides. }\end{array}$} \\
\hline н. & M. & & H. & M. \\
\hline 00 & 29 & $30 \cdot 3$ & 11 & 09 \\
\hline 12 & 59 & $29 \cdot 3$ & 11 & 07 \\
\hline 12 & 32 & $27 \cdot 1$ & 11 & 37 \\
\hline 00 & 09 & $28 \cdot 1$ & 11 & 35 \\
\hline 00 & 54 & $28 \cdot 3$ & 11 & 33 \\
\hline 12 & 09 & $30 \cdot 1$ & 11 & 19 \\
\hline 00 & 37 & $31 \cdot 5$ & 11 & 10 \\
\hline 12 & 03 & $27 \cdot 5$ & 11 & 45 \\
\hline 12 & 47 & $27 \cdot 8$ & 11 & 31 \\
\hline $00^{\circ}$ & 25 & $28 \cdot 2$ & 11 & 36 \\
\hline 12 & 21 & $28 \cdot 1$ & 11 & 18 \\
\hline 00 & 46 & $26 \cdot 9$ & 11 & 21 \\
\hline 12 & 05 & $29 \cdot 1$ & 11 & 08 \\
\hline 12 & 58 & $29 \cdot 8$ & 11 & 00 \\
\hline 00 & 29 & $28 \cdot 2$ & 11 & 15 \\
\hline Means 0 & 31 & $28 \cdot 7$ & 11 & 21 \\
\hline
\end{tabular}

Doing this for each group of transits we get the complete table on p. 232.

Finally we plot the mean times of the transits, as abscissae, against the lunitidal intervals as ordinates, and 


\section{AN INTRODUCTION TO OCEANOGRAPHY}

draw a smooth curve through these points: this gives the graph A of Fig. 40. Also the heights of the high waters are plotted as ordinates against the mean time of transits

\begin{tabular}{|c|c|c|c|c|c|}
\hline \multirow{2}{*}{$\begin{array}{l}\text { Times of } \\
\text { moon's } \\
\text { transits. }\end{array}$} & \multicolumn{2}{|c|}{$\begin{array}{l}\text { Mean times of } \\
\text { moon's } \\
\text { transits. }\end{array}$} & \multirow{2}{*}{$\begin{array}{l}\text { Mean heights of } \\
\text { H.W. of the } \\
\text { tides following } \\
\text { the preceding } \\
\text { transits. }\end{array}$} & \multicolumn{2}{|c|}{$\begin{array}{c}\text { Mean } \\
\text { lunitidal } \\
\text { intervals. }\end{array}$} \\
\hline & н. & M. & & II. & M. \\
\hline $\begin{array}{l}0-1 \text { hour } \\
12-13 ",\end{array}$ & 0 & 30 & 28.7 & 11 & 21 \\
\hline $\begin{array}{l}1-2 \text { hour } \\
12-14 \text { " }\end{array}$ & 1 & 30 . & $28 \cdot 8$ & 11 & 07 \\
\hline $\begin{array}{l}2-3 \text { hour } \\
14-15 \%,\end{array}$ & 2 & 30 & $28 \cdot 6$ & 10 & 57 \\
\hline $\begin{array}{l}3-4 \text { hour } \\
15-16 \text {," }\end{array}$ & 3 & 30 & $27 \cdot 6$ & 10 & 43 \\
\hline $\begin{array}{l}4-5 \text { hour } \\
16-17 ",\end{array}$ & 4 & 30 & $26 \cdot 2$ & 10 & 35 \\
\hline $\begin{array}{c}5-6 \text { hour } \\
17-18 \quad,\end{array}$ & 5 & 30 & $24 \cdot 7$ & 10 & 39 \\
\hline $\begin{array}{l}6-7 \text { hour } \\
18-19 \quad,\end{array}$ & 6 & 30 & $23 \cdot 3$ & 10. & 50 \\
\hline $\begin{array}{l}7-8 \text { hour } \\
19-20 \quad,\end{array}$ & 7 & 30 & $23 \cdot 1$ & 11 & 19 \\
\hline $\begin{array}{r}9-10 \text { hour } \\
20-21 \quad,\end{array}$ & 8 & 30 & $23 \cdot 9$ & 11 & 43 \\
\hline $\begin{array}{l}10-11 \text { hour } \\
21-22 \quad,\end{array}$ & 9 & 30 & $25 \cdot 3$ & 11 & 54 \\
\hline $\begin{array}{l}11-12 \text { hour } \\
22-23 \quad,\end{array}$ & 10 & 30 & $26 \cdot 9$ & 11 & 49 \\
\hline $\begin{array}{l}12-0 \text { hour } \\
23-24,\end{array}$ & 11 & 30 & $28 \cdot 1$ & 11 & 36 \\
\hline
\end{tabular}

as abscissae and a smooth curve is drawn: this gives the graph B of Fig. 40.

From these graphs we can interpolate any time of transit and find the corresponding lunitidal interval and 
height of high water. The example given deals only with three months' observations: in actual work some years would be taken. Also the low waters would be treated in a similar way.

These methods now enable us to find the times and heights of high and low water of the average luni-solar tide. Thus let it be required to predict the time and height of the tide at high water on September 1st, 1922.

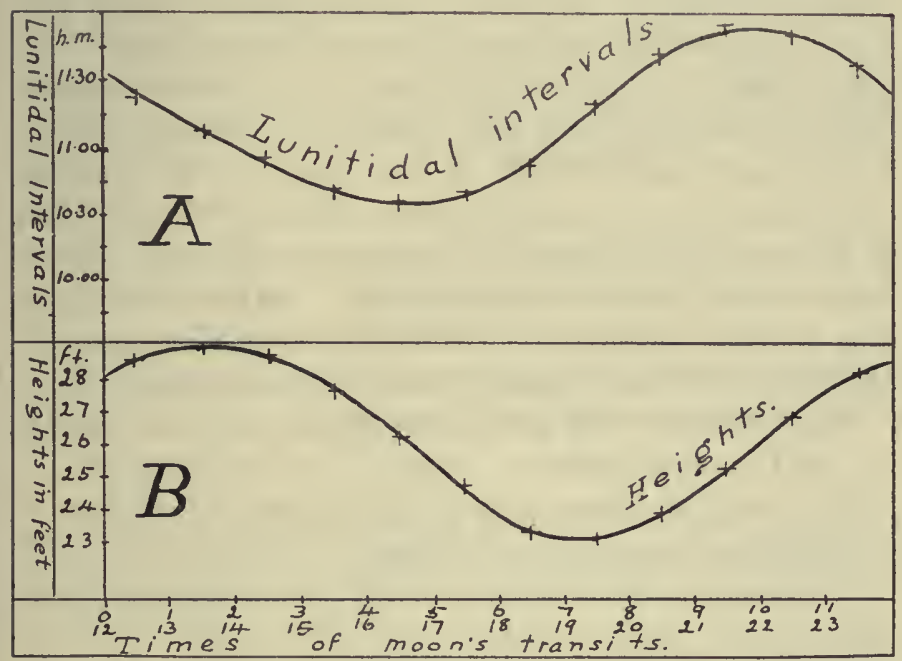

FIG. 40.

We look up the times of the moon's transits on the day before, and on that day. These are :-

August 31, upper transit at 19 hours 48 minutes.

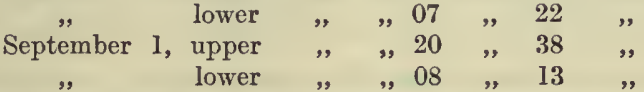

and next we find the lunitidal intervals for the tides following the transits at 19 hrs. 48 mins. (that is, 7.48 p.m.) on 31 Aug., and at $08 \mathrm{hrs.} 13 \mathrm{mins}$. (that is, $7.22 \mathrm{a.m}$.) on 1st Sept. The intervals read from Fig. 40, A are $11 \mathrm{hr} .26$ mins. and 11 hrs. 15 mins. respectively. The times of H.W. are 
therefore 7 hrs. 48 mins. +11 hrs. 26 mins. $=19$ hrs. 14 mins. (or 7.14 a.m.), and 08 hrs. 13 mins. +11 hrs. 15 mins. $=19$ hrs. 28 mins. (or 7.28 p.m.). The Admiralty predictions give 7.16 a.m. and 7.50 p.m. respectively. Next we find the heights from Fig. $40 \mathrm{~B}$, by reading the ordinates on the abscissae, 7.48 and 8.13 : these are 23.3 and 23.6 feet. The Admiralty predictions give 22.4 and 23.6 respectively.

A calculation of this kind, carried out on several years' data (or those for one and a quarter years at least) give the results called the establishment of the port. This states that high water will occur at a certain average interval after the moon has crossed the meridian (visibly at full moon and invisibly at new moon). This interval, as obtained from the three months data given on p. 232 is $11 \mathrm{hrs}$. and $28 \mathrm{mins}$. It also states that the average height of high water will be 28.4 feet. As deduced from a long series of observations recorded in the Hydrographic Department of the Admiralty the average constants are :High water at full moon and change of moon occurs at 11 hrs. 17 mins.

The height of spring tides at high water is $27 \cdot 66$ feet.

The former constant is abbreviated "H.W.F.C.-11.17."

The empirical predictions. So far we have found what will be the times of high and low water and the corresponding heights of the tides provided that the latter are generated by the moon and sun revolving round the earth with their present speeds, in circular orbits and in the plane of the equinoctial. The phase, that is, the angular distance between the two bodies is always changing but the method takes account of that and it is the combined luni-solar semi-diurnal tide that we predict. It includes what is called the phase inequality in the tide, that is, the effect on the lunar semi-diurnal tide, of the solar semidiurnal tide.

But (1) the orbits are ellipses so that the moon and sun are at variable distances from the earth and their tide- 
generating forces are proportional to the inverse cubes of their distances and (2) the planes of the orbits are not in the equinoctial. The moon's orbit is inclined $28 \frac{1}{2}^{\circ}$ and the sun's $23 \frac{1}{2}^{\circ}$ to the equinoctial. These are the maximal declinations of the two bodies. The moon may be as much as $28 \frac{1}{2}^{\circ}$ North or South of the Equator and the sun may be as much as $23 \frac{1}{2}^{\circ}$ North or South of the Equator.

It is necessary, then, to correct the values as obtained by the above methods. Because of declination each of the two principal tides-the lunar semi-diurnal and the solar semi-diurnal-is accompanied by a diurnal tide. Therefore one of the two tides of each day is usually higher than the other. This means that two corrections must be applied :-

(1) One for the lunar, tropical, diurnal inequality (or diurnal effect on the phase inequality of changes in the moon's declination). Period one synodic month.

(2) One for the solar, tropical, diurnal inequality (or diurnal effect on the phase inequality of changes in the sun's declination). Period, one solar year.

The changing declination of moon and sun also affect the principal lunar and solar tides so other two corrections must be applied :-

(3) One for the lunar, tropical, semi-diurnal inequality (or semi-diurnal effect on the phase inequality of changes in the moon's declination). Period, half synodic month.

(4) One for the solar, tropical, semi-diurnal inequality (or semi-diurnal effect on the phase inequality of changes in the sun's declination). Period, half solar year.

The changing distances of the moon and sun from the earth also affect the principal lunar and solar tides and two further corrections are required :-

(5) One for the lunar, anomalistic, semi-diurnal inequality (or effect on the phase inequality of changes in the moon's distance). Period, one anomalistic month. 


\section{AN INTRODUCTION TO OCEANOGRAPHY}

(6) One for the solar, anomalistic, semi-diurnal inequality (or effect on the phase inequality of changes in the sun's distance). Period, one solar year

Finally there is an annual variation in height due to seasonal meteorological changes. Period, one solar year.

How these inequalities affect the heights and times of high water may be seen from the graphs, Figs. 41 to 43 . In each of these the heights of the tides are represented by a simple linear run and fall. Above this the declination, or distance in degrees above and below the equator, of the moon and sun are shown. Above that again the phases of the moon are recorded, with the positions of this body in perigee and apogee.

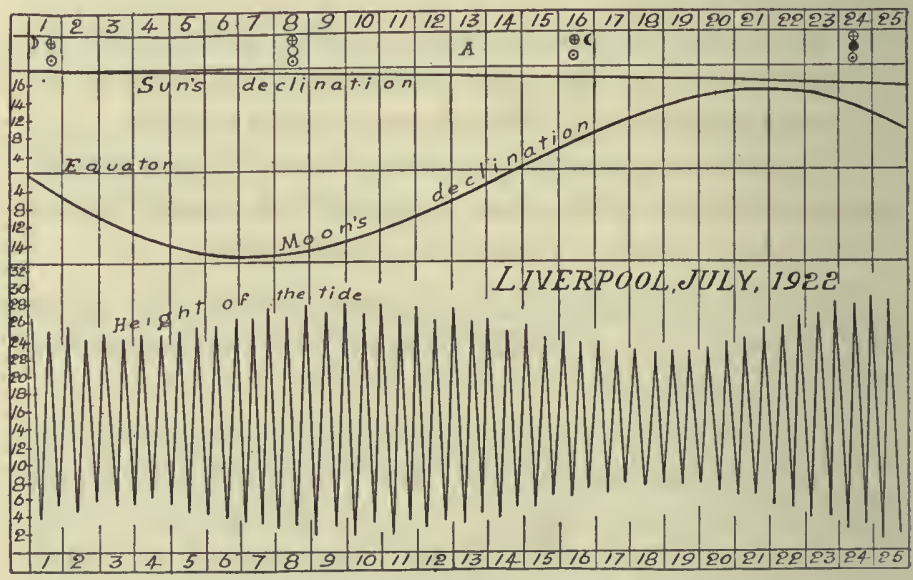

FIG. 41. Low spring tides.

[Fig. 41.-Low spring tides. This relates to the Liverpool tides in July of 1922 . The highest springs follow the moon in conjunction after an interval of $1 \frac{1}{2}$ days from the time of transit. The sun is very near his highest northerly declination. The moon is near her lowest southerly declination and she is nearer apogee than perigee. The sun is near his furthest distance from the earth. The 
maximal declinations lower the height of the tides and so do the positions of moon and sun (both being near their maximum distances from the earth). Therefore, we have low spring tides, the range being only $26 \cdot 3 \mathrm{ft}$.

Fig. 42.-High (equinoctial) spring tides. These are the tides of Liverpool, March, 1922. The springs occur about the middle of the month. On 13 March the moon is in opposition, is on the equator (no declination) and is in

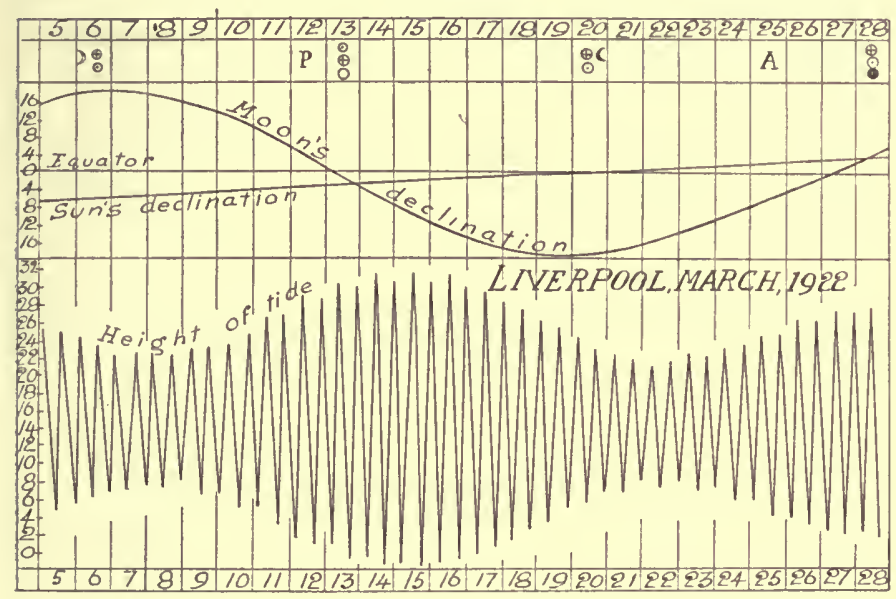

FIG. 42. High (equinoctial) spring tides.

perigee. The sun is nearly on the equator (the declination is very small) and he is about at his mean distance from the earth. The effect of no declination of the moon and very little declination of the sun, with the moon nearest to the earth, is to raise the height of the tide. The range is great, 32.9 feet.

Fig. 43.-Very high (equinoctial) spring tides. These are the tides of Liverpool, September, 1922. The sun and moon are together almost on the equator on Sept. 20, on which day the moon is in conjunction and in perigee. The sun is about at his mean distance (on the 21st there was a solar eclipse). All these conditions make for high tides and those graphed are the highest of the year. 


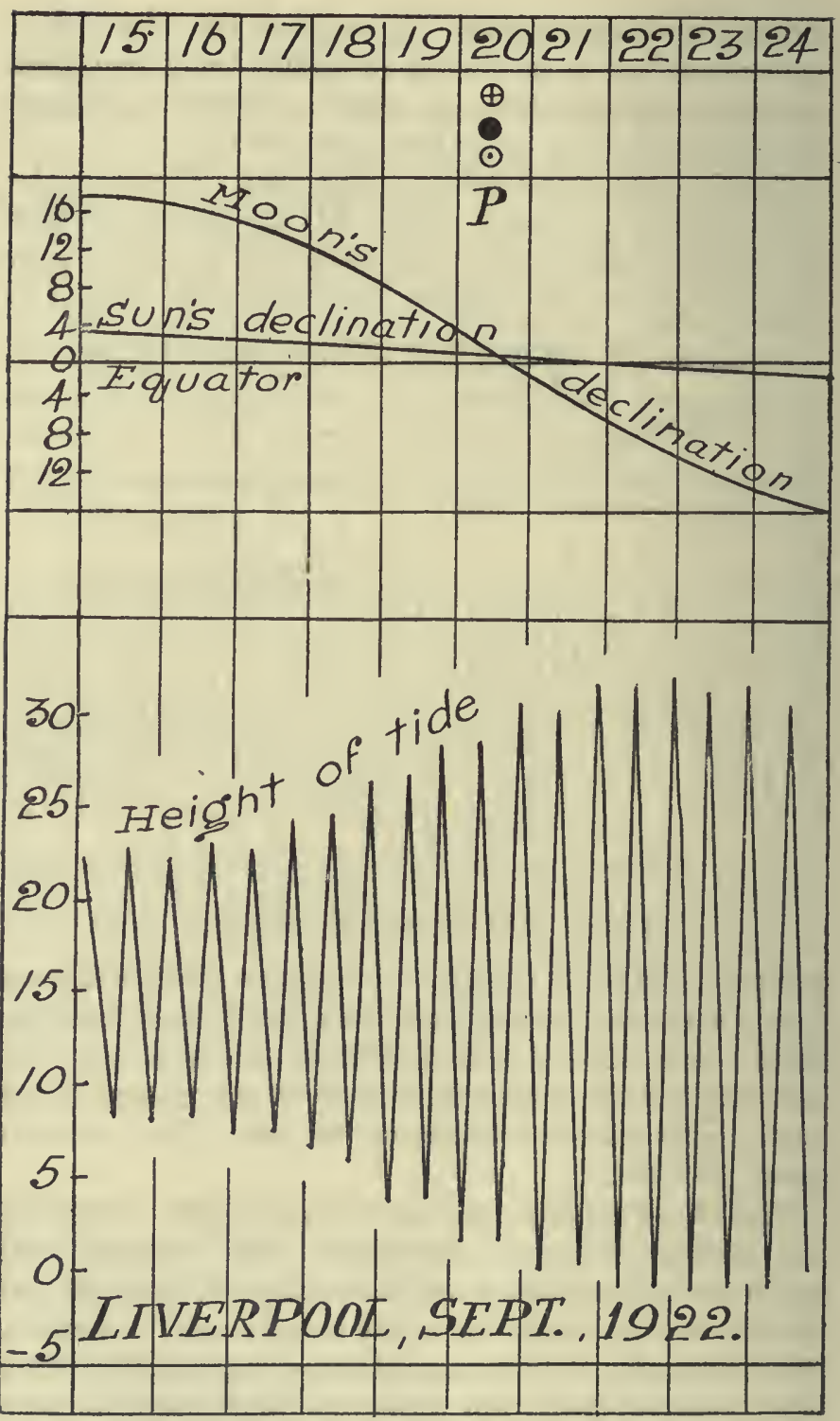

Fra. 43. Very high (equinoctial) spring tides. 
Application of the corrections. The approximate prediction, obtained by the method of pp. 226-34 are now compared with the actual records : there will be in each case, both a difference in the times and heights of high and low waters. This difference is the total correction which must be made to each prediction and it is due to all the seven factors mentioned on p. 235. Now by taking selected groups of tides it is found that, in each group the effect of each of the factors is different and, of course, in each of these cases the group of factors can be equated to a total value for the corrections. Thus we obtain a system of equations and by solving these a value of each factor can be found. The work is laborious and complicated, but not difficult and it involves a technique which is of interest only when one attempts the computations. It has been sufficiently indicated above.

(2) The harmonic method. Thus the periodic rise and fall of water level that we call the tide is considered to be due to a wave established by the sun and moon. This is an average wave and it is affected by a number of "inequalities." A value for each inequality is found empirically, and the average heights and times are corrected. accordingly. The method was developed during the 17 th and 18th centuries, and tide-tables for the ports of London and Liverpool were calculated by secret, or undivulged rules and were published by private individuals. Early in the 19th century the methods were studied by Whewell and Lubbock, and new tables, accompanied by a description of the modes of calculation, were published. It is incredible to read, in the works of Whewell, that the publication of these new tables "was resented as an infringement of the rights of property" though this is no more incredible than the proprietary status, at the present time, of other things which are public necessities. Towards the middle of the 19th century, however, an entirely new method of calculating tide tables was evolved from the work of Lord Kelvin, Sir George Darwin and others. 


\section{AN INTRODUCTION TO OCEANOGRAPHY}

This is the method of harmonic constituents and it is elegant in the extreme. To understand it we must remember that the tides are generated by the variable gravitational field established by the moon and sun, and that the intensity of this field can only vary because of the motions of the moon and sun relatively to the earth. These motions are absolutely periodic, are known with great accuracy and can be predicted. The configuration of the land and sea, and the depth of the latter, affect the progress of the tidal wave as well as its height, but these topographical conditions are invariable throughout any period of time that we need consider. By a study of the motions of the earth, moon and sun we can predict the variations in tide-generating force, and by an empirical study of the local tides we can find how they vary as the tide-generating force varies. There are certain aperiodic causes of variation in the heights of the tides and these we consider presently. Thus we find that a real tidal wave can be regarded as being made up of constituent waves. It is easier, however, to think about the matter in the following way.

Partial tides. The tidal wave is an undulation that is periodic. If we make a graph of the rise and fall of the water level at a certain place, and for a period of several years we can get a graph that repeats itself in time. (Here we neglect the very long periodic variations referred to in p. 217). A property of such a graph is that it can be decomposed into a number of partial waves, each of them absolutely periodic and having a certain (harmonic) form. The combination of these partial waves, that is, their algebraic summation, gives us the observed tidal undulation.

Thus the average tide referred to on p. 233 consists of two partials, one due to the moon and one to the sun. The period of the lunar partial tide is 12 hours 25 minutes and $14 \frac{1}{6}$ seconds, and the crests of the waves follow each other at exactly this interval. 
The period of the solar partial tide is exactly 12 hours and its crests follow each other at such intervals. At new and full moon the two bodies are together on the meridian and the crests of their tidal waves are together then, or at a certain fixed time afterwards. They reinforce each other so that the total tide is represented by $5+2$. At first and last lunar quarters the crest of the lunar partial wave coincides with the trough of the solar partial wave, and the total tide is now represented by $5-2$.

The tidal satellites. The following "fiction" also assists in understanding the process of harmonic analysis. The moon and sun move, not with an invariable orbit round the earth,* but in elliptical paths variously eccentric and variously inclined to the plane of the equinoctial. The variations are known and are precisely predictable. We can now replace the actual moon by a series of imaginary moons, each with a certain mass and orbit. The paths of these orbits are all precisely circular and either in the plane of the earth's equator, or in certain fixed planes parallel to the latter. The distance between the earth and each satellite is constant. Each satellite has a certain orbital speed and period and a certain phase. Acting together they will generate the same gravitational field as the actual moon does.

So also we replace the actual sun by a similar series of imaginary suns so chosen as to their masses, distances, orbits and phases of revolutionary paths as to set up exactly the same gravitational field as does the real sun. The advantage that all this additional complication gives us is that instead of a real moon and sun moving round the earth in paths that vary in disconcerting ways we now have a number of suns and moons round the earth in paths absolutely fixed and with constant periods, velocities and phases. At once they become amenable to mathematical treatment. * We regard the motions of sun and moon as explainable for the present
purpose, in this way.

R 


\section{AN INTRODUCTION TO OCEANOGRAPHY}

Tidal constituents. Each satellite, if it existed, would set up a tidal wave on an earth covered completely with ideal water to a certain ideal depth. This wave would be harmonic in form. It does not matter that the earth is as we know it, and that the water has friction, and that the depth of the ocean varies in a troublesome way. At any place these actual conditions retard and deform the waves due to the satellites, but the retardations and deformations are always the same. All the partial waves, set up by the tidal satellites combine to give us the resultant wave that we observe. We can now abandon our fiction of "tidal satellites" and think about the actual tidal wave as representing the effect of summation of a number of tidal constituents. There are various classes of the latter, and the most important ones are :-

(a) Semi-diurnal constituents.

$\mathrm{M}_{2}$, Principal lunar ;

$\mathrm{S}_{2}$, Principal solar;

$\mathrm{N}_{2}$, Larger lunar elliptical ;

$\mathrm{K}_{2}$, Luni-solar declinational ;

$\mathrm{V}_{2}$, Larger lunar evectional ;

$\mathrm{L}_{2}$, Smaller lunar elliptical ;

$\mathrm{T}_{2}$, Solar elliptical ;

$2 \mathrm{~N}_{2}$, Second order lunar elliptical ;

$\mu_{2}$, Lunar variational ;

$\lambda_{2}$, Smaller lunar evectional.

(b) Diurnal constituents.

$\mathrm{K}_{1}$, Luni-solar declinational ;

$\mathrm{O}_{1}$, Larger lunar declinational ;

$\mathrm{P}_{1}$, Larger solar declinational ;

$\mathrm{Q}_{1}$, Lunar elliptical ;

$\mathrm{J}_{1}$, Supplementary lunar elliptical ;

$\mathrm{OO}_{1}$, Second order lunar declinational ;

$\rho_{1}$, Lunar evectional ;

$2 Q_{1}$, Second order lunar elliptical ;

$\sigma_{1}$, Lunar variational. 
(c) Long period constituents.

Mf, Lunar fortnightly ;

MSf, Lunar fortnightly variational ;

Mm, Lunar monthly ;

Lunar monthly evectional ;

Three-monthly ;

Ssa, Solar semi-annual ;

$\mathrm{Sa}, \quad$ Solar annual ;

Nineteen-yearly.

(d) Other constituents applicable to shallow water.

All the constituents have periods that are accurately known and are deducible from astronomical constants. The semi-diurnals have periods of nearly half a day, and so on. The symbols $\mathrm{M}$ and $\mathrm{S}$ denote the application to the moon and sun respectively, and the suffixes 1,2, etc., indicate the periodicities.

Each constituent wave is of exactly harmonic formthis is absolutely necessary for the success of the predictions. Now an harmonic wave in deep water becomes nonharmonic in shallow water, that is, the front of the wave becomes steeper than the rear of the wave. But such a non-harmonic wave can be represented by the summation of two or more harmonic ones. If, then, the constituent $\mathbf{M}_{2}$ becomes non-harmonic in approaching a shallow water port it is replaced by the series of waves, $\mathrm{M}_{2}, \mathrm{M}_{3}, \mathrm{M}_{4}$ each of which is harmonic. $\mathrm{M}_{3}$ has twice the speed of $\mathrm{M}_{2}$, and $\mathbf{M}_{4}$ three times the speed of $\mathbf{M}_{2}$. Added together, with respect to phase, they make up a wave of non-harmonic form.

An example. A concrete example will enable the reader to visualise the process.

Here we have the complete wave that results from the algebraic summation of the constituent waves, $\mathrm{M}_{2}, \mathrm{~S}_{2}, \mathrm{~N}_{2}$, $\mathrm{K}_{1}, \mathrm{O}_{1}, \mathrm{~K}_{2}, \mathrm{P}_{1}, \mathrm{M}_{4}$ and $\mathrm{MS}_{4}$ (which is a compound of $\mathrm{M}_{2}$ and $S_{2}$ ). The mean line of each graph represents a height 
244 AN INTRODUCTION TO OCEANOGRAPHY

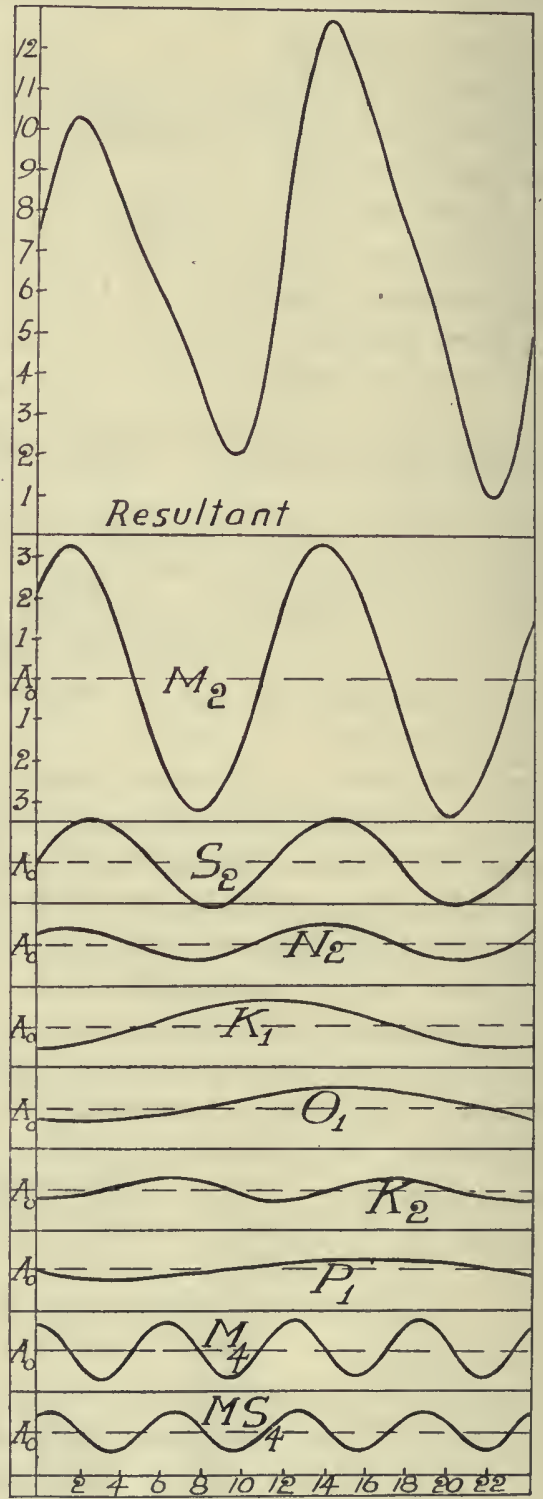

FIG. 44. 
above datum mark of 6.5 feet. To this are added, according to their signs, the ordinates of the other graphs. Thus we obtain the resultant, or predicted tidal undulation. The horizontal scale shows time, in solar hours, and the vertical one shows heights above and below the mean in feet.

The evaluation of the tidal constants : harmonic analysis. Each constituent is represented by a wave, or oscillation, which has an harmonic form. It can be put as a function of the time, thus:

$$
\text { Height of tide }=a \sin (b t+c) \text {. }
$$

Here there are three constants, $a, b$ and $c$. The amplitude of the wave, that is the distance it rises above, or sinks below its mean level, is defined by $a$. The period of the wave, that is, the time that elapses between every two complete oscillations, is defined by $b$. The initial phase of the wave, at zero time, is defined by $c$.

Now suppose there are only two tidal constituents in the whole tidal wave : the principal solar $\left(S_{2}\right)$ and principal lunar $\left(M_{2}\right)$ ones. At some one moment their high waters are coincident. In 12 hrs. 00 mins. 00 secs. the solar undulation again makes high water and this time (one half solar day) is its period. But not until 12 hrs. 25 mins. $16 \frac{1}{4}$ secs. will the lunar wave again make high water: thus there is a difference of phase of 25 mins. $16 \frac{1}{4}$ secs. between the two constituents. Also the lunar wave will rise to a height of (say) $5 h$ feet above sea level ( $h$ depending on the locality) whereas the solar one will only rise to a height of about $2 h$ feet. These maximum heights of the waves are their amplitudes.

The periods of the constituents are found from astronomical theory. Thus the mean sun is in the same position, with respect to some one place on the earth every 24 hours, but the mean moon comes back to the same position after 24 hours 50 mins. $32 \frac{1}{2}$ secs. Thus we get the periods of the tidal constituents by a priori reasoning, but the amplitudes and phase must be found a posteriori 


\section{AN INTRODUCTION TO OCEANOGRAPHY}

by analyses of the recorded tidal data for the place in question. The actual work is highly complex, but the principles involved are fairly easy to understand.

Assume, then, that the whole tidal undulation is made up of the two partial waves, $M_{2}$ and $S_{2}$. It may be simpler if the reader visualises the matter and thinks of the tide as being set up by $M_{2}$, which is an imaginary satellite revolving round the earth in the period of $24 \mathrm{hrs}$. 50 mins. $32 \frac{1}{2}$ secs., and $S_{2}$, which makes a similar revolution in $24 \mathrm{hrs} .00$ mins. 00 secs. There are, of course, two tides for each satellite.

If only $S_{2}$ existed the tide would recur every $12 \mathrm{hrs}$. exactly, and if only $M_{2}$ existed the tide would recur every 12 hrs. 25 mins. $16 \frac{1}{4}$ secs. As it is, however, the real tide is due to both $M_{2}$ and $S_{2}$, and the records of the tidal gauge, therefore, contain the effects due to the two gravitational fields. We have to disentangle them. It is assumed, of course, that there are absolutely no other causes of variability, in the tides, than those due to $M_{2}$ and $S_{2}$.

In the graph (Fig. 44a) the horizontal scale represents hours of solar time, and the vertical scale represents the heights of the two constituent tides, $M_{2}$ and $S_{2}$. Time and tide, so far as $S_{2}$ is concerned are one, for whatever makes solar time also makes solar tides. At any given moment on any number of days then, say 12 hrs. 00 mins. 00 secs the height of $S_{2}$ will always be the same. Graph 44a (A) is that of a whole series of tides occurring on the 1st, 2nd, 3 rd-15th days, say. Since there are two tides in each day there must be 30 graphs in the figure, but they all superpose exactly on each other to make one curve. High water, low water, mean tide, \&c., are always the same from day to day-the same heights and the same times of occurrence.

Fig. 44a (B) represents the corresponding series of tides due to $M_{2}$. Now this constituent has the period of $12 \mathrm{hrs}$. 25 mins. $16 \frac{1}{4}$ secs., so that when it is graphed on the same 
horizontal scale (of solar hours) as that of $A$ the individual $M_{2}$ tides will not superpose. Every high water will be about half an hour later in the solar day than the preceding one. The vertical line $a-b$ in the two graphs represents an arbitrary moment of solar time when we measure the height of the resultant tide, as it is given by the gauge records. Theory shows that the part of the tide due to $S_{2}$ will be exactly the same from day to day. So if we knew the parts due to $S_{2}$ on the 30 half days and summed them and took the average, we should get a certain height. Now notice that the line $a-b$ cuts a series of about 14 curves, each representing a lunar tide occurring a.m. and $p . m$. on the first day, a.m. and p.m. on the second day and so on. If we could find and sum these 14 heights and then take the average we should find that about 7 of them were above the mean and 7 were below the mean, and their average would be zero (approximately). Thus the summation and averaging of the $S_{2}$-tides as given by their heights at the same hour on each of a number of days will give us a certain height, that of $S_{2}$ at that hour. But the summation and averaging of the $M_{2}$ tides, at the same hour, on each of the same number of days will give us mean sea level.

This will evidently be the case whatever hour during the solar day we take. Draw a number of vertical lines on the graphs so that they represent 12 noon, 1, 2, 3, 11 o'clock and so on, and then measure the heights on the graphs. In every case the average for $M_{2}$ will be zero, while the average for $S_{2}$ will be the point on the A graph cut by the vertical time-line.

We cannot, of course, isolate the $S_{2}$-tide from the resultant graph given by the tidal gauge and treat it separately from the $M_{2}$-tide. But in the summing and averaging of the heights of the resultant tide, at the same moment of solar time, on a number of days we really do what has been imagined above. All the $M_{2}$ parts average out leaving mean sea level, while all the $S_{2}$ parts remain 


\section{AN INTRODUCTION TO OCEANOGRAPHY}

(all positive or all negative, or all zero, as the case may be) thus giving us the height of the tide due to $S_{2}$ above or below mean sea level. We have actually eliminated $M_{2}$ and left $S_{2}$.

The principle of harmonic analysis should he clear from this discussion. There are a number of constituents, $M_{2}$,

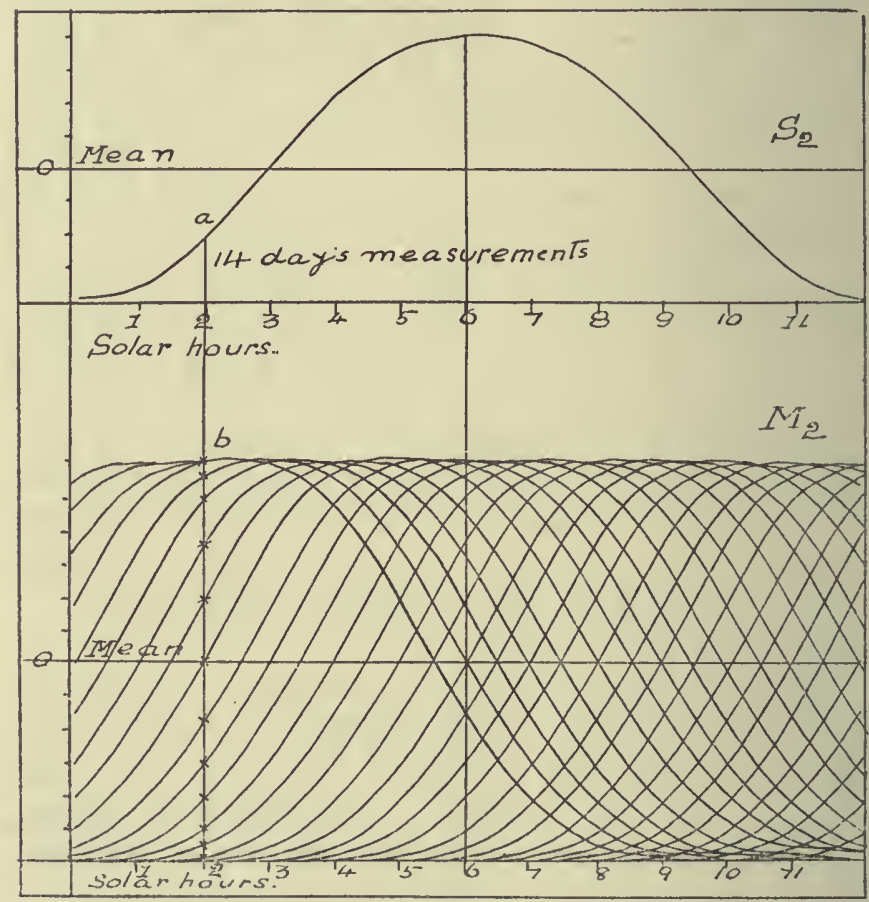

Fic. 44a.

$S_{2}, N_{2}$, \&c. All of them have different periods and all of them contribute to the resultant tide. We take them one by one. We take the solar day of 24 hours and then measure the height of the tide at (say) 12 noon on a great number of days, 1 p.m. on the same days, 2 p.m. on the same days and so on. We sum and average and are left with the height due to $S_{2}$ at (say) 12 noon. $M_{2}, N_{2}$, \&c. 
have been eliminated. We then take the lunar day of 24 hrs. 50 mins. 321 secs. and divide this into 24 lunar hours, each a little bit bigger than a solar hour, observe the heights of the tide at 12 noon, 1 p.m., 2 p.m., \&c., lunar hours, sum and average as before. This gives us the height of the tide due to $M_{2}$ and $S_{2}, N_{2}$, \&c., have been eliminated. Then we find an $N_{2}$ day, each hour of which differs from both the solar and lunar days, and we go through the same process, eliminating $M_{2}$ and $S_{2}$. We do this for each of the 30 or so constituents of the whole observed tide.

Also it is done for each hour in the particular kind of day. Thus we find the rise and fall of the tide throughout a complete period for each constituent.

Now note that the actual, practical methods of harmonic analysis are rather different from that indicated above (which would be impracticable because of the labour involved). Very beautiful methods were evolved by Sir George Darwin (and those who followed him) for shortening the labour of computation. Still more fastidious methods have been developed by the Liverpool investigators so that the process of harmonic analysis is now made very complete and accurate by ingenious artifices.

Harmonic synthesis. Thus we get a number of tidal constituents (30 or thereabout in some cases). From 10 to 30 perhaps may be necessary for tidal prediction by harmonic methods. Each constituent is a cosine function of the form given on p. 245. Calculation enables us to find the constants $a, b$, and $c$, and then solving the equations for the various constituents, for each hour (say) of the day we find the partial tides. (We can now dispense with the fiction of the tidal satellites). The work of analysis is done, once and for all for any particular port and is usually based on several years observations of the gauge records. The calculation of the times and heights of each partial tide must be made anew for each year. Summing all the partial tides we get their resultant-the predicted tide. 


\section{AN INTRODUCTION TO OCEANOGRAPHY}

Combine this with the labour of the harmonic analysis and the task of computation becomes prodigious. Compared with it the auditing of the accounts of the South African war-which, it is said, has not yet been completed owing to the meagre staff of clerks at the War Office-is as nothing! However the harmonic analysis can be greatly shortened as we have said, and the synthesis can be carried out by very beautiful machines which automatically sum the partial heights and record the results on a clock face, or as a graph. The machines can take up to about 30 constituents. They are "set" for the pairs of constants applying to each constituent. The machine is then actuated, when it writes a graph of the tides for the whole year, showing against a scale of time the height of the sea level from moment to moment. The graph is then measured and the times of the heights of its maxima and minima give the high and low waters of each day.

The tides as marine agencies. - The effects of the tidal streams, in co-operation with wave action in the erosion of the coast line have been referred to in Chapter V. The variations in height are of immense significance on those coasts where the tidal range is significant, for it means that a vertical distance of (say) some ten to twenty feet is daily exposed to disintegrative marine agencies. Further the flooding of extensive estuarine areas at high water adds enormously to the extent of coast exposed to marine agencies : the general tendency of tidal action in estuaries must be to accelerate the gradual planing down of the land, and the formation of submarine flats by attacking the land from the inside, so to speak.

Obviously the distributing effect of the tidal streams on eroded material is no less important. From the biological point of view the effect is no less significant. The tidal streams do not exactly reverse their directions when they turn (as Fig. 31 indicates), and there must always be some amount of residual drift in sea areas where the streams 
run strongly. The result of this is a gradual transference of water in a definite direction, and this leads to the wide distribution of the planktonic stages of demersal and nektonic animals and plants. It has an effect also on the distribution of the temperature and salinity of the sea and these conditions are of the highest importance as ecological agencies.

The effects of long-periodic variations in the tide-generating force. These we have already referred to in pp. 217-9. Take the maximum generating potential to be represented by 100 , then the variability can never be greater than about $6 \%$ and is less than this in any constellation considered above. Even such a variability in the potential must have had large effects in altering the tidal range, and so the velocities of the tidal streams. This has led to effects of the greatest significance in regard to the climate of Northern Europe: such effects have been traced by Pettersson.

The general tendency of the movement of the water of the North Atlantic is, we shall see, from South-West to North-East. Coming, then, from regions of higher temperature and salinity (because of increased solar radiation and evaporation) the north-easterly drift must transfer heat from South-West to North-East. This heat is conveyed by ocean drifts on the surface, in the temperate zones but by undercurrents in the more northerly zones, since as the water cools it must increase in density and so sink beneath the surface and continue to flow in the same general direction as an intermediate or bottom current. The original impetus which sets the water in motion we shall consider in the next chapter, but it may be noted here that it will be increased, or maintained, by the resultant tidal drift and this will be increased again by an increase in the tidal range.

Therefore, in those periods of increased tide-generating force the quantity of heat transferred to high northern latitudes must have been greater than when the generating 


\section{AN INTRODUCTION TO OCEANOGRAPHY}

force had average values. The relatively warm and dense surface currents must have gone further north before they lost sufficient heat to cause them to sink and flow on as bottom currents. Therefore polar ice must have melted at a rather higher latitude then than it does now. There must have been a greater disintegration of the pack ice that fringes the polar sea area and a greater dispersal south of hergs by the southerly flowing cold currents. Floating ice must have been relatively abundant in northern temperate latitudes compared with the present time. Even now the limits of this distribution are variable to a significant degree (from the point of view of navigation).

Connected with the more vigorous water circulation there were probably differences in the general distribution of atmospheric pressure leading to more violent storms than at the present. time. Occurring at times of high water of the increased tidal ranges there must, therefore, have been extensive tidal inundations on low lying coasts. In such conditions (about 1287) the North Sea transgressed on the Netherlands, breaking down the dykes and forming the present Zuider Zee from a previous lake.

In the Baltic exceptional conditions obtained during periods of higher tides. At the present time the undercurrent of relatively warm and dense Atlantic water that flows in through the Skagerak is not very thick, though even now tidal waves in this lower, denser and warmer current are easily detected. In times of high tidegenerating force the depth of the undercurrent must have been greater, that is, it was nearer to the surface and so the upper, nearly fresh layers of the Baltic in the region of the Belts and Sound became thinner and lost their heat more readily during the winters. During these seasons in the 13th, 14th and 15th (but not in the 16th) centuries, the Baltic between Denmark, Germany, Sweden, Gothland and Esthonia was frequently frozen over. 


\section{THE TIDES}

Finally the increased tide-generating force had also its effects on regions of earth-instability. There is evidence that Iceland was nearly free from volcanic eruptions and earthquakes during the period 800 to 1250 , but that such phenomena were relatively frequent during the period 1291 to 1348. 


\section{CHAPTER IX}

\section{THE OCEANIC CIRCULATION}

Thus we have (1) a periodic change in sea level and (2) a periodic streaming backwards and forwards of the water : these are the tidal movements, and they represent the responses of the hydrosphere to periodic change in the gravitational field generated by the moon and sun. They are complicated to a remarkable degree by the change of depth of the ocean and by the irregular distribution of land and sea.

In addition to them we have currents and drifts. "Currents," in the older sense of the term, are movements. of the water of the ocean that are of importance in navigation and which, like the tidal streams, must always be allowed for in fixing the position of a ship. "Drifts" are slow movements of large bodies of water which are, as a rule, imperceptible to seamen in the ordinary routine of working a ship. The currents have velocities that are of the same order of magnitude as those of the tidal streams, or even of the flow of the great rivers. The Gulf stream has velocities of from 1 to 5 knots; the Japanese stream flows at the rates of 2 to $3 \mathrm{knots}$, and the Agulhas current has a velocity of about 2 knots. Drifts are much slower: thus the North Atlantic Gulf stream Drift moves at about the rate of 10 miles per day while the creep of water along the sea bottom from the temperate regions towards the equatorial zone is slower still. Currents can be detected by direct measurements (see p. 298), while the movements of drifts are usually deduced by observations of surface or bottom floats set free and found again after some considerable time, or by observations on the salinity and temperature of the water. 
The general scheme of oceanic circulation.-The primary causes of oceanic circulation are everywhere the same, and so we have a general scheme that applies to each of the great oceans: the North and South Atlantics, the North and South Pacifics and the Indian Ocean. The Arctic and Antarctic Oceans are not included in this general scheme.

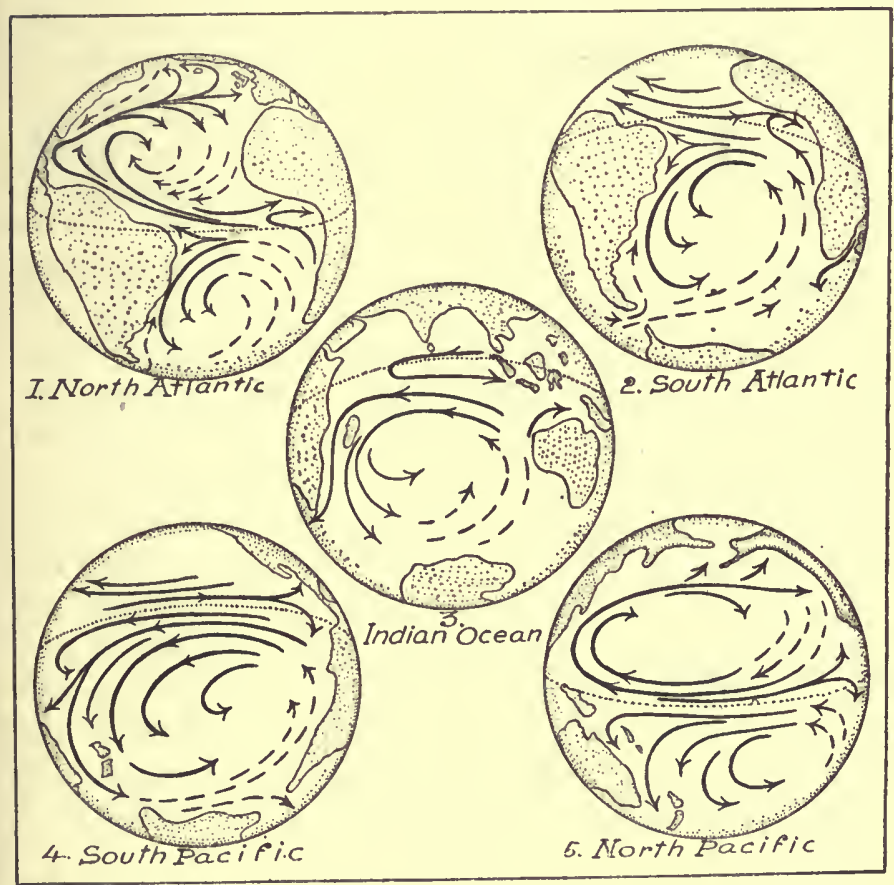

FIg. 45. Diagrams of the main current systems in the North Atlantic, the South Atlantic, the North Pacific, the South Pacific and the Indian Ocean. The drawings have been made from photographs of a marked globe.

Plainly there is a general scheme of circulation in each case. The origin of the movement is the flow of water along the equatorial zones from East to West-that is the great equatorial streams. In the northern hemisphere the current turns to the north, and in the southern to the south. 


\section{AN INTRODUCTION TO OCEANOGRAPHY}

In each case there is a single or double closed circulation or eddy, such that in the north the direction of flow changes continually towards the right hand side, while in the south the turning movement is towards the left. "Right" and "left " are the directions apparent to an observer swimming with the current. This deflection to the right or left is due to the force exerted by the earth's rotation on bodies free to move on its surface. Between the north and south equatorial streams, there is a smaller counter-equatorial stream flowing from West to East. From each main eddy a drift takes origin, flowing to the North-East, in the northern hemisphere, and to the South-East in the southern one.

These latter drifts tend to enter the Arctic and Antaretic Oceans from the North Atlantic and Pacific on the one hand, and from the South Atlantic and Pacific on the other. At the same time water flows South from the Arctic Ocean and North from the Antarctic, into the North Atlantic, and South Pacific respectively. These latter drifts are deflected towards the west in both cases, that is, towards the right hand side in the northern hemisphere, and towards the left hand side in the South. In the North, and in each of the two oceans (N. Atlantic and Pacific) the water turns round in the direction of the hands of a clock. In the South, in the S. Atlantic, S. Pacific and Indian Ocean the water turns round in the opposite direction to that of the hands of a clock.

Thus there is a general symmetry in all cases, but this is modified locally and seasonally to a notable degree by the configuration of land and sea, by the variations in depth of the ocean and by the seasonal changes of the winds. Further each of the great oceanic eddies shifts North and South as a whole during the year in consequence of the annual change in the sun's declination. This general scheme we shall study in detail later, noting how it is modified. 
The general cause of oceanic circulation.--It will help the reader if we consider first the circulation that would exist if the earth were covered with water everywhere to a uniform depth ; if it were devoid of rotational movement and if the sun were to revolve round it, in the celestial equator and with the apparent velocity that we observe.

In such conditions the water of the ocean would be strongly heated in the equatorial region; the quantity of heat received per unit area would diminish towards the North and South (being a function of the latitude) and would be minimal at the pole. The strongly-heated surface water near the equator would expand and become less dense, and a difference in sea level would tend to become established. Therefore there would be a surface flow everywhere from the equator towards the temperate latitudes in the north and south hemispheres.

At the same time the water would be evaporated to some extent and so its salinity would increase. This would tend to make it denser but the heating effect would prevail, and so the northerly and southerly flowing water would be less dense (because of its high temperature), although it would really be more saline. But since it flows into regions of lower air temperature it would lose heat by radiation and so, at some intermediate latitude (say $50^{\circ}$ to $60^{\circ}$ ), it would fall to the temperature of the water in situ. But being more saline than the latter it would become more dense and would, therefore, sink towards the sea bottom. Thus we have a surface flow North and South from the equator and then a downward movement towards the sea bottom as an undercurrent.

The evaporation at the equatorial zone would, however, add large quantities of water vapour to the atmosphere and this would be a continual process. It would be compensated by an equal amount of precipitation of this water vapour upon the surface of the sea as rain or snow. Much of this precipitation would take place in the regions roind the poles. There would be a very low temperature 


\section{AN INTRODUCTION TO OCEANOGRAPHY}

there, and so the precipitated rain and snow would accumulate to form the polar ice-caps. This process, like that of the excessive evaporation in the equatorial regions, would be a continual one. The ice caps would tend always to extend to south and north, breaking away as icebergs which' would, of necessity, drift outwards from their places of formation into the sub-polar seas. There they would slowly melt.

This melted ice would form water that would be less saline than that of the sea round it. Because of its lower salinity it would tend to be less dense, but because of its low temperature it would tend to be more dense. As it drifted towards temperate latitudes it would mix with the more highly saline water in situ and so it would become denser (because of its retained low temperature). It would, therefore, sink towards the bottom at some intermediate latitude and would continue to flow on in some direction as an undercurrent.

The general features of these undercirculations must also be noted. In the act of freezing, sea water becomes denser, because a certain mass of sea ice contains less salts than an equal mass of the sea water before freezing. Therefore the "mother liquor" in which the sea ice is formed becomes denser (by reason of its higher salinity) and so sinks towards the bottom. At the poles, then, there would be a downward movement of water from surface to bottom. This would lead to a slow drift outwards in all directions from the poles along the sea bottom radially towards the equator.

In equatorial zones the surface water becomes lighter and flows along the surface towards temperate latitudes. Cold water from the lower levels must, therefore, rise up to take the place of that which has drifted away to north and south, and thus the surface layers would be fed from the bottom. Therefore there would be a slow drift, along the sea bottom, of water from the temperate zones, towards the equator. 
Now so much can be deduced from first principles, but the further study of these water movements by means of hydrodynamical methods may be indicated, though the mathematical reasoning cannot be reproduced. At any depth in the sea the pressure on any small element of surface can be found from the depth itself and the coefficient of compressibility of sea water. All points subject to the same pressure lie on an isobaric surface and, in general, the isobaric surfaces are parallel to the sea level. The isobars increase, of course, in value from above downwards. As the pressure increases so the specific volume, that is, the volume of unit mass of sea water, decreases

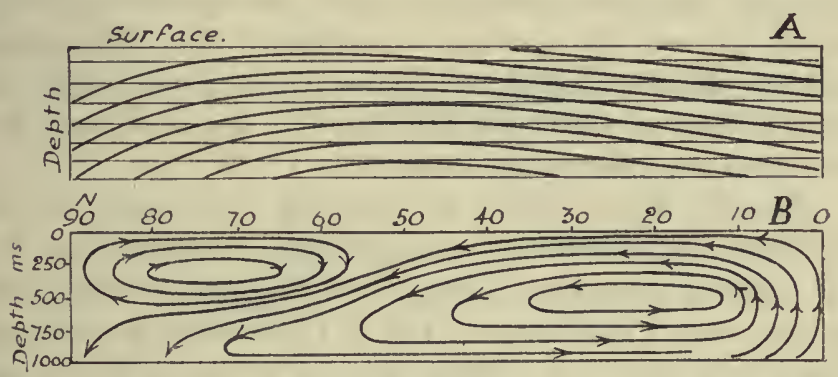

FiG. 46. (a) Part of a meridianal section of the ocean showing the isobaric surfaces (thin lines) the isosteric surface (thick lines) and the sections of the enclosed solenoids; $(b)$ A meridianal section between $0^{\circ}$ and $90^{\circ}$ (shown on the flat) with the deduced directions of water circulation.

(because of the compressibility). All points where the specific volume has the same value lie on an isosteric surface, and if the temperature of the sea were everywhere the same these isosteric surfaces would also be parallel to the sea level. The temperature, however, decreases from the surface towards the bottom and from the equator towards the poles (in the upper layers). Therefore the isosteres will not be parallel to the isobars, but the two systems of surface will cut each other as indicated in Fig. $46 \mathrm{~A}$, which represents a vertical section of the ocean in a meridianal plane. Where the surfaces cut each other 
they enclose prismatic blocks of water: these are called solenoids and they are seen in section in Fig. $46 \mathrm{~A}$. Now the further study of the subject will show that, given this distribution of isobaric surfaces, the movements of the water particles can be deduced. Further than this it is impossible to go here and we only note that a circulation such as is represented in Fig. $46 \mathrm{~B}$, can be deduced entirely a priori, given only the distribution of pressure and tiemperature.

Here we see the water rising vertically from the bottom towards the surface, then streaming along the surface towards the pole and sinking down in latitude 40-50. At the pole the water streams towards the equator and sinks down towards the bottom at latitude $60-50$. From these intermediate latitudes the water then streams along the sea bottom towards the equator, on the one hand and towards the pole on the other.

Ferrell's Iaw.-Next we consider the earth as still covered everywhere to a uniform depth by the ocean, but as rotating on its axis from West to East with a period of one day. The effect of this is to establish a deflecting force such that any particle free to move on the surface tends always to be deflected towards the right in the northern hemisphere, and towards the left in the South. The deflecting force is a function of the latitude, is maximal at the poles and is zero at the equator. It cannot set in motion a particle at rest and can only deflect particles that are already in motion.

I.-A particle moving eastwards on the earth's surface. The earth turns from W. to E. so that the centrifugal force on the particle $d$ is exerted in the plane of the circle in which the particle rotates, that is, the parallel of latitude ed. This force is represented in direction and magnitude by $d b$. At the same time there is a centripetal force due to gravitation and acting towards the earth's centre. This is represented by ad. Complete the parallelogram of forces and we get $d c$ as the component along the meridian 
$N E$. When the particle is at rest this component balances the poleward force (due to the tendency of the particle to move to a position nearest to the earth's centre. When, however, the particle moves to the East its motion is that of the motion of a point on the earth's surface, the proper motion of the particle. The centrifugal force $d a$, therefore, increases and with this the component $d c$. The poleward component remains the same and so the particle $d$ moves towards the equator along the meridian $N E$, that is, to the right.

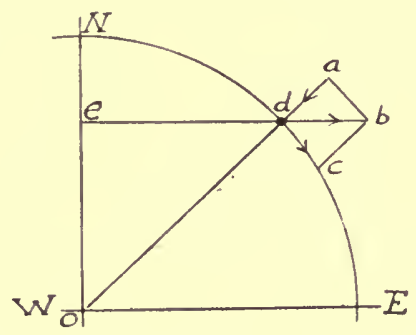

FIG. 47.

II.-A particle moving to the West. With the construction of Fig. 47 it is easily seen that the resultant velocity of the particle is the earth's velocity at the point in question minus the proper motion of the particle. Since the velocity of the particle is now less than it was relative to the velocity of the earth beneath it, its centrifugal force must decrease and, therefore, the poleward force is unbalanced and the particle moves towards the North along the meridian $E N$, that is, to the right.

(If the direction is between $\mathbf{E}$. and $\mathbf{N}$. there is an easterly component. If between $\mathrm{W}$. and $\mathrm{N}$. there is a westerly component. These components are treated in just the same way.) 


\section{2}

\section{AN INTRODUCTION TO OCEANOGRAPHY}

III.-A particle moving to the South. Fig. 48. Let the particle be at $a$ and have a proper motion to the South on the earth's surface, that is, along the meridian $N M$. First regard it as at rest at $a$, thus it has the velocity of a point on the earth's surface in that latitude. Let it now be given an impulse towards $b$ : obviously it will move South still preserving the same easterly velocity conferred on it at $a$ by the earth. But at latitude $o^{\prime} b$ the velocity of a point on the earth's surface is greater than at latitude oa and so the particle will move more slowly, relatively to the earth beneath it. Therefore it will lag behind the earth and so move to the West, that is to the right.

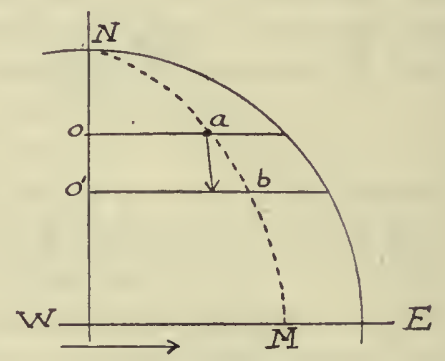

FIG. 48.

IV.-A particle moving to the North. Simply reverse the above construction. The particle will move to the East as it passes from latitude $o^{\prime} b$ to latitude $o a$. That is, it will move to the right. The above proofs apply to motion in the northern hemisphere. Reversing them we get the demonstration that deflection to the left occurs when a particle, free to move, changes its position on the surface of the earth in the south hemisphere. It is assumed that there is no friction between the moving particle and the earth but, of course, there is. Even when the friction is considered the deflecting force is still great enough to be a factor in the movements of water and air currents. 
Effect of the earth's rotation.-We can now replace the simplified scheme indicated above by one which still assumes an earth covered everywhere by water to a uniform depth but which rotates on its axis. The effect will be that water no longer flows North and South from the equator but to the North-East, in the northern hemisphere (that is, to the right) and to the South-East in the southern hemisphere (that is to the left). Also the currents flowing southerly from the north pole will turn to the right, that is, they will flow to the South-West. Those flowing northerly from the south pole will turn to the left, or will flow to the North-West.

The movements are, of course, continuous, that is, the right or left-hand deflection is experienced at all parts of the course of the currents. The latter will, therefore, flow in great eddies turning back on themselves and sinking beneath the surface as indicated on p. 258 . We should thus have two systems of eddies in the northern hemisphere. (1) The water flowing from the equator: this would gradually turn round to the East and then back to the South as it sinks towards the sea hottom. (2) The water flowing from the pole: this would gradually turn round to the West and then back again to the North as it, too, sank beneath the surface. A similar, but reversed circulation would be established in the southern hemisphere.

The currents as they are.-The modifications of this theoretical scheme must next be considered and we have to see in what ways it is changed by the winds; the distribution of land and ocean; the variations in depth of water; the temperature (as affected by the land) and the salinity (as affected by the drainage of fresh water into the sea. It is to be noted that, even when all these modifying factors have been given due weight, the theoretical scheme, as outlined above, can still be recognised.

The winds. Wind blowing along the surface of the sea exercises a very considerable force and this can be seen 


\section{AN INTRODUCTION TO, OCEANOGRAPHY}

at its maximum in the formation of spindrift, that is, spray whipped off trom the crests of waves and carried by a strong gale. There are certain permanent features of the atmospheric circulation that are of importance in our study of ocean currents. To the North of the equator, between latitudes about $30^{\circ} \mathrm{N}$ to $10^{\circ} \mathrm{N}$ we have the northeasterly trade winds. These blow strongly throughout the year. To the South of the equator and between latitudes about $20^{\circ} \mathrm{S}$. and $0^{\circ}$, there are the south-easterly trade winds and these also blow strongly throughout the year. Between the two belts of trade winds is the region of equatorial calms and rains. North from the north-east trades is the belt of south-westerly winds : this is between about $40^{\circ}$ and $60^{\circ}$ N. Lat. in the Atlantic and Pacific. South from the south-east trades is the belt of "brave west winds" extending also from about $40^{\circ}$ to $60^{\circ} \mathrm{S}$. Lat. and encircling the earth in the southern ocean.

The effects of these permanent winds is to modify the theoretical directions of the ocean currents to a remarkable degree. The trades blowing always from the North-East and South-East, and thus converging on the equatorial zone drive the water before them so that the direction of the theoretical currents from the equatorial belt becomes changed from North and South to due West. Thus we have the two (North and South) equatorial currents in each of the three great oceans and these are by far the most prominent features of the oceanic circulation. Water which rises from the depth is driven along the surface of the sea from East to West by the trade winds. There is, of course, the continual tendency for this westerly current to be deflected to the right (in the North) and to the left (in the South), but this is completely obscured by the powerful effects of the winds. Thus warm, highly saline water is driven up against the East coasts of Central and Northern South America; against the East side of the Austral-Asian islands and against the East coast of Africa. 
The circulations in the North Atlantic and North Pacific are also dominated by the great south-westerly wind currents. In the Atlantic we thus have the very prominent Atlantic European Stream, or Gulf Stream Drift, flowing: across from the North-West Atlantic towards northern Europe with its main axis cutting the 45th parallel at a small angle. In the Pacific we have the West Wind Pacific Drift flowing over towards California from the Japanese Islands and having its axis also near the 45th parallel. Nothing of the kind exists in the northern part of the Indian Ocean, where the oceanic circulation depends almost entirely on the seasonal monsoons, generated by the extraordinary powerful heating and cooling effect on the atmosphere of the great Asiatic land mass.

In the Southern Ocean the wind effect is even more strikingly exhibited. The brave west winds blowing on the average with considerable force propel the surface water of the Southern Ocean always from West to East, thus forming the Southern West Wind Drift round the whole earth. But, impinging on the toe of South America, this cold southern water creeps up the Pacific coast as far as Peru; deflected to the North (that is, to the left) the West Wind Drift flows up along West Africa as the Benguela current and, similarly deflected in the South Indian Ocean, it runs up North as the West Australian Drift. But the main part of the great Southern West Wind Drift encircles the globe.

The effect of the land.-Land masses interposed in the course of a current or drift thus divert the latter. So the water driven along by the equatorial streams piles itself up against the eastern continental shores and sets up actual differences of sea level. Thus the level of the Gulf of Mexico is raised significantly by the water of the Atlantic Equatorial Stream entering it through the Islands of the Antilles and the consequence is the rapid Gulf stream that issues via the Straits of Florida. Much the same thing happens in the Pacific, where the Japanese Current is the 


\section{AN INTRODUCTION TO OCEANOGRAPHY}

analogue of the Atlantic Gulf Stream. But even then the excess of water driven along by the trades is not wholly distributed, and all along the axis of the North and South equatorial currents in each of the three oceans there is a counter-equatorial current. That is (as shown in Figs. 51-53), some of the water flowing West recurves inwards towards the axis of the North and South streams and flows back to the East. This occurs in the region of the Equatorial Calms where there is heavy rainfall and so the counter streams are warm and less saline than is the water to the immediate North and South. These examples show the effect of land barriers on the great scale, but everywhere the same effect may be observed in localised conditions. Some of these smaller deviations will be noted later in this chapter.

The effects of variations in depth. Just the same mechanical obstructions act when the sea bottom shallows. All currents tend to flow along regions of sea where the depth is maximal and a shoaling, up to, say, 100 fathoms from the surface, offers a very considerable impediment to the flow of the current. Thus the Gulf Stream Drift flows freely across the Atlantic towards the coasts of North East Europe and then further to the North East along the West of the British Islands. But towards the North of Scotland the sea bottom shallows and an actual submarine barrier to the unimpeded drift is established by the extension of the Continental Shelf between the Shetland Islands and Iceland. At only one place is the sea deep enough to allow of a notable current to the NorthEast, that is in the Channel between the Shetland and the Faeroe Islands. Here, however, the shoaling restricts the north-easterly drift to the upper layers of the ocean and leads to a very remarkable distribution of bottom temperature.

This well-known submarine barrier is represented in Fig. 49. On the Atlantic side there are depths in the neighbourhood of 2,000 metres, and on the Norwegian Sea 
side the depth falls more rapidly to about 1,000 metres. The water which is flowing, with the Atlantic Stream, over the ridge has a temperature of $8^{\circ} \mathrm{C}$. at a depth of about 600 metres, and the temperature at a depth of 1,000 to 1,200 metres in the Atlantic is about $7^{\circ}$ to $8^{\circ} \mathrm{C}$. But the onflow of water is checked by the barrier so that, while there are still temperatures of $8^{\circ}$ to $9^{\circ}$ on the surface in the Norwegian Sea adjacent to the Ridge, the bottom water is not affected by the North-Easterly Stream and so we find temperatures of $0^{\circ} \mathrm{C}$. to $3^{\circ} \mathrm{C}$. at depths of 1,000 to 1,100 metres on the northern side of the Ridge.

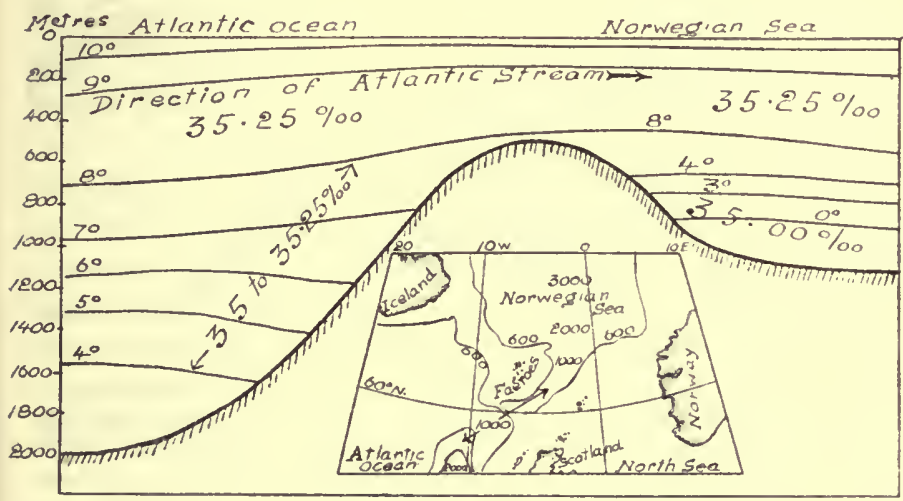

FIG. 49. A diagrammatic section across the Wyville-Thompson (Shetland-Faeroe) Ridge. The horizontal scale is much smaller that the vertical one. The inset is a sketch chart of the area. The soundings are in metres.

The effect of changes of salinity.-The enclosed, or partially enclosed seas are of two main types: (1) Those in which the temperature is high and where there is much evaporation. Here the salinity tends to be higher than the value which is normal for the zone of latitude in which the sea is situated. Examples are the Roman Mediterranean and the Gulf of Mexico, and a glance at Fig. 22 will show that the salinity in these areas is markedly greater than in the adjacent Atlantic. (2) Those in which 


\section{AN INTRODUCTION TO OCEANOGRAPHY}

there is much precipitation (rain or snow) or where large volumes of fresh water enter from the land via rivers. Here the salinity tends to be lower than that normal to the adjacent ocean. Examples are the Baltic and the Arctic Ocean.

In such cases current systems are set up. Thus Atlantic water flows into the Roman Mediterranean on the surface, through the Straits of Gibraltar, because evaporation tends to lower the level and there is an inward flow of water to compensate this.

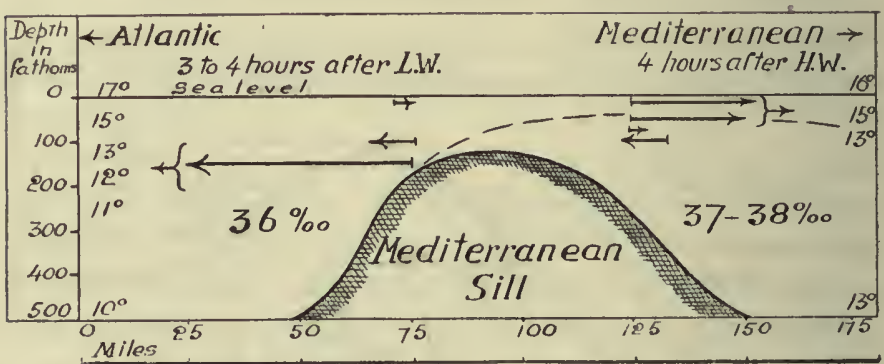

Fig. 50. A diagrammatic vertical section of the sea in the Straits of Gibraltar. The vertical scale is very much greater than the horizontal one. The line at the bottom represents, by its variable thickness something of the order of the natural scale-the horizontal and vertical ones being the same.

The western basin of the Mediterranean, that is, the sea to the West of the Italian Peninsula has an average depth of about 2,000 fathoms; its temperature, on the surface, is about $19^{\circ}$ to $21^{\circ} \mathrm{C}$, and the salinity is mostly between $37 \%$ and $38 \%$. The water is thus relatively warm and salt because of the high air temperature, much evaporation, and a limited supply of fresh water from great rivers. On the outside the Atlantic has a depth of 2,000 fathoms at 200 miles from Gibraltar; the temperature on the surface is about $17^{\circ} \mathrm{C}$. (the average for the year) and the salinity is seldom higher than $36 \%$. 
The Mediterranean communicates with the Atlantic through the Straits of Gibraltar. Here the least width between the European and African shores is about 8 miles. The average depth in the straits is about 350 fathoms and the least depth is about 250 fathoms. At a distance of about 50 miles on either side from the shallowest part of the straits the depth is about 500 fathoms. In the straits, then, we have a " sill " separating the two basins, Atlantic and Mediterranean. The former is about 2,000 to 3,000 fathoms, and the latter about 2,000 fathoms in depth.

Because of the much greater evaporation in the Mediterranean the level of the sea tends continually to fall. At the same time the surface water must become denser because of evaporation and so it will tend to sink towards the bottom. The result of the latter condition is seen in the Figure : at about 50 miles on either side of the sill the depth is about the same- 500 fathoms-but on the Atlantic side the temperature and salinity are about $10^{\circ} \mathrm{C}$. and $36 \%$ respectively while, on the Mediterranean side the corresponding values are about $13^{\circ} \mathrm{C}$. and $37 \cdot 5$.

Because the level of the Mediterranean tends to fall there is an inflow on the surface of relatively cold and low salinity water from the Atlantic and, at the same.time, there is an outflow along the bottom of relatively warm and dense water into the Atlantic. This is, of course, the net effect : what really happens is that the outgoing bottom tidal stream runs stronger than the ingoing bottom one and the ingoing, surface tidal stream runs stronger than the outgoing, surface tidal stream. At about 3 to 4 hours after low water the conditions are as shown in the figure on the left hand side while at about 4 hours after high water the conditions are as represented on the right hand side. The positions of the arrows, as read off on the vertical scale, give the depths of the currents, and their lengths give the velocities : the longest arrow represents a velocity of about 4 knots. 
In the case of the Baltic the large influx of fresh water from the rivers tends to raise the water level and so an outward surface current is set up: this flows into the Norwegian Sea through the Cattegat and Skagerak. Accompanying these surface currents (as in the case of the Mediterranean) there is a compensatory bottom current.

The great oceanic currents.- We can now proceed with a description of the main features of the superficial water circulation in the various oceans, premising that there is no end to the amount of detail with which this subject might be treated. So we can only deal with the broad, generalised, average current systems. Some of the detail we shall refer to later on in order that the reader may fully understand the complexity of the phenomena dealt with in a description of oceanic current systems.

(1) The North Atlantic. The motive force of the North Atlantic current system is the equatorial streaming of the water. This occurs along a zone lying mainly to the North of the equator, between parallels $0^{\circ}$ to $10^{\circ} \mathrm{N}$. Lat. Driven to the West by the continual action of the NorthEast and South-East Trade Winds the water flows along the surface with a velocity of $\frac{1}{2}$ to $2 \frac{1}{2}$ knots as a warm and relatively dense current. The axis of this lies between N. Lats $0^{\circ}$ and $10^{\circ}$, inclining to the North with the general direction of the N. coast of N. America. Impinging on the land barriers formed by the Greater and Lesser Antilles the North Equatorial Stream is split. Part of it enters into the Caribbean Sea and then into the Gulf of Mexico where the temperature is relatively high and where the water undergoes further evaporation. Part, however, flows to the East of the West Indian Islands, as the Antilles Stream, recurving continually to the North and East to form the Sargasso Sea Eddy. This is probably by far the greater part of the North Equatorial Stream. It is to be noted that the deflection to the North is due, apparently, to the land barrier formed by Central America and the West 
Indian Islands, but it is certain that the deflecting force due to the earth's rotation would lead to a turning of the equatorial stream to the right hand side apart altogether from the influence of a land barrier.

The Gulf Stream. The quantity of water thus driven into the Gulf of Mexico is so great that an appreciable rise of level is established. The salinity in the Gulf is over $36.5 \%$ and the temperature rises to over $27^{\circ} \mathrm{C}$., values that are greater than those that are the averages for the zone of latitudes within which the Gulf is situated. Issuing from the Straits of Florida we have the Gulf Stream, which at its narrowest part is about 5 miles wide, 60 fathoms deep, and has a temperature of about $26^{\circ} \mathrm{C}$. It flows to the North along the North American Coast as far as N. Lat. $40^{\circ}$ and W. Long. $50^{\circ}$, widening somewhat as it tends to the North. At about $41^{\circ} \mathrm{N}$, the Gulf Stream impinges on the southerly flowing Labrador Stream.

The Labrador Stream. This represents the theoretical drift of water of low salinity and temperature from the sub-polar to the temperate seas. It takes origin, for the most part, in Baffin Bay and Davis Strait and it receives relatively little contribution from the cold water that flows down along the East Coast of Greenland. It tends to be deflected to the right hand side, that is, to the West and so it hugs the coast of North America, from Halifax to Cape Cod, forming there the "Cold Wall" : about here it tends to penetrate through and below the water of the Gulf Stream so that a kind of variable stratification is actually set up. It carries much ice, broken away as bergs from the glaciers of West Greenland and these melt. in the sea to the West and South of Newfoundland, depositing their stones and mud to form the Great Banks. The area of distribution of this ice is variable with the season and year and it depends to a very marked extent on the volume, velocity and temperature of the Gulf Stream.

The Sargasso Sea and Atlantic Stream. Between N. latitudes about $40^{\circ}$ and $50^{\circ}$ and $\mathrm{W}$. longitudes $50^{\circ}$ to 


\section{AN INTRODUCTION TO OCEANOGRAPHY}

$60^{\circ}$ the Gulf Stream widens out, loses velocity and decreases in temperature. It tends always to become deflected to the right hand side, that is, to the South in this region and then still to the right hand side and so to the West again. Thus we have an anticyclonic circulation of the surface water of the North Atlantic, that is, a continued turning in the same direction as that of the hands of a clock. This is shown in Fig. 51 and it should be noted that the easterly part of the eddy is represented by broken lines, that is, it is a drift of cold water there. "Cold" and "warm" are, of course, relative terms, and since the water of the Gulf Stream is continually losing heat as it flows away from the Straits of Florida it is evident that by the time that the drift has turned to the South and then to the West again it has become colder than the water into which it is flowing. It is also to be noted that there are asterisks in Fig. 51 off the African Coast: these are placed on the regions where water wells up from the bottom to replace that which is being driven to the West by the North-Easterly winds. This upwelling water is colder than that on the surface and it joins the general Atlantic Anticyclonic circulation, becoming heated as it is propelled South-West to enter the North Equatorial Stream.

In the middle of the Atlantic Anticyclone to the West and with its centre approximately in N. Lat. $40^{\circ}, \mathrm{W}$. Long. $50^{\circ}$ is the Sargasso Sea. This is an extensive area of ocean where there is no perceptible stream. It is characterised by the presence of large quantities of drifting "Gulf weed" (Sargassum) carried out from the Gulf of Mexico. This floats on the surface and carries a very characteristic fauna. It is never so dense as significantly to impede the way of a ship under sail or steam.

The Atlantic Stream (European Stream, Gulf Stream Drift) takes origin from the Atlantic anticyclonic eddy along its northerly margin. The main motive force of this very prominent north-easterly drift of Atlantic water is, of course, the prevalent south-westerly winds which blow 
strongly in these latitudes throughout the greater part of the year. The result is a slow drift of relatively warm and dense water from the South-West towards the NorthEast: this is the Atlantic Stream. It enters the coastal water of North-West Europe from Spain to the English Channel, penetrating through the Straits of Dover into the North Sea and even entering into the Irish Sea through St. George's Channel. The main core of the stream is off the West Coasts of the British Islands, then to the North of the latter, along the deeper sea bottom between the Shetlands and Faeroes and then along the West Coast of Norway and round North Cape.

The outlying branches of the Atlantic Stream. A branch enters through the English Channel into the southern part of the North Sea (the Flemish Bight) and another (though much smaller branch) enters the Irish Sea. A prominent branch flows round the North of the Shetlands and so down to about the middle of the North Sea (see Fig. 51), and then across towards the coasts of Holland and Denmark. Part of the stream bends round to the North-West, over towards Iceland and Greenland and Atlantic water even reaches the coasts of Spitzbergen. About the latitude of North Cape, however, the water of the Atlantic stream has cooled down to such an extent that it has become denser (by reason of its higher salinity) than the water normal to these latitudes and from this region it flows on as an undercurrent, close to the sea bottom. This also occurs in the Skagerak with the Atlantic Water that has entered into the North Sea. The result is that water which is of Atlantic origin, and is warmer and denser than that characteristic of the latitudes in question flows into the deeper parts of the Baltic and also along the bottom of the Barentz Sea. These warm and dense undercurrents are seasonal to some extent.

(2) The South Atlantic.-Fig. 51. The Southern Equatorial Stream, flowing to the West just South of the equator, impinges on the East Coast of South America, 


\section{AN INTRODUCTION TO OCEANOGRAPHY}

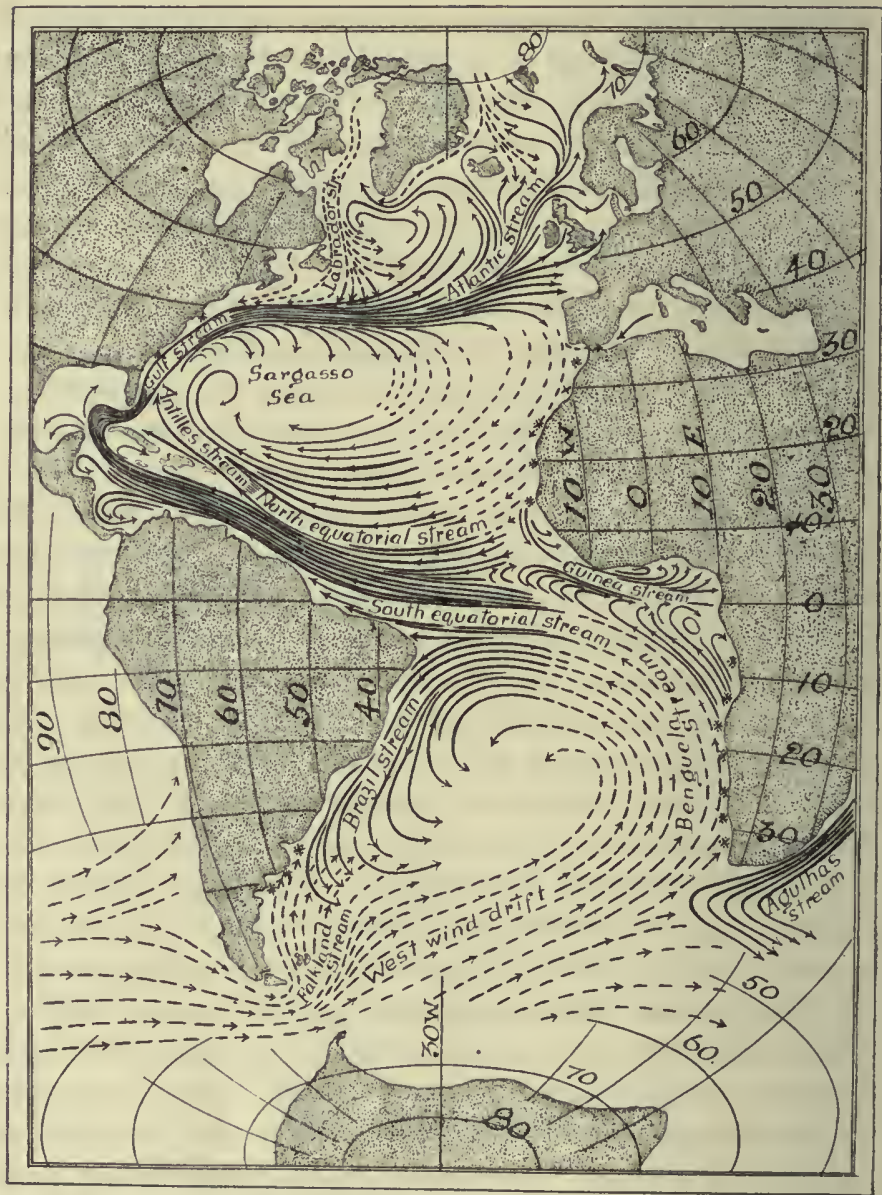

Fia. 51. The current systems of the Atlantic Ocean. Only the surface currents and drifts are shown and the condition represented is the average, generalised one : in many details there is variation with the season of the year. Continuous lines represent "warm" currents and broken lines "cold" ones. The closeness to each other of the lines gives some indication of the rapidity of the currents. The stars along the continental coast indicate the principal places where cold water wells up from the sea bottom towards the surface. 
splitting on Cape San Roque. From thence it flows to the North-West, joining the North Equatorial Stream, and to the South, along the East coast of South America, as the Brazil Stream. Between latitudes about $20^{\circ}$ to $40^{\circ} \mathrm{S}$. the Brazil Stream bends round to the East, being deflected to the left hand side (just as the Gulf Stream is deflected to the right) by the earth's rotation. This is the Western half of the South Atlantic cyclonic water circulation.

Just as there is a drift to the North-West, in the North Atlantic, due to the prevalent winds, so there also is a West wind drift in the Southern Atlantic. This, however, is much stronger than in the North, partly because the winds are stronger and more persistent, but mainly because of the uninterrupted sweep of the western wind drift round the whole world in the Southern Ocean. The west wind drift is continually deflected to the left and so it turns round long before it approaches the West coast of Africa and finally it enters the South Equatorial Stream. Along the African coast the drift is known as the Benguela Stream. It is cold (relatively to the water of the latitudes into which it is flowing) because it has its origin in the southern sub-polar seas and also because it contains water which has welled up from the lower strata of the Atlantic. The areas of this upward motion of the South Atlantic water are marked by asterisks, placed near the coasts of Patagonia and West Africa. As this cold, northerly flowing, west wind drift water enters the South Equatorial Stream circulation it becomes heated up.

Between the North and South Equatorial Streams there is a counter-current, the Guinea Stream. Note that there is a kind of convergence of the two great currents so that the western part of the common stream must move more rapidly than does the eastern part. This is not all : there is an actual curving inwards towards the axis of the joint equatorial stream, and then an eastward flow of the surface water. This enters into the Gulf of Guinea and there its further course is very complicated 


\section{AN INTRODUCTION TO OCEANOGRAPHY}

and is also variable with the season. To this matter of seasonal variation in the Atlantic Equatorial Stream circulation we return in p. 288.

Thus there is an obvious symmetry in the water circulation of North and South Atlantic. In each case there is a great gyral occupying the central parts of the two oceans. That in the North is anti-cyclonic, while that in the South is cyclonic in direction. In each case there is a westerly drift-the Atlantic Stream (or North Atlantic West Wind Drift) in the North, and the South Atlantic West Wind Drift in the South. Here the water flows from West to East. In each case there is a cold current flowing equatorially : the Labrador Stream, and the West Greenland Stream in the North, and the Falkland Stream in the South. The latter is the stronger of the two because of the much greater volume of the Southern Ocean as compared with the northern one.

(3) The Pacific Ocean circulation.-Fig. 52. We consider the two circulations, those of the North and South Pacific Ocean together. The conditions are rather more complicated than they are in the two Atlantics, first because of the lack of a geographical differentiation into North and South Pacific basins, and second, because of the great variety of depths in the western part of the Pacific.

We see, however, just the same strongly marked North and South Equatorial Streams with the easterly flowing counter stream in the axis: that is the westerly flowing water continually turns inwards to South and North and flows backwards towards the ocean off the coasts of West Central America where it forms complicated cyclonic eddies on a small scale. Then, as in the case of the Atlantics, we have the two great gyrals, anticyclonic in the North Pacific and cyclonic in the South. In the central parts of these gyrals there are entensive regions where there are no perceptible permanent currents. It is to be noted that the North Pacific gyral extends over the greater part of the ocean whereas the South Pacific one is markedly 
restricted to the eastern region. This is because the latter is the true South Pacific basin, the western region being characterised by extensive areas of relatively shallow water and numerous archipelagoes.

The circulation in the western part of the North Pacific is analogous in every way with that in the western region of the North Atlantic. As the North Equatorial Stream impinges on the islands of the Australasian complex it is deflected to the right hand side, that is, to the North and it becomes concentrated as the Japanese Stream, which flows strongly towards the North-East and is the Pacific counterpart of the Atlantic Gulf Stream. Offshoots from this enter into the Sea of Japan, the Yellow Sea and the China Sea. Further a very evident north-easterly drift takes origin on the northern margin of the North Pacific gyral and here water, impelled strongly by the prevalent West winds, flows over towards the coasts of North-West North America. The communication between the North Pacific and the Arctic Ocean (through Behring Strait) is, however, very much more restricted than that between the North Atlantic and the Arctic, and so the greater part of the northern west wind drift in the Pacific is deflected (by the earth's rotation) to the South and West again, thus re-entering into the North Equatorial Stream. Off the coasts of California, this southerly flowing Californian current thus carries on the gyral circulation, but it also contains water that has welled upwards from great depths in the regions, off the coasts, marked in Fig. 52 by the asterisks. It is also to be noted that, just because the north-easterly drift into the Arctic Seas is much less prominent in the North Pacific than in the North Atlantic, the gyral is more symmetrical and so the course of the equatorial streams is almost truly parallel to the equator, though (as in the Atlantic) the axis of the two streams lies just to the North of the Equator.

Just as in the case of the North Atlantic circulation there is a southerly flowing stream of cold water. Little 


\section{AN INTRODUCTION TO OCEANOGRAPHY}

of this (if any) comes through the Behring strait from the Arctic Ocean and most (or all) of it takes origin in the shallow North Pacific Ocean and in the Sea of Okhotsk. Most of it flows southwards outside the Japanese Islands impinging on, and cutting through the warm Japanese current, just as the Labrador Stream impinges on the North Atlantic Gulf Stream.

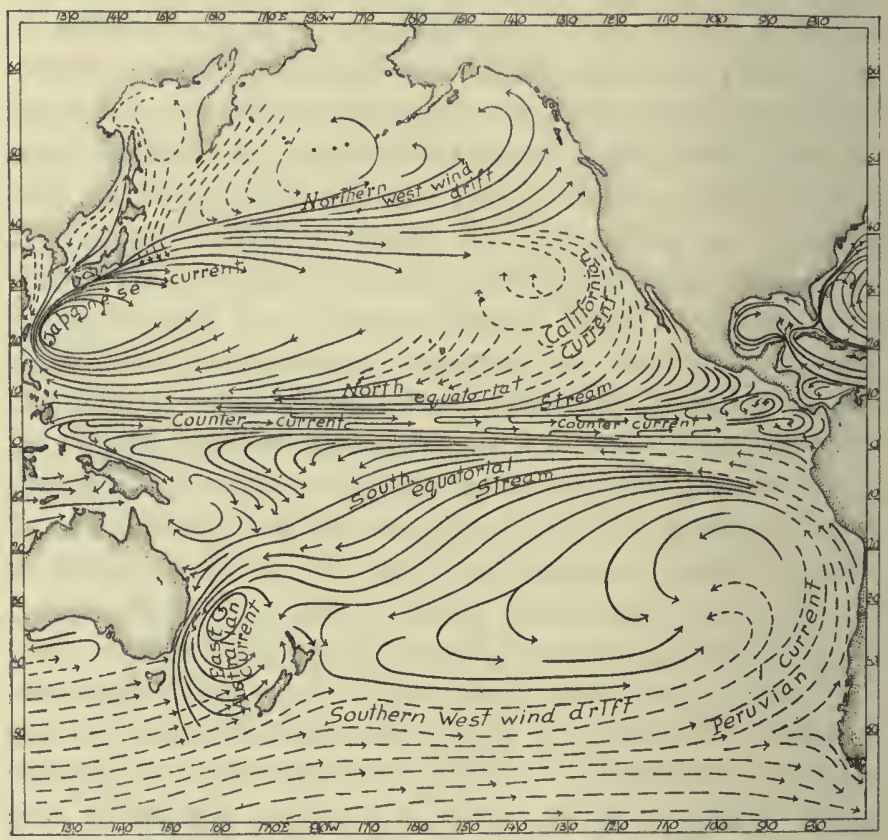

FIG. 52.

The same general scheme is to be seen in the South Pacific oceanic circulation, though it appears, in the Figure, to be much less regular. This is the result of the shoaling which extends over the South Pacific in its western regions. There is, however, a counterpart to the Brazil stream in the strongly developed East Australian current which carries a considerable volume of warm and dense water 
from the Pacific into the Indian Ocean. Here, also, we have a prominent southern west wind drift, as in the case of the South Atlantic and this impinges on the western coast of South America and is deflected to the North as the Peruvian current : it is analogous, in every way, with the Benguela Stream of the South Atlantic. Like the latter it enters into the equatorial stream circulation. The great southern west wind drift is more prominent in the Pacific than in the South Atlantic because of the much greater area of ocean and the consequent greater effect of the brave west winds in setting up a surface drift.

The Pacific Ocean, then, exhibits the two typical gyral circulations, the northerly anticyclonic, and the southern cyclonic ones. There is also the drift of cold and relatively light water towards the equator, on both sides, from the North and South.

(4) The Indian Ocean.-Fig. 53. The Indian Ocean differs from the Atlantic and Pacific regions inasmuch as it represents only one half of the theoretical scheme, the northern basin being absent. We consider, then, the region adjacent to the equator and South of this to the great Southern Ocean. Here we have the theoretical scheme in an evident form, although it is modified by the absence of a great, elevated, continental land mass on the eastern side, such as we have in both the Atlantic and Pacific regions, particularly in the southern basins. In the South Indian Ocean, then, we see the typical gyral circulation, cyclonic in direction. The South Equatorial Stream has its main axis (during the winter months) between latitudes $10^{\circ}$ and $15^{\circ} \mathrm{S}$. and it impinges on the eastern shore of Africa and Madagascar in the usual way. Part (the major one) is deflected to the left, that is to the South and East to form the eyclonic gyral and a smaller part passes into the Mozambique Channel to form the Agulhas Current, with a system of eddies between Africa and Madagascar. The Agulhas Current flows South along the African coast and a small part of it rounds the Cape 

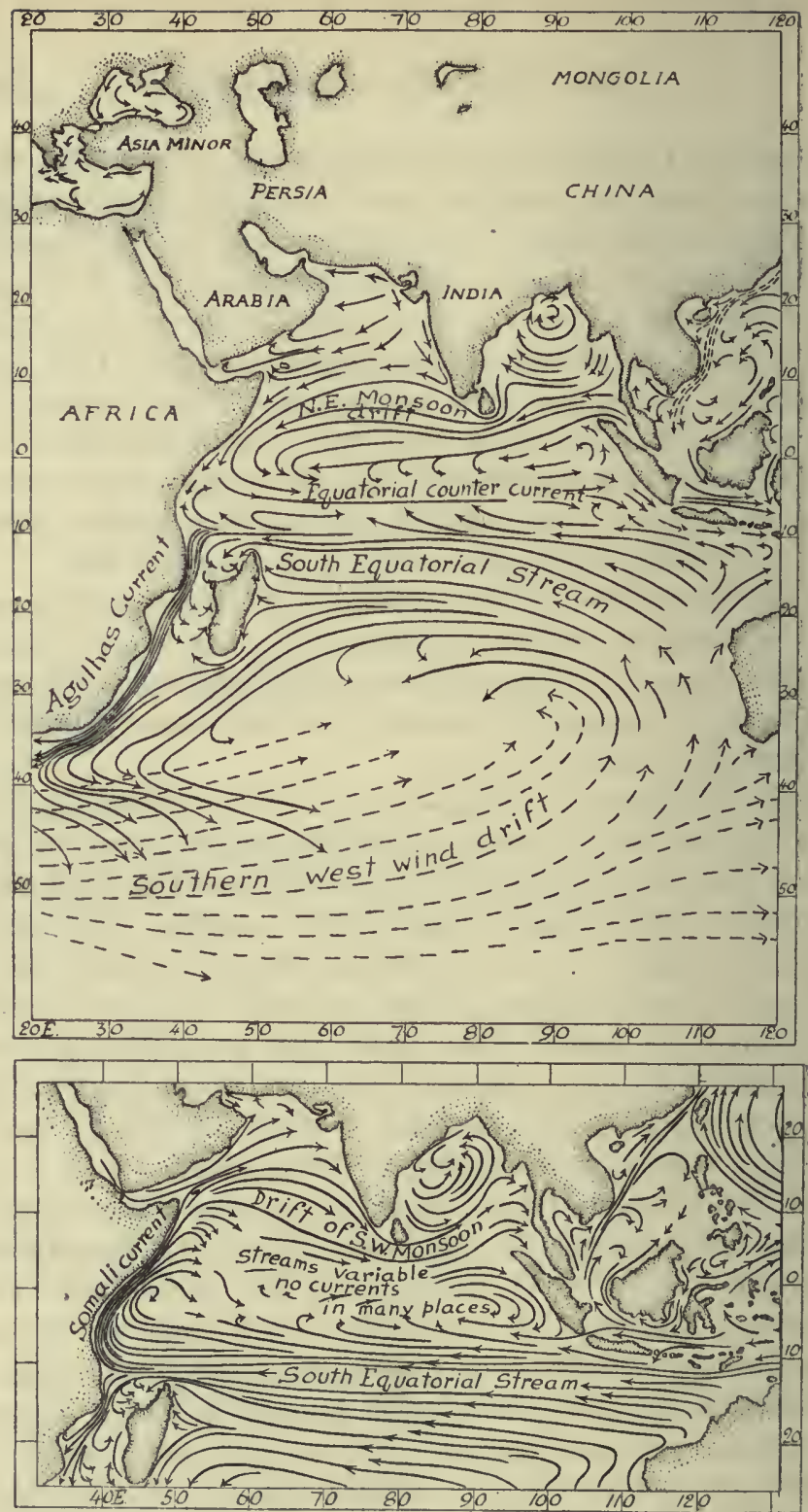

F1G. 53. The current systems of the Indian Ocean. As before continuous lines represent warm currents and broken lines. cold ones. The upper figure represents the generalised conditions during the winter months and the lower figure shows the summer conditions in that part of the Ocean. where the circulation reverses with the season. 
and enters the Atlantic Ocean to join the Benguela Stream. The greater part, however, becomes deflected to the left (that is back to the East) by the earth's rotation and also by the shoaling of the sea adjacent to the Cape. It then disperses in the Southern Ocean, cutting through the southern west wind drift and slowly sinking towards the bottom.

South of the Cape and the Australian continent we see the same prominent West wind drift that has been noted in both the South Atlantic and Pacific Oceans. Here, however, this has a more uninterrupted sweep to the East. and South of Australia, but it also suffers deflection to the left, that is, to the North, so that it passes as a cold current towards the West Australian coasts, then warms up and joins the South Equatorial Stream circulation, completing the Indian Ocean gyral. In the centre of the latter we have the usual absence of any perceptible permanent streaming.

North of the equator the streaming of the Indian Ocean is dominated by the monsoon wind systems. Fig. 53 (the upper one) represents the winter conditions when the North-East Monsoon has been established, while the lower figure shows the streaming set up in the conditions of the South-West Monsoon which blows during the summer months. The monsoons are due to exactly the same causes that lead to the land and sea breezes. During the day the land becomes heated, by solar radiation, to a much greater extent than the sea. It heats the atmosphere in contact with it and so ascending air currents are established. To compensate for these a breeze blows from the sea towards the land, becoming deflected, of course, by the earth's rotation. During the night the conditions. are completely reversed: the atmosphere over the land cools down more rapidly than that over the sea and so descending air currents are set up and these blow out from land to sea as the land breezes.

Such effects are produced on the great scale, but with a period of a year instead of a day. As a rule the heating 


\section{AN INTRODUCTION TO OCEANOGRAPHY}

and cooling effect of the continental land masses is insufficient to do more than set up local modifications of the prevailing wind currents, but the Indian Ocean, in its relation to the great and high Asiatic continent, is a striking exception. In the summer months the elevated lands become so strongly heated that a wind system, lasting for some months is established, this is the SouthWest Monsoon. In the winter months the continental land is strongly cooled and then a reversed condition is set up : the North-East Monsoon is established and blows also for some months.

During the period of the N.-E. Monsoon, then, the streaming is represented in a generalised way, by the upper figure of Fig. 53. A Northern Equatorial Stream runs curving in towards the axis of both $\mathrm{N}$. and $\mathrm{S}$. streams (in about $5^{\circ} \mathrm{N}$. Lat.) as a distinct equatorial counter current. There is no obvious gyral, for the drift of water North of the equator is one to the South-West, that being the point to which the North-East monsoon blows. In both North Atlantic and Pacific, it will be remembered, we have West wind drifts: in the Indian Ocean in the winter we have a North-East wind drift, that is a current running to the South-West and joining the equatorial counter-current. In the Arabian Sea and the Bay of Bengal the conditions are complicated and large eddy systems are established.

During the summer months, however, when the S.-W. Monsoon blows, the current system of the Indian Ocean becomes very much the same as that in the North Atlantic and North Pacific basins (except, of course, that there is no current of cold and light water running South from sub-polar seas). A North Equatorial Stream is established, but there is no very evident counter current. There is a West wind drift in latitude between $0^{\circ}$ and $10^{\circ} \mathrm{N}$, and this is deflected to the right (that is, to the South) so that it rejoins the North Equatorial Stream thus completing the North Indian Ocean anticyclonic gyral. In the central 
regions of this are places where the streaming is variable, or quite unappreciable. Further a part of the North Equatorial Stream is strongly deflected to the North by the African coast, thus forming the very prominent Somali current. While it runs this is the analogue of the Gulf Stream of the Atlantic and of the Japanese Stream of the Pacific.

Between Australia and the Asiatic continent the current systems are very complex, and it would be unprofitable to consider them except in detail and illustrated by large scale charts.

(5) The Polar Seas.-Figs. 12, 51. Far less is known concerning the current system of the Polar Seas than is the case with the g-eat oceanic regions dealt with above. Exploration in these seas is much more laborious than elsewhere, and the presence of ice introduces the most formidable difficulties.

The Antarctic currents are still very imperfectly known. Obviously there must be a resultant drift to the North since icebergs, detached from the Antarctic ice-cap, are found far North of the land where they have been formed. The really important water movement (as apart from the local seasonal streams that certainly exist in the neighbourhood of the continent) is that represented in Fig. 51. Round the whole earth in the great Southern Ocean, there is a continuous drift of water from West to East, set up by the very strong winds that blow mainly from the West throughout the greater part of the year. This is the southern west wind drift. It tends always to be deflected to the left, that is, to the North, and it thus enters the South Atlantic (as the Falkland and Benguela Streams), the Pacific (as the Peruvian current) and the Indian Ocean (as an ill defined current flowing to the North along the coast of West Australia. Ultimately the water entering the three southern oceans from the Antarctic joins the South Equatorial Stream circulations. 


\section{AN INTRODUCTION TO OCEANOGRAPHY}

The Arctic currents.--(Figs. 12, 51.) These are better known though few experimental investigations have been made, and our knowledge is derived mainly from observations on floating wreckage and on the famous drift of Nansen's ship, the "Fram" when she was frozen into the ice. Fig. 12 shows that relatively warm and salt water enters the Arctic Ocean with the Atlantic Stream. Offshoots of this penetrate as far as the West coast of Spitzbergen and round North Cape into the Barentz Sea (that is, the Arctic Ocean between the entrance to the White Sea and the ice pack). Here, however, these drifts of water sink to the bottom and flow on to the North and West as under currents which are warmer than is the water normal to those latitudes. This is the water that enters the Arctic Basin; it comes entirely from the Atlantic. Far more water flows out from the North Polar seas than enter it as oceanic streams whether superficial or deep.

The general drift across the Arctic Ocean is from East to West and the main directions indicated in Fig. 12 are based not only on the course taken by the Fram when she was carried by the ice pack, but also on the general drift of waterlogged wood, etc. The water thus moves from the Siberian coast across the basin towards the North-East coast of Greenland. Some appear to pass through Banks Strait and Hudson Strait into Baffin Bay and there is also a marked drift, through Kennedy Channel into Baffin Bay. The main drift flows down the East coast of Greenland through Denmark Strait, then round Cape Farewell into Davis Straits. Reinforced there by water coming down from Hudson's Bay and Baffin Bay the drift continues to flow to the South as the Labrador Stream and the further course of this belongs to the Atlantic system and is indicated in Fig. 51. But there is also a drift of Arctic water to the South along the East coast of Iceland and this may extend well down in some years. Evidence that water of Arctic origin may actually enter into the North Sea is afforded by a study of the plankton, for organisms 
having their normal habitat to the North may exceptionally be taken in the Skagerak, or even in the North Sea itself.

Finally there is a restricted outflow from the North Polar Basin into the Pacific Ocean through Behring Strait. The volume of this is, however, much smaller than that which enters the Atlantic.

(6) The Marginal Seas. It is to be noted particularly that all that has been said so far constitutes a generalised description of the main currents and drifts of the great oceans. The charts from which Figs. 51 to 53 have been drawn are all very small scale ones and what they represent are average directions, the averages being really those made from observations taken over considerable periods of time. Thus the student will note a kind of symmetry about them which certainly does not exist at any one moment of time. The directions are shown by boldly drawn sweeping "lines of least curvature" and this must be the case whenever currents and drifts are shown on small scale charts. If small parts of the North Atlantic, for instance, were charted on a large scale the directions of the Atlantic Stream would certainly be far more irregular than they are represented in Fig. 51 and it would also be noticed that the drift of relatively warm and salt water towards northern Europe would advance rather irregularly. On the whole, however, and taken over a long period of time these irregularities would "average out" and we should have the generalised pictures that are shown by Figs. 51 to 53 .

And so, when the marginal seas are studied, the streaming is seen to be much more complex than we have indicated. There is an almost illimitable detail when small areas are represented on a big scale. In these seas the tidal streams are really the important and most striking movements of the water and a current chart made for any particular moment of time would, as a rule, show how the tides are running, and nothing more. But the tidal streams do not exactly reverse themselves and so there is a general 


\section{AN INTRODUCTION TO OCEANOGRAPHY}

resultant movement of the water which is indicated not only by float experiments but also by observations of the changes of salinity and temperature from place to place. Further in any small sea area, and for any short period of time, the winds are most important factors for they are variable and so very considerable deviations from the generalised directions may be seen from day to day in a small sea area which is minutely investigated.

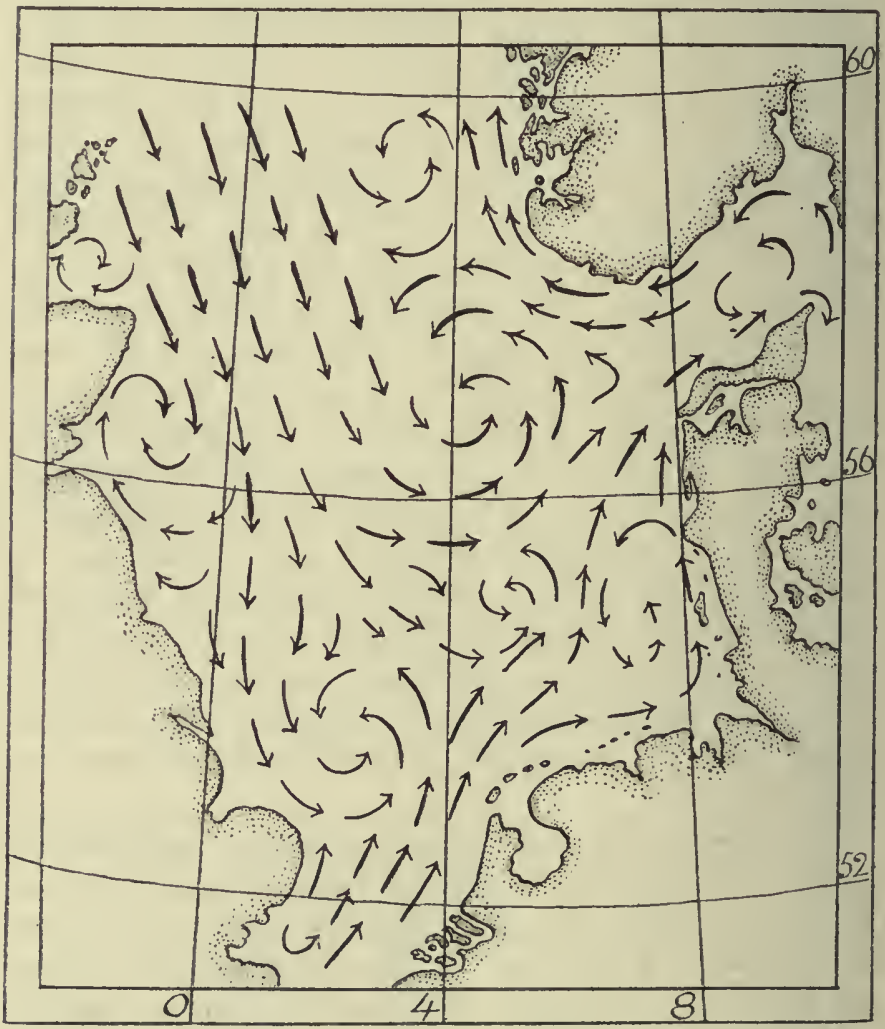

Fia. 54. The current system of the North Sea for the month of August.

The North Sea. It would be quite impossible to give even a summary account of the water circulation in the marginal seas without taking up very considerable space 
and so the North Sea circulation only is referred to here. It may be taken as illustrative of the complexity to which we refer above.

Here we see a complicated system of vortices. The main factors are (1) the entrance of Atlantic water that comes from the Faeroe-Shetland Chamnel and is deflected to the right and so into the northern part of the North Sea. (2) The entrance of Atlantic water from the English Channel, through the Straits of Dover : this entrance is much more restricted than is the northern one and so the volume of water coming from the South is much less than that from the North. (3) The outflow of relatively fresh water from the Baltic through the Cattegat and Skagerak : this flows on to the North along the coast of Norway. (4) The configuration of the North Sea itself, and the varying depth of the bottom.

From a study of these factors, the observation of directions of streaming taken over considerable periods of time and the distribution of changes in the salinity of the water the figure has been compiled. The resultant tidal movement is considered and the effects of variable winds are supposed to be eliminated by spreading the observations over a period of time long enough to smooth out irregularities traceable to these causes. Generalised in this way we get the somewhat symmetrical arrangement shown in the figure, but at any one moment the picture would certainly show considerable deviations from the average condition.

The seasonal variations.-Almost everywhere there are seasonal variations both in the directions and volumes of the current systems of the ocean and the greater part of the investigations now being carried on deal with these seasonal variations and with their causes. The practical value of this knowledge, to navigation and to the sea fisheries is such that every well-known sea area has been investigated to an extent that makes it impossible to deal here with the results in detail. 


\section{AN INTRODUCTION TO OCEANOGRAPHY}

Several instances may, however, be given: (1) the Indian Ocean, Fig. 53, shows the two conditions, (a) when the North-East Monsoon blows during the winter months and (b) when the South-West Monsoon blows during the summer. In (a) the direction of the gyral characteristic for a northern oceanic area is reversed. Thus we have a South Equatorial Stream but no corresponding North Equatorial one. There is an apparent counter-equatorial current but this is a wind effect being due to the cyclonic circulation set up by the monsoon rather than to a backward spilling of the equatorial streams. In (b) there is a North Equatorial Stream, due obviously to the dragging of water away from the East African coast by the S.-W. Monsoon Drift.
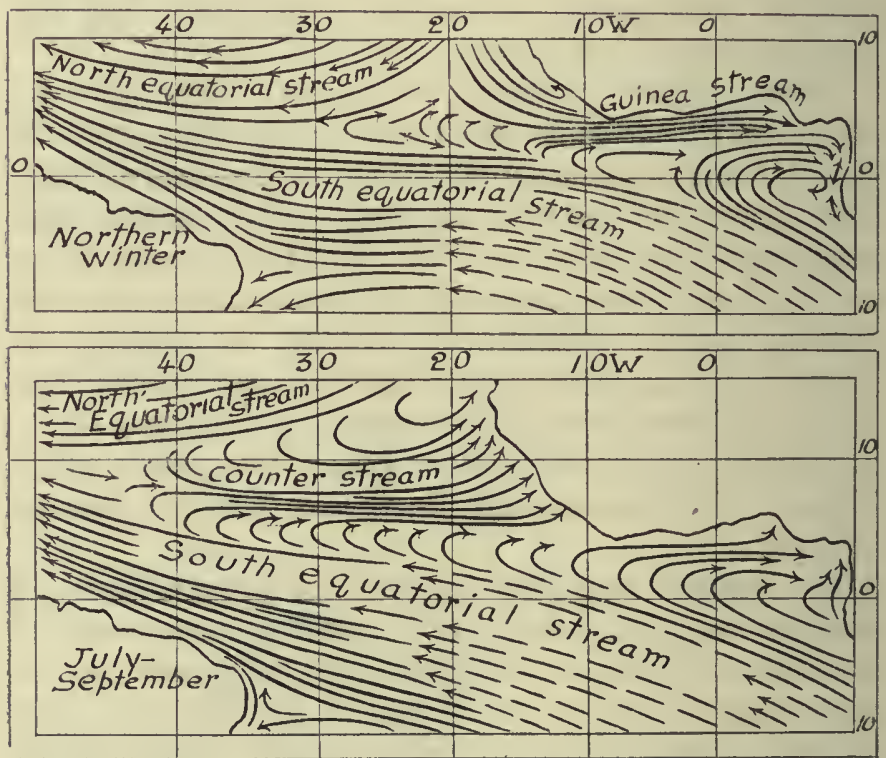

Fic. 55. Upper: the Atlantic equatorial stream circulation in the northern winter; Lower: the same during July and September.

(2) The Mid-Atlantic circulation.-The changes that occur in the course of the year are represented in Fig. 55. 
Here the current-systems are represented on the same scale and with the reference lines of latitude and longitude superposable. In the northern winter (the upper figure) the axis of the South Equatorial Stream lies just South of the equator while that of the northern stream may be taken to be somewhere between latitudes $5^{\circ}$ and $10^{\circ} \mathrm{N}$. There is a counter-current between the two streams : this is the Guinea Stream, and its axis is two or three degrees North of the Equator. It is not important, so far as its volume and intensity are concerned, West of about $10^{\circ} \mathrm{W}$. long.

Now note how, during the months of July and September, the whole current system is shifted bodily to the North. The South Equatorial Stream lies mostly North of the Equator while the northern stream lies well above $10^{\circ} \mathrm{N}$. lat. The counter stream is also very much stronger than in the winter months: it has its axis in about $7^{\circ} \mathrm{N}$. lat. and it extends as far West as $40^{\circ} \mathrm{W}$. long. The Guinea Stream, as it is shown in the winter chart, still exists, and it can now be seen to be due to the recurving backwards of the South Equatorial current. There is, however, a very evident counter stream in addition to this. The increased volume of these latter streams is evidently due to the greater quantity of water that is set in motion from East to West.

(3) The Atlantic gyral. The matter may now be looked at from another standpoint, that of the distribution of salinity and temperature.

The two figures have been constructed from observations which may, without much error, be regarded as simultaneous and they indicate approximately the area of ocean which is filled with highly saline water of a relatively high temperature. In March, then, the $36 \%$ water does not extend North of the 40th parallel of latitude and nowhere does it come near the African or European coasts. The isotherm on $15^{\circ} \mathrm{C}$. has very much the same general situation as the $36 \%$ isohaline. In November, 


\section{AN INTRODUCTION TO OCEANOGRAPHY}
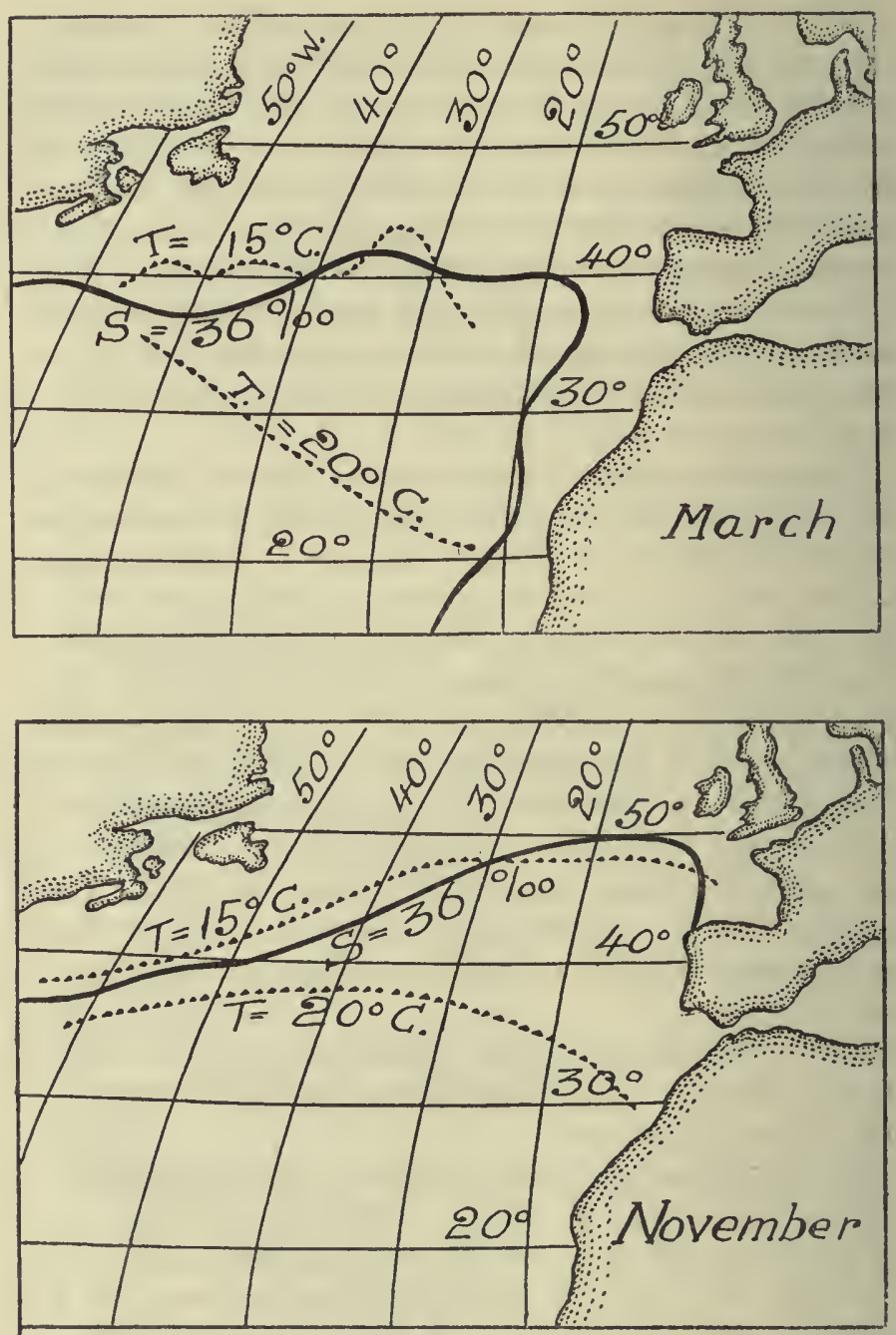

Fra. 56. Two charts of the distribution of salinity and temperature in the North Atlantic during the year and in the months of March and November. The northern boundary of the area of ocean filled with water of salinity of 36 or more is represented by the heavy contour line. The dotted lines show the isotherms of $15^{\circ}$ and $20^{\circ} \mathrm{C}$. 
however, a very marked change has occurred: the $36^{\circ} \%$ isohaline now reaches up to the N.E. as far N. as the 50 th parallel and as far E. as about $10^{\circ} \mathrm{W}$. long., while all the coast of Europe and Africa, South of Cape Finisterre is bathed with water of this, or some greater salinity. The $15^{\circ}$ isotherm has shifted North with the $36^{\circ} \%$ isohaline. Evidently an extensive region of the North Atlantic, towards the North-East, has been flooded with relatively warm and salt water.

Now the primary cause of oceanic circulation, whether this is set up directly by evaporation and rise of temperature, or indirectly by the driving force of the winds, is solar radiation. In the course of the year the sun moves between the tropics; he is directly overhead in $23 \frac{1}{2}^{\circ} \mathrm{S}$. lat. at the winter solstice (Dec. 22nd); he is on the Equator at the vernal equinox (March 21st); he is in $23 \frac{1}{2}^{\circ} \mathrm{N}$. lat. at the summer solstice (June 22nd), and he is again on the Equator at the autumnal equinox (Sept. 23rd). Where he is overhead, there the ocean receives most heat from his radiation and the intensity of the water circulation becomes maximal for a short period.

Between the vernal equinox and the summer solstice, then, the zone of ocean in the northern hemisphere most greatly heated up shifts from South to North and so we have the more northerly position of the axis of the North Equatorial Stream in the summer, as shown in Fig. 56. The result is, therefore, that the area covered by the Atlantic Stream gyral extends northerly from about March to November, then contracts to the South again. The minimum extension North is in March, the maximum one in November.

The gyral or "Gulf Stream Eddy," thus pulsates with a period of about a year and accompanying this pulsation there is an annual periodicity in the inflow of Atlantic water into the northern marginal seas. Normally the North Sea should contain water of about 34.5 to $35 \%$, but water of over $35 \%$ enters it from the Faeroe-Shetland 
Channel, in the North, and from the English Channel in the South. In March the area of North Sea which is covered by water of over $35 \%$ is maximal ; in August it is minimal. Thus the annual culmination in the flow of the Atlantic Stream into the North Sea is in March. Wo have seen, from Fig. 56, that the greatest extension northeasterly of Equatorial Stream water occurs in the Atlantic in November: the period November to March represents, then, the time taken for the water of the Atlantic Stream gyral to drift from somewhere about $50^{\circ} \mathrm{N}$. lat. and $20^{\circ} \mathrm{W}$. long. into the North Sea. In the Irish Sea the maximal inflow of water occurs usually about May or June: thus a little longer time is required because of the more restricted entrance into this marginal sea.

Further North the same annual periodicity can be observed. Thus the Baltic is penetrated-but by a deep current of relatively warm and salt water-and this happens later than in the North Sea, for the slowly moving undercurrent has to pass through the Cattegat: in some years it does not pass at all. It penetrates into some of the deeper Norwegian fiords and here we have the interesting condition of a distinct fortnightly periodicity. The dense undercurrent is affected by the tides : that is, there is not only a periodic rise and fall of the surface level of the sea but there is also a rise and fall (a true tide) in the upper level of the under stratum of salter water. Daily changes are difficult to notice but the fortnightly ones, brought about by the alternation of springs and neaps have been observed.

The Atlantic Stream, as we have seen, can be traced into the Barentz Sea, and to the shore of Spitzbergen. In the Barentz Sea it becomes an undercurrent, for by the time the relatively salt water of the Atlantic has reached these latitudes it has cooled considerably, has become denser than that in situ and so sinks to the bottom and flows on as an undercurrent. This culminates in November, which is, therefore, the summer of the bottom water of 
this remote region. The culmination of the Atlantic inflow in the Barentz Sea, towards the end of the year is, however, due to the flow to the North of water which was present in the Atlantic Stream gyral one to two years previously to its appearance in the extreme North. This period of time, then gives us an approximate measure of the rate of the drift.

Such studies of the translation of the Atlantic water to the North are very numerous and their results are of much scientific and practical importance. To some extent the precise nature of the seasons, the air temperatures, the times and abundance of harvests, the flowering of certain plants, the quantity of ice in the sea, the times at which certain Baltic and White Sea ports freeze up and re-open again and even the abundance of certain marine fisheries depend on this inflow of warm and salt water. The times of these phenomena are not strictly periodic but vary a little from year to year, and the variability may be of very practical importance : a forecast, for instance, of the exact times at which certain Baltic ports may be expected to become icebound, or of the time of harvest in . Northern Germany, or of the frequency and southern limits of extension of icebergs round Newfoundland are results that have obvious practical significance. There is little doubt that persistent investigation of the periodic and aperiodic changes in the North Atlantic gyral will ultimately give us this information.

It is mainly in the North Atlantic, and its marginal seas, that investigations of this kind have been made. Lately however, similar research has been prosecuted by the American oceanographers in the Pacific Ocean off the Californian coasts.

The vertical circulation.-So far we have only considered the movements of water on the surface of the ocean. Besides these horizontal surface currents there are also deeper ones : this is evident from a consideration of the theoretical scheme whereby a circulation is deduced from 


\section{AN INTRODUCTION TO OCEANOGRAPHY}

the effect of solar radiation in heating and evaporating the superficial water. This raises the sea level so that a current is established and the theoretical direction of this is from the Equator towards the poles. Somewhere between the tropics and the sub-polar seas this highly saline water cools, becomes denser and sinks towards the bottom.

In the polar seas the sea water freezes. Some of the dissolved salts are then incorporated in the ice so that immediately around and beneath the latter the water in situ contains more dissolved salts and so becomes denser and, therefore, sinks towards the bottom. When the ice melts in the following summer the water which is formed is less saline than that in situ and being at about the same temperature it floats on the surface and flows away from the polar seas towards the temperate zones. Somewhere there it mixes with the water into which it flows and so becomes denser. Since it is still colder than the seas into which it enters it therefore becomes denser and tends to sink below the surface.

At the same time there are ascending currents. Water rises up from beneath in the Equatorial zones. Along the coasts of Western Africa and America (see Figs. 51, 52)

- there are regions where water "wells" up from beneath to take the place of that which is driven towards the West in the Equatorial Streams.

Besides these descending and ascending currents there appear to be horizontal ones, both at the bottom and in intermediate levels. It appears to be the case that there s almost everywhere in the ocean a slow creep of cold water from the polar seas towards the equator. Also there appears to be a greater volume of water driven from North to South, across the equator on the surface in the Atlantic and Pacific and Indian Oceans, than is propelled in the opposite direction: therefore, a lower current, crossing the equator at an intermediate stratum has been postulated. This mid-level current returns to the North, 
the excess of water which enters the Southern Ocean on the surface.

Fig. 57 represents in a very schematic way, the probable (and generalised) system of lower currents : it is based on the results obtained during the German "Valdivia" expedition. The detection of the directions and velocities of bottom and intermediate currents and drifts is far more difficult than in the case of those flowing on the surface, which are much more accessible to direct observation. In shallow seas they can be measured by means of the readings made with current meters (see p. 298), but the use of these instruments is hardly practicable in great depths. Bottom currents can be traced by the use of bottles or other floats so weighted that they drag or roll along the sea floor.

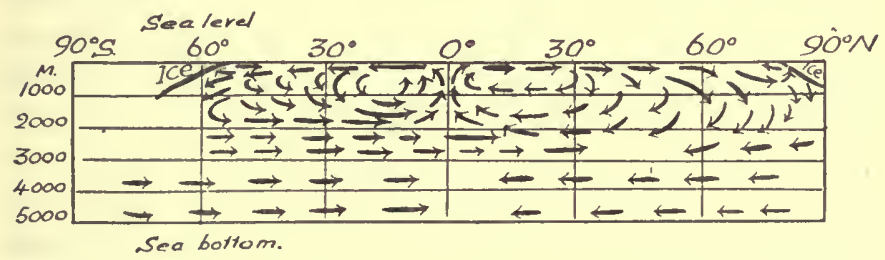

FrG. 57. An imaginary section of the ocean in a north and south direction. The superficial, intermediate and bottom currents flow in all directions, and generally obliquely to a meridian but only the meridional components are represented in the section.

It is necessary that they should come ashore, or become taken by trawls, in order that their average paths may be deduced. Thus direct observation of intermediate or bottom currents is practicable only in the marginal seas, and it is mainly there that such investigations have been made.

The figure represents, then, the main features only of the vertical circulation, and it must be admitted that there is considerable doubt even about these. It is probable, however, that the principal interchange of water between the equatorial and temperate zones goes on in a rather limited stratum which does not extend to a much 


\section{AN INTRODUCTION TO OCEANOGRAPHY}

greater depth than about 1,000 metres. Below this we probably have an intermediate drift of water from the Southern Ocean into the North Atlantic and Pacific Oceans, and below that again there is the very slow creep of water along the sea bottom at the greater depths from both North and South poles towards the equatorial regions.

The methods of investigating ocean currents.-Dead reckoning. To the seaman a current, or tidal stream, is an effect that can often be deduced from the difference between a position that he expects, and that which is actually observed. The position after so many days sailing may be expected from the "dead reckoning," that is the account which is kept of the course steered and the distance sailed (as shown by observations of the log towed astern). An astronomical observation, or a landfall, may show a very different position and if there is no reason to suspect unusual error in observation, or leeway that is not accounted for, the conclusion will generally be that the course of the ship was affected by a current. In some cases these differences between expected and experienced positions of ships at sea are the main reasons for giving values to the directions and velocities of ocean drifts. Currents having the velocities of tidal streams can usually be detected in other ways.

Drifter observations. Large slow movements of the sea water can generally be traced by observations of floating objects, and much of the investigation of ocean currents and drifts have been made in this way. Sealed bottles, weighted so as to float with their corks just submerged, and containing papers or cards with instructions for reporting their occurrence at sea or on shore, are set free at certain positions. They are found at other positions and the average drift and time occupied by this are then ascertained. A small light object floating at the surface of the sea is generally affected to a greater extent by the winds than by any movement of the water independent of the winds. Therefore the bottle is usually a rather large 
one and is so weighted that it is just submerged. When it is desired to observe the drifts at the sea bottom the bottle is so weighted that its specific gravity is just a little more than that which is expected of the sea water in situ. It therefore sinks to the bottom and is slowly rolled along there.

Sometimes a long, stiff wire is used as the weight and this drags on the bottom with the bottle bouyed upwards. Thus friction is minimised and the bottle is exposed to the drift to as great an extent as is practicable.

It is particulardy to be noted that these methods can usually give only average results. In many parts of the ocean the winds are variable, and so objects floating at the surface of the sea may drift about very irregularly as the wind-direction and velocity change. In shallow water near the land the tidal streams act powerfully on the drifters and since they change their directions every six hours or so a bottle under their influence may simply oscillate backwards and forwards over a path of several miles, at least, in length. The tidal streams also vary during the fortnightly period of neaps and springs and they and the winds may, together, give the drifters all sorts of paths. If, then, the time that elapses between the liberation and recovery of the drift-bottles is short, say only a few days, the paths taken by the individual drifters may vary in the most perplexing way-this is, indeed the usual experience. The point noted here is important because its full consideration shows that ocean currents are far more complicated in detail than the figures representing them usually indicate.

Nevertheless the method is valuable. When a sufficiently long period elapses between liberation and recovery of the drifter, say several weeks or months, it may usually be assumed that the wind has been blowing in many directions and with very variable velocities. Also the tidal streams may have been moving about as much in one direction as the other and any combination of the two factors may 


\section{AN INTRODUCTION TO OCEANOGRAPHY}

have occurred. Therefore the observations-especially if they are numerous-may give us the average or resultant effects of the winds and tides in causing movements of the surface water and this is very often the information that is wanted. Very much of what we do know about ocean currents and drifts has been obtained by such observations as those of drift bottles and other instruments ; floating wreckage; derelict ships; exotic seeds, plants, timbers, etc.

Direct current measurements. Various instruments have been designed to measure and record the movement of water at the surface of the sea or at lower levels. A log streamed out from a ship at anchor will record the velocity, and the direction is easily observed. There are, of course, numerous errors to be expected and compensated in such observations but we cannot deal with them here. Current meters can be used at any depth. In the best known of these instruments (the Ekman meter) a large vane sets the apparatus in line with the direction of flow of the water. A delicately pivoted and balanced propeller revolves as the water flows past it and this actuates a mechanism that counts and records the revolutions of the propeller. The direction is indicated by a compass attached to the instrument. This has a heavy magnetic needle bent downwards on either side of its point of suspension on the pivot and there is a slot on one of the arms of the needle. At certain intervals the recording mechanism allows a small metal ball to fall on to the needle and it then rolls along the slotted upper part of the latter and drops on to the compass card. The latter is a metal box divided into 32 compartments. The box is rigidly fixed to the frame of the apparatus, but the needle sets itself in the magnetic meridian and so its direction relative to the box is recorded. The velocity is deduced from the number of turns of the propeller made in unit time.

In other forms of current meter there is a pendulum which is lowered to a certain depth. From the direction 
and amplitude of swing of the pendulum the direction and rate of current is deduced. In others the pendulum swings above a compass card which is covered with wax. The centre of suspension of the pendulum is vertically over the centre of the card. When the apparatus has set itself the frame carrying the pendulum is allowed to fall a short distance, and then the pointed bob makes a mark on the compass card which indicates direction in which the current has swung it and the extent of the swing. In other instruments again a vane is suspended by two wires and the direction and velocity of the current are deduced from the torsion of the wires. And so on. All these forms of current meter must be calibrated by observations made in a flow of water of known velocity, or in a shipmodel tank.

Salinity and temperature observations. At any place in the ocean the salinity and temperature have values which are to be regarded as "normal" to that place and for a certain season. Thus the average temperature of the Atlantic in N. lat. $40^{\circ}$ and $\mathrm{W}$. long. $30^{\circ}$ is about $16^{\circ} \mathrm{C}$., and the average salinity at the same place is about $36^{\circ} \%$. Assume that the temperature varies throughout the year with the sun's declination. The salinity, however, does not vary in this way yet in some years its value may be $36^{\circ} \%$ and in other it may be $36.5 \%$. These variations can only he explained by assuming variability in the quantity of highly saline water drifting up from the S.-W. Atlantic. Or take the isotherms in the same region: we must suppose that these would be parallel to the lines of latitude if the temperature at any place depended only on the declination of the sun yet they are bent up towards the N.-E. in a very remarkable way. This can only be explained by postulating a flow of warm water from the S.-W. Atlantic towards the N.-E.

Plankton abservations. The pelagic animal and vegetable microscopic life of the sea varies from place to place, and its nature and abundance depend on the local conditions 


\section{AN INTRODUCTION TO OCEANOGRAPHY}

and on the time of year. Thus there are plankton animals (such as the Salpidae) which are oceanic in habitat yet in some years they may be found in great abundance in the North Sea. This can only be explained by assuming an invasion of water from the open Atlantic carrying the Salps with it.

Thus large bodies of water are characterised by their salinities, temperatures, faunas and floras. In these respects the water masses change very slowly. If these characteristics are found exceptionally in some sea area the conclusion is that they are present because of water movements. The latter can be traced by observation of the physical and biological characters. Animals of the planktonic category behave as minute drifters. 


\section{CHAPTER X}

\section{SECULAR CHANGES IN THE OCEAN}

We are now in a position to consider, in rather more detail, some of the matters discussed in Chapter II. The prominent features of the surface-morphology of the earth are :- (1) the shield-lands with their surrounding continental regions; (2) the occanic depressions and (3) the continental margins. Both the shield-lands and the oceanic depressions have a certain character of endurance in time when compared with the transitional regions between them. These latter regions comprise that zone of sea bottom round the continents which is less in depth than about 1,000 fathoms and the lands adjacent to the coasts but, on the whole, outside the areas of the shields. Relative instability, when compared with either the shieldlands, or the ocean bottoms, characterises this transitional region.

Its general character varies in different parts of the world. Consider first the continental shelf : we have seen that this has a relatively great width in the North Atlantic and on the South-West of the Pacific, and that it is mostly narrow and contracted along much of the South Atlantic, on the East and North Pacific and on the East side of Africa. Now take the continental land margins and we find analogous differences. In the North Atlantic the coastal land has, in general, moderate elevation and it is old land which is much eroded and is relatively stable. On the other hand the coastal lands bounding the eastern and northern sides of the Pacific have high elevation, and the presence of numerous volcanoes indicates their relative instability. But, again, there are other coastal landsthose on the western side of the Pacific, in the West Indies 


\section{AN INTRODUCTION TO OCEANOGRAPHY}

and in the Cape Horn Antarctic region, where the elevation is moderately low, but where the presence of chains of islands indicate an immediate past, or a present instability.

How did these prominent earth-features originate, and to what extent have they endured throughout the great geological periods? Several hypotheses of earth-shaping were discussed in Chapter II. These were: (1) the older hypothesis based on a gaseous-molten stage in the evolution of the earth. The materials of the latter solidified, first at the centre and then progressively towards the surface. The central parts retained heat for very long periods but continued to contract, and do still contract. With the contraction the surface layers became distorted in various ways. One of these ways is very frequently supposed to have given the earth a tetrahedral figure and the coigns, or solid angles of the tetrahedron (twinned in the way some crystals are) are now said to be represented by the shield-lands ; (2) Still assuming a gaseous-molten stage it is argued that a difference in position between the centre of figure of the earth and its centre of rotation would arise as the materials of the earth stiffened into the rigid state. Then a certain distribution of elevated surfaces above the mean level, and depressed surfaces below the mean level would come into existence; (3) Assuming that the earthbody grew by the accretion of planetesimals there were probably differences in the rates of rotation. The latter would gradually steady down to its present value as the materials of the earth became rigid under the strains set up by self-gravitation. But while the earth-body grew and was assuming this condition of high rigidity it must have yielded whenever the rate of rotation changed. It would tend to yield along certain zones.

Now on these hypotheses there would be regions of elevation and depression (1); regions of deformation set up by internal strains (2); and zones of segmentation (3): in any case the earth-body would tend towards a condition of stability (which is already attained, or is approaching) 
such that the surface features-that is, the continental elevations, the oceanic depressions and the marginal zones. -would be as they are now. The continents and oceans, as we know them, would be permanent features of the earth's surface.

It now remains for us to examine the nature of the marginal, continental-oceanic zones, and what other evidence we have as to the past distribution of land and sea, in order to test this conclusion of oceanic and continental permanence. We have already considered the morphology of the oceanic bottoms and we may, very summarily, say something about the continental elevations and their marginal regions.

The shield lands. - These are--in the Eastern Hemisphere --(1) Angara (Northern Asia and Siberia); (2) Baltica (the Scandinavian-Russian region); (3) Ethiopia (the greater part of Africa); (4) and (5) Lemuria (Madagascar across to India) and (6) Australia (the major part of that continent). In the West we have (1) Laurentia (the region round the Gulf of St. Lawrence); (2) Columbia (in Mexico); Antillia (the West Indian region); (4) Amazonia (Brazil and N.-W. North America); (5) Archiplata (Patagonia). There is also the Antarctic shield-land (Antarctica). The terminology, and descriptions of the shield-lands differ somewhat in the books and Suess' original conception has been greatly extended.

The shields are represented by the roughly oval areas on the series of maps, Figs. 64, A-F. They consist mainly of archean rocks which are highly metamorphosed by long-continued stresses. In these masses of metamorphic rocks are igneous intrusions of more recent date. On the shields there may be strata of Paleozoic or later origin. The general level of the shield-lands is rather low, and the fact that they may be overlaid with sedimentary rock indicates that they have, at times, been at the bottoms of shallow seas. What distinguishes them from other continental regions is the absence of 


\section{AN INTRODUCTION TO OCEANOGRAPHY}

folded strata and this means that they are highly resistant land masses which have been able to withstand horizontal pressures, or thrusts, exerted from the regions around them. This character of stability they must owe to some conditions in the earth-mass beneath them and so the existence and situations of the shield-lands is, in some way, to be traced back to the processes that have made the earth body as a whole.

Whatever we may conclude as regards the permanence of the oceanic depressions we may be fairly certain that the shield-lands have always been regions of elevation above mean spheroidal level. They are the nuclei of the continents: fixed points in a shifting, superficial earthstructure.

The oceanic depressions.-What we do know with regard to the beds of the great oceans has been summarised in the earlier chapters of this book. The floor that is indirectly accessible to our observation is, of course, a layer of ooze or mud and we know it only to a depth of about a foot or so. Its nature depends on the processes-chemical, physical and biological-that are in operation in the waters lying on the sea bed. What lies beneath the stratum of ooze that we can sample we do not know and there is no immediate prospect of such knowledge being attained. For our ideas, such as they are, about the nature of the lithosphere beneath the floors of the ocean we have to depend on the examination of the rocks that compose the substance of the oceanic islands. These are volcanic and that is all we can say about them with safety. The oceanic regions, then, represent depressions of the earth's surface beneath the mean spheroidal level. The nature of the lithosphere beneath these depressions is unknown, and there are no sedimentary rocks accessible to our observation that indicate, in any way, that they have been deposited on the floor of a deep ocean.

The oceanic-continental margins.-Round the shieldlands, but still on the general continental region we have a 
great variety of conditions. On all this area, and at some time or other in the past, the sea has transgressed, so that much of the continental surfaces have formed the bottoms of epi-continental seas, or great lakes, or lagoon formations. These lands have been eroded, or have undergone peneplanation, or even subsidence. Although all this may have occurred over the continental regions we need not assume that there has been a depression of level there to a depth greater than over the average continental shelf region. We are not concerned here with the vicissitudes of the continental regions between the shield lands and the oceanic margin. That is a subject of pure geology.

The marginal zones, that is, the continental shelves and the borders of the continents inland from the coasts, are regions of instability and topographical change. The causes of this instability may be put into two categories:-

(1) Those due to the evolution of the earth-body itself. From the gaseous-molten hypothesis we deduce that the earth is still cooling and, therefore, contracting. The contraction is least of all at the surface and so the thin film of sedimentary rock there must be thrown into folds or wrinkles as it falls inwards upon an earth-body that is shrinking away from it. The folding or crumping will, obviously, be greatest on the borders of the continents, since here we have, not only a slope from elevated to depressed regions, but also strata which, on the one hand are being lightened by erosion, and on the other, are being weighted by deposition. The marginal zones are, therefore, instable.

Also on such a hypothesis as that formulated by Chamberlin from the planetesimal conception we have regions of weakness in the earth-body itself. These will obviously tend to be the transitional zones between regions of elevation and depression.

(2) Apart from any hypothesis of the shaping of the present superficial features of the earth we can easily see how the oceanic-continental margins must be zones of 


\section{AN INTRODUCTION TO OCEANOGRAPHY}

instability-just because they are the transitions between elevated and depressed regions. There is, everywhere on the surfaces of the continents, erosion by the gases of the atmosphere, by rivers and by ice. On the coast itself there is disintegration of rock by the action of the seas. Rivers and glaciers and winds transport material in the form of boulders, stones, mud and dust, while gravels, sands and muds are transported by tidal streams, heavy seas and currents. The result is that enormous masses of material are removed from some regions and re-deposited on others-in general eroded rock materials are taken from regions of higher elevation and laid down in other regions of lower elevation. This may occur in the interiors of continental regions where sediments are being deposited in lakes and lagoons, but the deposition must occur, on the great scale, on the sea bottom adjacent to the continental land. Eroded earth material is, therefore, taken from the elevated continental land and is laid down on the adjacent sea bed.

But it is very important to note that the deposition must take place almost entirely on a very restricted zone of the sea bed close to the land. Stones and gravel can only be transported for great distances out to sea by icebergs, and this accounts for relatively little material. Gravels and sands are not carried in suspension by currents which have the velocities which we have studied, but are rather moved along the sea floor itself by breaking seas and wave action. At very moderate depths wave action must cease to affect the sea bottom in so far as the carriage of gravels and sands is concerned. Muds may be carried in suspension by water which is moving with the velocities of spring tidal streams (in British seas), but even at a very few miles from the land, muds are usually deposited largely because of the precipitating effect of the ions in sea water. Therefore, nearly all the materials that are eroded away from the land and are carried down to the sea by rivers are deposited on the continental shelf usually within a 
distance of, say, ten to a hundred miles from the land. The quantity of material taken from the land and laid down on the ocean bed beyond the 1,000 fathom line is so small that it may be neglected altogether.

That means that nearly all the material resulting from the erosion of very extensive land regions is laid down along a very narrow zone of sea bottom immediately adjacent to the land. A glance at the charts of depths given in Chapter II. will show that extensive masses of eroded materials can only accumulate indefinitely on the continental shelves in the vertical direction. It is indeed possible that the continental shelves may grow out seawards as they become loaded with sediments, and this may be the case with the shores of the North-East and North-West North Atlantic. But it secms probable that long before this outward growth of the shelves has occurred the loading will have proceeded so far as to bring ahout isostatic readjustment.

That is to say, there must be an always increasing load on the sea bottom adjacent to the land, in such regions where there is extensive land erosion. Masses of sediments must, therefore, accumulate and press downwards on the stratum of lithosphere where the earth materials are selfcrushed or are potentially "flowable" or plastic. The processes mentioned on pp. 22-23, occur in the yielding stratum and the material of the latter is squeezed out, so to speak, laterally from the zone of excessive loading. It may "flow" into the regions beneath the ocean bed or into those beneath the land and, in the meantime we assume that the latter direction is taken. Therefore an horizontal, lateral pressure will be exerted from the loaded continental shelf region upon the strata beneath the adjacent land. This is a thrust.

Its effect will be to fold those strata-should that be possible without rupturing them. How the fold occurs can easily be represented. Place the tips of the spread-out fingers on the right hand page of this book laid open on 


\section{AN INTRODUCTION TO OCEANOGRAPHY}

the flat, and then push gently towards the left. The upper page or pages (the strata) will rise up in a fold and the crest of this will move from right to left with its advancing side steeper than the trailing one. At the centre of the book the fold will turn over so that the advancing side turns in underneath the crest. This represents an overfold and its effects. Now place the spread-out fingers of the left hand lightly on the right hand page along a line about an inch or so from the centre and push as before. A fold will form and will move towards the left, but its advancing side will be less steep than the trailing side and the latter will ultimately turn in under the crest. This represents an under fold and its effects.

Such thrusts on a gigantic scale must be produced, on the theory of isostasy, when a large part of the continental shelf becomes so weighted down by accumulated sediments as to lead to readjustment. The load just off shore is largely increased while that over the eroded area is reduced. Thrusting from the continental shelf must, therefore, have notable effects on the uneroded horizontal strata of the adjacent land regions, folding them over or under. What actually will happen must, of course, be highly complex depending on a host of conditions. Upper strata undergoing the thrusting pressure may be broken and faulted with the production of earthquakes. Enormous pressures may transform into heat with the result that accumulations of fluid rock (magmas) may form in the cores of the folded strata and give rise to volcanic effects. The underlying strata may be folded and metamorphosed while the superficial ones may be broken into series of faults. Such foldings will form the flanks, at all events, of mountain ranges but, it would appear, some other factors leading to actual uplift must be at work to account for the elevations that are to be seen on the margins of the oceans.

The regions where such earth-folds occur are those between the coasts and the margins of the shield-lands. The latter show no indications of mountain ranges produced 


\section{SECULAR CHANGES IN THE OCEAN 309}

by the foldings of strata : they resist the lateral thrusts set up by loading of the adjacent sinking areas and upon the directions in which this resistance to the thrusting pressures is exhibited, as well as upon the ways in which the loads are distributed in the area of sedimentation will depend the directions of the earth-folds.

Thus the marginal oceanic regions (the shelves) are characteristically areas of sedimentation and vertical loading, resulting in periodic crises of thrusting stresses. The continental margins will exhibit the results of these stresses in under- and over-thrusting pressures sustained by the strata and leading to folds that mark the directions of coastal (or even submarine) mountain ranges. There will be the subsidiary effects of yielding of the strata by fault-formation-and thus earthquake phenomena. There will be great heat development that finds its expression in volcanic effects. In these ways the instability of the oceanic-continental margins is manifested.

We may now examine the conformation of the oceanic margins with the above observations in mind.

(1) The Pacific Ocean.-The following sketch chart gives a general representation of the morphology of the Pacific Ocean. The main features are (1) the long, slightly curved folds that mark out the situations of the American, coastal mountain ranges; (2) the shorter, curved folds on the Asiatic coast and round Australia, and (3) the curved chains of islands on the western coast. These are the most elevated parts of earth folds that are mostly submarine.

The long arcuate folds. These lie along the coasts of South and North America and mark out the situation of the great Pacific geo-syncline. They give us the existing mountain ranges-the South American Andes, the Andean Cordilleras, the Sierras in Chile and Mexico, the Cascade Mountains in North America and the Alaskan ranges. The folds run in long, gentle curves with the convexities turned towards the ocean. On the Pacific side the slopes 


\section{AN INTRODUCTION TO OCEANOGRAPHY}

are less steep than they are inland. Behind these coastal arcs are others, or the indications of others, which mostly face the other way: thus in North America we have the

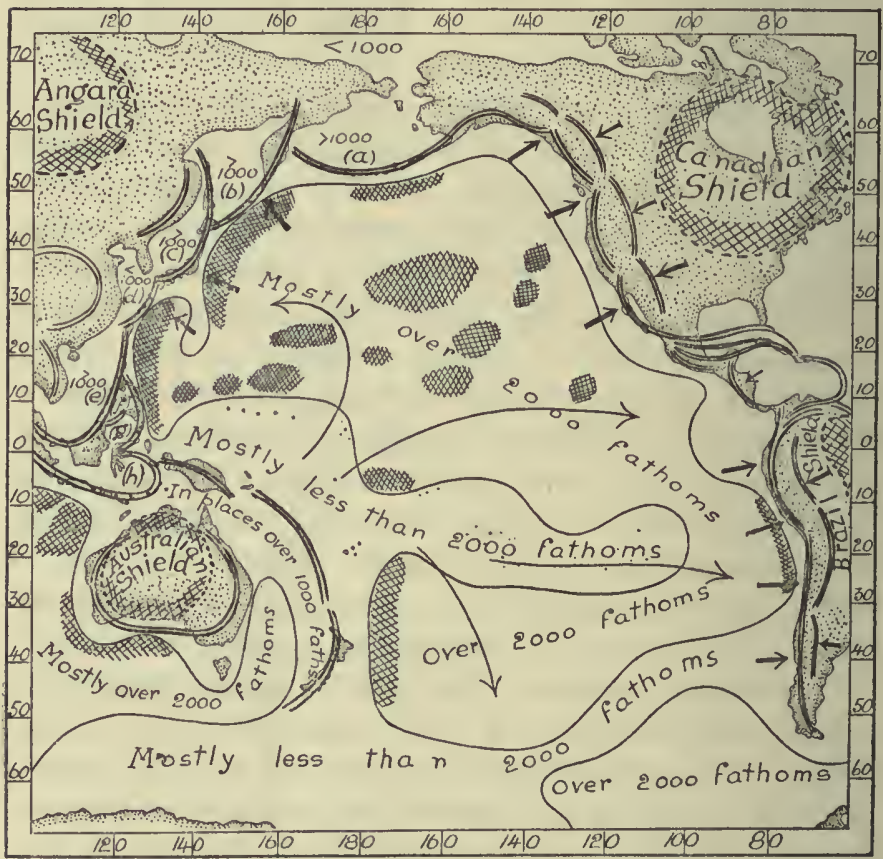

Fig. 58. The Pacific Ocean showing (by double contours) the lines of foldings; the shield-lands and the ocean deeps. The shields are cross hatched and so are the deeps (over 3,000 fathoms). The continuous contour line on the surface of the ocean follows roughly the 2,000-fathom depth contour but it is also drawn so as to include between it and the land most of the large and small Pacific Islands and to exclude the deeps. The short arrows indicate the directions of the thrusts (when known) and the long curved arrows suggest the general directions along which the Pacific floor has been tilted downwards, or depressed, with the Australian Shield as a kind of pivot. The reader should examine the sketch chart, along with the one on p. 57, and a large scale general chart of the entire region.

Rocky Mountains running roughly parallel to the coastal ranges and between the two is the situation of the Great 
Basin, the locus of a North American inland sea of Cretaceous to Tertiary date. Several series of thrusts have contributed to the formation of these long arcuate foldings-from the ocean to the land, and from the Cretaceous sea outwards to the coasts of this old basin in both directions.

The coastal ranges mark out a region of instability characterised by the events that have lifted up the mountain folds on the continental margin and depressed the sea bottom on the oceanic one. There are both earthquake and volcanic phenomena along this geo-synclinal zone. It has been regarded as the typical oceanic margin-a narrow continental shelf, outside which the ocean bed goes down to great depths and within which the land rises to as great heights. So far from being typical the Eastern Pacific coast is really exceptional.

Round Australia and on the Asiatic Continental Coast, in China and Siberia we have similar foldings laid out in long arcs and turned with their convex sides to the Pacific. Far more characteristic, however, of this Western Pacific region are :-

The Insular arcuate foldings. These are represented in Figs. 59 and 60 . What we see here are earth-folds that are mostly buried beneath the ocean, showing only their most elevated parts as chains of islands. The latter are laid out in short curved lines and also turn their convex sides towards the ocean. Here also we find evidences of instability in the presence of numerous volcanic vents along these island ares and in the occurence of earthquakes. On the oceanic side of the island arcs the ocean bottom goes down to greater depths than on the outside of the great American geo-syncline. Within the arcs, that is, between the islands and the continental coasts we have epi-continental seas. These are not merely situated on the continental shelf but may go down to depths of 1,000 to 2,000 fathoms.

The great Pacific Island arcs are : (Figs. 58-9)-(a) The 


\section{AN INTRODUCTION TO OCEANOGRAPHY}

Aleutian arc which begins with the Alaskan mountains and runs out into the Pacific as the Alaskan Peninsula. It is continued West as the line of Aleutian Islands ending on the East on the Kamtchaktan Peninsula. Within it is the Behring Sea with depths of 1,000 to 2,000 fathoms.

(b) The Kurile arc. The Kamtchaktan Peninsula is continued to the South as the line of Kurile islands. These turn gently towards the East and end in the Japanese island of Tezo. Within them is the sea of Okhotsk with a depth of rather over 1,000 fathoms.

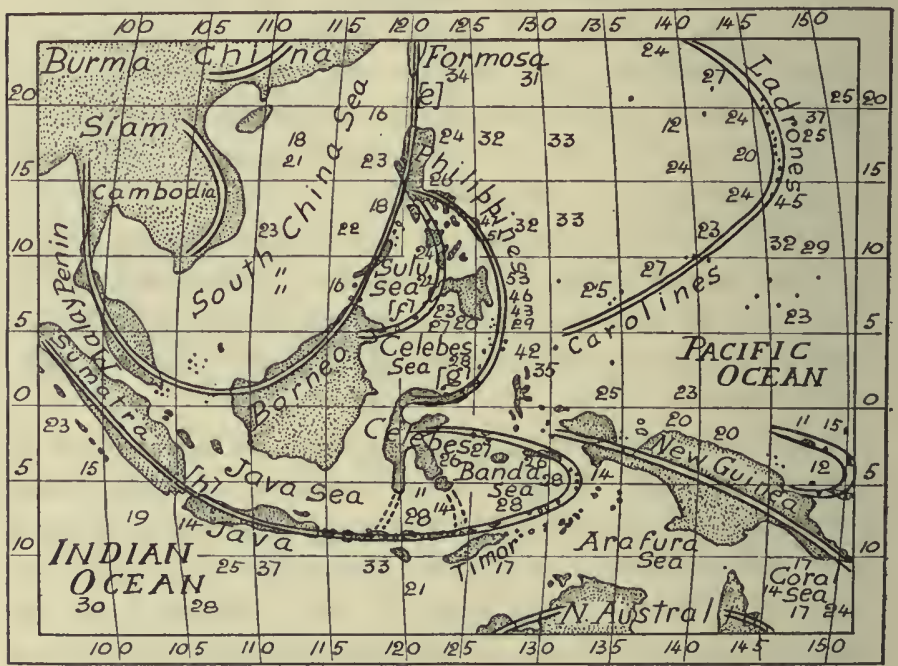

Fic. 59. The East Indian Islands showing the lines of foldings. The soundings (to be multiplied by 100) are in fathoms.

(c) The Japanese arc. The Japanese Islands run mainly meridionally and then turn towards the West. The fold represented by them is continued on to the Asiatic Continent through the Korean Peninsula. Within this arc is the Sea of Japan with depths of over 2,000 fathoms. Outside the Kurile and Japanese arcs is the greatest of the Pacific deeps, where soundings of over 5,000 fathoms have been recorded. 
(d) The Lu-chu arc. This starts in the North with the Japanese Island, Kinsiu, and is continued by the line of Lu-chu Islands. It turns to the South-West and ends in Formosa. Within it is the Yellow Sea. This is situated on the continental shelf though we may regard it as an epi-continental sea rapidly filling up with sediments.

The Festooned East Indian Arcs.

(e) The Phitippine-Bornean-Malayan arc is formed by the Islands of Formosa, the inner Philippines, the earthfolds on the North-West border of Borneo, a series of small islands and the Malayan Peninsula, through which it is continued into Cambodia. Within it is the epi-continental South China Sea with occasional depths of over 1,000 fathoms. Without it are the island festoons.

(f) The Philippine-Sulu arc which is formed by the Western Philippines and the Sulu Islands connecting the latter with the North-East corner of Borneo. It, and the inner Philippine arc enclose between them the Sulu Sea. This is an epeiric sea situated on the continental shelf.

(g) The Philippine-Celebes arc. Outside the last island chain is another beginning with a strung-out series of Philippines and carried on into the northerly process of Celebes. Between it and the Philippine-Sulu arc is the Celebes Sea, an epi-continental with occasional depths of over 1,000 fathoms.

(h) The Javanese arc. Obviously the elongated islands of Sumatra and Java form an earth-fold continued to the East through Flores, Timor and the Moluccas and ending in the eastern process of Celebes.

All the arcs mentioned so far are of late Mesozoic date. But the two southerly processes of Celebes appear to represent arcs of Pre-Cambrian age. Within the Javanese arc, and bounded by Celebes and Borneo, are the Javanese and Banda Seas which are epi-continentals with occasional depths of over 1,000 fathoms.

The exterior West Pacific arcs. Well outside the East Indian festoons there are indications of yet other submarine 


\section{AN INTRODUCTION TO OCFANOGRAPHY}

earth-folds. The island chains of the Ladrone and Caroline groups suggest such a line of folding carried out away from the Philippines and then in towards Celebes. From Celebes again another fold seems to run through New Guinea and then into the New Zealand group. Doubtless a more detailed survey of the Pacific sea bottom on this central part would indicate the existence of other lines of folding. In these cases we could have, of course, no indications of the actual geological structure, and the interpretation of the series of elevations as actual earthfolds is based on the analogy of the lines of elevation with those other ones the structure of which is known.

The Pacific borders, then, are formed by great earthfolds produced by thrusts from the oceanic, towards the continental regions. These thrusts have raised up the strata into long, gently curved folds (the American coastal regions), or into short, more sharply curved folds (the Western Island series). The convex sides of all the folds turn towards the ocean and nearly everywhere the folded regions are characterised by volcanic and earthquake phenomena. To these characters of the Pacific we return at the end of this chapter.

(2) The Atlantic Ocean.-At first sight the Atlantic differs strikingly from the Pacific Ocean. Nowhere do we have such a coast in the Western Ocean as we see in the West margins of the American Continents. The long, sweeping folds with their convexities turned to the ocean; the narrow continental shelves sloping down quickly to nearly 3,000 fathoms and the lines of volcanoes on the back slopes of the mountains are features which are absent from the Atlantic oceanic-continental margins. In the northern part of the Western Ocean we have a remarkable extension of the Continental Shelf that we do not see in the Pacific region. The chains of islands arranged in arcs of quick curvature are indeed present in the Atlantic but not to nearly the same extent as they are exhibited in the West Pacific region. Finally the great stable land 
mass of Africa dominates the South Atlantic (as it does the Indian Ocean). There the long, arcuate, coastal foldings are almost entirely absent and instead of them we have a great, fractured table-land: a "mosaic of alternating plateau and plain " covering and surrounding the shieldareas. In spite, however, of these apparent differences we shall find that the morphology of the Atlantic region is fundamentally the same as that of the Pacific and that it is the phase in the process of evolution that distinguishes between the two oceans.

The characters represented in Fig. 60 are really the same as those shown in the two charts of the Pacific on pp. 310, 312. The long arcuate folds, as well as the short, sharply convex ones, also occur but the fundamental resemblance is obscured by the condition that the Atlantic is an older oceanic basin. Thus emphasis is laid, in Fig. 60, on the distinction between longitudinal and transverse coasts, the former being represented by mountain ranges running roughly parallel with the sea margins and the latter by ranges running down into the sea perpendicularly, or at high angles to the general directions of the coasts. In the Atlantic such transverse coasts are the loci of Rias and Fiords.

Ria and Fiord Coasts. The typical Ria coasts are those of Galicia, where the Calabrian mountains tilt downwards into the ocean. Here are ancient earth-folds, the oceanic extremities of which have subsided, so that we have valleys in which the seaward parts are drowned, so to speak. They are the depressions between the crests of the folds. Passing down them towards the ocean both the widths and depths of the valleys increase. Similar Ria coasts are to be seen on the shores of Nova Scotia, Cape Breton Island and Newfoundland. Here the ancient Appalachian mountains range dips down into the Atlantic.

Probably fiords have much the same origin but their subsequent history has been very different. They are depressions of elongated form, with rather greater depths 


\section{AN INTRODUCTION TO OCEANOGRAPHY}

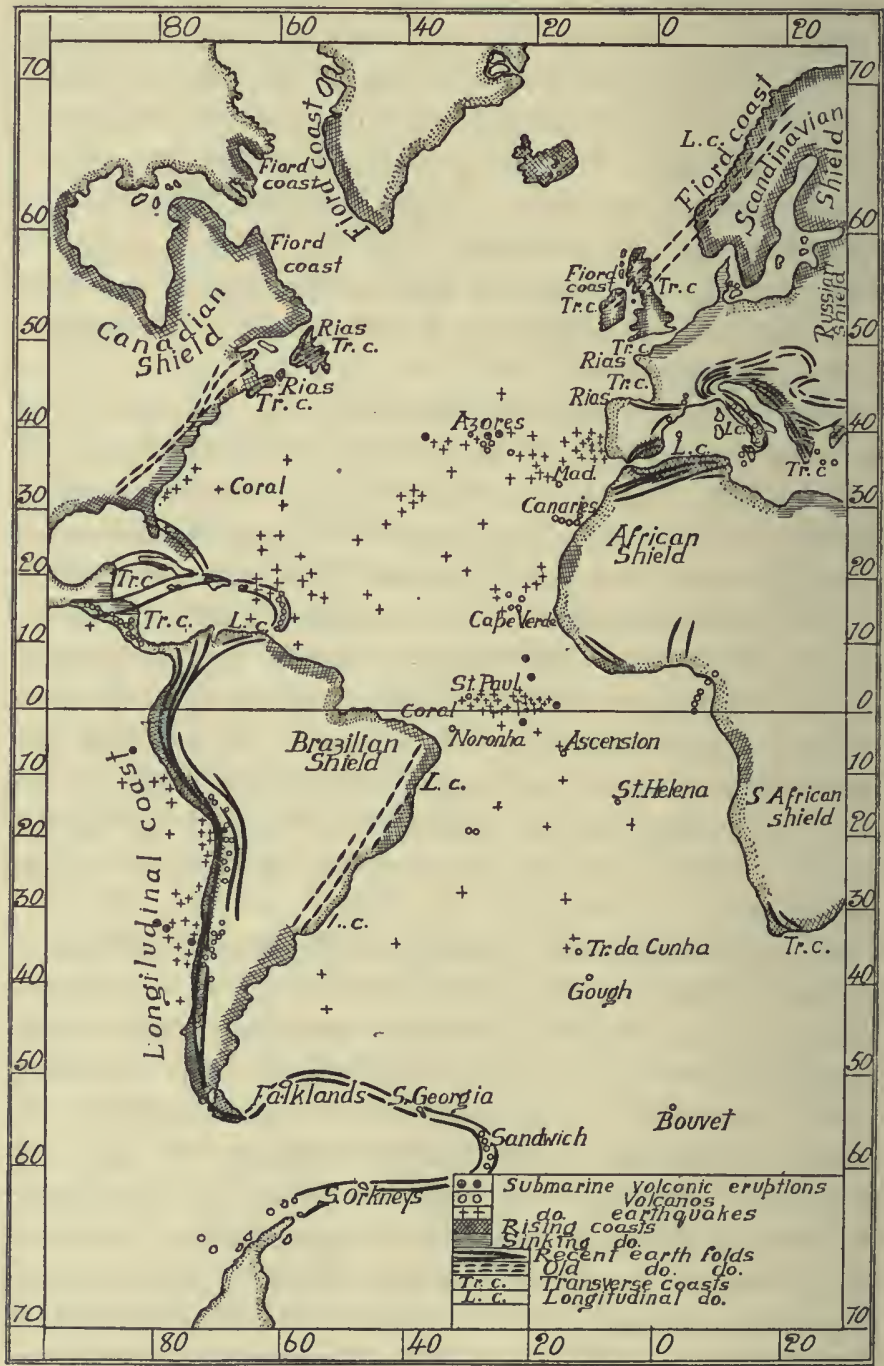

Fig. 60. The Atlantic Ocean showing the shield lands and the characters of the oceanic-continental margins. 
than the Rias, with very much the same width and depth throughout except at the seaward extremities where there is usually a shoaling of the bottom in very much the same way as a dock sill separates the basin from the sea outside. These peculiarities are ascribed to the scouring action of ice on the bottom of the fiords. As the glaciers which formerly filled them projected outwards into the sea they broke off as icebergs, or melted. Therefore material was laid down at the mouths of the fiords to form the sills while the bottoms, landwards from the sills, were ground away by the ice.

The longitudinal and transverse Atlantic coasts nevertheless reveal to us just the same series of long arcuate and insular folds that we have studied in the Pacific. But the Atlantic oceanic-continental margins have undergone long-sustained changes in comparison with the Pacific, so that our longitudinal coasts are a kind of marginal debris and the transverse ones are the ends of other folds, the greater parts of which have been eroded away. So far we are rather emphasising the similarity between the two basins, but we shall see later (p. 334) that there are some characters in which the Atlantic appears to differ in a striking way from the Pacific.

The long arcuate folds. These are represented in Fig. 60, by the broken lines running along the East coast of $\mathrm{N}$. America ; the coast of Scandinavia and the East coast of $\mathrm{S}$. America. They are old folds, of early Mesozoic origin and are much eroded. Without doubt, the East N. American fold, represented now by the Appalachian mountains, was originally continuous with the Scandinavian fold, which extended across the North Sea and Scotland as the ancient Caledonian mountains. A rather similar, ancient, long arcuate fold is seen as the debris of mountain ranges running along the East coast of S. America. We refer further to these structures on p. 332.

The short arcuate folds. The only typical instance, in the Atlantic, of a short sharply curved fold is that which 


\section{AN INTRODUCTION TO OCEANOGRAPHY}

encloses the Mediterranean. The Sierras in Granada appear to curve round to the South across the Straits of Gibraltar and become continuous with the coastal mountains in Northern Morocco.

The Insular Arcuate folds. Just the same conditions are to be seen in the Atlantic as those which we have studied in the case of the West Pacific coasts.

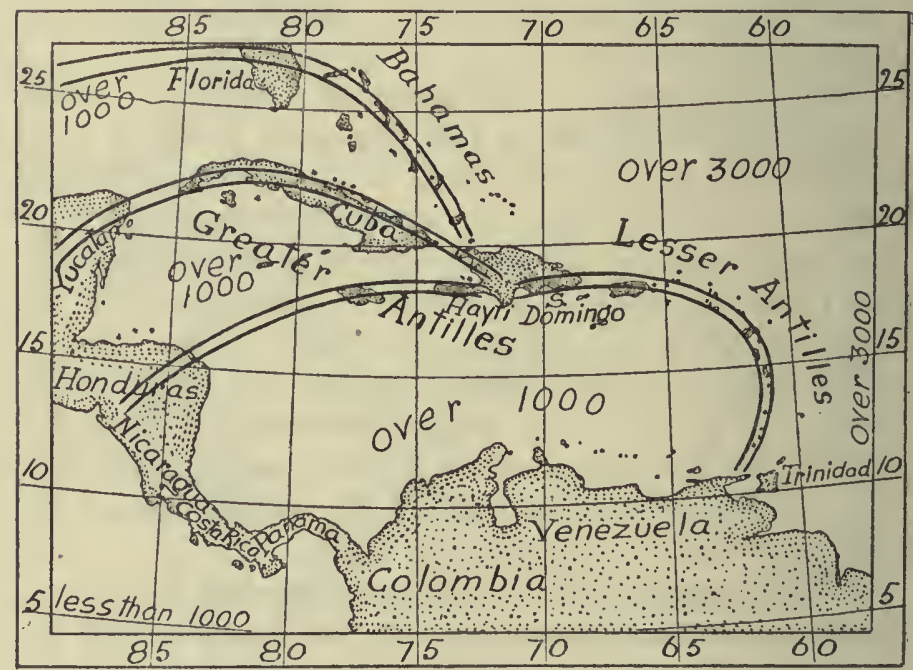

Fig. 61. The West Indian Archipelago showing the arcuate arrangements.

The West Indian arcs are represented by rows of islands acranged in sharply curving lines.

The great foldings that run along the East Pacific coasts, turn inwards in Central America and Southern Mexico, and run transversely across the Continent to emerge into the Atlantic as the Islands that bound the Gulf of Mexico and the Caribbean Sea. The Venezuelan 
fold runs out into the Atlantic at Trinidad and is continued as the line of the Lesser Antilles and terminates at San Domingo. The Mexican fold runs out through Florida and is continued as the Bahamas, also terminating in San Domingo. There are two interior arcs also pivoting on the latter island: one turns in towards Honduras, the other runs through Cuba to Yucatan. Within these island arcs are true epi-continental seas of over 1,000 fathoms in depth. They are the loci of numerous volcanoes and are thus regions of earth instability.

The American-Antarctic arc is not so well known. The great Andean mountain system of folds turns East in Tierra del Fuego, is continued along a sharply curved line marked by the Falklands, South Georgia, the Sandwich group, the South Orkneys and Shetlands and is terminated in Graham Land in the Antarctic Continent. This island arc is peculiar in that there is behind it no continental hinterland, as is the case with both the West Pacific and the West Indian arcs.

The Indian Ocean.-Something must be said about the larger features of the Indian oceanic margins although less that is interesting is known about this region than in the case of the Pacific and Atlantic.

The only features that we notice here are :-

(1) The apparent dominance of the African continental shield-land. Here we have the greatest area of land on the earth that is unmarked (except in the extreme North and at the Cape region) by mountain folds. It has been elevated and depressed and great land blocks are marked out by lines of faults but the thrusts from the ocean have not been powerful enough to form the folds that are characteristic of the American and Asiatic coastal margins.

(2) The relative shallowness of the western margin. The continental shelf, and the zone of sea-bottom between 1,000 and 2,000 fathoms in depth is greater in area on the western than on the eastern side of the Indian Ocean. 


\section{AN INTRODUCTION TO OCEANOGRAPHY}

Madagascar, the Sevchelles, the Chagos, Maldives and Laccadives Archipelagoes may very probably have been the highest parts of a land region connecting Africa with India and lying to the East and South of an Arabian basin-a former epi-continental sea.

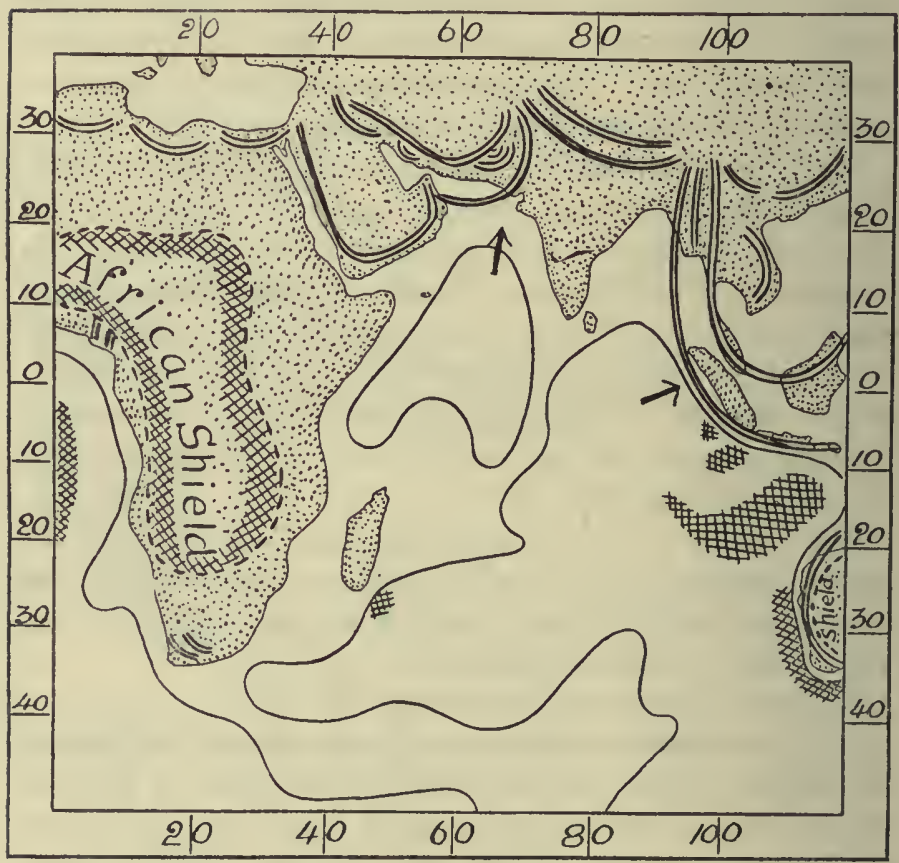

Fra. 62. The Indian Ocean region, showing the shield-lands (cross hatched); the greater earth-folds (double lines); the ocean deeps (cross hatched) and the depth-contours. The latter follow approximately the 2,000 -fathom line and are drawn so as to include the shoal regions and to exclude the deeps (over 3,000 fathoms).

(3) The absence of deeps on the western side. This is in strong contrast with the frequency of oceanic depressions on the eastern side of the Indian Ocean. 


\section{THE HISTORY OF THE OCEANS.}

We are now in a position to examine the question of the permanence, throughout geological time, of the great oceanic depressions. There have always been two opinions-(1) that founded on the various hypotheses of earth-origin and holding that the oceans have always been regions of earth depression, and have occupied their present places, and (2) the other holding that oceans and continents have changed places more than once during the period of time represented by the series of sedimentary rocks. Nowadays the latter hypothesis has been modified to some extent. It is generally believed that the shield-lands have always been regions of elevation, and that they are traces of an original earth-structure on the great scale. It must also be made clear to the reader that all parts of the continental regions may, at one time or another, have been at the bottoms of shallow seas, even though thay may have yet been placed above the mean spheroidal level. Our question then, is this: have bottoms of the present oceans been at any past time, dry land?

The evidence available.-In considering this question various lines of evidence are available. These are-(1) the larger geological structures, in particular those of the oceanic-continental margins with regard to the earth-folds, and the lines of weakness that are indicated by volcanic and earthquake phenomena; (2) Stratigraphical facts, that is, the occurrence and distribution of marine sedimentary rocks on the continental regions; (3) The evidence afforded by fossils as to the lines along which both terrestrial and marine animals have migrated; (4) The absence, in the sedimentary rocks, of any strata similar to the oozes that are now being deposited at the bottoms of deep oceans. These various lines of evidence may now be briefly summarised.

(1) We have dealt with in the earlier part of this chapter. Presently we shall look into its significance. 

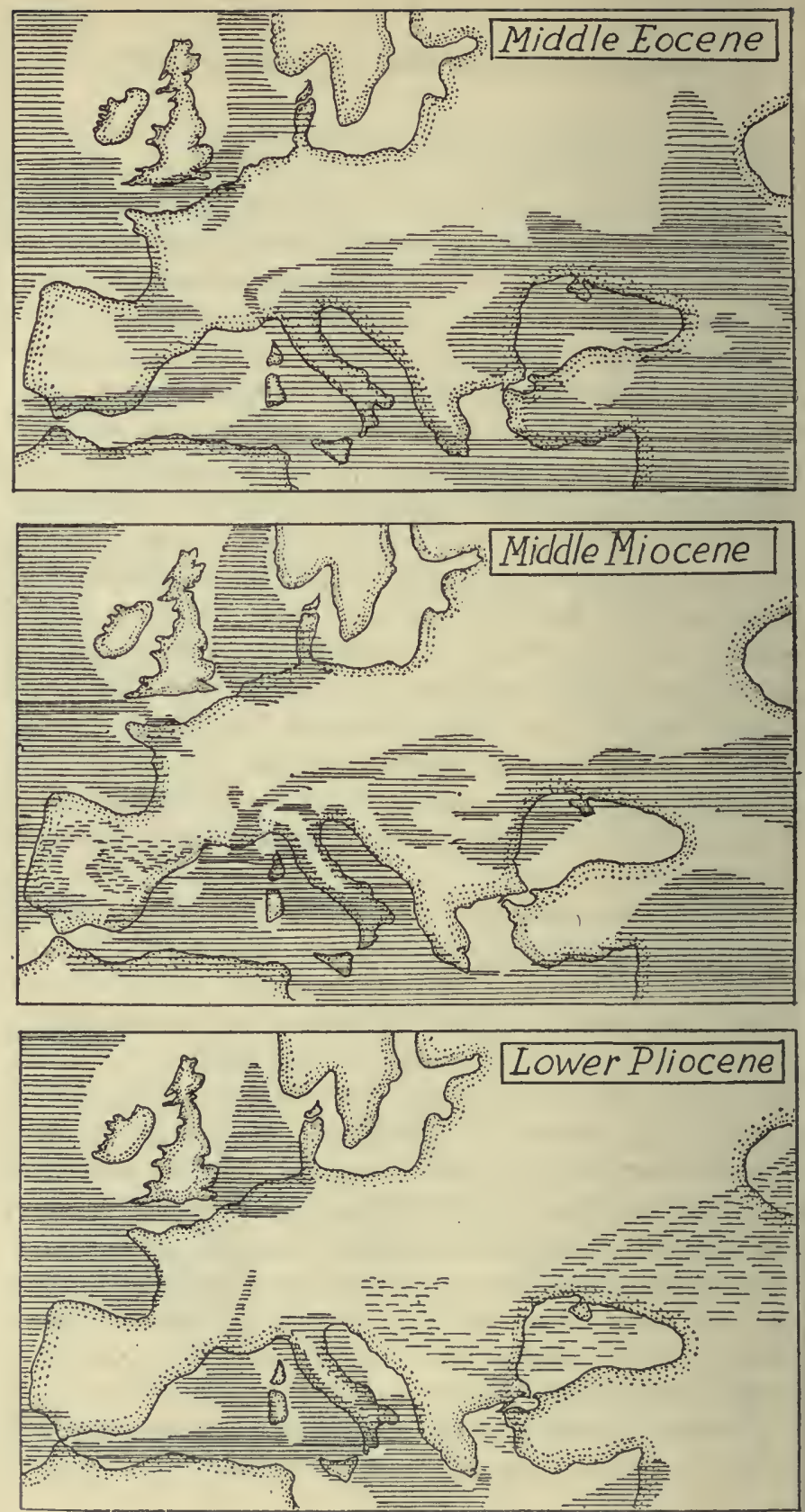

Fra. $63 \mathrm{~A}$ to C. Central Europe at various times during the Tertiary Period. Horizontal lines=sea; broken lines=lagoon lands. 
(2) Is a matter for pure geology. It is sufficient to say here that in very many places on the continental regions there are sedimentary rocks that must have been laid down at the bottoms of shallow seas. Large parts of North America and Central Europe, for instance, have been under water (the sea, fresh lake water, or lagoon water). To illustrate this we give here three charts showing Europe in tertiary times.

(3) We must deal with in rather more detail.

The paleontological evidence.-It is now generally agreed that all species of plants and animals on the earth have evolved from simpler forms and that the process of evolution has been a single one. It is possible that large regions of the earth may have heated (by radio-active changes in the interior) so strongly as to have destroyed all life and that evolution may then have begun anew. It is simpler, however, to assume that this has not been the case and that there has only been one evolutionary process-all the existing form of animal life being thus blood-related. Further we assume that each great group of animals (the mammalia for instance) have originated in some one area and have spread over all accessible and suitable regions from this original focus. As they so spread they became modified or evolved: with the spreading there was adaptation to new conditions. The process is one of adaptive radiation.

In spreading, the animals encountered barriers. Broad seas would be a barrier to the movements of terrestrial mammals and so would extensive desert areas, very high and long mountain ranges, or great forests populated with enemies-say parasitic insects. There might be other less unfavourable conditions such as relatively high or low air temperatures, etc., but to these the migrating animals might be able to adapt themselves.

So also with other terrestrial animals and plants. Barriers or obstructions, depending on the habits of the species would exist in many cases. 


\section{AN INTRODUCTION TO OCEANOGRAPHY}

Similarly there would be barriers to the spreading of marine animals. Many such can only live and reproduce on the sea-bottom in relatively shallow water: many species of molluses, crustacea, polyzoa and foraminifera, for instance. These animals, although living in shallow water on the inner edges of the continental shelves may produce pelagic larvæ, that is, young stages which drift about in the sea near the surface. But these pelagic (or planktonic) stages are of short duration. At the end of its development the animal must find its habitat in a sea bottom below shallow-water. If this metamorphosis from the larval, to the adult stage occurs in the open ocean, over deep water, the animal must perish. Thus broad and deep oceans are barriers to the spreading of these bottomliving, shallow water (or neritic) marine animals. There might (as in the case of the terrestrial mammals, be unfavourable conditions. Thus the Cod is a northerly, cold-water fish, and the Hake is a southerly, warm-water one, each inhabiting water of a certain range of temperature and avoiding sea regions where the conditions are outside these ranges. In course of time, however, adaptation would lead to new varieties and so to the range of such animals.

Further the question of convergent evolution must always be considered. Species of animals which appear to be very like each other need not have evolved from the same common stock but may have evolved quite independently. We can usually trace this convergence in character, although accompanied by divergent origin, in the embryological history of the species in question. In paleontology, however, we generally have only the hard parts, or skeletons, of animals. We can conclude, however, that if the hard parts are alike so will be the other parts, but this is not necessarily the case.

The paleontological evidence is, then, not absolutely reliable still it is safe to accept it so long as it is consistent with the other lines of evidence available. Now consider, 
as instances, the present distribution of (1) mammals and (2) certain neritic foraminifera, and the distribution of the same animals in past time, as shown by their fossil remains.

Marsupial mammals are found only in Australia (and some adjacent islands) and in South America. We are justified, at present, in concluding that both the Australian and South American pouched mammals had a common origin. Therefore there must have been land connections between Australia and South America in the past. It is very probable that Australia was connected with Asia and that America and Asia were connected across Behring straits. It is also probable that Australia and S. America were both connected with Antarctica. So we have the land connections-via the North of Asia and North America, on the one hand, and via Antarctica on the other -necessary for the spread of mammals from South America into Australia, or vice versa.

But, again, there is evidence of the existence of very similar fossil neritic marine species on both sides of the Atlantic Ocean. These animals (Foraminifera, Polyzoa and Mollusca) are such that they could, apparently, only have migrated along a zone of shallow sea bottom not far from a coast line. It is true that the northerly and southerly land connections just mentioned afford this coastal zone of shallow water but, on the other hand, there was probably a considerable difference of temperature between the sub-tropical regions in which these fossil forms were living and the northerly and southerly seas. This temperature difference would, very probably be a barrier to the spreading North and South of our sub-tropical neritic species, whereas no such marked temperature-differences would exist in the East and West dimension.

The ancient land and sea.-Considering the lines of evidence indicated above we seem obliged to assume such a distribution of land and sea, on the face of the earth, in 
former geological periods, as would permit of the distribution of the various forms of terrestrial and marine life. This leads us to the conclusion that the Pacific, Atlantic and Indian Ocean depressions cannot always have been such that they now are. Reasoning, then, from the results of paleontology many reconstructions of past geography have been made and from these we have selected a series illustrating what is, at least, a possible evolution of the surface features of the earth.

Jooking at these reconstructions we see that:-

(1) There has always been continental land round the situations of the Shields ;

(2) From Devonian until about Tertiary times there was a Pacific Continent;

(3) There were North and South Atlantic Continents until the end of the Mesozoic period and between these land masses there was an inland sea-the Tethys;

(4) There were land connections between Australia and the African and South American Coutinents ;

(5) There was, apparently, much less water on the earth from Devonian to Tertiary times than there now is.

In considering the probability of these conclusions we must see, first of all, whether the structure of the oceaniccontinental margins-as we have dealt with it in the earlier part of this chapter is consistent with the conception of past continental lands on the regions now occupied by deep oceans and next what consequences flow from the conclusions. It is to be noted that we reckon with stable and permanent continental bosses, or shield-lands. There is nothing to indicate that these have ever been at the bottoms of the deep sea basins. And we have not to account for the elevation of a former oceanic floor-all that the charts of Fig. 64 assume is the subsidence of continental lands to the bottoms of the present Atlantic, Pacific and Indian Oceans. So we are not troubled by the fact that no sedimentary rocks known to us are such as they would be had they been deposited at the bottom 


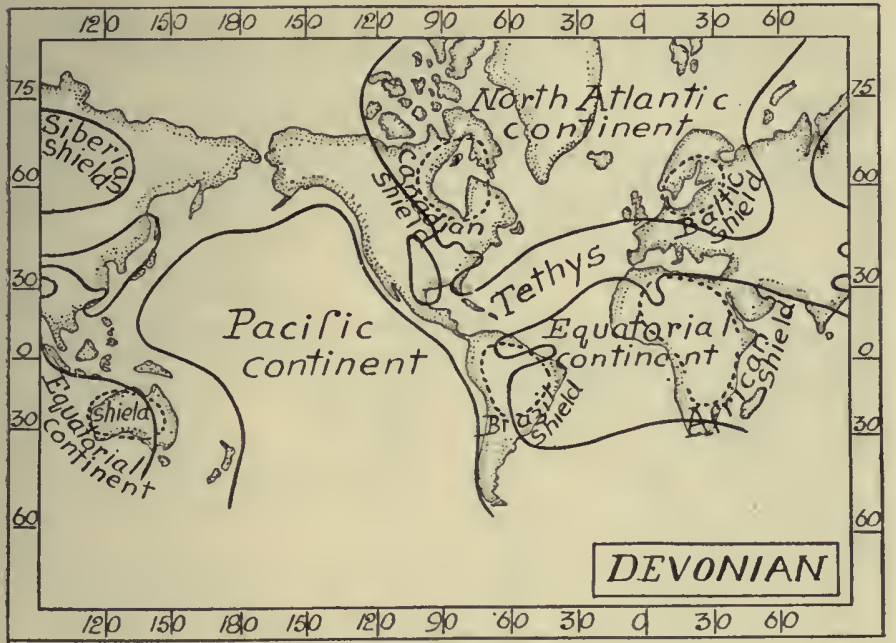

Fig, 64 A.

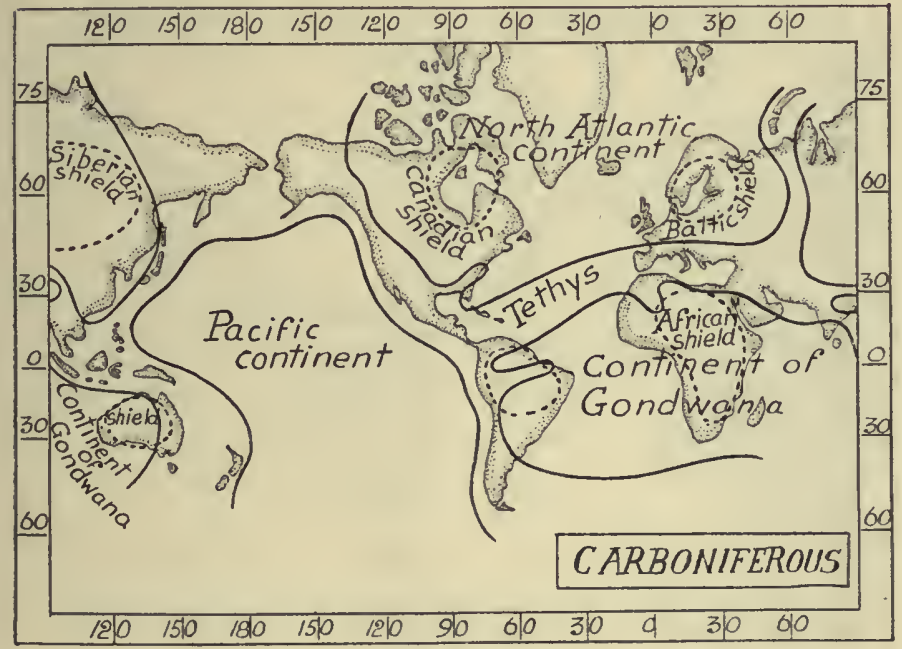

Fig. 64 B. 


\section{AN INTRODUCTION TO OCEANOGRAPHY}

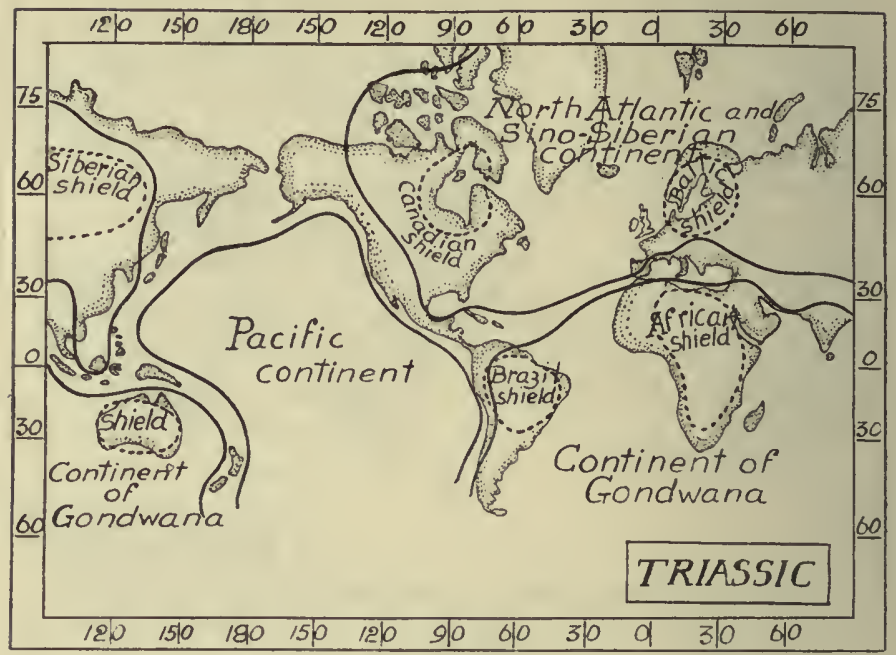

Fig. 64 C.

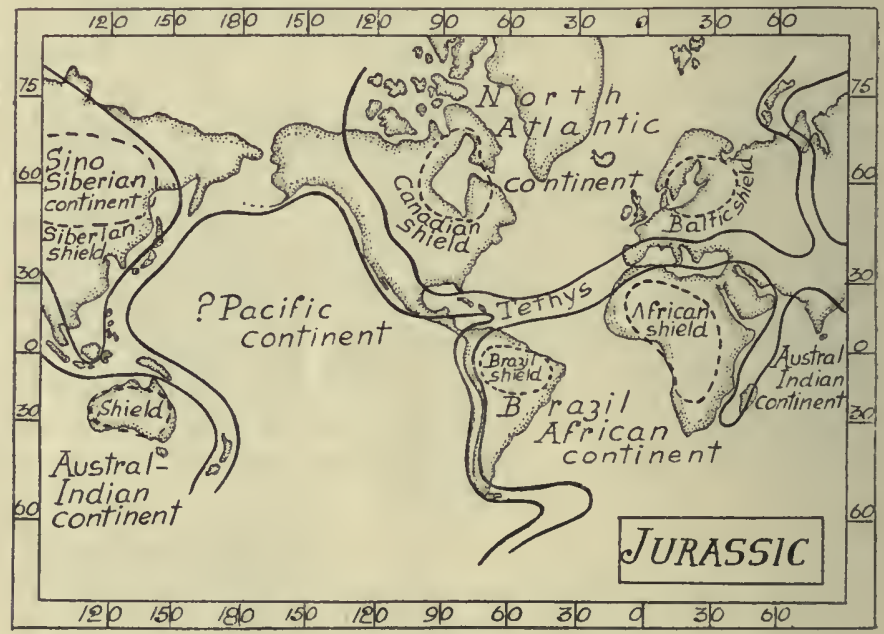

FIG, 64 D. 


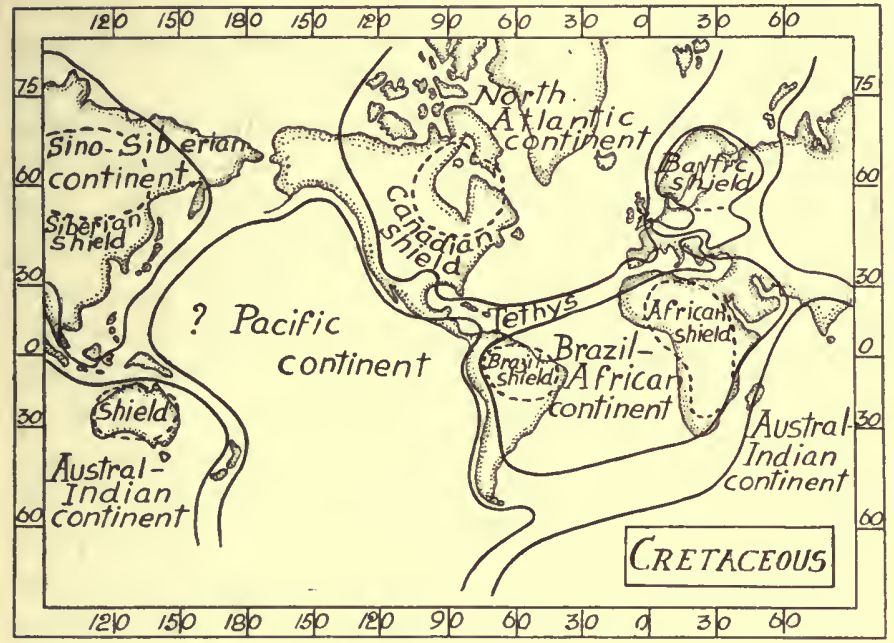

FIG. 64 E.

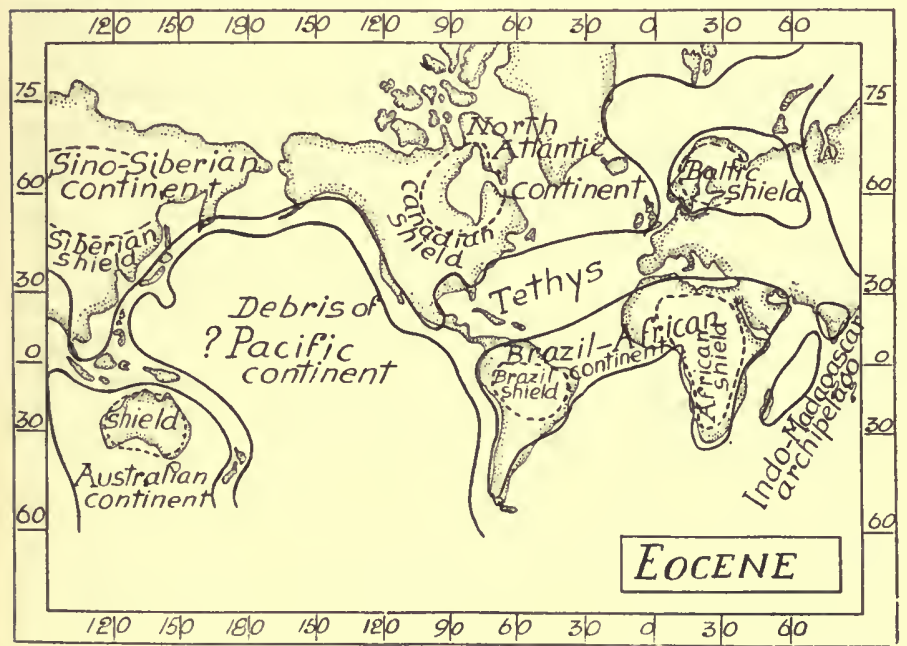

FIG. 64 F. 


\section{AN INTRODUCTION TO OCEANOGRAPHY}

of a deep ocean-because the charts do not assume the elevation of a past abyssal sea bottom.

What, then, appears to be the meaning of the present oceanic-continental margins?

The Pacific region. The character of the whole region suggests instability. On the East and North-East the instability is tending towards stability. The present West American coast is an almost continuous geo-syncline formed by foldings superposed on foldings in roughly parallel rows. The folds are generally gently convex towards the ocean and behind them the continental land is high. There has been actual uplift brought about by the intrusion of magmatic rock into the cores of the folds. There are volcanoes and earthquake phenomena so that the region is still unstable. In front of the foldings there is a slope down to sea level, next a narrow continental shelf and then a continuous depression of about 2,500 fathoms in depth, that is, about the average for the Pacific. There are few deeps. The whole American Pacific coast looks like one that has resulted from a process that is nearly completed.

Turning to the North and West margins the appearances are rather different. It is not the actual continental margin that is folded but rather the adjacent oceanicbottom margin. This means that sea bottom itself consists of rock capable of being thrown up into foldsthat is, sedimentary rock. The northerly Pacific folds are long ones and their highest parts are represented by the line of Aleutian Islands. In front of this island arc there are deeps, but these are not profound though their depths are greater than the average depth of the Pacific.

The next system of foldings are those ares indicated by the Japanese and Philippine Islands. They are not so long as the Aleutian arc and they are more sharply curved. In front of them are deeps and these go down to much more than the average Pacific depth-to over 5,000 fathoms in some places. 
Then we have, South of the Japanese and Philippin foldings, the much shorter and still more sharply curved ones that form the East Indian festooned system. Soutl of this again the whole series of West Asiatic ares seem tc pivot on the Australian shield.

Undoubtedly we find a progressive process at work here. Such other evidence as there is shows that the Pacific originated in late Mesozoic or early Tertiary times. Its site we may take to have been a great land surface broken up by seas of moderate depth which were filling with sediments : this condition is far more probable than that the Pacific area was purely an elevated land region. On the eastern side these postulated epi-continental seas were more extensive than elsewhere and sedimentations went on more rapidly. There was loading of the regions, of deposition, and isostatic readjustment, which set up thrusts against the West American continental margin, thus establishing the great systems of foldings that we have already studied. Subsidence occurred over the entire East Pacific region, and extended towards the North and West-how it was that so great an area became involved we do not know and it is certain that factors other than isostatic loading of even an extensive marginal area must have been in operation: just as some other factors than isostatic readjustment only seem to be required in order to account for the uplift of high continental regions. But a general process of subsidence starting on the eastern side of the postulated Pacific land area, and spreading towards the west, does seem a plausible hypothesis-a general tilt downwards on the great scale from the Australian shield-region to North-East and East and South-East (see Fig. 58).

Beginning then, at the eastern side the whole Pacific area subsided so that the process is now being completed off the Siberian and Chinese coasts. As the epi-continental seas within the island arcs there fill up and exert thrusts in both directions we shall have such conditions as are 


\section{3:2 AN INTRODUCTION TO OCEANOGRAPHY}

nw seen on the North American Pacific margin-a line of castal folds and behind these, and separated from them by fled-up basins, other parallel foldings. The eastern Pacific is thus older and more nearly stable than the vestern part of the ocean. In the South-West the stable tustralian land mass dominates the general area just as Ifrica does the South Atlantic and Indian Oceanic regions. There is, of course, nothing "inconceivable" in the idea of a subsidence on such a scale-indeed it is consistent with whatever other evidence we have. Paleontological results point to it, as we have seen in the series of charts reproduced from Haug (Fig. 64). Darwin's hypothesis of coral reef formation assumed a general depression of the Pacific region in order to account for the numerous atolls and fringing reefs. The later hypotheses of Semper and Murray pointed rather in the other direction in that they indicated reef building in regions of actual elevation. Later still, however, the American geologists, Daly, Vaughan and bthers have shown that coral reefs are generally laid down on platforms eroded from a subsiding land surface.

Very notable also are the indications of exterior island arcs (see Fig. 58). With a more exhaustive hydrographic survey of the Pacific Ocean than we now possess insular arcs East of those that pass through the Ladrones and Carolines may probably be found. Now does an earth fold always indicate a crumpling of stratified rock? If so the conclusion seems inevitable-a large area of the Central Pacific Ocean consists of sedimentary rocks laid down on the bottoms of shallow seas.

The Atlantic Ocean. In the infrequency of occurrence of volcanoes and earthquake phenomena on the Atlantic margins, when compared with those of the Pacific, we see a more stable condition. Here the supposition we take (on the paleontological evidence mainly) is that subsidence has occurred in both the North and South Atlantics. This bccurred at the end of the Mesozoic period, prior to which ending the great folds now represented by the Appalachian 
and Caledonian systems in the North and th contemporaneous Brazilian coastal foldings in the Soutl occurred. It seems probable that the northern folding: formed a great geo-syncline round the West, North anc East of the North Atlantic, similar in all respects to the geo-syncline that bounds the Pacific on the East and NorthEast. In the process of subsidence the northern part of this system of folds became destroyed and its materia is now represented by the very extensive continental shel that forms the real margin of the North Atlantic. Thus there was a Paleozoic, or early Mesozoic North Atlanti Continent, subsiding in late Mesozoic times, with destruction of its northern land margins. Into the South of the ocen so formed the Sea of Tethys opened out. On the SoutlEast the process of subsidence still continues and its result is the formation of the series of West Indian Island aris. The "transverse" coasts of the North Atlantic, on the Newfoundland side as well as on the Scandinavian-Scottih side represent the broken-off ends of the originaly continuous North Atlantic geo-syncline.

The South Atlantic seems to be similar except in so ar that the African shields have given a character to this region which is not represented in the North. The ancient Brazilian coastal folds, on this view, formed the westen part of the South Atlantic geo-syncline which extendid along the East coast of South America and then, from about Cape San Roque, across towards Africa, abutting on the latter continent somewhere near Cape Verde. Here we have traces of an African "transverse" coast, folls which are perpendicular to the oceanic margin. Thus ve have a South Atlantic land mass subsiding, with the resut that a northerly and westerly geo-syncline was established behind which was a folded region crossing the preseit Atlantic region from about Cape San Roque to Caje Verde. North of the land connecting Africa and Brail was the Sea of Tethys. Subsidence occurred and tie South Trans-Atlantic land connection was broken throug. 


\section{AN INTRODUCTION TO OCEANOGRAPHY}

As in the case of the North Atlantic the process of subsidence was latest in the South-West, where insular arcs, essentially similar to those in the South-West Atlantic and the SouthWest Pacific are to be seen in the Cape Horn-Graham Land chain of islands.

The new feature in the Atlantic. In the Atlantic, however, we have a new feature, one which-so far as we know-is not exhibited by any other oceanic depression. This is the remarkable Central Atlantic Rise, or Swell-the slongated elevation of the sea bottom that runs from North to South on the average, and nearly equidistant rom the Old and New World Coasts. It is very tempting to try and explain this feature on the theory of isostasyand the explanation "strikes one in the eye," so to speak, a looking at a chart of the depths of the Atlantic Ocean. The depression is an old one-as old as the end of the Vesozoic, or the beginning of the Tertiary period. There has been enormous erosion on all the Atlantic Coasts asd here and there the continental shelves are exceptionally wide. Therefore there was loading of the isostatic, yelding stratum, a "flowage" of material out from boneath the loaded zone and thrusts. Are the latter exerted only towards the continental margins? We appear to have no good reason for assuming that they are mly exerted towards the nearest land and we may suppose that they are also directed towards the axial line of the osean, that is both East and West. Readjustment due to isostasy may, therefore, have led to the lifting up of the Central Atlantic Rise, which is thus to be regarded as a growing sub-oceanic anticlinal region.

The other oceans. So little is known about the Indian, srctic and Antarctic oceanic regions (in comparison to our howledge of the Pacific and Atlantic) that not much can le said as to their past history. The great stable tablelnd of Africa dominates the Indian Ocean on the West: $\mathrm{b}$ the East the latter is to be regarded as a part of the lacific region. On the western side there is apparent 
evidence of general subsidence. But the absence of the arcuate earth folds on the East African margin is remarkable. Here we have had instead a process of faulting on the great scale along the broad zones marked out by the Red Sea, and the great African lakes.

The Arctic Ocean has all the appearance of an old epi-continental sea on the big scale, filling by sedimentation : thus we have the very extensive continental shelves indicated in Fig. 12. The Southern Ocean is simply to be regarded as the extreme South parts of the three great Oceanic basins with Antarctica placed nearly symmetrically. The structure of the South Polar land, and the depths of the adjacent oceans, are far too little known to justify any speculations as to the morphology of these regions.

Some consequent results.- (a) It seems to be probable : (1) that the shield-lands have always been regions of elevation and thus the nuclei of the continents; (2) that the present oceanic regions have either been areas of depression or of very low elevation with respect to mean spheroidal level and (3) that the zones between these two series of regions have always been areas of marked instability. Therefore there is a definite surface morphology of the earth the origin of which must be traced back to the processes by which the earth-body assumed its present magnitude and figure.

(b) There has been an evolution of the surface features of the earth. It does not appear to have been simply the case that regions of elevation and depression originated with the assumption of the present figures of the earth and have persisted throughout geological time without any changes other than that "embroidery" of outline and elevation which has always been, and still is in operation. There has been a kind of " settling down " of the lithosphere as the earth-body lost heat and became more rigid. In this process of settling down the present distribution of land and sea has been attained.

(c) Apparently there has been an increase in the quantity 


\section{AN INTRODUCTION TO OCEANOGRAPHY}

of water on the earth. The charts of Fig. 64 seem to show that the ocean was far less extensive in the Paleozoic and Mesozoic periods than it is now. The variation may have been apparent only: it may have been the case that water was accumulated in the polar areas-either as liquid water or as solid ice-caps. There may have been changes in the rotational speed of the earth causing a shifting of water from polar to equatorial regions or vice versa; the Paleozoic and Mesozoic oceans may have been much deeper than they now are or there may have been an actual increase in the quantity of water on the earth, the origin of this being either from volcanic magmas reaching the surface from the deeper layers, or from outer space. Such consequences of the distributions that we have assumed will be investigated with results that must be in some ways the tests of the probability of those distributions. 


\section{APPENDIX}

\section{PRINCIPAL AUTHORITIES CONSULTED}

The following notes refer to some of the more important books and papers consulted in the preparation of the present work. The general books are :-

Chamberlin, T. C. "The origin of the earth"; University of Chicago Press, Chicago, 1916.

Chamberlin, T. C. and Salisbury, R. D. "Geology"; Vols. I and II, London, J. Murray, 1909.

Clarke, F. W. "Data of Geochemistry"; Bulletin No. 695, U.S. Geological Survey Govt. Printing Office, Washingtoin, 1920.

DARwIN, G. "The tides and kindred phenomena in the Solar System"; 3rd Ed., London, J. Murray, 1911.

Fowler, G. (Editor). "Science of the Sea"; London, J. Murray, 1912.

Grew, E. S. "The growth of a planet"; London, Methuen, 1911.

Hоввs, W. H. "Earth evolution and its facial expression" ; New York, Macmillan Co., 1921.

KR rimmelL, O. "Handbuch der Oceanographie"; Vols. I and II, Stuttgart, Engelhorn, 1907 and 1911.

Murray, J. and Hrort, J. "The Depths of the Ocean"; London, Macmillan, 1912.

Murray, J. and Renard, A. J. "Deep Sea Deposits"; Challenger Report, 1891.

Schотт, G. "Geographie des Atlantischen Ozeans"; Hamburg, Boysen, 1912.

There are, of course, many other well known works on oceanography and allied subjects and an exhaustive list cannot be given here. The following notes refer to the above works and to special papers.

Chapter II. Earth origin, \&c. Chamberlin's books deal with the planetesimal hypothesis. See also Grew, and Chamberlin and Salisbury. For the nebular hypothesis and its development and criticism see Darwin, Chamberlin and Hobbs. Grew gives a short account of Love's $\mathbf{Y}$ 337 


\section{AN INTRODUCTION TO OCEANOGRAPHY}

hypothesis of earth features by harmonic deformation. J. W. Gregory, in "The making of the earth" (Williams and Norgate, Home University Library), gives a good, short account of the tetrahedral earth hypothesis. For an account of the shield-lands (and for a good account of the ocean as a geological agent) see L. V. Pirsson and C. Schuchert, "Text book of geology," Wiley \& Sons, New York, 1920. Suess' "Face of the earth," of course, must be consulted.

Chapter III. Oceanic depths. The chart of the Atlantic is simplified from Schott. Those for the Pacific and Indian Ocean are taken from Murray and Hjort. The North polar char' is from Schott. The South polar chart has been prepared from the latest Admiralty chart and the German "Deutschland," observations are included (see Brennecke, Archiv. Deutschen Seewarte, 39, 1921). Other Admiralty charts have been used in this chapter in the preparation of sections.

Chapter IV. Sea-bottom deposits. Schott's chart of the Atlantic is simplified as Fig. 17. The charts of the Indian and Pacific Oceans are from "Science of the Sea." Some of the illustrations of deposits are from the Challenger Report and others are original. A fine, general account of sea-bottom deposits, in general, is given by J. Murray in the "Depths of the Ocean." The later views of the origin of coral reefs are taken from a paper by Wayland Vaughan in the Annual Report of the Smithsonian Institution for 1917 (1919), where there are other references. See also Crossland, "Desert and water gardens of the Red Sea," Cambridge University Press,1913. (This book is otherwise of much general interest.)

Chapter V. The ocean margins. The charts and sections are based on the British Admiralty charts. A good, general account of the theory of isostasy is contained in the Smithsonian Institution Reports (Willis, 1910; Chamberlin, \&c., 1916 (1917), Weichert, 1908 (1909). There is a symposium on the subject, published in Bull. 
American Geol. Soc., Vol. 33, 1922. These papers give lists of references. For the variations of latitude, tidal stresses, \&c., in the earth-body see the appendices in G. Darwin's book. Suess, of course. See also Hobbs. A translation of Wegener's book on the "Displacement of continents' hypothesis" is being published by Methuen.

Chapters VI. and VII. Chemistry and Physics of sea water. The literature is most abundant and no summary account can be given. The analyses of sea water are collected by F. W. Clarke and there is a wealth of data in Krümmell's book. There is an enormous quantity of descriptive detail, as regards variations in salinity and temperature of the sea in all sorts of publications. (See the "Bulletins" and "Publications de Circonstance" of the International Council for the exploration of the sea; the English fishery blue books; the Danish Meddelelser Komm. f. Havundersøgelser; the "Annalen die Hydrographie" for instance).

The subject of ionic dissociation is well done by W. C. McC. Lewis in his "System of Physical Chemistry," London, Longmans, 1918. For gases in sea water see Fox, “Publications de Circonstance," Nos. 21 (1905), 41 (1907), 44 (1909). Some later work is described in Archiv. Deutschen Seewarte, XL, 1922 by B. Schulz. See also Murray and Hjort. For $\mathrm{CO}_{2}$-assimilation, $\mathrm{H}$-ion investigations see B. Moore; Report Lancashire Sea Fisheries Laboratory for 1914; Liverpool, C. Tinling, 1915. See also W. R. G. Atkins, a series of important papers (with further references) in Journal Marine Biological Association, Vol. 12, No. 4, Plymouth, 1922.

The salinity and temperature distributional charts of the Atlantic are from Schott. Those for the Pacific and Indian Ocean are from "Science of the sea." The graphs in the chapter are mostly taken from data given by Krämmell. For the interesting superficial micro-measurements of the temperature gradient, see A. Merz, Veroff. 


\section{AN INTRODUCTION TO OCEANOGRAPHY}

Inst. Meereskunde Berlin, N.F., Geog-Naturwiss. Reihe $5,1920$.

The classical work on nitrogen, phosphorus and silicon compounds in sea water has been done by Raben. See the Reports of the Kiel and Helgoland Biological stations.

Chapter VIII. The tides. The only popular book is G. Darwin's "Tides." See also Warburg, "Tides and tidal streams," Cambridge University Press, 1922.

Methods of prediction of the tides, in the old way, are explained (with difficulty) in the "Tide Tables" published by the British Admiralty. These methods, and also the newer ones, are dealt•with by Warburg.

Harris' "Manual of the Tides," (U.S. coast and Geodetic Survey) made a new start after G. Darwin. Lately the study, both of the theory of the tides and of the methods of prediction, has been greatly developed by the Tidal Institute at the University of Liverpool. (See "Reports of the Tidal Institute," Liverpool University Press, 1920, 1921, 1922).

The Liverpool workers have shown that there is considerable inaccuracy in the existing tidal predictions and have developed marked improvements on the Darwinian methods. See J. Proudman, "Harmonic analysis of tidal observations in the British Empire"; British Association Report for 1920 (1921) ; A. T. Doodson, "Intensive analysis of tidal observations" and "Harmonic analysis of tidal observations" in Brit. Assoc. Reports for 1920 and 1921 (1921 and 1922). In this series of papers the question of the accuracy of the predictions is investigated and new analytical methods of power are developed. The effect of meteorological changes on the tides is also examined; see Brit. Assoc. Rept. for 1923. Bibliographies are given in these papers.

There is a description of the various tidal machines in Publication No. 32 of the U.S. Coast and Geodetic Survey ; Govt. Printing Office, Washington, 1915. 
A short historical account of tidal investigations is given by H. A. Marmer in "Science Monthly," March, 1922.

The figure of co-tidal lines on p. 224 is from Sterneck, (Sitz. Akad. Wiss. Wien.; Math.-Nat. kl. ; Abt. IIa, Bd. 130, Vienna, 1921). Figs. 30 and 44 in Chapter VI are modified from Warburg's book. Figs. 29, 41-43 are plotted from the "Tide tables" and the "Nautical Almanac."

The interesting subject of long-periodic tidal effects is the work of Otto Pettersson. See Svenska hydro.-biol. Komm. skrifter V. 1914.

Chapter IX. Ocean currents. There is a huge literature on the subject. See Krümmell for detailed accounts of the currents in the various oceans and seas (there are, however, no satisfactory illustrations in this work). The various government hydrographic departments (Great Britain, Germany and the United States, in particular) publish periodic charts, pilot charts, atlases of currents, sailing directions, \&c. There is also very much in the publications of the fishery departments of Great Britain, Germany, Norway, \&c. See also the publications of the International Council for the exploration of the sea : the Bulletins Hydrographiques, the Publications de Circonstance, and the Procés-Verbaux (particularly Vol. III. of the latter series). There are also the reports of the voyages of exploration, which are very numerous.

The figures showing the current-systems of the Atlantic, Pacific and Indian Oceans are reduced and simplified from the Weltkarte prepared by G. Schott and published by the Deutsche Seewarte in 1917. Fig. 12, the North Polar circulation is from Schott's book on the Atlantic Ocean. Fig. 54 representing the currents of the North Sea is from G. Bohnecke, Saltgehalt u. Strömungen der Nordsee. Veroff. Inst. f. Meereskunde, Berlin, N.F. geog.-naturwiss. Reihe 10, 1922. The figure on p. 295 showing the vertical ocean circulation is based on the work of the German Valdivia-Expedition. 


\section{AN INTRODUCTION TO OCEANOGRAPHY}

For the theory of solenoids (Fig. 46, p. 259) see Sandstrom and Helland-Hansen, "Mathematical investigation of ocean currents," Rept. Fishery and Hydrographic investigations in the North Sea and adjacent waters. Blue Book, Cd. 2612, 1905.

Fig. 50 ; streaming in Straits of Gibraltar, is based on the data given in "Depths in the Ocean"-so also Fig. 49, the streaming in the Faeroe Channel. Fig. 56 showing the salinity and temperature in the Gulf Stream Drift, is from P. Cleve. Svenska Hyd.-biol. Komm. Skrifter.

Chapter X. History of the oceans. The appendix for Chapter V, oceanic margins, contains most of the authorities used in writing Chapter $\mathrm{X}$. The charts showing the island arcs in the Atlantic and Pacific (Figs. 58 and 59) are drawn from Admiralty charts and are based mainly on Hobbs. The figure on p. 316 , showing the structure of the Atlantic shores is reduced and simplified from Schott. The series of paleogeographic Mercator charts (Figs. 64, A-F) are from Haug.

The three paleogeographic maps of Europe in tertiary times are from Osborn, "Age of Mammals" Macmillan Co., New York, 1910. Here the reader will find the hypotheses of geographical distribution of animals well described. 


\section{INDEX.}

Abyssal life, 89.

Nutrition of, 90 .

Achil Head, 40.

Adaptive radiation, 323 .

African yield tracts, 26 .

Age of tide, 222.

Air in seawater, 146.

Andrews (Corals), 84.

Agulhas current, 254, 279.

Alaskan folds, 309 .

Aleutian arc, 312,330 .

Alkalinity, 148.

American yield tracts, 25.

Amphidromic points, 205, 223, 224.

Andes, 124, 129.

Andes, foldings, 309.

Andes, soundings off, 43 .

Auimals, marine, 157, 324.

Animal colonies, 76 .

Animal migrations, 324 .

Antarctic continent, 11, 53, 58. Yield tracts, 25.

Antarctic ocean, 1, 47.

Currents of, 283.

Sectors of, 2.

Nitrogen in, 159.

Antilles stream, 270.

Antillean yield tracts, 26.

Anticyclonic currents, 272, 276, 282.

Appalachian mountains, 219, 325.

Foldings, 124.

Aral sea, 110.

Arabian sea, currents, 282.

Arctic ocean, 48, 49, 110.

Morphology of, 335 .

Currents of, 284.

Islands of, 48 .

Arcs (earth folding), 311.

Insular, 319, 331.

Arcuate foldings, 309 .

Ascension Island, 53.

Atmospheric circulation, 30 .

Atolls, 81.

Atlantic ocean, 5 .

Ancient, 333.

Arcs on coast, $315,317$.

Central rise, 52, 334.

Chart of, 51.

Coasts of, 124, 314.
Atlantic Ocean-cont.

Coastal folds, 317 .

Continental shelf, 51 .

Currents of, 273, 274.

Depths, 55.

Depth contours, 50 .

Evolution of, 333.

Equatorial stream in, 270.

Equatorial stream variations, 288.

Morphology, 316, 332.

Nitrogen in, 159.

Oceanic islands of, 53 .

Salinity of, $142,289$.

Sea bottom deposits, 93 .

Section of, 42 .

Temperature of, 175, 191.

Yield tracts of, 27 .

Atlantic stream, 273, 274.

Variations of, 293.

Australia and Antarctica, 325

and South America, 325.

Barrier reef, 80.

Currents at, 278, 283.

Avonmouth, tides at, 203 .

Azores, 53, 56.

Bacteria, nitrogen, 146. and corals, 87 .

Baffin Bay, 49, 108, 271.

Currents in, 284.

Baltic Sea, 108, 110.

and Atlantic inflow, 292.

Currents of, 252, 287.

Freezing of, 252.

Temperature of, 177.

Bank, 45.

Banks straits, currents, 284.

Bareutz sea, currents, 284, 292.

Barriers to migrations, 323.

Barrier reefs, 80.

Basin, 45.

Bathymetric contours, 46.

Behring sea, 108.

Behring straits, 48.

Currents in, 285.

Salinity in, 145.

Bengal Bay currents, 282.

Benguela stream, 275, 283.

Benthos, 88.

Bermuda, 79 .

Black sea, 110 . 


\section{AN INTRODUCTION TO OCEANOGRAPHY}

Bottom samplers, 77 .

Brazil stream, 275.

Brazil coasts, 124 .

Calcareous algae, 76.

Canary Islands, 53.

Cape Breton, 124.

Cape Horn, 48.

Cape Verde islands, 53.

Carbonic acid in sea, 146, 148, 158.

Carbonic acid and heat absorption, 172.

Carboniferous land and sea, 327.

Caribbean sea, temperature, 177.

Cascade mountains, 309.

Celebes Sea, 109.

Ares off, 313.

Chagos islands, 320 .

Challenger expedition, 39, 135.

Chamberlain, planetesimal hypothesis, $15,23,26,305$.

Champlain, lake, 110.

Charts, 45.

China Sea, 108.

Currents of, 277.

Clay, Red, 96.

Coasts, age of, 301 .

Atlantic, 124, 126.

Biscayan, 125.

Brazil, 124.

Canadian, 125.

European, 125.

- Greenland, 125.

Growing, 126.

Longitudinal, 124, 317.

Pacific, 124.

Ria, 315.

Scottish, 125 .

Transverse, 124.

Collecting apparatus, 77 .

Colloids in seawater, 72 .

Compressibility of seawater, 166.

Continents.

Antarctic, 2, 47.

Antipodal to oceans, 5 .

Characters of, 126.

Elevation of, 122.

Erosion of, 122.

Forms of, 6.

Movements of, 12 .

Origin of, 10, 12 .

Outlines of, 102.

Continental regions, 29.
Continental shelf, $40,45,54$.

Atlantic, 54 .

British, 40.

Deposition on, 123, 306.

Gradients of, 44, 107.

Irish, 40.

Loading of, $127,307$.

Movements of, 124.

Width of, 40 .

Continental margins, 113.

Instability of, 114.

Continental displacement theory, 127.

Continental slope, 41 .

Gradient of, 41, 43 .

Contour lines, 40, 45 .

Making of, 46 .

Convection currents, 171.

Copepods, 91.

Corals, 79.

and depth, 86.

Distribution of, 79 .

Disintegration of, 81 .

and hydrography, 86 .

and lime metabolism, 87.

and sea temperature, 184 .

Coral sediments, 87 .

Coral mud, 81.

Coral precipices, 80 .

Coral polyps, 85 .

Coral reefs, 80,332 .

Origin of, 82 .

Channels, 81.

Elevation theory, 85.

Ecology of, 85.

Foundations of, 80 .

Fringing, 80.

Glacial control theory, 84 . Growth of, 81 .

and isostasy, 83.

Lagoons, 86.

Platforms, 82, 84 .

Subsidence theory, 84 .

Talus, 80.

Corallina, 76.

Coral-like organisms, 79 .

Cordilleras, 309 .

Cosmic spherules, 64, 97.

Cotidal lines, 222, 224 .

Cretaceous land and sea, 329.

Croll (cause of ice age), 173.

Cup dredge, 62.

Currents, 254.

Ascending, 294.

Causes of, 257.

Convection, 257, 259.

Descending, 294. 
Currents-cont.

Equatorial, 264.

Ice, 258.

Investigation of, 296.

Southern, 265.

Seasonal, 287.

Vertical, 259.

Currents and

Depth, 266.

Earth's rotation, 256.

Evaporation, 257.

Declination of sun, 256, 291.

Land barriers, 180, 189, 265.

Plankton, 299.

Precipitation, 257, 266.

Salinity, 267, 299.

Shoals, 180, 266.

Temperature of sea, 178, 293.

Winds, 263.

Current meters, 298.

Cyclonic storms, 172.

Cyclonic currents, 275.

Daly (coral reefs), 84, 332.

Darwin, C. (coral reefs), 82, 332.

Darwin, G. (origin of earth), 14.

Tides, 239, 249.

Davis straits, 271.

Currents of, 284.

Diatoms, 91.

Diatom ooze, 96.

Deeps, ocean, 45, 320, 330 .

Deformation of earth, 32 .

Demersal organisms, 89.

Denitrifying bacteria, 87 .

Denmark strait, currents, 284.

Density (seawater), 193.

Depressions, 45.

Deposits, see "Sea bottom deposits."

Depths, ocean, 39.

near coral islands, 42.

off Japan, 42.

off Peru, 42.

Devonian land and sea, $32 \%$.

Disruptive approach, 16.

Dover, tides of, 205.

Dredging apparatus, 62 .

Drifts, ocean, 254.

Drift bottles, 296.

Earth,

Age of, 161 .
Earth-cont.

Contraction of, 10, 14.

Density of, 115 .

Depressions of, 30, 302 .

Elevations of, 30,302 .

Growth of, 22.

Interior of, 114, 117.

Internal heat of, 9 .

Tides in, 14.

Rigidity of, 115.

Rotational stresses in, 28.

Segmentation of, 24, 28.

Telescopic views of, 1 .

Temperature of, 114 .

Yielding of, 22, 333.

Earth, figure of, 12.

Changes of figure, 21.

Diameters of, 22 .

Rotation of, 260, 263.

Rotational changes, 13, 21, 24 .

Earth folds, 125, 305, 309, 311, 319,330 .

Earth, orgin of, 8, 10, 302.

Earth, superficial features, 8, 11,335 .

Earthquakes, 116, 308.

Earbones (in bottom deposits), 97.

Ebb tide, 200.

Ecology (and bottom deposits), 76.

English Channel (currents), $273,287$.

Eocene land and sea, 329.

Epicontinental seas, 108.

Temperature of, 177.

Epeiric seas, 108.

Eruptive suns, 16.

Establishment of a port (tides), 230.

Euler (change of latitude), 13.

Europe in tertiary period, 322 .

European stream, 272.

Evolution, convergent, 324 .

Equatorial streams, 264, 270, $275,277,279,281,288$.

Counter streams, 282.

Seas, nitrogen in, 159.

Faeroe islands, 48.

Currents at, 287.

Falkland islands, 53, 319.

Falkland stream, 276, 283.

Ferrell's law, 260.

Fiji, corals at, 83 .

Fiords, 125, 315. 


\section{AN INTRODUCTION TO OCEANOGRAPHY}

Fishes (and sea temperature), 324.

Floodtide, 200

Florida current, 271.

Foraminifera, 91, 113.

Formby shore, section, 105.

Foreshore, 103.

Charts of, 101.

Deposits on, 111.

Gradients of, 104.

Sections, 105.

Tides of, 100 .

Fram (polar currents), 284.

Fringing reefs, 80 .

Funafuti atoll, 42.

Galicia (rias), 315.

Gases in sea, 154.

Geosynclines, 43, 127, 309 .

Geoisotherms, 9.

Gibraltar, 9, 203.

Tides at, 268.

Glaciation, 84 .

and coral reefs, 84

Glacial periods, 174 .

Glauconite, 75, 122, 163.

Globerina ooze, 92.

Gondwanna, 129.

Gradients (sea bottom), 39.

Graham land, 48, 319.

Gravels, organic, 76 .

Gravity, variations, 118.

Greenland, 48.

Greenland currents, 273, 276, 284.

Greenock, tides at, 203.

Guinea stream, 275.

Gulf stream, 176, 271 .

Drift, 272.

Drift and temperature, 176.

Eddy, 291.

Velocity of, 254.

Gulf of Mexico, 109.

Salinity of, 139, 267.

Temperature of, 177.

Gulf of St. Lawrence, 108.

Yield-tracts of, 27.

Gulf weed, 272.

Gyrals, atmospheric, 30 .

Harmonic analysis (tides), 245. Synthesis (tides), 249.

Haug (paleogeography), 332.

Hecker (variations of latitude), 116.

Heligoland (tides), 203.

Heteropods, 90.
Himalayas, 129.

Holophytic organisms, 90 .

Horsts, 126.

Hudson (sounding cup), 37.

Hudsou's Bay, 108, 178.

Humphreys (corals), 84 .

Hydrogen-ious, 149, 153.

Hydrometer, 193.

Ice (sea), 184.

Barriers, 48.

Caps, 48.

Ages, causes, 174.

Forms of, 188.

Formation of, 187.

Iceland, 48.

Currents at, 273, 284.

Indian Ocean, 58.

Currents of, 279.

Corals in, 79.

Islands of, 60 .

Morphology of, 319, 334.

Nitrogen in, 159.

Salinity of, 144 .

Temperature of, 178.

Insular ares, 311, 332.

Irish Sea, 101.

Atlantic inflow, 292.

Isohalines, 146.

Isotherms in ocean, 174.

and currents, 176.

Isostasy, 117.

and coral reefs, 83.

Isostatic layer, 119.

Isostatic equilibrium, 32, 120.

Isosteres (currents), 259.

Japanese deep, 43.

Arc, 312, 330.

Current, 277.

Seas, 108.

Stream, 254.

Javanese arc, 313.

Joly (age of Earth), 161.

Jurassic land and sea, 328.

Kant (nebular hypothesis), 8, 16.

Kennedy Channel, 284.

Knudsen (seawater analysis), 137, 194.

Kurile arc, 312.

Labrador stream, 179, 271, 276, 284.

Laccadive islands, 59,320 .

Lagoons, Coral, 81, 87.

Lands, ancient, 325. 
Lands, ancient connections, 326. Lands End, 40.

Land and sea breezes, 281.

Laminarian seaweeds, 89.

Laplace (nebular hypothesis), $8,16$.

Latitude, variations of, 13.

Leads, deep sea, 37.

Lime metabolism, 87, 162.

Lithothamnion, 76 .

Littoral deposits, 68.

Liverpool, tides at, 203.

Lough Neagh, 110.

Love (earth features), 31.

Lubbock (tides), 229.

Lucas sounding machine, 36 .

Lucas bottom sampler, 37 .

Lu-chu arc, 313.

Lunitidal intervals, 229.

Madagascar, 59, 320.

Magmas, volcanic, 308 .

Maldive islands, 59, 320 .

Manx foreshore, 105.

Mammals, migrations of, 323 .

Manganese nodules, 97.

Marginal seas, deposits of, 111. Currents in, 285.

Margins, oceanic, 7 .

Marine life, abyssal, 89.

Categories of, 88 .

Density of, 89 .

and light, 89.

Mars, surface of, 9 .

Marsupials, migrations of, 325 .

Mediterranean seas, 109.

Mediterranean, currents of, 268. Nitrogen in, 159.

Salinity of, 139, 267.

Temperature of, 177 .

Metamorphic rocks, 22.

Michelson (rigidity of earth), 116.

Migrations of animals, 324. and barriers, 325 .

Molluscan shells, 75 .

Monsoons and currents, 281.

Moon, surface of, 9 . Origin of, 9 .

Morecambe Bay, 100.

Moulton (planetesimal theory), 15.

Mountain folds, 308.

Muds, agglutination of, 72 . Blue, 73.

Distribution of, 73.

Green, 73.
Muds-cont.

Lines, 72 .

Red, 73.

Volcanic, 73.

Murray, J. (coral reefs), 82, 332.

Sea bottom deposits, 66 .

Nansen (polar currents), 284.

Nansen-Pettersseu water bottle, 37 .

Neap tides, 202.

Nebular hypothesis, 8.

Criticism of, 14.

Consequences of, 14.

Nebulae, spiral, $16,19$.

Nekton, 88 .

Neritic animals, 324.

Migrations of, 325.

Neritic sea bottom deposits, 66 , 74, 113.

Composition of, 75 .

Distribution of, 76 .

Foreshore, 112.

Shallow water, 112.

New Brunswick (rias), 124.

Newfoundland, currents, 271. Rias, 315.

New Zealand, plateau, 58. Yield tracts, 27.

Nitrogen compounds in sea, 158.

Destruction of, 163.

Nodal points (tides), 223.

North Sea, 108.

Currents, 273, 285, 292.

Depths, 40.

North American islands, 28.

Norwegian Sea, 48, 109.

Nullipore gravels, 76 .

Ocean.

Antarctic, 1, 47.

Arctic, 3, 48.

Atlantic, 5 .

Indian, 4, 47 .

Pacific, 3.

Polar, 5.

Ocean.

Abysses, 107, 122.

Accumulating, 336 .

Antipodal to continents, 5 .

Bottom, 304.

Bottom deposition, 306.

Circulation, 34, 255

Depressions, 30, 32, 304.

Floor of, 44, 61 .

Gradient of floor, 44 . 


\section{AN INTRODUCTION TO OCEANOGRAPHY}

Ocean-cont.

Gulfs, 3.

Heat received by, 172 .

History of, 321, 326.

Permanence of, 7,31 .

Salts in, 135. 160.

Soundings (methods), 34, 40, 56.

Volume of, 131.

Oceanic islands, 78 .

Oceanic regions, 29.

Oceans, pairs of, 29.

Ocean margins, $7,100,124,304$. Instability of, 7, 309 .

Ocean, origin of, $7,10,12,131$.

Okhotsk, Sea of, 108.

Currents in, 278.

Ontario, Lake, 110.

Ooze, deep sea, 66.

Diatom, 96.

Globerigina, 92.

Pteropod, 92.

Radiolarian, 94.

Ordnance datum, 201.

Orloff (variation of latitude), 116.

Organic skeletons in bottom deposits, 74 .

Oscillating tidal systems, 223.

Pacific Ocean, 56.

Ancient, 330.

Ares in, 311, 313.

Chart of, 57 .

Coasts of, 124, 311 .

Coral islands, 79 .

Currents of, 276.

Evolution of, 331 .

Geosynclines, 43, 309, 330.

History of, 57, 332 .

Islands of, 58 .

Morphology of, 309 .

Salinity of, 144.

Temperature, 178, 191.

Yield-tracts of, 27.

Pacific slope, 42.

Patagonian seas, currents, 275.

Patagonian coast, 53.

Paleontology and ocean history, 323.

Partial tides, 240.

Pelagic deposits, $66,88,97$.

Peridinians, 91.

Persian Gulf, 145.

Peruvian current, 279, 283.

Petterssen (tides), 251.

Philippine islands, 313, 330.
Philipsite, 97.

Photosynthesis, 151.

Rate of, 152.

Physics of sea, 165.

Planetary systems, origin of, 16.

Planetesimal hypothesis, 15, 18, $20,23,28$.

and ocean, 132 .

Plankton, 77, 88.

Categories of, 90 .

and sea-bottom deposits, 98 .

Density of, 91 .

and currents, 284.

Plant life in the sea, 157.

Plateau, 45.

Poles, shifting of, 13, 116.

Polar oceans, 6.

Currents in, 283.

Temperature of, 191.

Polyzoan gravels, 76 .

Potassium in sea, 163.

Prediction, tidal, 225.

Pressure in sea, 165.

Production in the sea, 152.

Primitive ocean, 31 .

Pteropods, 90.

Pteropod ooze, 92.

Pumice, 64.

Pycnometer, 193.

Radiolarian ooze, 94 .

Red clay, 960.

Red Sea (salinity), 139, 145.

Reefs, 45.

Reef-building corals, 79 .

Relict seas, 109.

Renard (bottom deposits), 66 .

Ridge, 45.

Rias, 45, 125, 315.

Rise (ocean floor), 45.

Rock, cleavage of, 22 .

Contraction of, 23.

Flowage of, 22, 116, 307.

Strength of, 22, 119.

Rocky Mountains, 125, 310.

Ross Sea, 48.

Salinity of sea, 137. Atlantic, 142 .

Bay of Biscay, 139.

Charts of, 140 .

(and) density, 194.

English Channel, 139.

Epicontinental seas, 143.

Gulf of Mexico, 139.

Indian Ocean, 144. 
Salinity of sea-cont.

(and) latitude, 139.

Mediterranean, 139, 143.

Pacific, 144.

Red Sea, 139.

(and) rivers, 140, 144.

(and) trade winds, 144.

Variations of, 138, 289.

Salts of sea, 161 .

Composition of, 134.

Dissociation of, 150 .

in sea ice, 187 .

Origin of, 133, 162.

Salt in rivers, 162 .

Salt marshes, 102.

Sandhills, 106.

Sand, wind blown, 106.

Sandwich islands, 54; 319 .

Sargasso Sea, 271.

Eddy, 276.

Sargassum, 272.

Scandinavian coast, 125 .

Schistosity of rocks, 22.

Sea Areas.

Aral, 110.

Baltic, 108.

Barentz,

Behring, 108.

Black, 110 .

Caribbean, 109.

Celebes, 109.

China, 108.

Japan, 108.

North, 108.

Norwegian,

Okhotsk, 108.

Yellow, 108.

Seas, ancient, 325.

Epicontinental, 108.

Epeiric, 108.

Landlocked, 111.

Marginal, 107.

Relict,

Sea level, 202.

Sea and land, interchange, 122.

Sea-bottom deposits.

Analysis of, 63,70 .

Calcareous, 64 .

Categories of, 66 .

Chemically altered, 64 .

Classification of, 65 .

Clays in, 71.

Collection of, 62 .

Continental, 66.

Sea-bottom deposits, 62 .

Distribution of, $67,71,93,95$, 98.
Sea-bottom deposits-cont.

Description of, 63.

Extra-terrestrial, 64.

Grading of, 68 .

Levigation of, 71 .

Littoral, 65.

Neritic, 74.

Oceanic, 77.

Organic, 64, 74 .

Original nature, '63.

Pelagic, 65.

Radio-active, 167.

Rate of formation, 61 .

Sampling of, 38 .

Shallow water, 65 .

Shore materials, 64 .

Siliceous, 64 .

Terrigenous, 65 .

Terrestrial, 64 .

Transport of, 63.

Solution of, 98 .

Vertical range of, 98 .

Sea-bottom life, 77 .

Sea temperature.

Atlantic,

Currents, 178, 180.

Epicontinental seas, 182.

Bottom, 191.

Indian Ocean.

Latitude, 176.

Marine life, 182.

Micro-measurement, 189.

Pacific, 178.

Polar Seas, 182.

Southern ocean, 178.

Surface, 189

Tides, 181.

Temperate seas, 182.

Tropies, 182.

Sea temperature variations, $170,181$.

Annual, 171, 181.

Seasonal, 171 .

at bottom, 192 .

Long periudic, 172.

Vertical, 188, 190.

Sea water.

Alkalinity, 148.

Analyses, 136.

Boiling point, 198.

Carbon dioxide, 158.

Chlorine and density, 194.

Colour, 196.

Compressibility, 166, 195.

Density, 186, 192.

Electric conductivity, 196.

Elements in, 134. 


\section{AN INTRODUCTION TO OCEANOGRAPHY}

Sea water-cont.

Food substances in, 156.

Freezing, 185.

Gases, 146, 154.

Heat conductivity, 171.

Ionisation, 134.

Optical characters, 196.

Osmotic pressure, 186.

Oxygen, 155.

Salinity, 137.

Titration, 137, 193.

Transparency, 196.

Upwelling, 180.

Vapour pressure, 196.

Viscosity, 196.

Sediments, agglutination of, 72 .

Seiches, 200.

Semper (corals), 82, 332.

Shallow water deposits, 68 .

Composition of, 70 .

Shark's teeth, 97.

Shoal, 45.

Shore line changes, 102.

Shell gravels, 76 .

Shield lands, $120,301,319,321$, 326.

Siberia, currents at, 284.

Silica in sea, 160.

Sierras, 125.

Seychelles, 59.

Solar radiation, 172.

Sclenoids, 260.

Somali eurrent, 282.

Soundings.

On charts, 41.

By electric oscillators, 39 .

Lines, 34, 39.

Machines, 36.

Sinkers, 36.

Tides, 46.

Sound waves, 39.

Technique of, 35 .

South Georgia, 319.

Southern ocean currents, 275, 283.

Yield-tracts, 25.

Sonth Orkneys, 54.

South Shetlands, 54 .

South Polar seas, 17.

Spitzbergen currents, 273, 284.

Stars, new, 19.

Stellar collisions, 15.

Spring tides, 202.

Strand, 103.

Submarine volcanoes, 64 .

Symbiotic algea, 85 .
Tanganyika Lake, 110.

Telegraphic plateau, 53 .

Temperature of sea, 167.

Estimation of, 168.

Temperature of earth's interior, 10.

Terrigenous muds, 71 .

Tethys, Sea of, 326, 333.

Tetrahedral earth theory, 10, 31.

Tides, 199.

Tides and astronomy, 217, 228. Age of tides, 222.

Declination of sun ard moon, 214.

Diurnal and scmidiurnal, 204.

Erfuinoxes, 203, 216.

Moon's transits, 227.

Rotation of earth, 223.

Luni-solar, 232.

Lunitidal intervals, 229 , 233.

Tides.

Atmospheric circulation, 252.

Baltic, 252.

Datum marks, 201.

Ebb and flow, 200.

English coastal, 205.

Evolution, y.

Foreshore, 103.

Gauges, 200.

Generating force, 210.

Variations of, 212, 217, 251.

and volcanic eruptions, 253.

Tides.

Land contours, 223.

Marks, 103.

Marine agencies, 250.

Prediction, 225.

Constituents, 242, 244.

Corrections, 239.

Empirical methods, 226, 234.

Establishment of port, 230.

Harmonic methods, 239.

Harmonic analysis, 245.

Harmonic synthesis, 249.

Inequalities, 234.

Non-harmonic, 226.

Machines, 250.

Partial tides, 240.

Meteorological effects, 236. 


\section{INDEX}

Tides, Prediction-cont. Resultant tides, 249. Satellites (tidal), 241. Range, 102, 202.

Rise and fall, 199.

Streams, 206. Bores (tidal), 209. (and) deposits, 69. (and) heat transfer, 251. North Sea, 208.

Overfalls, 209.

Races, 209.

Resultant, 251, 285, 297. Tides. Velocities, 207.

Skagerak, 252.

Springs and neaps, 202, 213.

Submarine, 252, 292.

Tables of, 226, 239.

Theories of, 219.

Equilibrium, 220.

Forced wave, 220, 223.

Progressive wave, 220.

Stationary wave, 222. Types of, 204 .

(and) Topography, 240.

Periodicity of, 202.

(at) Victoria, B.C., 205.

Thermometers, sea-water, 168.

Deep sea, 37, 169.

Reversing, 168.

Thomson (age of carth), 161.

Thrusts, 307 .
Trawl net, 77.

Trench, 45.

Triassic land and sea, 328 .

Tristan d'Acunha, 53.

Valdivia expedition, 295.

Vaughan (corals), 332.

Vital production, 156 .

Vertical currents, 293.

Volcanoes, submarine, 74 .

Volcanic dusts, 64.

Eruptions, 172.

Muds, 73.

Waterbottles, 37, 168 .

Water on ancient earth, 326.

Wave action and deposits, 69 .

Weddell Sea, 48.

Wegenel (continental displacements), 128.

West Indies, 54, 318.

Whewell (tides), 239.

White Sea, 108. 284.

Winds and currents, 179.

World ocean, 1.

Wyville-Thompson ridge, 45 , $50,269$.

Yellow Sea, 73, 108.

Currents in, 277.

Yield-tracts on earth, 24-29.

Zuider Zee, 252. 
$0,516-3 P B$

0 






\section{PLEASE DO NOT REMOVE CARDS OR SLIPS FROM THIS POCKET}

UNIVERSITY OF TORONTO LIBRARY

GC

15

J6

$$
\begin{aligned}
& \text { Johnstone, James } \\
& \text { An introduction to } \\
& \text { oceanography }
\end{aligned}
$$


